Universidade de São Paulo

Instituto de Física

\title{
Aplicações da espectroscopia de dicroísmo circular e da tensiometria em monocamadas de Langmuir no estudo de proteínas e peptídeos antimicrobianos
}

\author{
Victor Klein de Sousa
}

Orientador(a): Prof. Dr. José Luiz de Souza Lopes

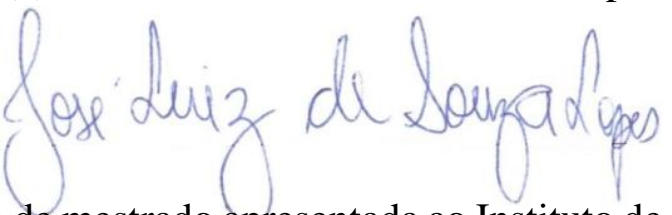

Dissertação de mestrado apresentada ao Instituto de Física como requisito parcial para a obtenção do título de Mestre em Ciências.

Banca Examinadora:

Prof. Dr. José Luiz de Souza Lopes - IFUSP

Prof(a). Dr(a). Leila Maria Beltramini - IFSC USP

Prof(a). Dr(a). Sheila Gonçalves do Couto Carvalho - UFG 
FICHA CATALOGRÁFICA

Preparada pelo Serviço de Biblioteca e Informação do Instituto de Física da Universidade de São Paulo

\section{Sousa, Victor Klein de}

Aplicações da espectroscopia de dicroísmo circular e da tensiometria em monocamadas de Langmuir no estudo de proteínas e peptídeos antimicrobianos. São Paulo, 2021.

Dissertação (Mestrado) - Universidade de São Paulo. Instituto de Física. Depto. de Física Aplicada

Orientador: Prof. Dr. José Luiz de Souza Lopes

Área de Concentração: Biofísica Molecular

Unitermos: 1. Espectroscopia de dicroísmo circular; 2. Tensiometria; 3. Monocamada de Langmuir; 4. Síntese de peptídeos em fase sólida; 5. Método tipo-Monte Carlo. 


\author{
University of São Paulo \\ Institute of Physics
}

\title{
Applications of circular dichroism spectroscopy and tensiometry in Langmuir monolayers to study proteins and antimicrobial peptides
}

\author{
Victor Klein de Sousa
}

Supervisor: Prof. Dr. José Luiz de Souza Lopes

Examining Committee:

Prof. Dr. José Luiz de Souza Lopes - IFUSP

Prof(a). Dr(a). Leila Maria Beltramini - IFSC USP

Prof(a). Dr(a). Sheila Gonçalves do Couto Carvalho - UFG 

Ao meus pais, Verônica e Fabiano, e à Lu, obrigado por tudo. 


\section{Agradecimentos}

Eu aprendi muitas coisas durante meus anos na USP, mas uma das mais importantes foi que não se produz ciência sozinho. Existem muitas pessoas que estão dispostas a nos ajudar quando precisamos. Meu orientador, Prof. Dr. José Luiz de Souza Lopes é uma dessas pessoas. Me lembro da primeira vez que ele me conversou comigo, foi no meu segundo ano da graduação, estávamos a alguns minutos da sua aula mecânica dos corpos rígidos e fluidos. O Zé Luiz me perguntou se eu tinha interesse em fazer pesquisa e em qual área. Eu respondi que sim, e que não tinha certeza da área, mas "talvez alguma coisa em mecânica estatística" (motivado pelas aulas de física do calor do Prof. Dr. Alvaro Vannucci), a gente conversou mais um pouco e a aula começou, estávamos aprendendo como calcular o momento de inércia de um corpo rígido. Alguns dias depois tive a oportunidade de conversar novamente com o Zé e ele me apresentou a biofísica e seus trabalhos com peptídeos antimicrobianos, naquele exato momento eu me encantei com a possibilidade de fazer pesquisa em uma área interdisciplinar. Tudo isso aconteceu há cinco anos, e de lá para cá eu só tenho agradecimentos ao Zé, não poderia ter tido um primeiro orientador melhor, ele sempre esteve presente para me ajudar, ensinar e motivar. Dentre tantos ensinamentos que ele me transmitiu, talvez o maior foi o de sempre "sonhar grande" e me esforçar para alcançar meus objetivos.

No IFUSP tive a chance de conhecer diversos outros gigantes que de alguma forma me "apoiaram em seus ombros" e me ajudaram a enxergar mais longe, como por exemplo os professores e professoras Rosangela Itri, Cristiano L.P. de Oliveira, Márcia Fantini, Nora Maidana, Alvaro Vannucci, Adriano Alencar, Cristiano Mattos, Marcia Rizzutto, Nilberto Medina, Zwinglio. Sou imensamente grato por todo conhecimento e apoio que vocês, e todos os demais docentes que tive o prazer de chamar de "professor(a)", me garantiram ao longo desses anos, muito obrigado.

Durante o meu mestrado, tive a oportunidade de conhecer diversas outras instituições de ensino e pesquisa brasileiras, que me ajudaram não só neste trabalho, mas também a desenvolver meu pensamento científico. Sou grato à UNIVESP, na qual fui facilitador bolsista durante o último ano, e que me deu suporte financeiro para me dedicar ao meu mestrado. Sou grato ao Grupo de Biofísica Molecular "Sérgio Mascarenhas", IFSC, e a todos os seus membros, em especial a Dra. Patrícia Suemy Kumagai, a Profa. Dra. Leila Beltramini e a técnica Bel, que me acompanharam durante minhas primeiras medidas de $\mathrm{CD}$ e minha primeira síntese de peptídeos. Sou grato também ao Laboratório de Neurobiologia Estrutural, UNIFESP, 
ao Prof. Dr. Manuel Arcisio-Miranda e seus alunos. Sou grato ICTP-SAIFR, pelos diversos eventos científicos nele sediados. E sou grato à Sociedade Brasileira de Biofísica, que promoveu diversos congressos e eventos ricos em ciência.

Nestes anos também tive o privilégio de conhecer vários jovens cientistas que acabaram se tornando grandes amigos, fonte de inspiração e apoio nos momentos difíceis, como a Jéssica, o Lufe, a Maressa, o André, o Pedro, o Fernando, o Gustavo, a Juliana, além de todos os meus colegas da licenciatura, obrigado por terem feito parte da minha jornada científica.

Ademais, tenho que agradecer outras grandes pessoas que fizeram parte da minha vida nestes anos, e que sempre demonstraram seu suporte e carinho por mim, como os meus amigos, Rafinha, Bidu, Seiji, Ju, Lasso, Nat e Luca, tive sorte de fazer amigos tão inteligentes e divertidos. Um agradecimento especial ao Bidu que compartilhou a sua conta do spotify comigo, com a qual tive acesso playlists do Angra e ao Dragonforce que deram o boost de energia que faltava para finalizar as análises contidas nessa dissertação.

Além disso, quero agradecer a minha família, em especial os meus pais Verônica e Fabiano que sempre me deram amor e suporte incondicional, sou eternamente grato por toda a educação que eles me deram, sem eles não teria chegado até aqui, obrigado por tudo. Também às minhas avós Marlene e Lucília, que sempre me inspiraram, e à Chris, ao Roberto e meus avós de consideração, Manuel e Betty, que me apoiaram em todas minhas decisões e conquistas. E aos doguinhos floki e jamie.

Por fim, gostaria de ressaltar a minha pessoa favorita e parceira de vida, Lu. O apoio que você tem me dado durante todos esses anos é algo imensurável, seja na vida acadêmica, ou pessoal, eu sei que posso contar com você para tudo, obrigado. Obrigado por me fazer acreditar em mim, obrigado por me fazer feliz e querer sair saltitando pelos lugares, obrigado por me motivar a correr atrás dos nossos sonhos e construir o nosso futuro, simplesmente, obrigado, Lu. Te amo. 
"A ciência é um diálogo com a natureza. [...] A realidade do devir é a condição sine qua non de nosso diálogo com a natureza." (PRIGOGINE, 1996) 


\section{RESUMO}

A espectroscopia de dicroísmo circular (CD) é uma técnica biofísica amplamente difundida e utilizada para fornecer informações estruturais a respeito de proteínas e peptídeos. Compostos quirais apresentam espectro de CD característico devido à diferença de absorção da luz circularmente polarizada à direita e à esquerda. Do espectro de CD de uma proteína, extraemse informações acerca de sua estrutura secundária no ambiente e nas condições em que se encontra, sendo possível estimar as frações de cada tipo de estrutura secundária presentes na molécula. Todavia, assim como qualquer técnica experimental, deve-se ter cautela na escolha dos parâmetros de entrada ao coletar um espectro de $\mathrm{CD}$, visto que eles afetam diretamente a qualidade do sinal obtido. No primeiro capítulo deste trabalho, foi investigado como a escolha e a variação de sete parâmetros de entrada afetam os resultados de CD. Um método Tipo-Monte Carlo foi implementado para estimar as incertezas nas porcentagens de estrutura secundária predita. Uma mudança sutil em alguns parâmetros foi capaz de afetar significativamente as análises de $\mathrm{CD}$, em destaque as variações na concentração da amostra e na presença de aditivos (tais como os íons cloreto) na solução. No segundo capítulo deste trabalho, descreve-se a implementação das reações de síntese de peptídeos em fase sólida no IFUSP, e a interação do peptídeo Pln149 com diferentes monocamadas fosfolipídicas, utilizando medidas de pressão superficial em monocamadas de Langmuir. Estes resultados evidenciam que a Pln149 pode interagir tanto com monocamadas lipídicas negativamente carregadas (o que já se conhecia previamente) quanto com superfícies zwitteriônicas.

Palavras-chave: Espectroscopia de Dicroísmo Circular. Tensiometria. Monocamada de Langmuir. Síntese de peptídeos em fase sólida. Método Tipo-Monte Carlo. 


\begin{abstract}
Circular dichroism (CD) spectroscopy is a widely used biophysical technique employed to obtain structural information of proteins and peptides. Chiral compounds present a typical CD spectrum due to the difference in absorption of right and left circularly polarized light. From the $\mathrm{CD}$ spectrum of a protein one can extract information about its secondary structure in the experimental conditions that the protein is found, and it is possible to estimate the content of each type of secondary structure present in the molecule. However, as any other experimental technique, caution must be paid in setting the data collection parameters, since they can directly affect the quality of the $\mathrm{CD}$ signal. In the first chapter of this work, it was investigated how the choice and the variation of seven collection parameters might affect the CD results. A Monte Carlo-like method was implemented to estimate the uncertainties in the percentages of predicted secondary structures. A slight change in some parameters was enough to significantly affect the $\mathrm{CD}$ analysis, in special the changes in sample concentration and the presence of additives (such as chloride ions) in the solution. In the second chapter of this work, the implementation of solidphase peptide synthesis reaction at IFUSP, the interaction of the peptide Pln149 with different phospholipid monolayers, and measurements of surface pressure in Langmuir monolayers are described. These results pointed out an evidence for Pln149 interaction with both negatively charged monolayers (as was previously described by literature) and zwitterionic phospholipid surfaces.
\end{abstract}

Keywords: Circular Dichroism Spectroscopy; Tensiometry. Langmuir monolayers; Solid Phase Peptide synthesis; Monte Carlo-Like Method. 


\section{Lista de Figuras}

Figura 1 - Sobreposição de duas ondas linearmente polarizadas ...........................................2 22

Figura 2 - Sobreposição de duas ondas lineares com diferença de fase de $90^{\circ}$..................... 23

Figura 3 - Sobreposição de duas ondas circularmente polarizada com sentidos de rotação

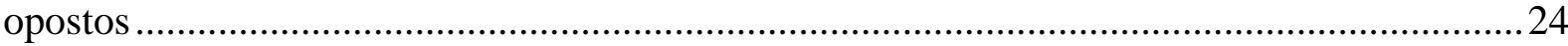

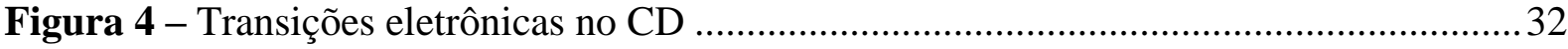

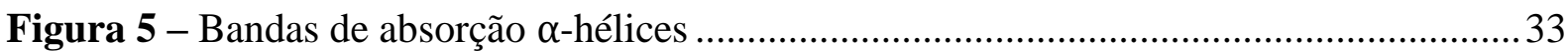

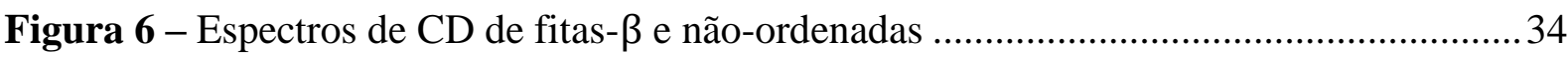

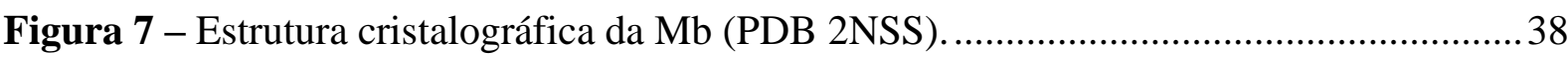

Figura 8 - Esquematização dos componentes presentes em um espectrômetro de CD. .........39

Figura 9 - Espectro de calibração do espectrofotômetro com CSA......................................... 46

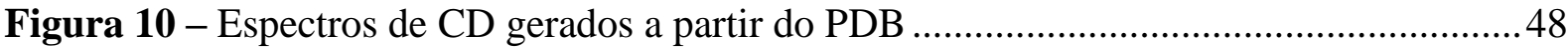

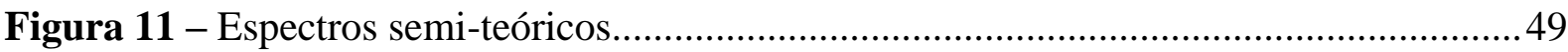

Figura 12 - Resultado das desconvoluções para os quatro algoritmos utilizados...................51

Figura 13 - Espectros de CD variando o número de varreduras. ...........................................53

Figura 14 - Espectros gerados pelo método tipo-Monte Carlo para diferentes n..................54

Figura 15 - Espectros de CD com diferentes velocidades de varredura. ..............................56

Figura 16 - Espectros gerados pelo método tipo-Monte Carlo, para diferentes v. ................56

Figura 17 - Espectros de CD com diferentes respostas de varredura. .................................57

Figura 18 - Espectros gerados pelo método tipo-Monte Carlo para diverentes D.I.T ............58

Figura 19 - Espectros de CD com diferentes intervalos de varredura. ..................................59

Figura 20 - Espectros gerados pelo método tipo-Monte Carlo, para intervalos de (a) 0,2nm e (b) $0,5 \mathrm{~nm}$ 60

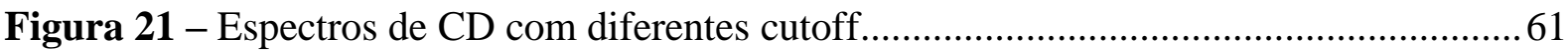

Figura 22 - Espectros gerados pelo método tipo-Monte Carlo para diferentes cutoff............62

Figura 23 - Espectros de CD com diferentes concentrações de proteína

Figura 24 - Espectros gerados pelo método tipo-Monte Carlo, para diferentes concentrações de proteína.

Figura 25 - Ajuste linear da elipticidade contra a concentração de mioglobina para (a) $192 \mathrm{~nm}$ e (b) $208 \mathrm{~nm}$ 64

Figura 26 - Espectros de $\mathrm{CD}$ com diferentes concentrações de $\mathrm{NaCl}$ 66 
Figura 27 - Espectros gerados pelo método tipo-Monte Carlo para diferentes concentrações de $\mathrm{NaCl}$.

Figura 28 - Comparação do desvio padrão por Monte Carlo com o NRMSD 69

Figura 29 - Valores de $\delta \theta$ calculados para os espectros médio da Mb. 73

Figura 30 - Curtose e Assimetria estimadas por Monte Carlo da distribuição de valores de $\Delta \varepsilon$ em $192 \mathrm{~nm}$. .76

Figura 31 - Resultados de 10000 variações de Monte Carlo para diferentes razões $\delta c$ 77

Figura 32 - P(A'), $\mathrm{P}\left(\mathrm{B}^{\prime}\right)$ e a diferença entre eles em função de $\delta c$ variando de 0 a 2 em passos de 0,01 .

Figura 33 - Espectro de SRCD da Pln149 em solução aquosa e na presença de lipossomas de POPC e POPG. 82

Figura 34 - Espectros de SRCD da Pln149 na presença de NaF 83

Figura 35 - Comparação dos espectros de Pln149 na presença de NaF com a sobreposição dos espectros da fase desordenada com a fase em $\alpha$-hélices. 84

Figura 36 - Reações de acoplamento 92

Figura 37 - Coquetéis para clivagem dos peptídeos utilizando a química Fmoc/tBu. 96

Figura 38 - Etapas da SPFS. 97

Figura 39 - Protocolo da SPFS implementado no IFUSP. 97

Figura 40 - Esquematização de um ensaio de tensiometria em monocamadas de Langmuir. 103

Figura 41 - Diagrama de fase das monocamadas de Langmuir........................................ 104

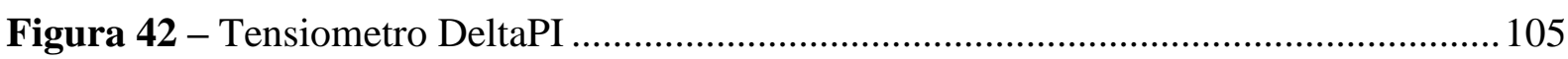

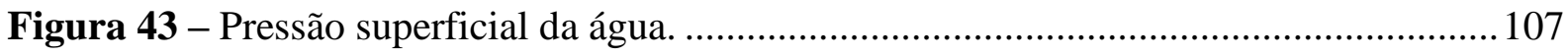

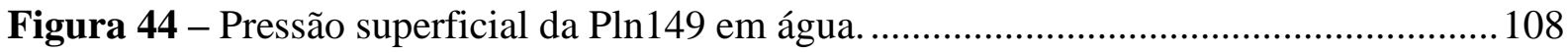

Figura 45 - Interação da Pln149 em monocamadas lipídicas em diferentes regimes de concentração.

Figura 46 - Cinética de tensoatividade de Pln149 $(5 \mu \mathrm{M})$ em diferentes monocamadas lipídicas......

Figura 47 - Curvas $\Delta \pi \times \pi 0$ da Pln149 em diferentes monocamadas. 111 


\section{Lista de Tabelas}

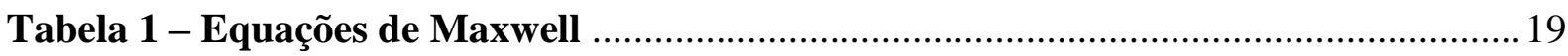

Tabela 2 - Valores dos parâmetros selecionados........................................................... 43

Tabela 3 - Estimativa do conteúdo de $\boldsymbol{\alpha}$-hélices para os espectros semi-teóricos............48

Tabela 4 - Estruturas cristalográficas selecionadas e comparação de seu conteúdo de $\alpha$ hélices.

Tabela 5 - Resultados de desconvolução e testes estatísticos para o número de varreduras.

Tabela 6 - Resultados de desconvolução e testes estatísticos para a velocidade de varredura.

Tabela 7 - Resultados de desconvolução e testes estatísticos para a resposta de varredura.

Tabela 8 - Resultados de desconvolução e testes estatísticos para o intervalo de varredura.

Tabela 9 - Resultados de desconvolução e testes estatísticos para o menor comprimento de onda..

Tabela 10 - Resultados de desconvolução para a concentração de Mb.

Tabela 11 - Região de Cutoff para cada concentração de $\mathrm{NaCl}$ 66

Tabela 12 - Resultados de desconvolução e testes estatísticos para a concentração de NaCl.

Tabela 13 - Resultados do teste F de Fisher comparando os desvios padrões do CDSSTR com os demais algoritmos

Tabela 14 - Probabilidade de encontrar valores de $\Delta \varepsilon$ nos intervalos acima de 2 desvios padrões calculados $\operatorname{com} \delta c=0$.

Tabela 15 - Probabilidade de encontrar valores de $\Delta \varepsilon$ nos intervalos acima de 2 desvios padrões considerando os valores de $\delta c$.

Tabela 16 - Projeção em hélice da Temporina 1Ca e análogos..................................... 100

Tabela 17 - Massas de aa pesadas para cada etapa de acoplamento (em mg) ............... 102

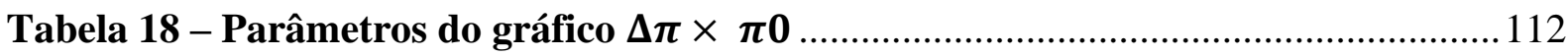




\section{Lista de abreviaturas}

aa

Fmoc

TFA

$\varepsilon$

$\lambda$

CSA

DCM

CD

DPPG

SDS

EDT

LCP

LLP

Mb

MFE

DMF

HOBt

NRMSD

POPC

POPG

POPS

PAM

Pln149

PMI

HT

Boc

TIS

UV aminoácido

9-Fluoronilmetiloxicarbonila

ácido trifluoracético

coeficiente de extinção molar

Comprimento de onda

D-(+)-10-ácido camforsufônico

Diclorometano

Dicroísmo Circular

Dipalmitoilfostatidilglicerol

dodecil sulfato de sódio

etanoditiol

Luz circularmente polarizada

Luz linearmente polarizada

Mioglobina

modulador fotoelástico

$\mathrm{N}, \mathrm{N}$ - Dimetilformamida

N-Hidroxibenzotriazol

Normalized root-mean-square deviation, Raiz do erro quadrático médio normalizada

palmitoiloleoilfosfatidilcolina

palmitoiloleoilfosfatidilglicerol

palmitoiloleoilfosfatidilserina

Peptídeo antimicrobiano

Plantaricina 149

pressão de máxima inserção

tensão aplicada no fotomultiplicador

Terc-Butiloxicarbonila

triisopropilsilano

Ultravioleta 
Capítulo 1 - A espectroscopia de dicroísmo circular 15

I - Introdução 15

II- Objetivos 18

III - Teoria do dicroísmo circular 19

III.1 - O fenômeno do dicroísmo circular ............................................ 19

III.2 - A luz circularmente polarizada ............................................... 21

III.3 - Interação da LCP com a matéria................................................ 24

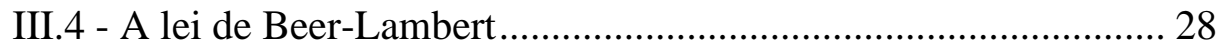

III.5 - O CD aplicado ao estudo de proteínas e peptídeos. .................. 29

III.6 - Métodos, servidores e algoritmos para análise do CD de proteínas

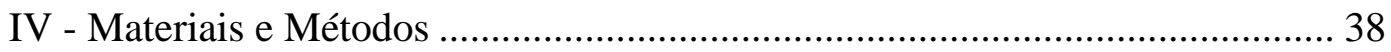

IV.1 Proteína e peptídeo modelo ....................................................... 38

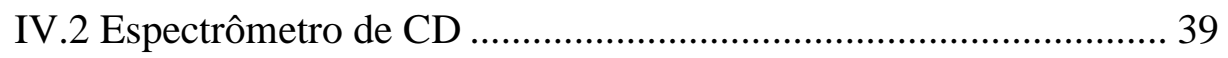

IV.3 Parâmetros variados para os espectros da Mb ............................. 41

IV.4 Tratamento dos espectros: EasyCD e CDtool ............................. 43

IV.5 Método tipo-Monte Carlo: CDgenerator ..................................... 44

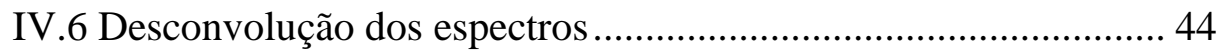

IV.7 Modelo Semi-Teórico da Mb e testes de hipótese ........................ 44

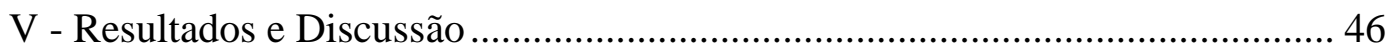

V.1 Calibração do espectrofotômetro .................................................. 46

V.2 Modelo semi-teórico da Mb........................................................ 47

V.3 Resultados de desconvolução da Mb .......................................... 51

V.4 Número de varreduras.......................................................... 52

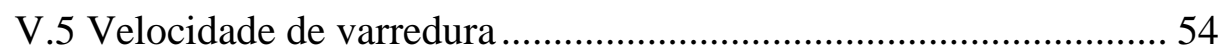


V.6 Resposta de varredura

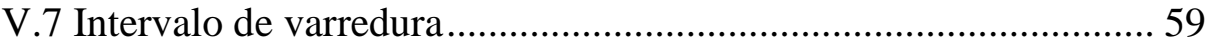

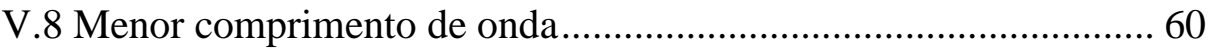

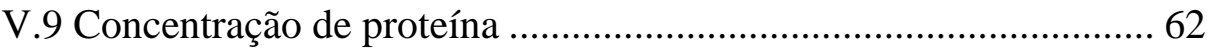

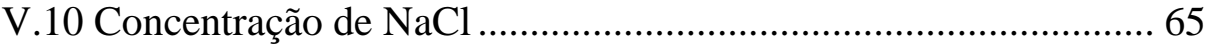

V.11 Desvio padrão por Monte Carlo x NRMSD ............................... 68

V.12 O problema da normalização .................................................... 70

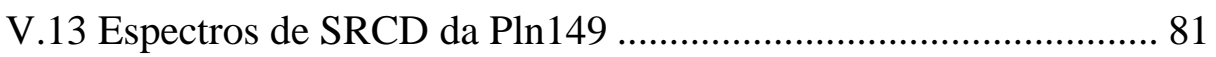

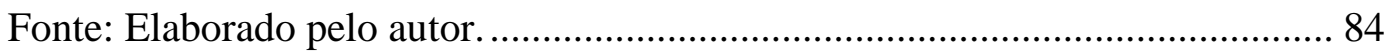

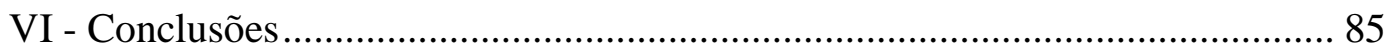

Capítulo 2 Estudos de peptídeos antimicrobianos: síntese de peptídeos em fase sólida e tensiometria em monocamadas de Langmuir.

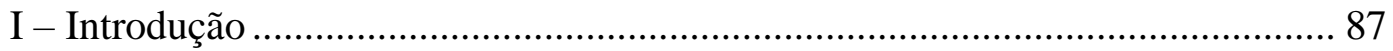

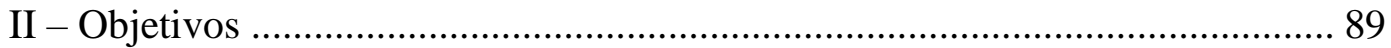

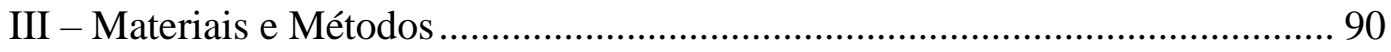

III.1 - Síntese de peptídeos em fase sólida......................................... 90

III.1.1 - Protocolo SPFS manual .................................................... 93

III.1.2 - SPFS de peptídeos da família das temporinas ........................ 98

III. 2 - Tensiometria em monocamadas de Langmuir........................ 102

III.2.1 - Tensiômetro DeltaPI........................................................... 105

III.2.2 - Ensaios com a Pln149 ......................................................... 106

IV - Resultados e Discussão ...................................................................... 107

IV.1 - Pressão superficial da água................................................... 107

IV.2 - Tensoatividade da Pln149 em água...................................... 107 
$\mathrm{V}$ - Conclusões

Referencias

Apêndice I - Absorção da luz e dicroísmo linear 


\section{Prólogo}

Esta dissertação está dividida em dois capítulos. No Capítulo I é discutida a origem física do fenômeno de dicroísmo circular (CD) com uma revisão da literatura, sua importância no estudo da estrutural de proteínas e peptídeos, e o uso complementar de ferramentas bioinformática disponíveis atualmente para a análise de $\mathrm{CD}$. Neste mesmo capítulo é apresentada uma análise experimental sobre como os espectros obtidos a partir da técnica de CD podem ser afetados por escolhas indevidas nos ajustes dos parâmetros da medida. Por fim, são analisados os espectros de CD da Plantaricina 149.

No Capítulo II, objetivando-se melhor investigar a Plantaricina 149 (e outros peptídeos antimicrobianos), a interação deste peptídeo com modelos de membrana é investigada com análises de tensiometria em monocamadas de Langmuir. Neste capítulo também são discutidos a teoria e protocolo da síntese de peptídeos em fase sólida, que é utilizada para a síntese de peptídeos antimicrobiano da família das temporinas.

Com este trabalho, espera-se ajudar novos usuários a se familiarizarem com algumas das principais técnicas implementadas pelo grupo Biofísica Aplicada do IFUSP, e desta maneira, servir de referência para futuros estudos. 


\section{Capítulo 1 - A espectroscopia de dicroísmo circular}

\section{I - Introdução}

A técnica espectroscópica conhecida como dicroísmo circular (CD) é utilizada para a caracterização de sistemas quirais. Este método é baseado no fenômeno óptico da absorção da luz circularmente polarizada (LCP). O dicroísmo é a propriedade de um composto de absorver luzes com polarizações diferentes de forma distinta. O fenômeno de CD ocorre quando duas componentes de LCP, com sentido de polarização opostos (uma a direita, e a outra a esquerda) interagem com compostos quirais. Cada uma destas ondas é absorvida em proporções diferentes, e essa diferença de absorção dá origem ao sinal de CD (WALLACE; JANES, 2009; FASMAN, 1996; BEROVA et al, 2012).

$\mathrm{O}$ efeito de $\mathrm{CD}$ pode ser observado em diversas regiões do espectro eletromagnético. Atualmente, existem duas principais faixas de interesse: A região do infravermelho dá origem ao dicroísmo circular vibracional (MAGYARFALVI et al., 2011) e a região do ultravioleta - de interesse desse trabalho - é conhecida como dicroísmo circular eletrônico, ou ainda dicroísmo circular convencional (WALLACE; JANES, 2009; FASMAN, 1996; BEROVA et al., 2012) ${ }^{1}$.

Após a segunda metade do século XX, o CD se tornou bastante popular, e diversas abordagens experimentais foram derivadas dessa mesma técnica, seja com a intenção de melhorar/aprimorar a aquisição do sinal de CD, ou então de obter informações extras sobre a molécula estudada. Como exemplo podemos citar dicroísmo circular orientado (BÜRCK et al., 2016), que nos permite obter a orientação de peptídeos em $\alpha$-hélices inseridos em modelos de membrana lipídicas; o dicroísmo circular magnético, que adiciona um campo magnético na direção do feixe de luz incidente (HALES, 2011) ou ainda o considerado "estado-da-arte" do método, o SRCD. O SRCD surge com a utilização da radiação sincrotron como fonte de luz para as medições dos espectros (KUMAGAI et al., 2017(a); KUMAGAI et al., 2017(b)).

Na natureza muitas biomoléculas (proteínas, carboidratos e ácidos nucleicos) apresentam quiralidade intrínseca (MIYAHARA et al., 2016; MATSUO; GEKKO, 2018; AMDURSKY; STEVENS, 2015). Entre estas, as proteínas possuem um lugar de destaque na literatura de CD, com um grande número de estudos realizados utilizando a técnica. Esta técnica é interessante para o estudo de proteínas, uma vez que com ela é possível identificar e estimar as estruturas

\footnotetext{
${ }^{1}$ Nessa dissertação quando nos referirmos ao CD estará subentendido que estamos falando do dicroísmo circular eletrônico.
} 
secundárias e terciárias de uma proteína, detectar mudanças conformacionais na molécula, estudar a dinâmica da proteína quando exposta a diferentes condições experimentais e/ou estudar interações do tipo proteína-proteína, proteína-membrana, ou com diversos outros interagentes (WALLACE; JANES, 2009; FASMAN, 1996; BEROVA et al., 2012).

Para cada tipo de estrutura secundária (e.g. $\alpha$-hélices, folhas- $\beta$, voltas- $\beta$, e não ordenadas) existe um espectro de CD característico, que possui posições de bandas muito bem definidas, e que surge devido a diferenças no momento de dipolo elétrico resultante de cada tipo de estrutura secundária. Geralmente, o espectro de CD de uma proteína complexa é a sobreposição dos espectros das diversas estruturas secundárias presentes na molécula. As proporções de cada estrutura podem ser estimadas por softwares que realizam os processos de desconvolução, muito dos quais estão disponíveis online (WALLACE; JANES, 2009; FASMAN, 1996).

A maioria dos algoritmos de desconvolução necessitam que haja uma normalização do espectro para uma escala independente da concentração e do caminho óptico do porta amostras utilizado, o que exige que ambas informações sejam conhecidas com grande precisão. Além disso, com frequência os algoritmos apresentam uma maior precisão nos resultados quando a proteína estudada possui um conteúdo mais elevado de $\alpha$-hélices (MANAVALAN; JOHNSON, 1987). Isso acontece principalmente porque essa estrutura apresenta o maior momento de dipolo magnético, o que realça a sua interação com a LCP, gerando sinais de CD mais intensos. Além disso, estruturas do tipo fitas- $\beta$ apresentam características morfológicas mais distintas, as quais produzem um leque mais diversos de espectros de CD. (WALLACE, 2003). Com o passar dos anos, alguns outros algoritmos e base de dados, como o BeStSel (MICSONAI et al., 2015), surgiram com o intuito de melhorar a qualidade na predição de estruturas secundárias diferentes das $\alpha$-hélices.

As análises de $\mathrm{CD}$ são normalmente usadas complementarmente a outras técnicas biofísicas, tais como a difração de raios-x, a fluorescência, a ressonância magnética nuclear, a dinâmica molecular e cryo-microscopia eletrônica. A vantagem do CD é a capacidade de se obter uma informação estrutural global sobre a proteína de interesse nas mais diversas condições experimentais, inclusive em forma nativa. Além disso, é uma técnica não destrutiva (que possibilita a reutilização da amostra em outras medidas), requer pequena quantidade de material ( $400 \mu L$ de uma solução a $\sim 0,2 \mathrm{mg} / \mathrm{mL})$, e apresenta um resultado rápido ( 20 min é, normalmente, o suficiente para a aquisição de um bom espectro) (WALLACE; JANES, 2009). 
A informação estrutural adquirida com o CD pode, muitas vezes, ser prejudicada pela baixa qualidade do sinal medido. Kelly et al. (2005) apresentam uma revisão bibliográfica completa sobre os cuidados que devem ser tomados durante a obtenção de um espectro de CD. Em resumo, os autores encontram evidências de que um espectro de boa qualidade apresenta um valor alto de relação sinal ruído e minimiza a contribuição de solventes. Dessa forma, prestar atenção nos parâmetros de coleta (tanto relacionados com a varredura, quanto com o preparo da solução) é um cuidado fundamental na hora de preparar o experimento, uma vez que eles podem afetar significativamente o espectro final e, consequentemente, os resultados da quantificação estrutural a ser obtida com o processo de desconvolução. 


\section{II- Objetivos}

O presente trabalho possui como objetivo geral verificar como a variação dos parâmetros de coleta afeta os espectros de dicroísmo circular e os seus resultados de desconvolução, com intuito de guiar futuros usuários da técnica que pretendem estudar sistemas proteicos. Nesse trabalho, sete parâmetros de coleta foram variados como uma forma de verificar os limites aceitáveis de cada um, de tal forma que não haja uma mudança significativa na qualidade do espectro final e no resultado de desconvolução. Além disso, foi implementado um método de tipo-Monte Carlo capaz de produzir um resultado de desconvolução considerando a incerteza experimental. Por fim, foi realizada uma análise estatística sobre a acurácia da concentração necessária para se obter uma distribuição de pontos no espectro normalizado que obedeça a uma função de distribuição gaussiana.

Para tanto, o trabalho se constituiu das seguintes etapas:

- Revisão da literatura de dicroísmo circular.

- Preparação das amostras de mioglobina (Mb) e Plantaricina 149 (Pln149) utilizadas.

- Medida dos espectros de dicroísmo circular da proteína modelo em diferentes condições.

- Desenvolvimento e implementação de programas de tratamento e análise dos espectros, tais como o EasyCD e CDgenerator.

- Utilização de algoritmos de desconvolução disponíveis no Dichroweb e BeStSel.

- Implementação de ferramentas estatísticas para a análise e comparação dos resultados. 


\section{III - Teoria do dicroísmo circular}

\section{III.1 - O fenômeno do dicroísmo circular}

Durante séculos perdurou-se a discussão em torno da natureza da luz. No século XVII surgiram duas teorias concorrentes capazes de descrever fenômenos luminosos, a primeira, proposta por Isaac Newton no seu livro “Óptica”, propunha o caráter corpuscular para a luz. A segunda, proposta por Christiaan Huygens no seu "Tratado sobre a Luz", postulava a luz como uma onda. Ambas teorias são capazes de explicar fenômenos como a reflexão e refração da luz, mas foi apenas no século seguinte, com o famoso experimento de Thomas Young de fendas duplas, que a comunidade científica passou a aceitar de forma consensual a teoria de Huygens.

$\mathrm{Na}$ década de 1861, o físico James C. Maxwell reuniu quatro equações diferenciais capazes de descrever qualquer fenômeno do eletromagnetismo clássico. Estas ficaram conhecidas como as Equações de Maxwell (Tabela 1), e são formas reescritas/modificadas das leis de Gauss, Ampère e Faraday. A surpresa para época, foi que a descrição da luz como uma onda eletromagnética (JACKSON, 2007; GRIFFITHS, 2005), o que trouxe ainda mais prestígio para o tratamento ondulatório. Todavia, no século XX, com o advento da física moderna, houve uma grande quebra de paradigma, isto é, alguns fenômenos só podiam ser explicados com uma teoria corpuscular. Assim, físicos como Einstein e Max Planck propuseram a dualidade da luz, a considerando tanto uma partícula (o fóton), quanto uma onda eletromagnética.

Tabela 1 - Equações de Maxwell

\begin{tabular}{cc}
\hline Lei de Gauss & $\vec{\nabla} \cdot \vec{E}=\frac{\rho}{\epsilon_{0}}$ \\
Lei de Gauss para o magnetismo & $\vec{\nabla} \cdot \vec{B}=0$ \\
Lei de Maxwell-Faraday & $\vec{\nabla} \times \vec{E}=-\frac{\partial \vec{B}}{\partial t}$ \\
Lei de Ampere & $\vec{\nabla} \times \vec{B}=\mu_{0}\left(\vec{J}+\epsilon_{0} \frac{\partial \vec{E}}{\partial t}\right)$ \\
\hline
\end{tabular}

A teoria capaz de explicar o CD surge de um tratamento semiclássico da mecânica quântica, ou seja, considerando-se a luz como uma onda eletromagnética e utilizando o formalismo quântico para descrever a interação desta onda com os elétrons presentes na molécula de interesse. Portanto, para entender a origem do CD é necessário retomar alguns 
conceitos básicos do eletromagnetismo, que possibilitam a compreensão da natureza ondulatória de uma luz, dita circularmente polarizada.

Seguindo as demonstrações presentes em Jackson (1983) verifica-se que em um meio simples, não condutor, com permeabilidade $\left(\mu_{0}\right)$ e susceptibilidade $\left(\epsilon_{0}\right)$ constantes e na ausência de cargas externas, os campos elétrico $(\vec{E})$ e magnético $(\vec{B})$ presentes na luz seguem as equações de onda tridimensional:

$$
\begin{aligned}
\nabla^{2} \vec{E} & =\frac{1}{\mu_{0} \epsilon_{0}} \frac{\partial^{2} \vec{E}}{\partial t^{2}} \\
\nabla^{2} \vec{B} & =\frac{1}{\mu_{0} \epsilon_{0}} \frac{\partial^{2} \vec{B}}{\partial t^{2}}
\end{aligned}
$$

A solução para cada um dos campos elétrico e magnético é descrita como uma onda plana e monocromática (frequência angular, $\omega$, constante), como nas equações (3) e (4). As quais mantém a natureza vetorial de $\vec{E}$ e $\vec{B}$, implícita nos vetores constantes (e complexos) $\vec{E}_{0}$ e $\vec{B}_{0}$. A direção de propagação da onda é descrita pelo vetor de onda $\left(\vec{k}=k \hat{e}_{3}\right)$, em que $k=\frac{\omega}{c}$ , e $c^{2}=\frac{1}{\mu_{0} \epsilon_{0}}$ é a velocidade da luz no meio (JACKSON, 1983; GRIFFITHS,2005).

$$
\begin{aligned}
& \vec{E}=\vec{E}_{0} e^{i(\vec{k} \cdot \vec{x}-\omega t)} \\
& \vec{B}=\vec{B}_{0} e^{i(\vec{k} \cdot \vec{x}-\omega t)}
\end{aligned}
$$

Devido a não existência de cargas, e pela lei de Gauss, decorre-se que os divergentes dos campos são nulos, acarretando a simplificação $\vec{k} \cdot \vec{E}_{0}=\vec{k} \cdot \vec{B}_{0}=0$. Logo, os dois campos são ortogonais à direção de propagação. Da lei de Faraday é possível obter que $\vec{B}_{0}=$ $\frac{1}{\omega}\left(k \times \vec{E}_{0}\right)$. Portanto, $\vec{E}$ e $\vec{B}$ também são ortogonais entre si. Assim, os versores das direções dos campos e do vetor de onda $\left(\hat{\mathrm{e}}_{1}, \hat{\mathrm{e}}_{2}, \hat{\mathrm{e}}_{3}\right)$ formam uma base de $R_{3}$. Essa última relação é importante, pois mostra como obter o campo magnético conhecendo a equação para o campo elétrico. Dessa forma, torna-se possível descrever apenas o campo elétrico (JACKSON, 1983; GRIFFITHS,2005).

O produto vetorial entre $\vec{E}$ e $\vec{B}$ gera um vetor paralelo à direção de propagação. Assim, é definido o vetor de Poynting (5), que representa a energia por unidade de área, por unidade de tempo (fluxo de densidade de energia). A média temporal (por ciclo) do módulo do vetor de 
Poynting é igual à intensidade (ou irradiância) da luz (6), em que $\alpha$ é o ângulo entre os vetores de Poynting e normal à superfície incidente. Caso o feixe de luz seja perpendicular a amostra, $\cos \alpha=1$. Para uma onda plana monocromática é válida a segunda igualdade da equação (6), na qual a intensidade da luz é proporcional ao quadrado de $E_{0}$, que é o módulo da parte real da amplitude do campo elétrico (JACKSON, 1983; GRIFFITHS,2005).

$$
\begin{gathered}
\vec{S}=\frac{1}{\mu} \vec{E} \times \vec{B} \\
I=\langle|\vec{S}|\rangle \cos \alpha=\frac{1}{2} c \epsilon E_{0}^{2} \cos \alpha
\end{gathered}
$$

\section{III.2 - A luz circularmente polarizada}

A onda descrita pelas equações (3) e (4) é linearmente polarizada, uma vez que possui o seu campo elétrico (portanto, magnético) apontado sempre para a mesma direção $\hat{e}_{1}$ (e $\hat{e}_{2}$ para o magnético). Nesse caso, falamos que a luz está polarizada na direção ê. ${ }_{1}$. A princípio, duas ou mais ondas linearmente polarizadas podem ser sobrepostas para formar uma onda mais geral. Por exemplo, podemos somar duas ondas com o mesmo vetor de onda e frequência, mas com vetores de polarização linearmente independentes (7) (JACKSON, 1983; GRIFFITHS,2010).

$$
\vec{E}(\vec{x}, t)=\left(E_{i} \hat{\mathrm{e}}_{i}+E_{j} \hat{\mathrm{e}}_{j}\right) e^{i(\vec{k} \cdot \vec{x}-\omega t)}
$$

Os valores $E_{i}$ e $E_{j}$ são, a princípio, números complexos e podem ser escritos como $E_{i, j}=$ $\left|E_{i, j}\right| e^{i \varphi_{i, j}}$, em que $\varphi_{i, j}$ é um fator de fase. Caso as ondas possuam a mesma fase, o campo elétrico resultante será: $\vec{E}(\vec{x}, t)=\vec{E}_{r e s} e^{i(\vec{k} \cdot \vec{x}-\omega t+\varphi)}$, em que o módulo de $\vec{E}_{r e s}$ é igual à $\sqrt{E_{i}^{2}+E_{j}^{2}}$, e a direção de polarização forma um ângulo $\theta=\tan ^{-1} \frac{E_{i}}{E_{j}} \operatorname{com}$ relação a ê $\hat{1}_{1}$. Note então que é recuperada uma onda plana linearmente polarizada (JACKSON, 1983; GRIFFITHS, 2010).

Quando as ondas apresentem fases distintas, a sobreposição será elipticamente polarizada. Caso a diferença de fase seja de $\frac{\pi}{2}$, e a amplitude das ondas seja igual $\left(\left|E_{i}\right|=\left|E_{j}\right|=\right.$ $E \sqrt{2}$ ), chegamos no tipo de polarização mais importante para este trabalho: a circular (8) (WOODY,1996). Em que $\vec{E}_{ \pm}=E \sqrt{2} \hat{\mathrm{e}}_{ \pm}$, e $\hat{\mathrm{e}}_{ \pm}=\frac{1}{\sqrt{2}}\left(\hat{\mathrm{e}}_{i} \pm i \hat{\mathrm{e}}_{j}\right)$. 
Figura 1 - Sobreposição de duas ondas linearmente polarizadas

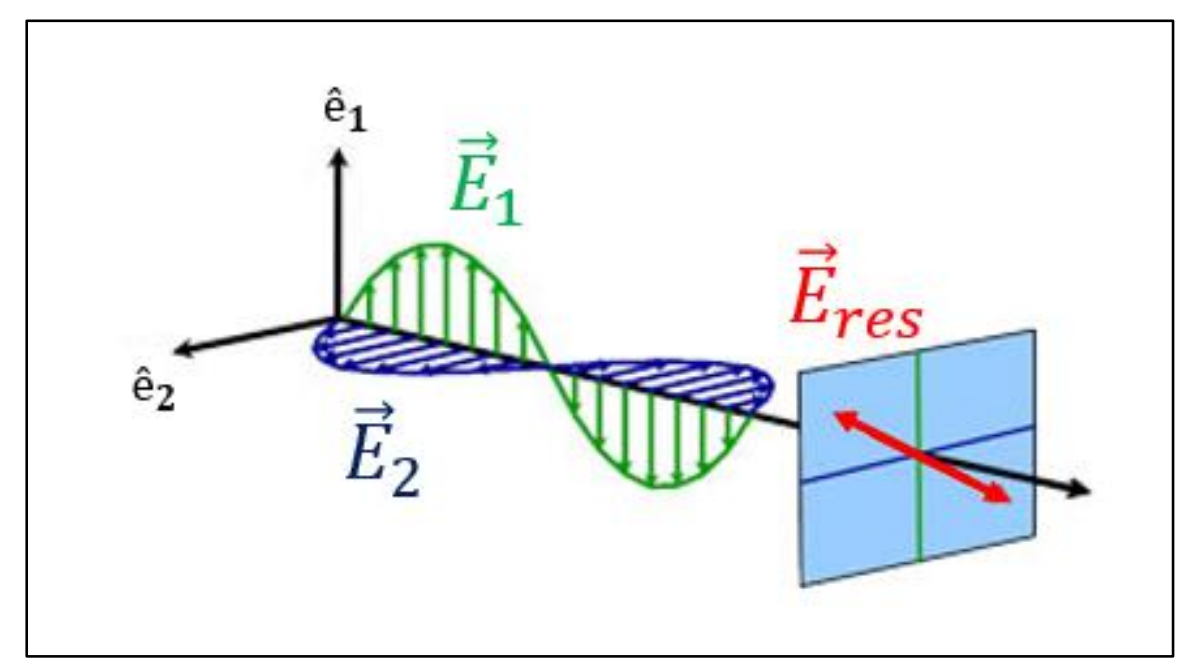

Sobreposição de duas ondas linearmente polarizadas (nas direções $\hat{e}_{1}$ e $\hat{e}_{2}$ ), representadas pelos seus campos elétricos $\left(\overrightarrow{E_{1}}\right.$ e $\left.\overrightarrow{E_{2}}\right)$, gerando uma onda linearmente polarizada na direção do campo elétrico resultante $\vec{E}_{\text {res }}$. Adaptado de: J.A. Woollam $(2021)^{2}$.

$$
\vec{E}(\vec{x}, t)=\vec{E}_{ \pm} e^{i(\vec{k} \cdot \vec{x}-\omega t)}
$$

A resultante, portanto, é a soma dos dois versores, na qual o campo elétrico realiza um movimento circular uniforme no plano formado por $\hat{\mathrm{e}}_{i}$ e $\hat{\mathrm{e}}_{j}$ (digamos, plano XY) girando em sentido anti-horário. Assim, esta onda é nomeada como sendo circularmente polarizada à direita (dextrogira), ou ainda com helicidade positiva. Já quando subtrai-se os dois versores, o campo elétrico realiza um movimento circular uniforme, girando no sentido horário. Nesse caso, a onda é chamada de circularmente polarizada à esquerda (levogira), ou ainda com helicidade negativa (JACKSON, 1983).

A combinação de duas ondas circularmente polarizadas com a mesma amplitude, frequência e vetor de onda, mas com helicidades opostas gera uma onda plana linearmente polarizada. Isso pode ser verificado com a adição $\hat{\mathrm{e}}_{+}+\hat{\mathrm{e}}_{-}=\sqrt{2} \hat{\mathrm{e}}_{i}$, indicando a direção do campo elétrico da onda resultante. Agora, se as amplitudes dos campos elétricos diferirem, a sobreposição das ondas gerará uma luz elipticamente polarizada (JACKSON, 1983).

\footnotetext{
${ }^{2}$ Disponível online: 〈https://www.jawoollam.com/resources/ellipsometry-tutorial/polarized-light >. Acesso em: 19 maio 2021
} 
Sejam $\vec{E}_{e}$ e $\vec{E}_{d}$ duas ondas circularmente polarizadas, à esquerda e à direita, respectivamente, descritas pela equação (8). Ambas com mesmo comprimento de onda e vetor de propagação e com amplitudes dadas por $E_{e}>E_{d}>0$. O campo elétrico resultante será dado pela equação (9).

Figura 2 - Sobreposição de duas ondas lineares com diferença de fase de $90^{\circ}$

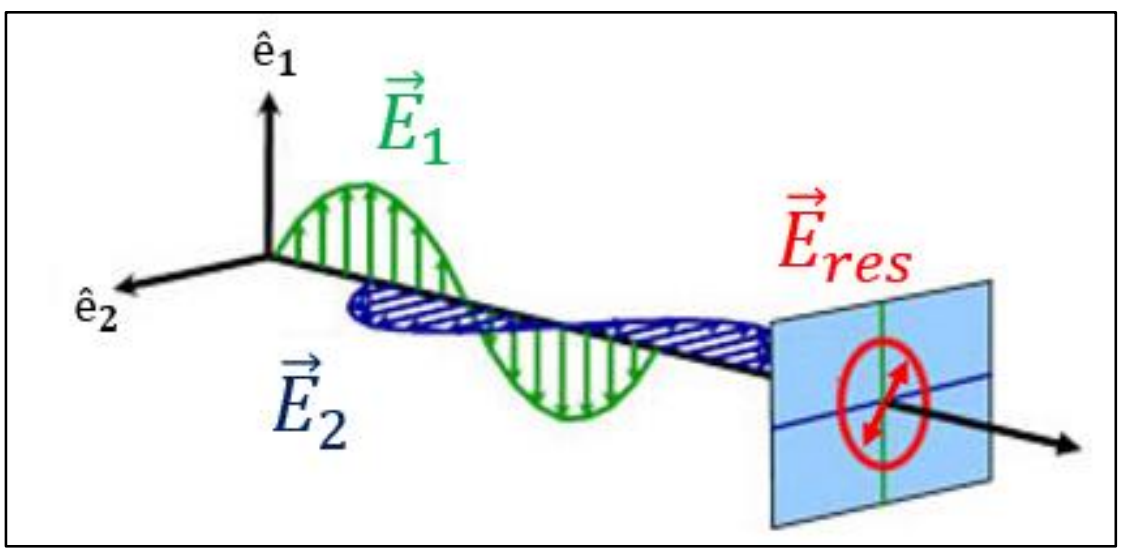

Sobreposição de duas ondas linearmente polarizadas (nas direções $\hat{e}_{1} \mathrm{e} \hat{e}_{2}$ ), entretanto com uma diferença de fase de $90^{\circ}$, gerando uma onda circularmente polarizada. Adaptado de: J.A. Woollam (2021) ${ }^{3}$.

$$
\vec{E}(x, t)=\left(E_{d} \hat{\mathrm{e}}_{+}+E_{e} \hat{\mathrm{e}}_{-}\right) e^{i(\vec{k} \cdot \vec{x}-\omega t)}
$$

O semieixo maior da elipse será quando $\hat{e}_{+}$e ê_- apontam para a mesma direção, e o seu valor é: $E_{d}+E_{e}$. Já o semieixo menor será quando o ângulo entre os versores é $\pi$, e o seu valor é: $E_{e}-E_{d}$. A razão entre os semieixos é igual à tangente do ângulo $\theta$ (como pode ser visto na Figura 3). Quando $E_{e}+E_{d} \gg E_{e}-E_{d}$, esse ângulo é bem pequeno, de tal forma que podemos realizar a aproximação expressa em (10). Esse ângulo é a grandeza mensurada em grande parte dos equipamentos de CD disponíveis atualmente (WOODY,1996).

$$
\theta \approx \tan \theta=\frac{E_{e}-E_{d}}{E_{e}+E_{d}}
$$

\footnotetext{
${ }^{3}$ Disponível online: <https://www.jawoollam.com/resources/ellipsometry-tutorial/polarized-light>. Acesso em: 19 maio 2021
} 
Figura 3 - Sobreposição de duas ondas circularmente polarizada com sentidos de rotação opostos

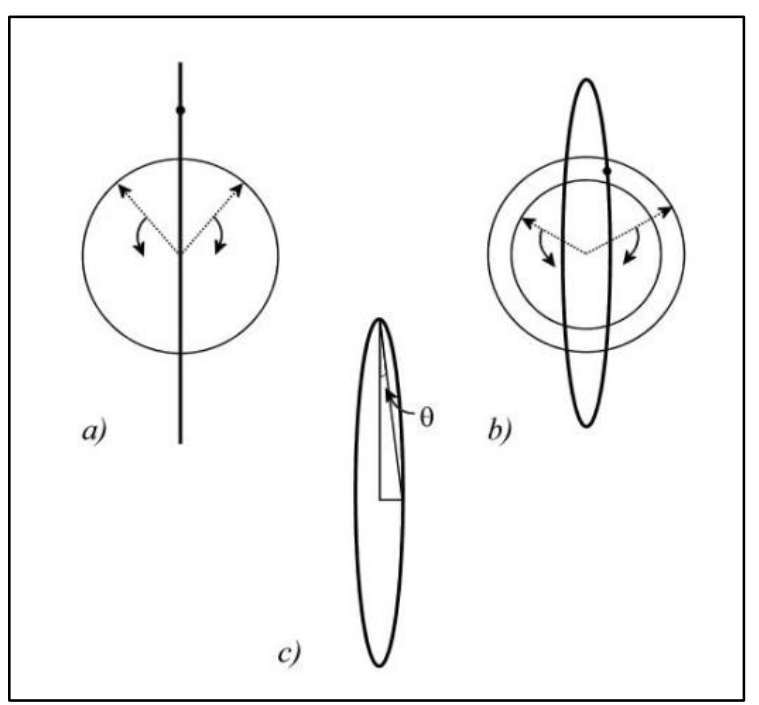

Sobreposição de duas ondas circularmente polarizada com sentidos de rotação opostos. (a) Ambas as ondas com a mesma intensidade, resultando numa polarização linear. (b) Com intensidades diferentes, gerando uma onda elíptica. (c) identificação do ângulo $\theta$ expresso na equação 10. Retirado de: Janes e Wallace (2009).

\section{III.3 - Interação da LCP com a matéria}

A explicação física do fenômeno de CD surge de um tratamento semiclássico da mecânica quântica. Primeiro, é necessário definir o Hamiltoniano de interesse e em seguida utilizar a teoria de perturbação dependente do tempo para calcular a probabilidade de transição de um estado fundamental (o) para um estado excitado (a) (11). O leitor interessado pode observar o apêndice dessa dissertação para os detalhes dessas operações, aonde apresenta-se a origem quântica da absorção da luz (TOMAKOFF, 2020; MCHALE, 2017; SCHELLMAN, 1975).

$$
P(o \rightarrow a)=\frac{\left|\left\langle a\left|V_{1}\right| o\right\rangle\right|^{2}}{2 \hbar^{2}} \mathrm{t} \delta\left(\omega_{\mathrm{ao}}-\omega\right)
$$

O potencial $V_{1}$ apresenta contribuições do campo elétrico e magnético conforme:

$$
V_{1}=-\hat{\mu} \cdot \vec{E}-\widehat{m} \cdot \vec{B}
$$


Em que $\widehat{m}$ é o operador momento magnético (13), e representa a soma das contribuições dos momentos angulares $(\hat{L})$ e spin $(\hat{S})$ de cada $i$ - elétron no sistema, e $\hat{\mu}$ é o operador momento de dipolo elétrico ( $\hat{\mu}=q \hat{x}$, em que $q$ é a carga) (SCHELLMAN, 1975).

$$
\widehat{m}=\frac{e}{2 m c} \sum_{i}\left(\hat{L}_{i}+2 \hat{S}_{i}\right)
$$

Para expressar o módulo quadrático do potencial $V_{1}$, será necessário reescrever as componentes dos operadores $\hat{\mu}$ e $\widehat{m}$ de forma análoga à equação (8) (SCHELLMAN, 1975).

$$
\begin{aligned}
\hat{\mu}_{ \pm} & =\frac{\hat{\mu}_{i} \pm i \hat{\mu}_{j}}{\sqrt{2}} \\
\hat{m}_{ \pm} & =\frac{\hat{m}_{j} \mp i \hat{m}_{i}}{\sqrt{2}}
\end{aligned}
$$

Desta forma, pode-se escrever:

$$
\begin{gathered}
\hat{\mu}=\hat{\mu}_{-} \hat{\mathrm{e}}_{+}+\hat{\mu}_{+} \hat{\mathrm{e}}_{-}+\hat{\mu}_{k} \hat{\mathrm{e}}_{k} \\
\hat{m}=\hat{m}_{-} \hat{h}_{+}+\widehat{m}_{+} \hat{h}_{-}+\widehat{m}_{k} \hat{h}_{k}
\end{gathered}
$$

Em que $\hat{e}_{ \pm}$são os versores que indicam o sentido da polarização circular do campo elétrico, como presente na equação (8), e $\hat{h}_{ \pm}=\left(\hat{\mathrm{e}}_{j} \pm i \hat{\mathrm{e}}_{i}\right) / \sqrt{2}$ é o análogo ao vetor $\hat{\mathrm{e}}_{ \pm}$, mas para o campo magnético. Esta notação facilita identificar que, para uma onda circularmente polarizada à direita por exemplo, os produtos internos da equação (12) serão:

$$
\begin{gathered}
-\hat{\mu} \cdot \vec{E}_{+}=-\left(\hat{\mu}_{-} \hat{\mathrm{e}}_{+}+\hat{\mu}_{+} \hat{\mathrm{e}}_{-}+\hat{\mu}_{k} \hat{\mathrm{e}}_{k}\right) \cdot E_{0} \hat{\mathrm{e}}_{+}=-E_{0} \hat{\mu}_{+} \\
-\hat{m} \cdot \vec{B}_{+}=-\left(\hat{m}_{-} \hat{h}_{+}+\hat{m}_{+} \hat{h}_{-}+\hat{m}_{k} \hat{h}_{k}\right) \cdot B_{0} \hat{h}_{+}=-B_{0} \hat{m}_{+}
\end{gathered}
$$

Assim sendo:

$$
V_{1, \pm}=-\left(E_{0} \hat{\mu}_{ \pm}+B_{0} \hat{m}_{ \pm}\right)
$$


Como o nosso objetivo é calcular o valor de $\left|\left\langle a\left|V_{1}\right| o\right\rangle\right|^{2}$, é conveniente escrever $V_{1}$ na forma $V_{1}=a+i b$, cujo módulo ao quadrado será igual à $\left|V_{1}\right|^{2}=(a+b)^{2}$. Para tanto, assumese que as amplitudes $E_{0}$ e $B_{0}$ são reais. Em seguida um operador $\hat{g}=-i \widehat{m}$ é introduzido. Por fim insere-se a equação (14) em (16) e o potencial é obtido:

$$
V_{1, \pm}=-\left(E_{0} \hat{\mu}_{i} \pm B_{0} \hat{g}_{i}\right)-i\left( \pm E_{0} \hat{\mu}_{j}+B_{0} \hat{g}_{j}\right)
$$

Agora, basta tomar os brackets, obter o módulo ao quadrado do potencial e realizar uma média orientacional sobre os produtos das componentes vetoriais de mesma direção $\left(\left\langle a_{i} b_{i}\right\rangle=\right.$ $\left.\left\langle a_{j} b_{j}\right\rangle=\frac{\langle\vec{a} \cdot \vec{b}\rangle}{3}\right)($ SCHELLMAN, 1975), o que resulta em:

$$
\left|\left\langle a\left|V_{1, \pm}\right| o\right\rangle\right|^{2}=\frac{|\langle a|\hat{\mu}| o\rangle|^{2}}{3} E_{0}^{2}+\frac{|\langle a|\hat{g}| o\rangle|^{2}}{3} B_{0}^{2} \pm 2 \frac{|\langle a|\hat{\mu} \cdot \hat{g}| o\rangle|^{2}}{3} E_{0} B_{0}
$$

A cada termo multiplicando os campos é dado um nome específico, mas apenas o último difere devido à polarização da luz (SCHELLMAN, 1975).

$$
\begin{array}{ll}
D_{o a}=|\langle a|\hat{\mu}| o\rangle|^{2} & \text { Capacidade de dipolo elétrico (electric dipole strength) } \\
G_{o a}=|\langle a|\hat{g}| o\rangle|^{2} & \text { Capacidade de dipolo magnético (magnetic dipole strength) } \\
R_{o a}=-|\langle a|\hat{\mu} \cdot \hat{g}| o\rangle|^{2} & \text { Capacidade rotacional (rotational strength) }
\end{array}
$$

Com essas redefinições e utilizando a equação (6), podemos finalmente reescrever a equação (18) como:

$$
\left|\left\langle a\left|V_{1, \pm}\right| o\right\rangle\right|^{2}=\frac{8 \pi I}{3 c}\left(\frac{D_{o a}}{n}+n G_{o a} \mp 2 R_{o a}\right)
$$

Em que $n$ é o índice de refração do meio (SCHELLMAN, 1975). Nesse sentido, a probabilidade de transição do estado fundamental para o estado excitado será dado ao inserir o resultado da equação (20) na equação (11).

No caso de moléculas mais complexas em solução, há uma imensidade de graus de liberdade de baixa energia excitáveis. Essas várias transições produzes uma banda de absorção, 
cuja estrutura fina dificilmente é identificada em um espectrômetro convencional. Para levar em conta todos esses outros possíveis estados intermediários, é introduzida uma densidade de transição específica para cada termo da equação (20) (SCHELLMAN, 1975). Considerando as densidades de transição devido a cada uma das "capacidades", respectivamente nomeadas de $\rho(\omega), \tau(\omega)$ e $\sigma(\omega)$, temos:

$$
\begin{gathered}
P(o \rightarrow a)=\frac{4 \pi I}{3 c \hbar^{2}} t \delta\left(\omega_{a o}-\omega\right)\left(\rho\left(\omega_{a o}\right) \frac{D_{o a}}{n}+\tau\left(\omega_{a o}\right) n G_{o a}\right. \\
\left.\mp 2 \sigma\left(\omega_{a o}\right) R_{o a}\right)
\end{gathered}
$$

Uma grandeza interessante de ser analisada é a taxa de absorção (22), definida como a derivada temporal da probabilidade de transição $\left(w_{a o^{ \pm}}\right)$.

$$
\begin{aligned}
w_{a o^{ \pm}}\left(\omega_{a o}\right)= & \frac{4 \pi I}{3 c \hbar^{2}} \delta\left(\omega_{a o}-\omega\right)\left(\rho\left(\omega_{a o}\right) \frac{D_{o a}}{n}+\tau\left(\omega_{a o}\right) n G_{o a}\right. \\
& \left.\mp 2 \sigma\left(\omega_{a o}\right) R_{o a}\right)
\end{aligned}
$$

A partir dessa grandeza, é possível calcular a seção de choque de absorção $\alpha(\omega)$ (23), que representa a energia total absorvida por unidade de tempo dividida pela intensidade total da luz incidente (TOMAKOFF, 2020). Como a equação (22) define a taxa de absorção apenas para $\omega_{a o}$, é necessário integra-la em $d \omega_{a o}$ (SCHELLMAN, 1975).

$$
\alpha_{ \pm}(\omega)=\frac{\hbar}{I} \omega \int_{-\infty}^{+\infty} w_{a o^{ \pm}}\left(\omega_{a o}\right) d \omega_{a o}=\frac{\hbar w_{a o^{ \pm}}}{I} \omega
$$

Substituindo o resultado de (22), tem-se:

$$
=\omega \frac{4 \pi}{3 c \hbar}\left(\rho(\omega) \frac{D_{o a}}{n}+\tau(\omega) n G_{o a} \mp 2 \sigma(\omega) R_{o a}\right)
$$

Portanto, o coeficiente de extinção molar da molécula para a onda circularmente polarizada (à direita e à esquerda, respectivamente) será: 


$$
\begin{aligned}
\varepsilon_{ \pm}(\omega)=\frac{\mathrm{N}_{\mathrm{A}}}{2303} & \alpha_{ \pm}(\omega) \\
& =\omega \frac{4 \pi N_{A}}{3(2303) c \hbar}\left(\rho(\omega) \frac{D_{o a}}{n}+\tau(\omega) n G_{o a} \mp 2 \sigma(\omega) R_{o a}\right)
\end{aligned}
$$

Um material dicroico pode absorver luzes com mesma frequência, mas polarizadas em direções diferentes, em quantidade distintas. O CD é então definido como a diferença na absorção das luzes circularmente polarizadas à direita e à esquerda. Essa diferença de absorção é refletida num valor distinto para os coeficientes de extinção molar $\varepsilon_{+}$e $\varepsilon_{-}$. Materiais que apresentam sinais de CD possuem uma capacidade rotacional não nula, a qual é a responsável pela diferença na absorção, dado que:

$$
\Delta \varepsilon(\omega)=\varepsilon_{+}(\omega)-\varepsilon_{-}(\omega)=\frac{-16 \pi \omega N_{A}}{3(2303) c \hbar} \sigma(\omega) R_{o a}
$$

Um espectro de CD, tipicamente, possui no seu eixo vertical a variável dependente $\Delta \varepsilon$, já em seu eixo horizontal a variável independente escolhida é o comprimento de onda da luz $(\lambda)$, que no que lhe concerne pode ser relacionada com a frequência angular. De acordo com Schellman (1975), devido a normalização de $\sigma(\omega)$ é possível mostrar que $\omega \sigma(\omega)=\lambda \sigma(\lambda)$. Dessa forma, pode-se recuperar a capacidade rotacional total do material estudado através de uma mudança de variável e uma integração na equação (26) (SCHELLMAN, 1975; WOODY, 1996).

$$
R_{o a}=\frac{3(2303) \hbar c}{16 \pi^{2} N_{A}} \int \frac{\Delta \varepsilon(\lambda)}{\lambda} d \lambda
$$

\section{III.4 - A lei de Beer-Lambert}

A Lei de Beer-Lambert é uma das equações fenomenológicas mais importantes para a espectroscopia. Ela relaciona a absorbância $(A)$ de uma amostra com a sua concentração $(c)$, o seu coeficiente de extinção molar $(\varepsilon)$ e o caminho óptico do recipiente em que a amostra se encontra (l). A absorbância é calculada como o logaritmo na base 10 da razão entre a intensidade da luz transmitida $\left(I_{1}\right)$ e emitida na amostra $\left(I_{0}\right)$. 


$$
A=\log _{10} \frac{I_{0}}{I_{1}}=c l \varepsilon
$$

Utilizando a relação expressa na equação (6) para uma luz incidindo perpendicularmente em uma amostra ( $\alpha=0$ ), e realizando uma mudança de base do logaritmo na equação (28), é possível obter a amplitude do campo elétrico transmitido pela amostra como:

$$
E_{1}=E_{0} e^{-\frac{A}{2} \ln 10}
$$

Essa relação também é válida para as amplitudes de ondas circularmente polarizadas à direita e à esquerda. Com isso, pode-se inserir a equação (29) na equação (10) para relacionar o ângulo $\theta$ com a absorbância. Como $\Delta A \ll 1$ é possível expandir em primeira ordem a exponencial da equação $(29)\left(e^{x} \approx 1+x\right)$ e desprezar o termo de ordem $\Delta A$ no denominador, e ainda escrever a diferença de absorbância em termos do $\Delta \varepsilon$. Desta forma, encontramos a equivalência entre $\theta$ e $\Delta \varepsilon$, e como converter uma unidade para a outra (WOODY, 1996).

$$
\theta[\mathrm{rad}]=\frac{\ln 10}{4} \operatorname{cl} \Delta \varepsilon
$$

Como $\theta$ é medido em graus, ainda é necessário converter a equação (30).

$$
\theta\left[^{\circ}\right]=\frac{\ln 10}{4}\left(\frac{180}{\pi}\right) \operatorname{cl} \Delta \varepsilon
$$

É comum encontrar em livros textos (WOODY, 1996; JANES; WALLACE, 2009) o valor numérico aproximado de 32,98 para a multiplicação das constantes da equação (31). Há uma vantagem clara na utilização do $\Delta \varepsilon$ como a nossa variável dependente, uma vez que ele é normalizado para a concentração e para comprimento do porta amostra. Entretanto, para tal conversão, é necessário obter $c$ e $l$ com uma ótima precisão. Caso contrário haverá uma assimetria na distribuição de probabilidade de $\Delta \varepsilon$, e com isso uma tendência de se obter amplitudes maiores para essa grandeza. Uma discussão completa desse problema se encontra na seção V.12 desse capítulo.

Uma forma análoga ao $\Delta \varepsilon$ de representar os resultados de CD, ou seja, normalizada para $c$ e $l$ é a elipticidade molar: $[\theta]=3298 \Delta \varepsilon$.

III.5 - O CD aplicado ao estudo de proteínas e peptídeos. 
Sistemas que possuem uma capacidade rotacional nula não apresentam sinal de CD. Isto ocorrerá apenas se o produto escalar $\hat{\mu} \cdot \hat{g}$ for nulo, ou seja, se ao menos um dos momentos for igual a zero, ou então se eles forem perpendiculares entre si. Ambos casos só ocorrem se a molécula possuir um eixo de simetria especular (WOODY,1996). As moléculas que apresentam capacidade rotacional não nula são nomeadas de quirais. Um objeto quiral apresenta uma estrutura tridimensional que não pode ser superposta pela sua imagem especular (a mão humana é talvez o exemplo mais conhecido que ilustra esta assimetria). Uma molécula que possui quiralidade pode apresentar uma estrutura de "mão-esquerda" ("left-handed", como a maioria dos aminoácidos encontrados na natureza) ou de "mão-direita" ("right-handed", como a maioria dos açúcares no nosso organismo). Ao comparar uma molécula quiral com a sua molécula "especular", será possível notar que ambas possuem as mesmas propriedades físicas escalares (por exemplo, a massa molecular, entalpia de formação, e densidade), sendo então apenas distinguidas a partir da sua interação com a luz circularmente polarizada.

Grupos aquirais (formados por resíduos de moléculas que não possuem quiralidade intrínseca) também podem, todavia, apresentar uma capacidade rotacional não nula se fizerem parte de moléculas complexas e quirais (WOODY,1996). Isso pode acontecer devido à interação com outros grupos, que distorcem a estrutura eletrônica e quebram a simetria do resíduo. Desta forma, como uma molécula complexa possui diversas regiões capazes de apresentar um sinal de $\mathrm{CD}$, a estratégia para lidar com esse problema é dividir a molécula em grupos funcionais: os cromóforos. Estes são justamente separados em dois grupos: os inerentemente quirais e os aquirais com dissimetria (com simetria perturbada) (MOFFITT; MOSCOWITZ, 1959; MOSCOWITZ et al, 1962).

Diversas moléculas biológicas possuem quiralidade intrínseca (KWIT et al, 2012). Mas são as proteínas que destacam pelo grande número de estudos realizados utilizando o dicroísmo circular (KELLY et al, 2005). As proteínas, moléculas fundamentais para a vida, são polímeros de resíduos de aminoácidos capazes de se auto ordenar em estruturas complexas, que estão fortemente associadas com a função biológica da molécula. Um aminoácido (aa) é composto por um carbono central $\left(C_{\alpha}\right)$ que está ligado a um grupo carboxílico, um grupo amino, um hidrogênio e um terminal $\mathrm{R}$, que varia em cada aa. Todos aa são quirais, com exceção apenas da glicina, cujo R terminal consiste em um hidrogênio (NELSON; COX, 2004).

Dois aa são capazes de se ligarem através de uma ligação peptídica entre os grupos carboxílico e amino. Isto acontece através de uma reação que transforma ambos aa em resíduos de aminoácido, liberando uma molécula de água. A ligação peptídica é mais rígida do que uma ligação covalente convencional, assim sendo, ela forma um plano. Uma proteína então pode ser 
entendida como a junção de diversos planos formados pela ligação peptídica que podem rotacionar um em relação ao outro através de dois ângulos diédricos $(\phi$ e $\psi)$. Entretanto, nem todas as duplas $(\phi, \psi)$ são possíveis, como é descrito pelo diagrama de Ramachandran. Formam-se então estruturas canônicas locais que são estabilizadas através de ligações de hidrogênio entre resíduos de aa próximos. Estas estruturas são nomeadas como estruturas secundárias, enquanto a sequência dos resíduos de aa por si é chamada de estrutura primária. As estruturas secundárias mais comuns numa proteína são $\alpha$-hélice, fita- $\beta$, voltas e estrutura não-ordenadas, entretanto há diversas outras que também são capazes de serem identificadas com o CD (por exemplo, as hélices- $3_{10}$ e hélices poliprolina) (NELSON; COX, 2004; WALLACE; JANES, 2009; FASMAN, 1996).

É na ligação peptídica (mais especificamente, no grupo amida) que o principal cromóforo das proteínas e dos peptídeos é encontrado. As transições eletrônicas presentes neste grupo acontecem principalmente na região do UV-distante (160-240nm), sendo assim esta é a região mais utilizada para investigar a estrutura secundária dessas moléculas. É importante ressaltar que há outros possíveis cromóforos encontrados nas proteínas, como, por exemplo, os resíduos de triptofano, tirosina e fenilalanina, e as ligações dissulfeto. Entretanto, estes grupos apresentam um sinal de CD predominante apenas na região de UV-próximo $(\lambda>290 \mathrm{~nm})$. A figura 4 representa esquematicamente as transições passíveis de ocorrer no grupo amida, o qual possui três orbitais $\pi$ e dois pares não ligantes de elétrons (n) presentes no oxigênio. As transições possíveis são do tipo $\pi \pi^{*}$, que levam a molécula do estado ligante $(\pi)$ para o antiligante $\left(\pi^{*}\right)$, e as do tipo $n \pi^{*}$ (BULHELLER et al, 2007;WALLACE; JANES, 2009; FASMAN, 1996).

Quando se trata do espectro de CD de polipeptídios, que apresentam diversos cromóforos, a situação torna-se um pouco mais complicada para análise. Na metade do século XX surgiram os primeiros modelos capazes de explicar o espectro de CD de alguns polímeros com estruturas bem definidas (MOFFITT ,1956; MOFFITT et al,1957; TINOCO,1962). A maioria deles apresentou a estratégia de dividir a molécula em $N$ cromóforos independentes (cada um com $n_{i}$ estados) que possuem uma função de onda monomérica $\phi_{i s}$, em que $i$ é o índice do cromóforo, e $s$ o seu estado. A função de onda que representa o polímero em um estado excitado $k\left(\Psi^{k}\right)$ é então aproximada como sendo uma combinação linear de todas as configurações eletrônicas. Cada configuração eletrônica é, no que lhe concerne, definida como $\Phi_{i a}=\phi_{i a} \cdot \prod_{j \neq i} \phi_{j 0}$. Em outras palavras, tem-se o produto das funções de ondas de todos os 
cromóforos diferentes de $i$ no estado fundamental multiplicado pela função de onda do cromóforo $i$ no estado excitado.

Figura 4 - Transições eletrônicas no CD

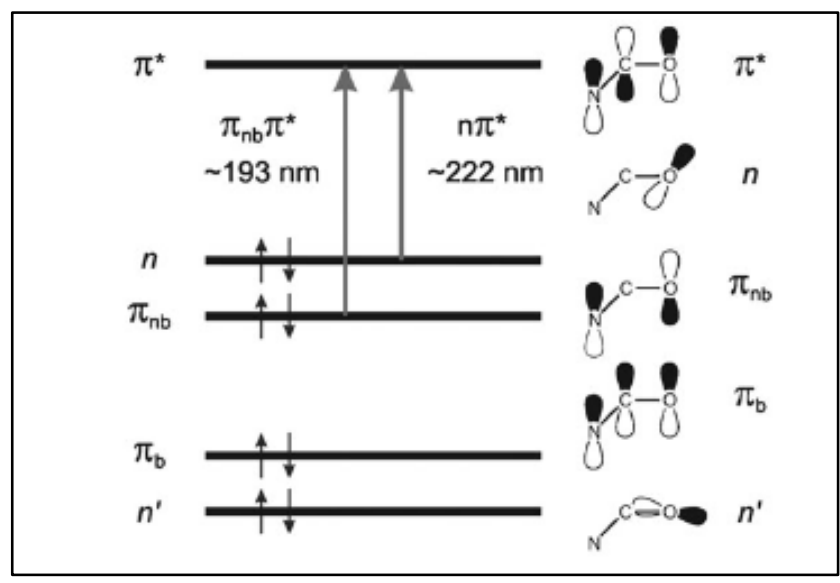

Adaptado de: Bulheller, Rodger e Hirst (2007).

$$
\Psi^{k}=\sum_{j}^{N} \sum_{a}^{n_{i}} C_{i a}^{k} \Phi_{i a}
$$

Moffitt (1956) foi uma das primeiras pessoas a propor uma teoria que descrevesse as transições eletrônicas presentes em polímeros helicoidais, estrutura modelo para uma $\alpha$-hélice. No trabalho, o autor utiliza um formalismo de perturbação para obter a solução da equação (32), com a qual é capaz de identificar duas transições eletrônicas possíveis, uma paralela à direção da hélice e outra perpendicular (duplamente degenerada) a esse eixo. A primeira apresenta uma capacidade rotacional negativa, já a segunda, positiva.

Entretanto, como descrito por Woody (1996), a teoria proposta por Moffitt (1956) estava incompleta e a sobreposição das bandas geradas por essas duas transições não era suficiente para reproduzir completamente um espectro de uma $\alpha$-hélice. Foi então que no ano seguinte, com o auxílio da teoria de osciladores acoplados degenerados de Kirkwood (KIRKWOOD, 1937), Moffitt e seus colaboradores (MOFFITT et al,1957), adicionam um termo na capacidade rotacional, cujo espectro de CD apresenta duas bandas: uma negativa por volta de $180 \mathrm{~nm}$ e outra positiva em torno $200 \mathrm{~nm}$. Essa contribuição foi nomeada posteriormente de bandas de hélice (WOODY,1996). As transições propostas inicialmente por Moffitt (1956) são hoje atribuídas a transições $\pi \pi^{*}$, e são chamadas de $\pi \pi_{\|}^{*}$ (paralela, que apresenta um vale centrado 
em $200 \mathrm{~nm}$ ) e $\pi \pi_{\perp}^{*}$ (perpendicular, apresentando um pico em $190 \mathrm{~nm}$ ). Além destas quatro bandas, ainda é necessário incluir uma banda de transição do estado n para $\pi^{*}\left(n \pi^{*}\right.$, com um vale em 220 nm), que surge devido a um efeito Cotton (SCHELLMAN; ORIEL, 1962) e é menos provável de acontecer e, portanto, apresenta uma capacidade rotacional com módulo menor (WOODY, 1968). A Figura 5 mostra todas as bandas de absorção presentes em uma $\alpha$ hélices, e a sobreposição destas, formando o conhecido espectro dessa estrutura secundária.

Figura 5 - Bandas de absorção $\alpha$-hélices

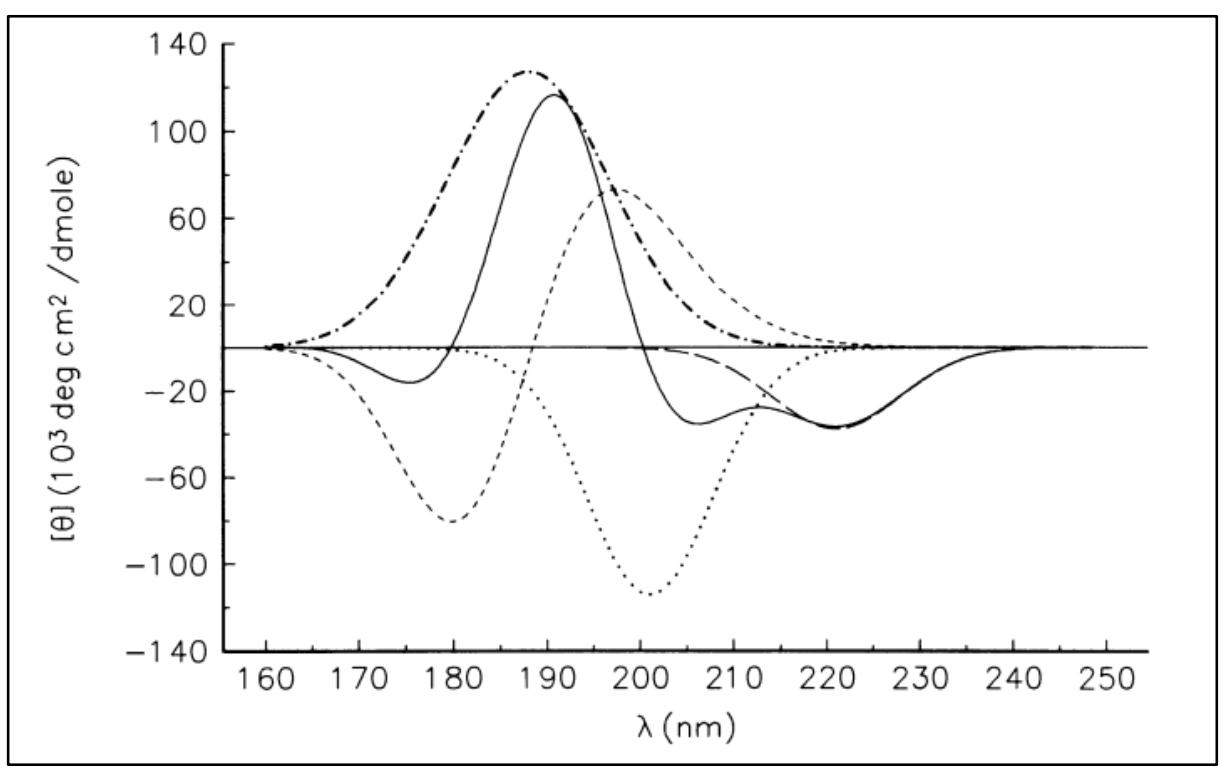

$(---)$ representa a banda $n \pi^{*},(\cdots)$ a banda $\pi \pi_{\|}^{*},(-\cdot-\cdot-\cdot)$ a banda $\pi \pi_{\perp}^{*},(---)$ a banda em hélice, e por fim a sobreposição de todas gera a linha contínua (espectro de CD de uma $\alpha$-hélice). Retirado de Woody (1996).

Na década seguinte, Tinoco (1962) desenvolveu o método matricial para resolver o problema expresso na equação (32) (WOODY,1996). Ele consiste em encontrar os autovalores e autovetores da equação de Schrödinger $\left(\widehat{H} \Psi^{k}=E^{K} \Psi^{k}\right)$, cujo o hamiltoniano é dado por uma matriz em que os elementos diagonais são os autovalores de energia de cada estado, e os elementos fora da diagonal são potenciais de interação entre diferentes transições. O leitor interessado pode referir-se à Bulheller et al (2007) para mais detalhes deste método com uma notação atual e de fácil compreensão.

Woody (1996) ainda descreve uma relação empírica (33) proposta primeiramente por Chen et al (1974), a qual permite a estimação do comprimento de uma $\alpha$-hélice através de seu espectro de CD. Essa ferramenta é importante no contexto desta dissertação, dado que traz argumentos para estimar a região de hélice e não-ordenada em peptídeos antimicrobianos. Na 
relação expressa em (33), $\Delta \varepsilon_{\text {exp }}$ é o valor experimental obtido para o espectro do polipeptídio, $\Delta \varepsilon_{\infty}$ é uma constante teórica para o valor do espectro de CD de uma hélice infinita, $k$ está relacionada ao número de amidas faltantes, e $n$ é o número de amidas presentes na hélice. Woody (1996) apresenta os resultados obtidos por Gans et al (1991) e Jackson et al (1991), os quais apontam um valor de $k=4,58$ e $[\theta]_{\infty}=-41000 \mathrm{deg} \frac{\mathrm{cm}^{2}}{\mathrm{dmole}}$ para $\lambda=222 \mathrm{~nm}$ (equivalente a $\Delta \varepsilon_{\infty} \approx-12,4 \mathrm{M}^{-1} \mathrm{~cm}^{-1}$ ).

$$
\Delta \varepsilon_{\text {exp }}=\Delta \varepsilon_{\infty}(n-k) / n
$$

Além da estrutura em $\alpha$-hélice, estruturas como fitas- $\beta$ e não-ordenadas também apresentam um espectro característico de $\mathrm{CD}$, como representado na figura 6 . A transição associada com a banda negativa das fitas- $\beta$ em $215 \mathrm{~nm}$ é a $n \pi^{*}$, enquanto a banda positiva na região dos $198 \mathrm{~nm}$ é referente a uma transição $\pi \pi^{*}$ (WOODY, 1996).

Figura 6 - Espectros de CD de fitas- $\beta$ e não-ordenadas

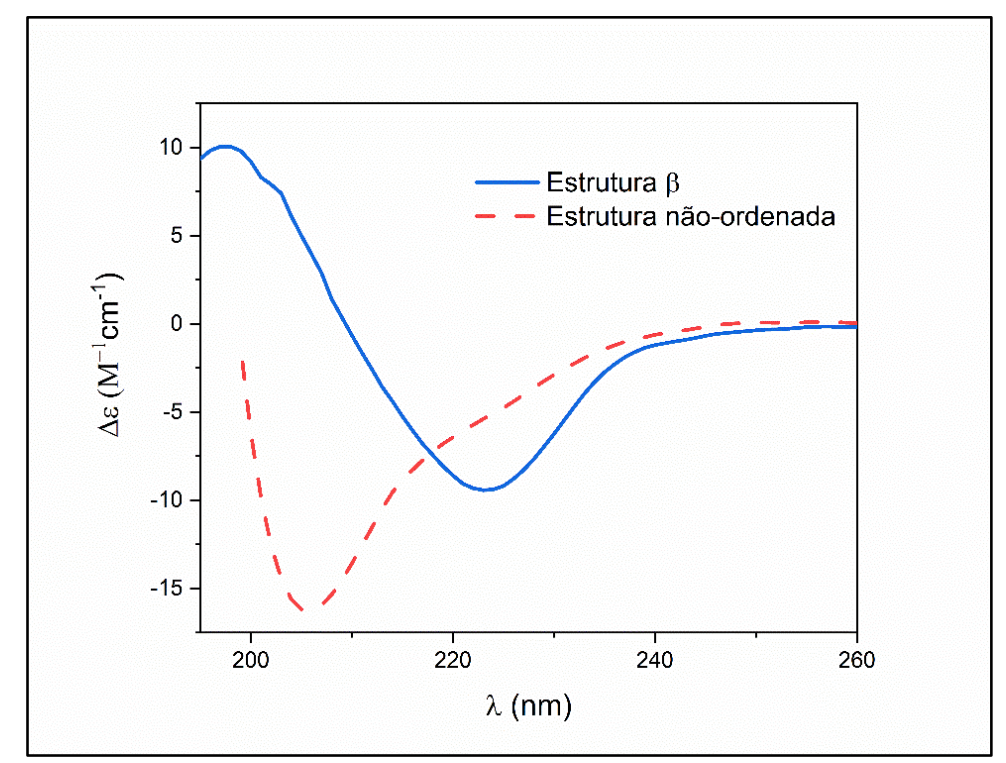

Espectros das proteínas Concanavalina A (Estrutura $\beta$ ) e Inibidor de Tripsina de Soja (Estrutura não-ordenadas). Espectros concedidos pela Jéssica A. Pedro, resultados ainda não publicados.

A estrutura não-ordenada será de grande relevância na discussão de peptídeos antimicrobianos desta dissertação. O espectro dessas estruturas, como descrito por Woody (1996), é um dos mais difíceis de ser calculado teoricamente, dado que essa categorização não é a princípio muito bem definida. Ela pode incluir proteínas com as mais diversas conformações 
(não canonizadas), sofrer influência de diversas combinações dipeptídicas diferentes e ainda o seu espectro pode ser facilmente confundido com um espectro de poliprolina tipo II. Tanto as estruturas não-ordenadas, quanto as poliprolina tipo II apresentam uma banda negativa em torno de $200 \mathrm{~nm}$, sendo levemente distinguidas pela banda positiva em 220nm presente nas poliprolinas tipo II (Lopes et al. ,2014).

\section{III.6 - Métodos, servidores e algoritmos para análise do CD de proteínas}

Proteínas apresentam, geralmente, mais de um tipo de estrutura secundária compondo sua estrutura terciária. Assim, o espectro de CD delas $(S(\lambda))$ pode ser interpretado como uma combinação linear das contribuições de cada uma das estruturas secundárias presentes $\left(A_{i}(\lambda)\right)$ (VENYAMINOV; YANG, 1996).

$$
S(\lambda)=\sum_{i} \alpha_{i} A_{i}(\lambda)
$$

Em que $\alpha_{i} \geq 0$ é a fração da proteína que possui estrutura secundária $A_{i}$, assim, a soma de todos os $\alpha_{i}$ é normalizada para um. O problema então se torna encontrar os coeficientes $\alpha_{i}$, dado um espectro de uma proteína e uma base de dados contendo os valores de $A_{i}$. Isto se traduz como uma desconvolução (VENYAMINOV; YANG, 1996). Entretanto, os valores exatos de $A_{i}$ não são facilmente obtidos e podem variar bastante dependendo dos modelos polipeptídicos escolhidos, principalmente para as estruturas em fitas- $\beta$ e não-ordenadas. Na década de 80 , Provencher, e Glockner (1981) desenvolveram um método mais moderno de desconvolução, optando por utilizar uma base contendo os espectros de CD de diversas proteínas com estruturas cristalográficas resolvidas. Desta forma, a equação (34) é reescrita como:

$$
S(\lambda)=\sum_{j} \gamma_{j} R_{j}(\lambda)
$$

Em que $R_{i}$ representa o espectro da proteína $j$ da base de dados e $\gamma_{j}$ pode ser relacionado com a porcentagem de cada estrutura secundária presente na proteína investigada por meio de:

$$
\alpha_{i}=\sum_{j} \gamma_{j} F_{j i}
$$


Onde, $F_{j i}$ é a fração dos resíduos da proteína $j$ na conformação $i$. Essa informação é obtida através da estrutura cristalográfica, assim, independe do espectro de CD da proteína contida na base de dados. O algoritmo proposto por Provencher,e Glockner (1981) capaz de resolver as equações (35) e (36) é conhecido como Contin, e se baseia em um método estatístico de regularização de Tikhonov. Nos anos seguintes, Stokkum et al (1990), propôs um método de resolução similar ao de Provencher conhecido como "modelo linearizado localmente" (LL), atualmente esse método é nomeado de ContinLL.

Outros dois métodos amplamente utilizados são o CDSSTR e o Selcon3. O primeiro foi desenvolvido na segunda metade da década de 80 pelo grupo do Dr. W.C Johnson, Jr. da Oregon State University, em duas publicações (COMPTON; JOHNSON, 1986; MANAVALAN; JOHNSON, 1987). A primeira versão desse método foi nomeada de VARSLC, e o método utiliza um algoritmo de decomposição de valores singulares (SVD). A maior diferença do CDSSTR para as suas versões anteriores é a restrição do número de proteínas utilizadas na base de dado para oito, que de acordo com Johnson (1999) aprimorou os resultados.

O Selcon3 é uma versão atualizada do algoritmo Selcon, que foi inicialmente desenvolvido na década de 90 pelo grupo do Dr. Woody, R.W (SREERAMA; WOODY, 1993). Neste método, o espectro da proteína a ser analisada é incluído junto a base que contém os espectros com estrutura resolvida. É dado um chute inicial para os valores de $\alpha_{i}$ como sendo igual ao da proteína contida na base cujo espectro de CD é o mais similar ao espectro da proteína estudada. O método então utiliza uma mistura do algoritmo SVD e do modelo LL.

Sreerama e Woody (2000) realizaram uma comparação entre os três algoritmos utilizando diversas bases de dados diferentes, e de forma geral os resultados obtidos foram similares. A recomendação dos autores é a utilização dos três métodos de forma conjunta, o que aumenta a confiança nos resultados. Atualmente, existem portais online que permitem os usuários acessarem estes métodos e à diferentes bases de proteínas. Entre estes um dos mais conhecidos é o Dichroweb (WHITMORE; WALLACE, 2004), que atualmente disponibiliza quatro principais bases de dados, os três métodos descritos e utiliza o valor do NRMSD (raiz do erro quadrático médio normalizada) (37) como parâmetro para analisar a qualidade do resultado.

$$
N R M S D=\left(\frac{\sum_{N}\left(S_{m o d}-S_{e x p}\right)^{2}}{\sum_{N} S_{\text {exp }}^{2}}\right)
$$


$S_{\text {mod }}$ representa o espectro modelo e $S_{\text {exp }}$ o espectro obtido experimentalmente para a proteína a ser analisada. $N$ é o número de pontos medidos, que está relacionado ao intervalo escolhido para o comprimento de onda.

O NRMSD representa o quão próximo o espectro modelo, gerado a partir da sobreposição dos espectros contidos na base de dados, é do espectro experimental. Assim, um valor baixo (NRMSD < 0,100) é essencial para garantir que o método utilizado gerou um resultado aceitável (WHITMORE; WALLACE, 2004). Entretanto, não é suficiente para garantir que os valores de $\alpha_{i}$ serão acurados, como mostra Miles et al (2005), e nem precisos (SOUSA et al ,2021).

Outro algoritmo disponível online é o BeStSel (MICSONAI et al,2018), o qual utiliza um método de deconvolução baseado no método dos mínimos quadrados, e possui uma base de proteínas desenhada para aumentar a acurácia na predição da estrutura secundária em folhas- $\beta$.

Como é descrito por Venyaminov e Yang (1996), todas as abordagens de deconvolução apresentadas aqui são válidas apenas a partir de algumas hipóteses. Primeiro, é necessário que a solução da estrutura das proteínas existentes na base de dados seja obtida em condição próxima a proteína estudada, uma vez que em outros meios pode haver alteração na estrutura da proteína. Adicionalmente, que assume-se que podemos negligenciar efeitos da estrutura terciária no espectro de $\mathrm{CD}$, que todas as proteínas em solução apresentam a mesma conformação, e que o seu resultado será expresso como na equação (34). Além disso, é necessário assumir que a ligação peptídica é o único cromóforo, e, por fim, que cada estrutura secundária apresenta apenas um espectro característico de CD. 


\section{IV - Materiais e Métodos}

\section{IV.1 Proteína e peptídeo modelo}

Neste trabalho, foram obtidos espectros de CD de dois modelos distintos, uma proteína globular, a mioglobina (Mb), e o peptídeo antimicrobiano (PAM), Plantaricina 149 (Pln149).

A Mb de músculo esquelético de equino foi adquirida da Sigma Aldrich e utilizada como proteína modelo para a maioria dos ensaios de CD aqui realizados. A Mb escolhida é uma proteína pequena, com 153 resíduos de aa, com massa molecular de aproximadamente 17kDa. Ela possui 8 hélices conectadas por regiões desordenadas, sendo 7 hélices ordenadas como uma estrutura em $\alpha$-hélices (equivalente a $70 \%$ da proteína), e a última uma hélice- $3_{10}$ (EVANS; BRAYER, 1990). Dessa forma, a Mb torna-se um ótimo modelo de proteínas em $\alpha$-hélices, e apresenta um espectro de CD muito próximo ao descrito na seção I.3.

Figura 7 - Estrutura cristalográfica da Mb (PDB 2NSS).

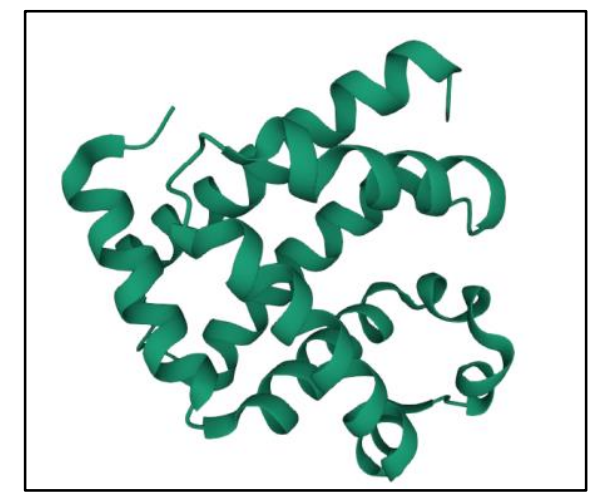

Adaptado do Protein Data Bank (PDB) ${ }^{4}$.

De acordo com a Sigma Aldrich, a amostra utilizada apresenta pureza entre 95\% e 100\%, é essencialmente livre de sais e possui um conteúdo de ferro entre 0,25 e 0,32\%. Para todos os ensaios, a mioglobina foi preparada em solução de tampão fosfato de sódio (PBS) $10 \mathrm{mM}$ em $\mathrm{pH} 7,0$.

Já a Pln149 é um PAM linear e catiônico, com a sequência de 22 resíduos de aa: YSLQMGATAIKQVKKLFKKKGG (KATO et al, 1994), naturalmente encontrado na bactéria Lactobacillus plantarum NRIC149. A amostra utilizada neste trabalho foi sintetizada em fase sólida pelo Prof.Dr. José Luiz de Souza Lopes, utilizando a química do Fmoc (mais detalhes da

\footnotetext{
${ }^{4}$ Disponível online: <https://www.rcsb.org/structure/2NSS />. Acesso em: 20 maio 2021
} 
técnica no capítulo 2). A pureza do peptídeo foi determinada como sendo maior que $95 \%$, e sua massa molecular calculada através de espectroscopia de massa como sendo 2423,7 Da (LOPES et al, 2010).

Na literatura, existem diversos estudos com a Pln149 (LOPES et al, 2009;LOPES et al, 2010; LOPES et al, 2013ª; LOPES et al 2013b; KUMAGAI et al, 2019) apontando que em solução puramente aquosa, esse peptídeo apresenta uma estrutura não-ordenada, mas na presença de membranas lipídicas é capaz de sofrer uma transição para uma estrutura em $\alpha$ hélice.

\section{IV.2 Espectrômetro de CD}

De acordo com Kelly et al. (2005) e Johnson (1996) existem pelo menos três métodos para medir o efeito de CD. O primeiro, utilizado pelo J-815, é a partir da modulação, em que a luz incidente é continuamente alternada entre a polarização à direita e à esquerda. Além disso, um espectro de CD poderia ser obtido através da subtração direta da absorbância de LCP medida separadamente. Por fim, os autores ainda descrevem que o efeito de CD pode ser medido através do ângulo $\theta$, como mencionado nas seções anteriores desta dissertação.

Figura 8 - Esquematização dos componentes presentes em um espectrômetro de CD.

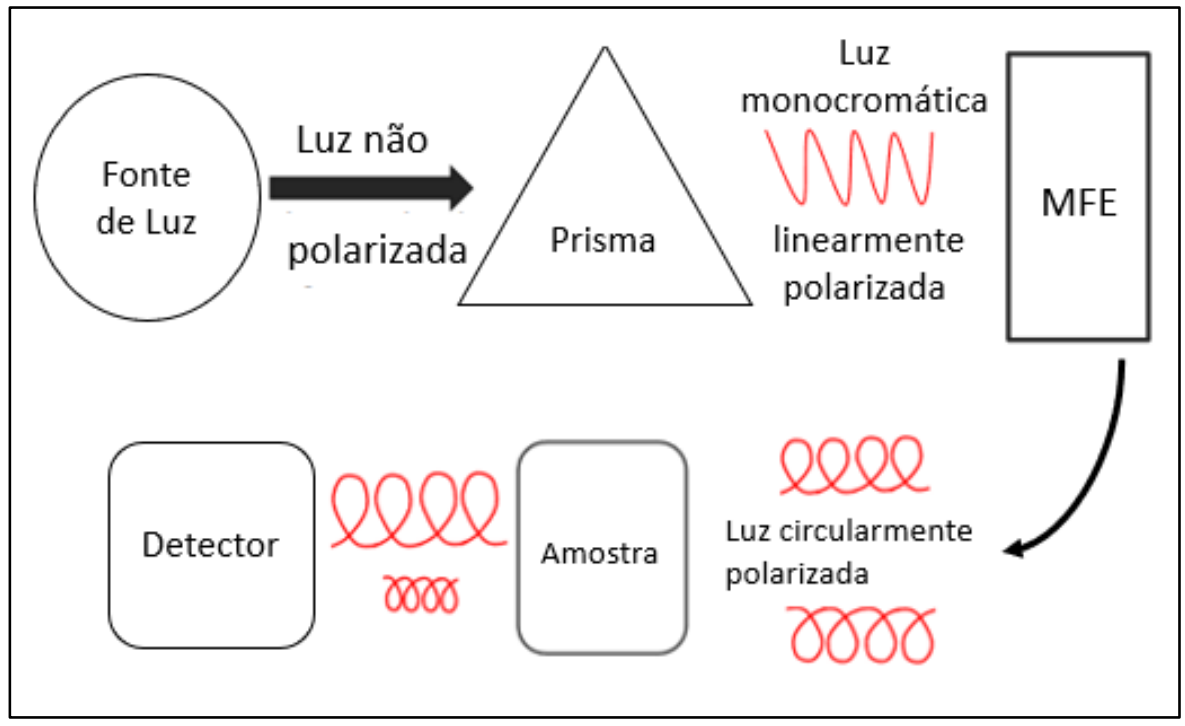

Adaptada de Jasco Inc. ${ }^{5}$

\footnotetext{
5 Disponível online: <https://jascoinc.com/learning-center/theory/spectroscopy/circular-dichroismspectroscopy/>. Acesso em: 20 maio 2021
} 
A figura 8 apresenta um esquema dos espectrômetros da Jasco, os quais possuem uma fonte de luz (normalmente uma lâmpada de Xenon 150W) e um conjunto de dois prismas, o primeiro sendo responsável por selecionar o comprimento de onda desejado, e o segundo por polarizar a luz linearmente. O equipamento também possui um modulador fotoelástico (MFE), uma peça de quartzo semirevestida por um material condutor. Tensão é aplicada nessa região, o que faz o material piezoelétrico vibrar gerando um estresse que induz uma birrefringência. Assim, uma das componentes da LLP ao atravessar o MFE, torna-se defasada em $90^{\circ}$, gerando uma LCP. A onda gerada será dextrogira se o quartzo é comprimido, e levogira no caso contrário (KELLY et al., 2005; JOHNSON,1996).

Em seguida, as LCP atravessam a amostra, que deve estar em algum porta-amostras transparente ao comprimento de luz utilizado. Para este trabalho, foi utilizada uma cubeta Suprasil de quartzo, com caminho óptico de 0,1 cm (Hellma, Alemanha). Por fim, a luz atinge um tubo de detecção fotomultplicador, o qual amplifica o sinal recebido. O quanto o sinal é amplificado está relacionado a tensão aplicada no fotomultiplicador (HT), que é a mesma aplicada no MFE. Valores de HT muito alto indicam que poucos fótons estão sendo detectados, logo, diminuindo a relação sinal-ruído $(S / N)$. A recomendação da Jasco é manter o HT menor que 700V (JASCO INC.,2021; KELLY et al, 2005; JOHNSON,1996).

A relação $S / N$ é diretamente proporcional a raiz quadrada da quantidade de fótons detectados $\left(n_{f}\right)$, visto que o sinal obtido (intensidade de luz) é proporcional a $n_{f}$, e a função de probabilidade que descreve esse fenômeno é próxima a uma Poisson, a qual possui seu desvio padrão como sendo aproximadamente $\sqrt{n_{f}}$. Portanto, aumentar a quantidade de fótons que chegam ao fotomultiplicador é fundamental para aumentar a qualidade do espectro obtido. Para tanto, é importante que haja um fluxo alto de nitrogênio, dado que o oxigênio pode absorver luz na região $190 \mathrm{~nm}$. Além disso, o oxigênio pode oxidar o conjunto de espelhos presentes no espectrômetro e diminuir a vida útil do equipamento (JASCO INC.,2021; KELLY et al., 2005; JOHNSON,1996).

Todos os espectros de $\mathrm{CD}$ para a $\mathrm{Mb}$ foram tomados utilizando o mesmo espectrômetro J-815 da Jasco (Japão), disponível no laboratório do Grupo de Biofísica Molecular "Sérgio Mascarenhas", São Carlos, IFSC, USP, com os parâmetros variados conforma a seção IV.3, e calibrado utilizando uma solução de D-(+)-10-ácido camforsufônico (CSA) (MILES; WALLACE, 2009; JOHNSON,1996). Já os espectros da Pln149 foram tomados utilizando a linha de luz AU-CD do sincrotron ASTRID2 no ISA (Universidade de Aarhus, Dinamarca). 
Uma das maiores vantagens da luz sincrotron para o CD é a alta intensidade da fonte de luz, que reduz consideravelmente os valores de HT e nos permite alcançar comprimentos de onda mais baixos (KUMAGAI et al., 2017(a); KUMAGAI et al., 2017(b)).

As amostras de Pln149 foram preparadas a $1 \mathrm{mg} / \mathrm{mL}(\sim 410 \mu \mathrm{M})$, em solução aquosa, na presença de lipossomos de POPG e POPC numa proporção molar de 1/50 (P/L). Ambos fosfolipídios foram comprados da Avanti Polar Lipids. A importância da carga na interação peptídeo-membrana para o POPG foi também investigada em solução aquosa contando 0,25 M ou 0,50 M de fluoreto de sódio. Foram realizadas três varreduras de cada amostra, medindo desde $280 \mathrm{~nm}$ até $170 \mathrm{~nm}$, em intervalo de $1 \mathrm{~nm}$, a $25^{\circ} \mathrm{C}$.

\section{IV.3 Parâmetros variados para os espectros da $\mathrm{Mb}$}

Sete parâmetros foram selecionados para serem variados conforme descrito a seguir:

1) O número de varreduras $(n)$ : esse parâmetro está diretamente relacionado com a relação sinal-ruído $(S / N)$ no espectro final, dado que este é uma média dos $n$ espectros medidos, e quanto maior $n$, maior ainda será o número de fótons $\left(n_{f}\right)$. Entretanto, realizar uma mudança sutil (por exemplo, de $n$ para $n \pm 1$ ) não haverá uma melhora significativa em $S / N$ (KELLY et al., 2005).

2) A velocidade de varredura (ou taxa de varredura, $v_{v}$ ): esse parâmetro representa a rapidez com que cada espectro é coletado, sendo muito relevante para os usuários, visto que interfere diretamente no tempo que será dedicado ao experimento (KELLY et al., 2005).

3) A resposta de varredura (constante temporal, ou ainda Digital Integration Time (D.I.T.)): esse parâmetro se relaciona com quanto tempo o detector permanecerá coletando fótons antes de transferir o sinal. Dessa forma, um valor alto de D.I.T gera uma melhora na relação $S / N$. Quando a fonte de fótons é bastante intensa esse parâmetro tende a não interferir bruscamente no experimento. A raiz quadrada do D.I.T também é diretamente proporcional à relação $S / N$, assim, a raiz quadrada do produto do D.I.T com $n$ pode ser relacionada com o $S / N$ através da proporção:

$$
\frac{S}{N} \propto \sqrt{n \cdot D . T . I}
$$

4) O intervalo de varredura: esse parâmetro representa o intervalo de comprimento de onda utilizado durante a varredura (KELLY et al., 2005). Há uma conexão deste parâmetro com a 
velocidade de varredura e o D.I.T. De acordo com (Jones et al. 2004), uma "regra de geral" para selecionar o intervalo ideal é dado pela inequação:

$$
\frac{v_{v}}{60} \cdot \text { D.I.T }<\text { Intervalo }
$$

5) O menor comprimento de onda (ou cutoff): o cutoff é um parâmetro importante, que representa o menor comprimento de onda em que um espectro de $\mathrm{CD}$ pode ser mensurado com precisão (sem haver uma relação $S / N$ baixa). Esse ponto é normalmente selecionado analisando os valores de HT, ele deve ser escolhido de tal forma que HT $<700 \mathrm{~V}$. Em um equipamento de CD convencional, é comum ultrapassar essa marca ao atingir comprimentos de onda próximos de $188-190 \mathrm{~nm}$.

6) A concentração de proteína: a importância da concentração da proteína numa medida de CD está expressa na Lei de Beer-Lambert, quanto maior for a concentração, mais luz será absorvida e mais intenso será o espectro de CD. A concentração das amostras foi determinada utilizando a absorção a ligação peptídica em 205 nm (ANTHIS; CLORE, 2013), utilizando um NanoDrop UV-Vis (ThermoFisher). Esse método garante uma incerteza na concentração no intervalo de $0,9 \%$ até $9,98 \%$ do valor medido, dependendo da proteína estudada, segundo Anthis e Clore (2013).

7) A concentração de $\mathbf{N a C l}$ : um bom tampão para medidas de CD não pode apresentar absorção na região do espectro que será medido. Isso não ocorre com tampões que apresentam $\mathrm{NaCl}$ em sua composição, sal muitas vezes utilizado para corrigir o pH da solução. Entretanto, esta molécula pode absorver luz UV na região dos 195 nm (KELLY; PRICE,2009).

Além dos espectros da Mb variando os parâmetros de entrada, também foram coletados espectros do tampão, que serviram como uma linha de base (a ser descontada das contribuições de cada amostra).

Cada um dos parâmetros selecionados foi variado conforme a tabela 2, para cada parâmetro foi escolhido um valor padrão que foi fixo durante a variação dos demais parâmetros. 
Tabela 2 - Valores dos parâmetros selecionados.

\begin{tabular}{|c|c|c|c|c|c|c|}
\hline$n$ & $\begin{array}{c}v_{v} \\
(\mathrm{~nm} / \mathrm{min})\end{array}$ & $\begin{array}{c}\text { D.I.T } \\
\text { (s) }\end{array}$ & $\begin{array}{c}\text { Intervalo } \\
(\mathrm{nm})\end{array}$ & Cutoff (nm) & $\begin{array}{c}{[\mathrm{Mb}]} \\
(\mathrm{mg} / \mathrm{mL})\end{array}$ & $\begin{array}{c}{[\mathrm{NaCl}]} \\
(\mathrm{M})\end{array}$ \\
\hline $\begin{array}{c}1 \\
3^{*} \\
4 \\
9\end{array}$ & $\begin{array}{c}20 \\
50 * \\
100 \\
200 \\
500 \\
\end{array}$ & $\begin{array}{c}0.25 \\
0.50 \\
1.00 * \\
2.00\end{array}$ & $\begin{array}{c}0.2 \\
0.5 \\
1.0^{*} \\
2.0\end{array}$ & $\begin{array}{c}183 \\
190^{*} \\
200\end{array}$ & $\begin{array}{c}0.02 \\
0.04 \\
\text { 0.08* } \\
0.12 \\
0.16 \\
\end{array}$ & $\begin{array}{c}\mathbf{0 . 0 0 0} * \\
0.075 \\
0.150\end{array}$ \\
\hline
\end{tabular}

*valores escolhidos como padrão para cada parâmetro

\section{IV.4 Tratamento dos espectros: EasyCD e CDtool.}

Os espectros obtidos para a Mb foram tratados por meio de um script escrito em MatLab nomeado EasyCD. Este programa foi desenvolvido como parte desta dissertação e realiza as seguintes operações:

1. Calcula a média, o desvio padrão e o desvio padrão da média das linhas de base.

2. Calcula a média, o desvio padrão e o desvio padrão da média dos espectros da proteína analisada.

3. Realiza a subtração da linha de base do espectro da proteína estuda, e propaga as incertezas desta operação.

4. Desloca e espectro de forma que a região entre 260 e $270 \mathrm{~nm}$ apresente um sinal nulo, propagando a incerteza nesse processo.

5. Normaliza o espectro e a sua incerteza para $\Delta \varepsilon$, podendo ou não levar em conta as incertezas na concentração e no caminho óptico.

O programa pode ainda estimar a concentração da proteína caso seja fornecido um espectro modelo, ou então um espectro da proteína que foi tomado com uma concentração específica. Mais adiante, é capaz de realizar alisamento da curva.

Já os espectros da Pln149 foram tratados utilizando o software CDTool (LEES et al, 2004), calculando a média das três varreduras, subtraindo a respectiva linha de base e suavizando os ruídos dos espectros utilizando um filtro Savitzly-Golay. 


\section{IV.5 Método tipo-Monte Carlo: CDgenerator}

Cada espectro tratado foi submetido ao processo tipo-Monte Carlo, utilizando o script em MatLab CDgenerator, que também foi escrito como um produto desta dissertação. O programa lê o espectro de CD e gera $n$ espectros novos somando ponto a ponto o produto de um número aleatório gaussiano no intervalo [-1,1] com o valor de uma barra de erro experimental.

Para este trabalho foram gerados 20 espectros de CD para cada espectro tratado, cada um destes foi submetido à processos de desconvolução utilizando os algoritmos disponíveis do DichroWeb e o BeStSel. Desta forma, foi possível estimar uma incerteza na porcentagem de estrutura de alfa hélice para o resultado de cada um dos parâmetros variados como sendo o desvio padrão dos 20 resultados.

\section{IV.6 Desconvolução dos espectros}

Os algoritmos CDSSTR, ContinLL, Selcon3 e BeStSel foram utilizados para a desconvolução dos espectros de CD gerados através do método tipo-Monte Carlo. Os três primeiros foram utilizados para todos os parâmetros, com exceção do cutoff. O Dichroweb não permite realizar desconvoluções com cutoff > $190 \mathrm{~nm}$, então, para este caso e para a concentração de $\mathrm{NaCl}$, foi implementado o BeStSel. A base de dados utilizada nos algoritmos presentes no Dichroweb foi a SP175 (LEES et al., 2006).

\section{IV.7 Modelo Semi-Teórico da Mb e testes de hipótese}

Atualmente existem cerca de 100 estruturas da Mb de Equus caballus disponíveis no Protein Data Bank. Dentre estas, soluções cristalográficas foram selecionadas de trabalhos diferentes (diminuindo efeitos de correlação) e com resolução mínima de 2,6 A. Algoritmos presentes no servidor 2StrucCompare (DREW; JANES, 2019) foram implementados para verificar se a proporção de estrutura secundária em cada um dos PDB's se manteve constante. O teste de chi-quadrado $\left(\chi^{2}\right)$ foi utilizado com um nível de significância de $1 \%$, e com a hipótese nula de que o valor médio de $\alpha$-hélices é uma boa representação para as estruturas selecionadas (HEUMANN; SHALABH, 2016). 
Em seguida, espectros de CD foram preditos para cada estrutura PDB utilizando dois métodos diferentes, o PDBMD2CD (DREW; JANES, 2020) e o SESCA (NAGY et al., 2019). Cada espectro foi então desconvoluido utilizando os quatro algoritmos citados na seção anterior e foram tomados as médias e os desvios padrões dos resultados de $\alpha$-hélices. Este valor foi utilizado como um resultado semi-teórico a ser comparado com os valores obtidos experimentalmente. Nesta etapa foram realizados o teste-z e o teste-t com um nível de significância de 5\% . A hipótese nula prevê os valores experimentais e semi-teórico como equivalentes (HEUMANN; SHALABH, 2016). 


\section{V - Resultados e Discussão}

\section{V.1 Calibração do espectrofotômetro}

É necessário ter bastante cautela nas condições experimentais para evitar erros na hora de interpretar os dados. Como todos os espectros da Mb foram tomados utilizando o mesmo espectrofotômetro, é preciso garantir que este não gere erros sistemáticos devido à má calibração. Além disso, uma boa calibração irá permitir a comparação de espectros obtidos por equipamentos distintos. Como mencionado em Miles e Wallace (2009), medidas de CD tomadas em dois instrumentos diferentes podem, muitas vezes, apresentar pequenas diferenças na magnitude espectral ou no comprimento de onda. Leves diferenças na polarização da luz incidente e a fonte de luz são exemplos de variáveis que podem produzir essa disparidade. Para evitar esses artefatos experimentais, é importante realizar a calibração de todos os equipamentos de CD (tanto calibração da magnitude espectral, quanto do comprimento de onda) antes de coletar os espectros.

A calibração do espectrofotômetro de CD é tipicamente feita utilizando compostos padrões que apresentam picos com elipticidade molar conhecida. $\mathrm{O}$ valor absoluto $\Delta \varepsilon$ no espectro de CD de uma solução de D-(+)-10-ácido camforsufônico (CSA) é utilizado nos comprimentos de onda de 290,5 nm e 192,5 nm. A razão destes picos deve ser próxima de 2. A figura 9 apresenta o espectro de CSA obtido com o equipamento utilizado nesse trabalho, a razão $\theta_{190,5} / \theta_{290,5}$ ficou próxima de 2,08 , o que indica que o equipamento estava bem calibrado durante as medições.

Figura 9 - Espectro de calibração do espectrofotômetro com CSA

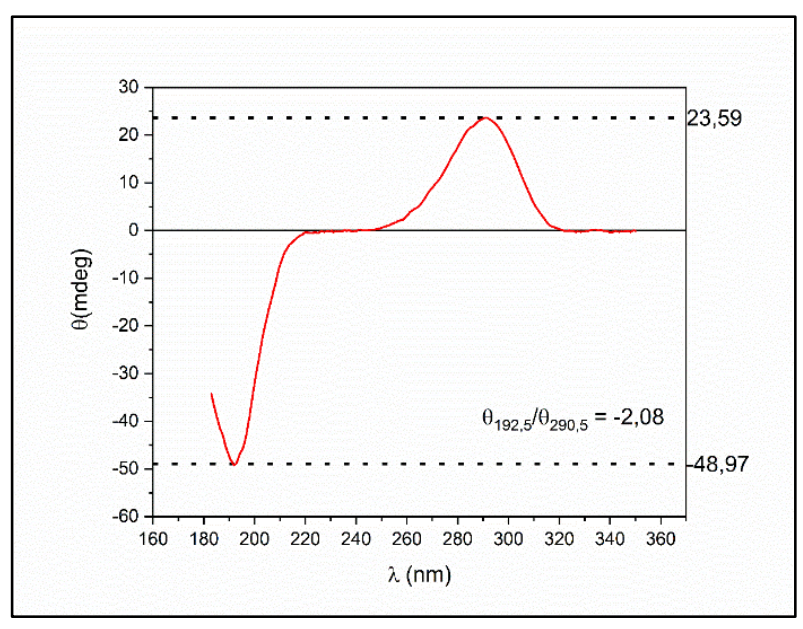

Fonte: Elaborado pelo autor 


\section{V.2 Modelo semi-teórico da Mb}

A tabela 4 resume os resultados de porcentagem de hélices alfa para cada um dos PDB selecionados para a Mb. Da segunda à quinta coluna são apresentados os resultados de quatro algoritmos presentes no 2StrucCompare (DSSP, STRIDE, PSEA e STICKS) e o resultado de consenso entre eles (Consensus). A tabela ainda apresenta as médias entre todos os PDB de porcentagem de hélices alfa para cada um dos algoritmos, e consenso, o qual resultou em $73,4 \pm$ 0,3\% ( 112 resíduos de aa) para essa estrutura secundária. O DSSP apresentou o maior desvio padrão $(1,6 \%)$ equivalente a uma diferença aproximada de 2,5 resíduos de aa, o que é insuficiente para completar uma volta de $\alpha$-hélice ( $\sim 3,6$ resíduos de aa). A última linha da tabela apresenta os p-valores encontrados utilizando o teste $\chi^{2}$, Assim, não é possível rejeitar a hipótese nula de que a média das porcentagens de $\alpha$-hélice é uma boa representação para o conjunto com um nível de significância de $1 \%$.

Em seguida, foi predito um espectro de CD para cada estrutura resolvida utilizando os métodos PDBMD2CD e SESCA. A figura 10 representa os espectros gerados para ambos os métodos. É notável a presença do pico em torno de 192 nm e dois vales em 208 e 222 nm, perfil característico de estruturas do tipo $\alpha$-hélice. Esses espectros foram então desconvoluídos individualmente utilizando o Dichroweb e o BestSel. As porcentagens para cada PBD do resultado obtido através dos espectros do PDBMD2CD estão representadas nas colunas 6 a 10 da tabela 4 .

A figura 11 apresenta o espectro obtido através da média ponto a ponto dos espectros de CD de todas as soluções cristalográficas para os dois métodos utilizados, cuja barra de erro representa o desvio padrão destas soluções. Na figura ainda está presente o espectro experimental obtido com três varreduras, velocidade de $50 \mathrm{~nm} / \mathrm{min}$, resposta de $1 \mathrm{~s}, 1 \mathrm{~nm}$ de intervalo, concentração de proteína de $0,08 \mathrm{mg} / \mathrm{mL}$ e sem $\mathrm{NaCl}$ em solução, esse espectro foi considerado padrão, pois cada variação de parâmetro manteve fixado os parâmetros restantes deste espectro. Analisando a figura 10 é possível observar que os três espectros são equivalentes, considerando as barras de erro.

Por fim, a tabela 3 compara os resultados de desconvolução da média dos espectros semi-teóricos com a média das desconvoluções individuais dos espectros para ambos os métodos implementados. É possível notar que por mais que haja uma pequena mudança nos valores, ao considerarmos a incerteza no valor médio, ambos são considerados equivalentes para todos os algoritmos. 
Tabela 3 - Estimativa do conteúdo de $\alpha$-hélices para os espectros semi-teóricos.

\begin{tabular}{ccccc}
\hline Método & Algoritmo & Espectro Médio & $\begin{array}{c}\text { Média dos } \\
\text { espectros }\end{array}$ & $\boldsymbol{\sigma}$ \\
\hline \multirow{3}{*}{ PDBMD2CD } & CDSSTR & 0,750 & 0,747 & 0,018 \\
& Selcon3 & 0,688 & 0,688 & 0,018 \\
& ContinLL & 0,721 & 0,713 & 0,021 \\
& BestSel & 0,650 & 0,656 & 0,022 \\
\hline \multirow{3}{*}{ SESCA } & CDSSTR & 0,730 & 0,735 & 0,014 \\
& Selcon3 & 0,698 & 0,697 & 0,014 \\
& ContinLL & 0,700 & 0,700 & 0,013 \\
& BestSel & 0,663 & 0,664 & 0,017 \\
\hline
\end{tabular}

Figura 10 - Espectros de CD gerados a partir do PDB

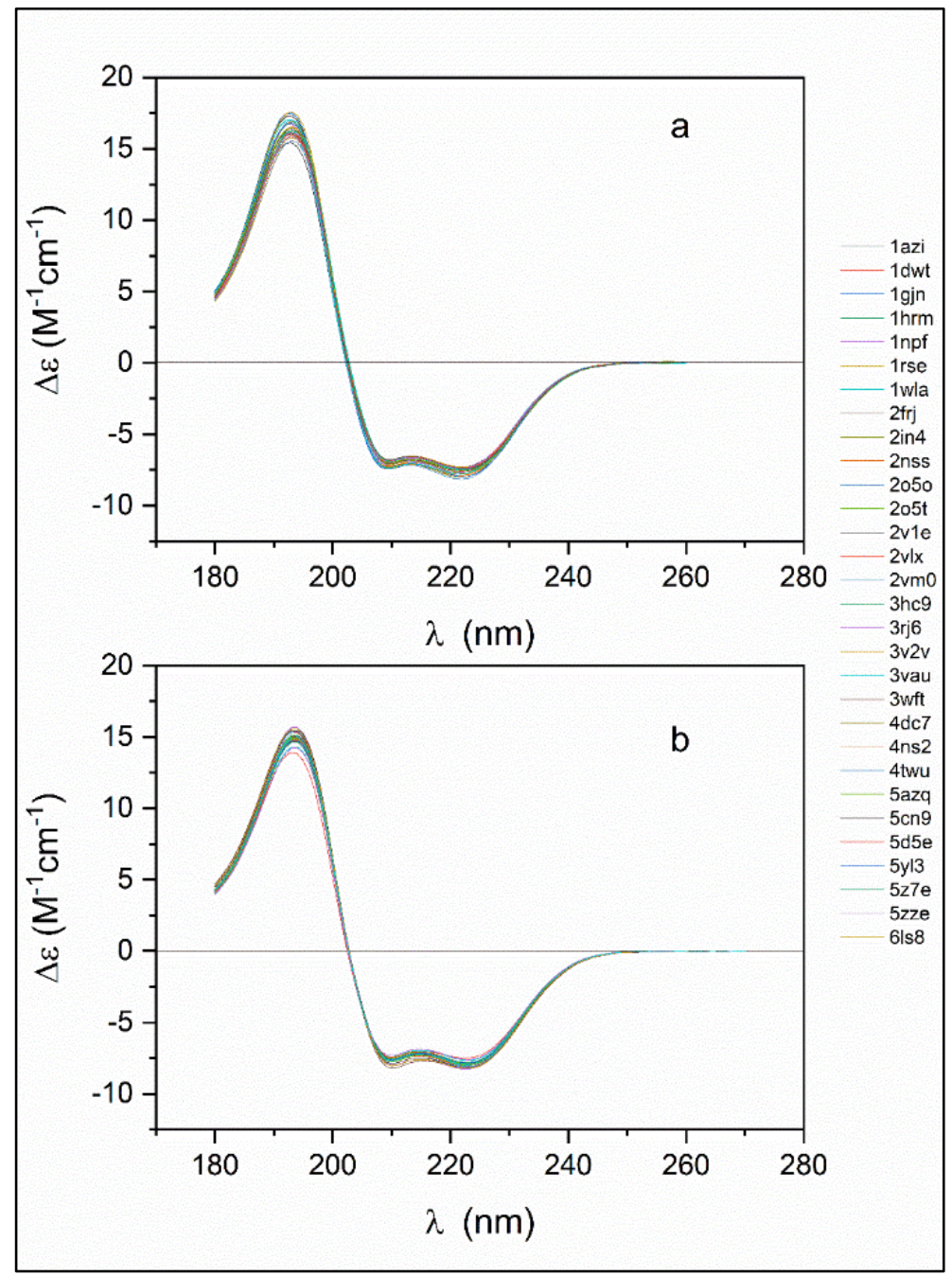

(a) PDBMD2CD (b) SESCA Fonte: Elaborado pelo autor 
Figura 11 - Espectros semi-teóricos

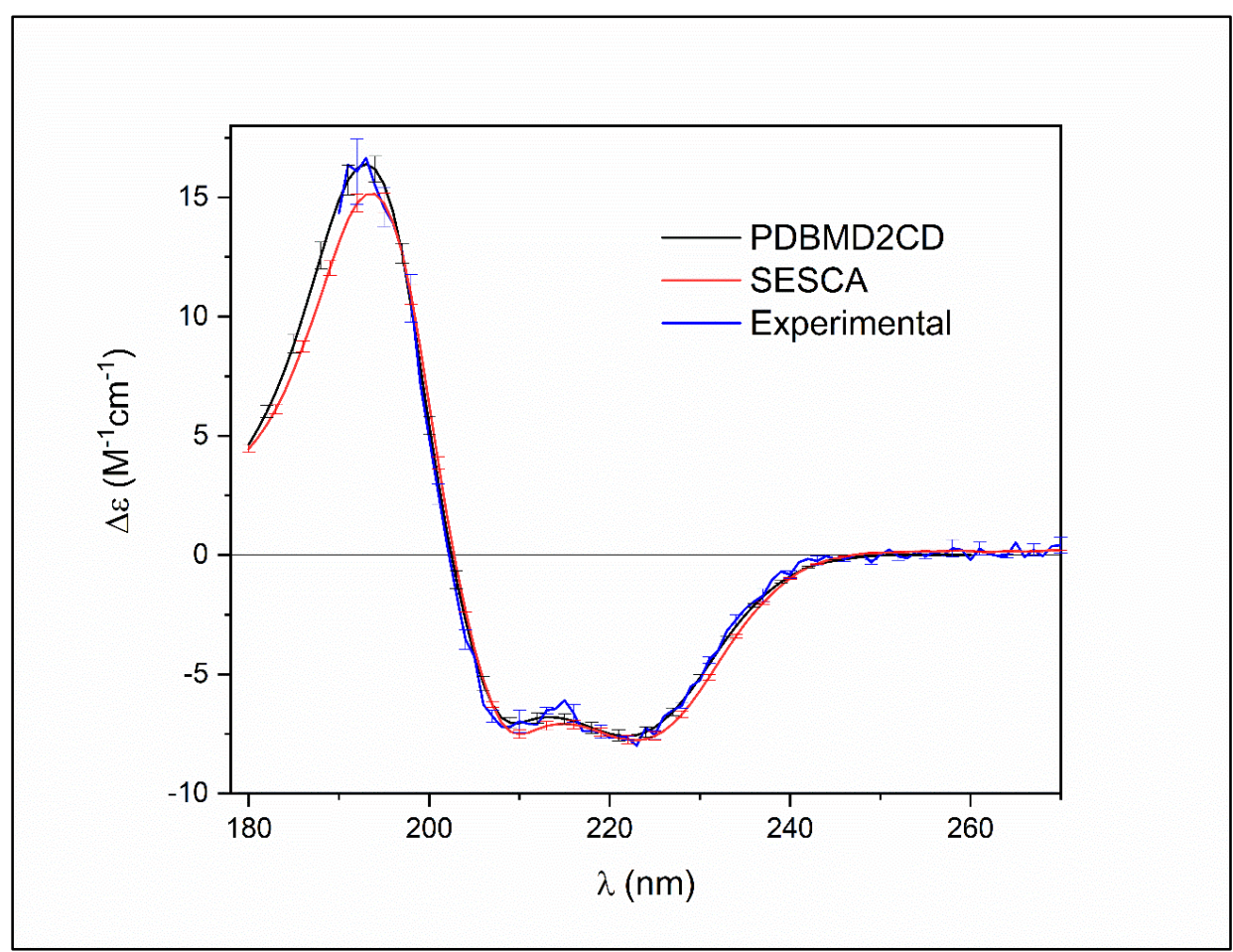

Média de 31 soluções cristalográficas gerados pelo PDBMD2CD e SESCA comparado com o espectro experimental tomado com os parâmetros padrões.

Fonte: Elaborado pelo autor 
Tabela 4 - Estruturas cristalográficas selecionadas e comparação de seu conteúdo de $\alpha$ hélices.

\begin{tabular}{|c|c|c|c|c|c|c|c|c|c|c|}
\hline PDB & 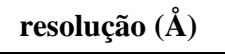 & DSSP & STRIDE & PSEA & STICKS & Consensus & Selcon & Contin-LL & CDSSTR & BeStSel \\
\hline $1 \mathrm{azi}$ & 2 & 0,730 & 0,780 & 0,800 & 0,740 & 0,710 & 0,659 & 0,670 & 0,680 & 0,633 \\
\hline $1 \mathrm{dwt}$ & 1,4 & 0,760 & 0,800 & 0,820 & 0,740 & 0,770 & 0,675 & 0,702 & 0,740 & 0,652 \\
\hline 1gjn & 1,35 & 0,750 & 0,800 & 0,780 & 0,740 & 0,730 & 0,679 & 0,704 & 0,740 & 0,658 \\
\hline $1 \mathrm{hrm}$ & 1,7 & 0,750 & 0,790 & 0,760 & 0,740 & 0,730 & 0,679 & 0,704 & 0,740 & 0,658 \\
\hline $1 \mathrm{npf}$ & 1,9 & 0,760 & 0,800 & 0,790 & 0,740 & 0,740 & 0,693 & 0,706 & 0,750 & 0,662 \\
\hline 1rse & 1,7 & 0,760 & 0,800 & 0,770 & 0,740 & 0,730 & 0,672 & 0,702 & 0,740 & 0,618 \\
\hline 1wla & 1,7 & 0,750 & 0,790 & 0,770 & 0,740 & 0,710 & 0,676 & 0,685 & 0,730 & 0,644 \\
\hline $2 \mathrm{frj}$ & 1,3 & 0,760 & 0,800 & 0,780 & 0,740 & 0,730 & 0,675 & 0,702 & 0,740 & 0,652 \\
\hline $2 \mathrm{frk}$ & 1,3 & 0,790 & 0,820 & 0,780 & 0,740 & 0,760 & 0,716 & 0,742 & 0,770 & 0,667 \\
\hline 2in4 & 2,15 & 0,780 & 0,820 & 0,770 & 0,740 & 0,730 & 0,707 & 0,734 & 0,770 & 0,655 \\
\hline $2 \mathrm{nss}$ & 2 & 0,800 & 0,800 & 0,800 & 0,740 & 0,720 & 0,730 & 0,744 & 0,790 & 0,675 \\
\hline 2050 & 1,6 & 0,770 & 0,800 & 0,790 & 0,740 & 0,750 & 0,708 & 0,723 & 0,770 & 0,687 \\
\hline $205 t$ & 1,6 & 0,770 & 0,800 & 0,780 & 0,740 & 0,740 & 0,704 & 0,727 & 0,760 & 0,688 \\
\hline $2 \mathrm{v} 1 \mathrm{e}$ & 1,3 & 0,760 & 0,800 & 0,780 & 0,740 & 0,730 & 0,670 & 0,708 & 0,730 & 0,635 \\
\hline $2 \mathrm{vlx}$ & 1,3 & 0,770 & 0,800 & 0,780 & 0,740 & 0,730 & 0,710 & 0,735 & 0,760 & 0,699 \\
\hline $2 \mathrm{vm} 0$ & 1,6 & 0,750 & 0,780 & 0,780 & 0,740 & 0,730 & 0,674 & 0,709 & 0,730 & 0,643 \\
\hline $3 \mathrm{hc} 9$ & 2 & 0,760 & 0,800 & 0,780 & 0,740 & 0,720 & 0,697 & 0,727 & 0,750 & 0,639 \\
\hline $3 \mathrm{rj} 6$ & 1,23 & $X$ & 0,800 & 0,790 & 0,740 & 0,750 & 0,668 & 0,693 & 0,740 & 0,643 \\
\hline $3 \mathrm{v} 2 \mathrm{v}$ & 1,65 & 0,770 & 0,790 & 0,780 & 0,720 & 0,750 & 0,686 & 0,693 & 0,760 & 0,657 \\
\hline $3 \mathrm{vau}$ & 1,7 & 0,760 & 0,80 & 0,820 & 0,750 & 0,770 & 0,684 & 0,717 & 0,760 & 0,658 \\
\hline $3 \mathrm{wft}$ & 1,3 & 0,750 & 0,790 & 0,810 & 0,740 & 0,760 & 0,699 & 0,710 & 0,730 & 0,67 \\
\hline $4 \mathrm{dc} 7$ & 1,5 & 0,770 & 0,800 & 0,780 & 0,740 & 0,730 & 0,679 & 0,714 & 0,750 & 0,635 \\
\hline $4 \mathrm{~ns} 2$ & 1,18 & 0,750 & 0,800 & 0,750 & 0,740 & 0,710 & 0,671 & 0,701 & 0,720 & 0,610 \\
\hline 4 twu & 1,08 & 0,750 & 0,780 & 0,750 & 0,740 & 0,730 & 0,688 & 0,720 & 0,750 & 0,657 \\
\hline $5 \mathrm{azq}$ & 1,4 & 0,740 & 0,800 & 0,800 & 0,740 & 0,770 & 0,673 & 0,703 & 0,740 & 0,646 \\
\hline $5 \mathrm{cn} 9$ & 1,8 & 0,760 & 0,790 & 0,770 & 0,740 & 0,730 & 0,675 & 0,702 & 0,740 & 0,652 \\
\hline $5 \mathrm{~d} 5 \mathrm{r}$ & 1,6 & 0,770 & 0,790 & 0,790 & 0,740 & 0,740 & 0,717 & 0,753 & 0,760 & 0,674 \\
\hline $5 y 13$ & 1,5 & 0,760 & 0,810 & 0,790 & 0,750 & 0,750 & 0,684 & 0,717 & 0,760 & 0,658 \\
\hline $5 \mathrm{z} 7 \mathrm{e}$ & 1,8 & 0,760 & 0,810 & 0,800 & 0,740 & 0,730 & 0,670 & 0,708 & 0,730 & 0,635 \\
\hline $5 z z e$ & 1,42 & 0,780 & 0,800 & 0,780 & 0,740 & 0,740 & 0,718 & 0,743 & 0,780 & 0,712 \\
\hline \multirow[t]{5}{*}{$61 \mathrm{~s} 8$} & 2,3 & 0,760 & 0,790 & 0,790 & 0,740 & 0,730 & 0,703 & 0,717 & 0,760 & 0,671 \\
\hline & Média & 0,763 & 0,798 & 0,783 & 0,739 & 0,734 & 0,688 & 0,713 & 0,747 & 0,656 \\
\hline & Desvio padrão & 0,016 & 0,010 & 0,014 & 0,005 & 0,016 & 0,018 & 0,018 & 0,021 & 0,022 \\
\hline & $\begin{array}{l}\text { Desvio padrão } \\
\text { da média }\end{array}$ & 0,003 & 0,002 & 0,003 & 0,001 & 0,003 & 0,003 & 0,003 & 0,004 & 0,004 \\
\hline & p-valor & 0,786 & 0,635 & 0,025 & 0,459 & 0,254 & - & - & - & - \\
\hline
\end{tabular}




\section{V.3 Resultados de desconvolução da $\mathrm{Mb}$}

A figura 12 resume os resultados de desconvolução obtidos para cada algoritmo e parâmetro variado. Em cada gráfico estão representados todos os parâmetros em ordem crescente da esquerda para direita. A linha preta representa a média entre os valores do SESCA e do PDBMD2CD para estrutura secundária obtida por cada algoritmo utilizando (ContinLL, CDSSTR, Selcon3 e BeStSel). A linha tracejada representa um intervalo de dois $\sigma$, que foi propagado através das incertezas estimadas por Monte Carlo para os dois modelos semiteóricos. Uma discussão para cada um dos parâmetros está presente nas seções seguintes (V.4 até V.10). Em seguida, as seções V.11 e V.12 interpretam resultados estatísticos extraídos através dos espectros da $\mathrm{Mb}$.

Figura 12 - Resultado das desconvoluções para os quatro algoritmos utilizados.

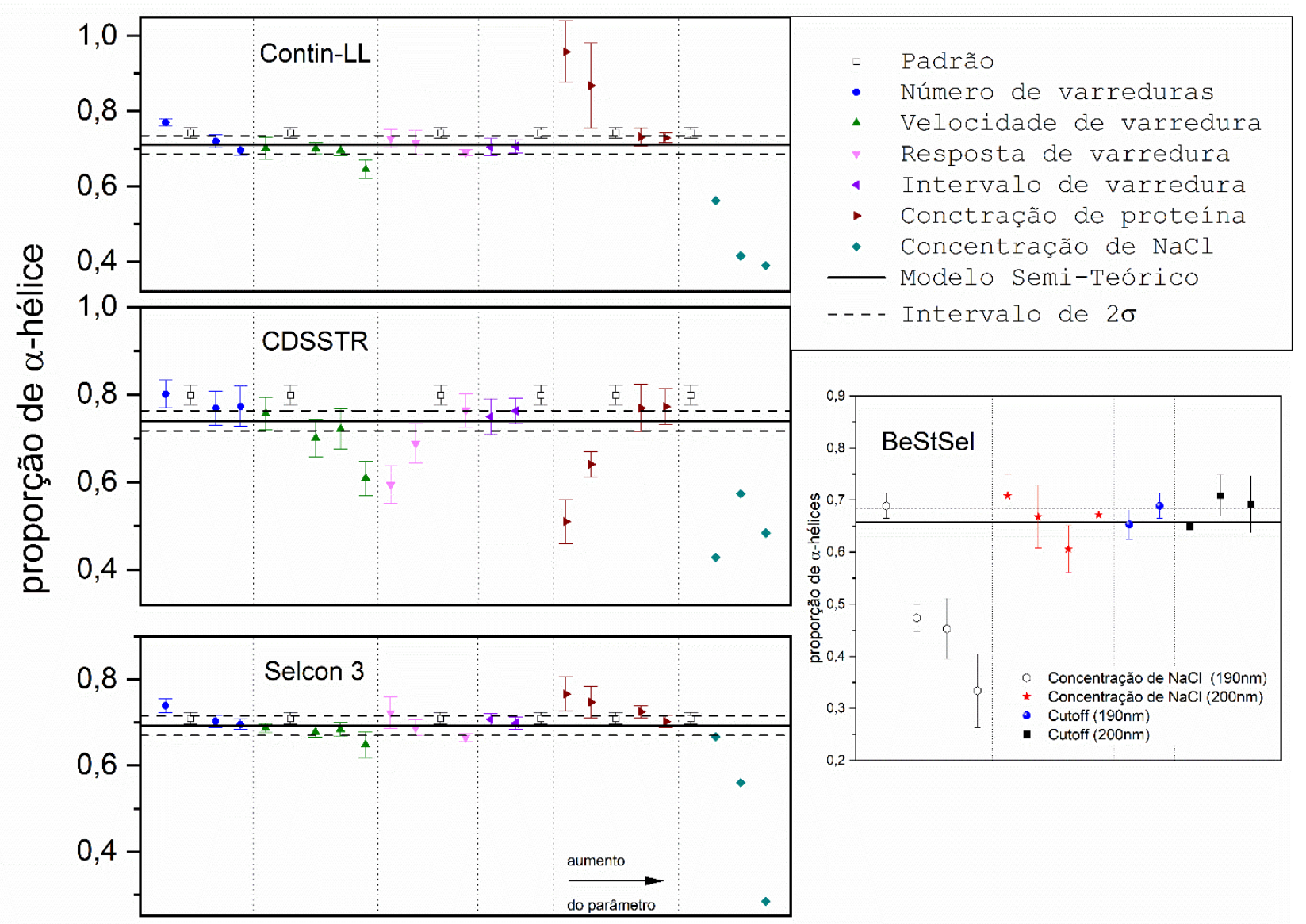

Fonte: Elaborado pelo autor 


\section{V.4 Número de varreduras}

A figura 13 apresenta os espectros tratados utilizando 1, 3, 4 e 9 varreduras independentes. Como o espectro final é uma média das varreduras, a incerteza no espectro é igual ao desvio padrão da média. Entretanto, neste trabalho, todos os espectros foram subtraídos de um espectro de base (tampão) o qual foi tomado apenas com 3 varreduras. Assim, as incertezas finais presentes no espectro são propagadas através da incerteza do espectro da $\mathrm{Mb}$ e do espectro do tampão. Dessa forma, na figura 13, por mais que com apenas uma varredura seria impossível definir um desvio padrão da média, o espectro em preto ainda apresenta uma barra erro, que representa justamente o desvio padrão da média do espectro do tampão. Todavia, em um cenário em que um usuário realizasse apenas uma varredura para a proteína e para o tampão, não seria possível estimar a incerteza da forma proposta neste trabalho, e por consequência seria impossível utilizar o método tipo-Monte Carlo para estimar a incerteza na porcentagem de desconvolução.

Não é possível notar uma mudança significativa no formato dos espectros obtidos utilizando mais do que 3 varreduras. Há apenas uma leve diminuição na barra de erro quando utilizamos 9 varreduras, visto que o desvio padrão da média é dividido por um fator de 3 . A figura 14 apresenta os espectros gerados pelo método tipo-Monte Carlo para cada caso, nela é notável que não houve grande alteração nos espectros preditos, o que é resultado direto do tamanho pequeno das barras de erro.

A tabela 5 apresenta os resultados de desconvolução para os 3 algoritmos presentes no Dichroweb, assim como o desvio padrão estimado pelo método tipo-Monte Carlo, o valor de NMRSD, e os p-valores para os dois testes estatísticos implementados. O único caso no qual é possível rejeitar a hipótese nula (de que o resultado de desconvolução experimental é equivalente ao Semi-Teórico) com um nível de significância de 5\% é quando utilizamos o algoritmo ContinLL para $\mathrm{n}=1$. Todos casos restantes não rejeitam a hipótese nula e apresentam valores de $\alpha$-hélices equivalentes dentro de um intervalo de dois $\sigma$. É interessante notar que para todos os casos, o CDSSTR indicou o maior valor para essa estrutura secundária, e maior $\sigma$, por mais que apresentasse menor NRMSD. 
Figura 13 - Espectros de CD variando o número de varreduras.

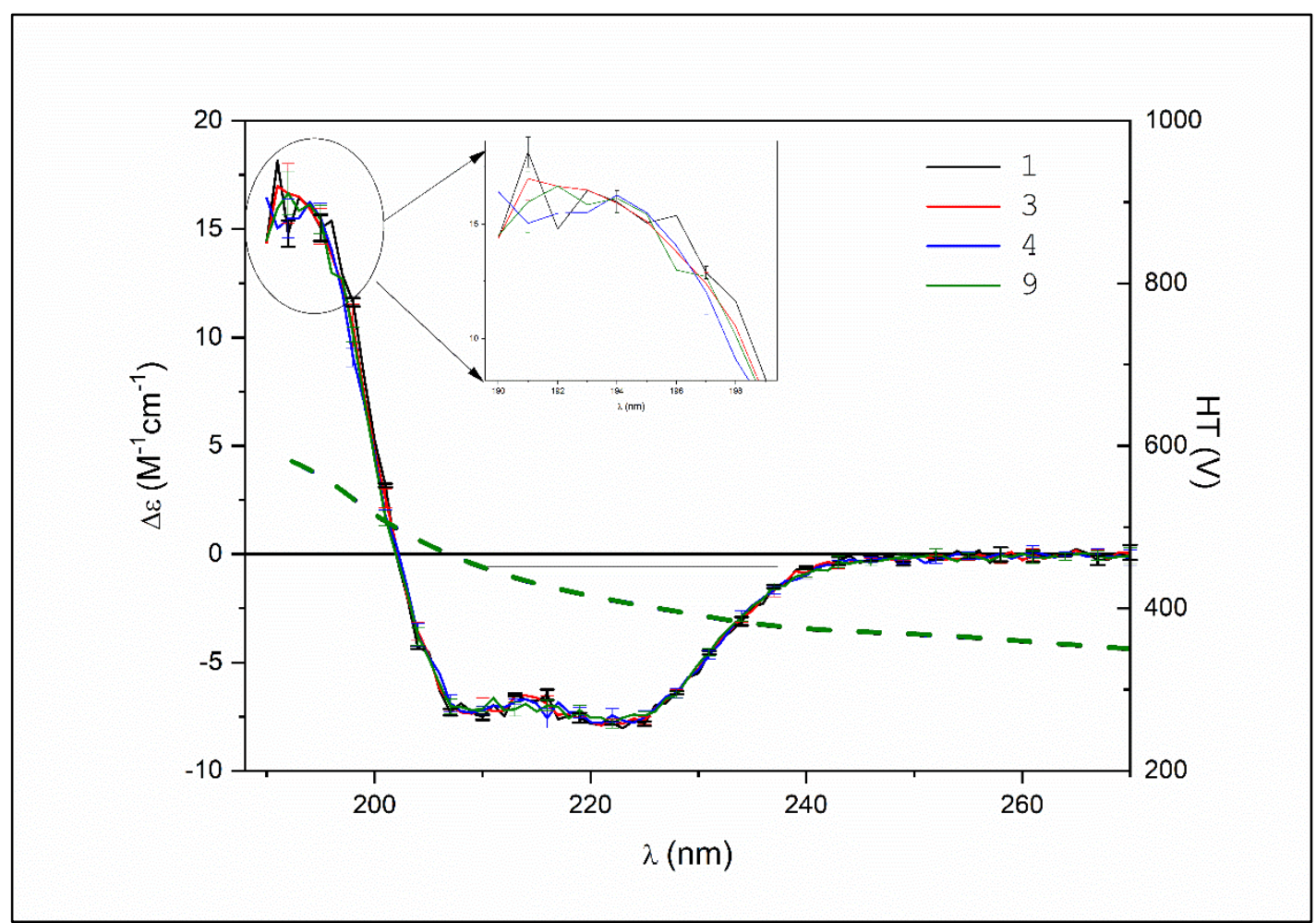

Fonte: Elaborado pelo autor

Tabela 5 - Resultados de desconvolução e testes estatísticos para o número de varreduras.

\begin{tabular}{|c|c|c|c|c|c|c|c|c|}
\hline \multirow{3}{*}{$\begin{array}{c}\text { Número de } \\
\text { varreduras } \\
(\mathrm{nm} / \mathrm{min})\end{array}$} & \multirow{3}{*}{ Método } & \multirow{3}{*}{$\begin{array}{c}\text { Proporção de } \\
\alpha \text {-hélices }\end{array}$} & \multirow{3}{*}{$\boldsymbol{\sigma}$} & \multirow{3}{*}{ NRMSD } & \multicolumn{2}{|c|}{ Modelo PDBMD2CD } & \multicolumn{2}{|c|}{ Modelo SESCA } \\
\hline & & & & & Teste $\mathbf{Z}$ & Teste $t$ & Teste $\mathbf{Z}$ & Teste $\mathbf{t}$ \\
\hline & & & & & \multicolumn{2}{|c|}{$\mathrm{p}$ valor } & \multicolumn{2}{|c|}{$\mathrm{p}$ valor } \\
\hline \multirow[t]{3}{*}{1} & CDSSTR & 0,801 & 0,032 & 0,010 & 0,155 & 0,164 & 0,055 & 0,065 \\
\hline & Selcon 3 & 0,740 & 0,016 & 0,085 & 0,034 & 0,039 & 0,046 & 0,052 \\
\hline & ContinLL & 0,770 & 0,008 & 0,081 & 0,004 & 0,006 & 0,000 & 0,000 \\
\hline \multirow[t]{3}{*}{3} & CDSSTR & 0,799 & 0,023 & 0,012 & 0,092 & 0,099 & 0,092 & 0,101 \\
\hline & Selcon 3 & 0,710 & 0,014 & 0,074 & 0,332 & 0,337 & 0,332 & 0,337 \\
\hline & ContinLL & 0,743 & 0,015 & 0,062 & 0,203 & 0,209 & 0,203 & 0,209 \\
\hline \multirow[t]{3}{*}{4} & CDSSTR & 0,766 & 0,039 & 0,011 & 0,679 & 0,682 & 0,459 & 0,466 \\
\hline & Selcon 3 & 0,702 & 0,012 & 0,072 & 0,536 & 0,539 & 0,798 & 0,799 \\
\hline & ContinLL & 0,717 & 0,016 & 0,069 & 0,856 & 0,857 & 0,411 & 0,416 \\
\hline \multirow[t]{3}{*}{9} & CDSSTR & 0,769 & 0,048 & 0,013 & 0,684 & 0,691 & 0,500 & 0,507 \\
\hline & Selcon 3 & 0,697 & 0,012 & 0,077 & 0,689 & 0,687 & 0,998 & 0,998 \\
\hline & ContinLL & 0,693 & 0,013 & 0,060 & 0,361 & 0,365 & 0,675 & 0,677 \\
\hline
\end{tabular}


Figura 14 - Espectros gerados pelo método tipo-Monte Carlo para diferentes $n$.

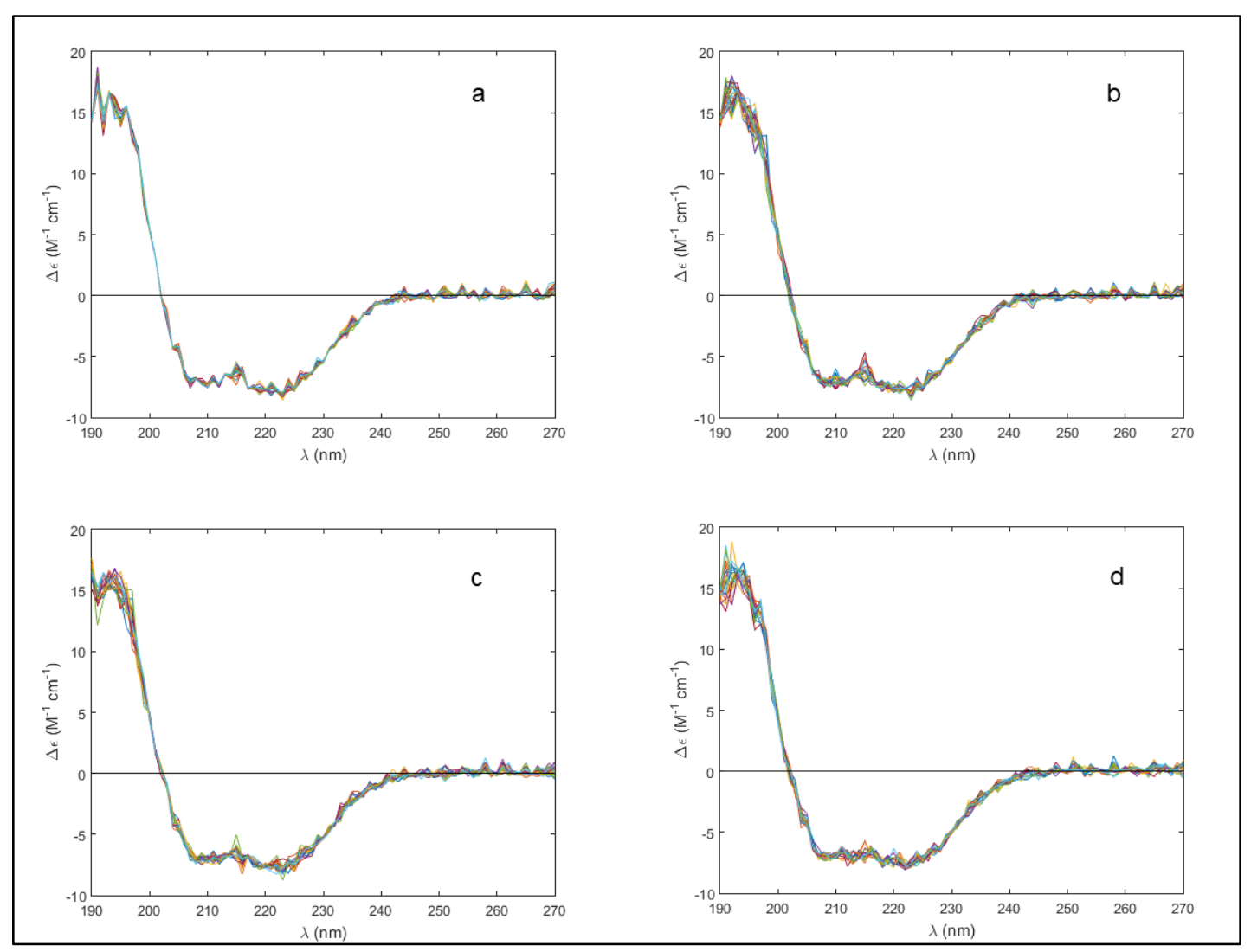

(a) $n=1$, (b) n=3 (padrão), (c) n=4 e (d) n=5.

Fonte: Elaborado pelo autor

\section{V.5 Velocidade de varredura}

Aumentar da velocidade de varredura é uma estratégia muito utilizada para obter mais varreduras em um intervalo de tempo limitado. Entretanto, as figuras 15, 16 e os resultados presentes na tabela 6 demonstram que escolher velocidades muito altas podem afetar significativamente a qualidade dos resultados obtidos. Na figura 15, nota-se que após tratar os dados, todos os espectros são equivalentes nas barras de erro, entretanto para a velocidade de $500 \mathrm{~nm} / \mathrm{min}$ há um aumento abrupto do HT próximo a $190 \mathrm{~nm}$ quando comparado com as outras velocidades. Isso demonstra que menos fótons estão interagindo com o fotomultiplicador, e, por consequência, há uma diminuição na relação $S / R$, o que aumenta a barra de erro presente nesta região. Este efeito se torna evidente ao analisarmos os espectros obtidos pelo método tipoMonte Carlo (figura 16), os quais apresentam uma maior dispersão na região acima de $195 \mathrm{~nm}$. 
Analisando a tabela 5, nota-se que para a velocidade de $500 \mathrm{~nm} / \mathrm{min}$ há uma perda de precisão e acurácia nos resultados. Para os três algoritmos as porcentagens de $\alpha$-hélices foram inferiores a 70\% e apresentaram os maiores $\sigma$. Esses valores se refletem nos p-valores obtidos, que foram os menores de todos, e para o CDSSTR foram tão baixos que somos capazes de rejeitar a hipótese nula com uma significância de 5\%. É interessante ressaltar que para o intervalo de medição de 270 a $190 \mathrm{~nm}$, com uma velocidade de $200 \mathrm{~nm} / \mathrm{min}$ é possível obter 3 varreduras em $72 \mathrm{~s}$. Nesse mesmo período, com uma velocidade de $500 \mathrm{~nm} / \mathrm{min}$ é possível obter apenas 7 varreduras completas. De acordo com a seção anterior, não é esperado que um aumento de 4 varreduras seja o suficiente para melhorar significativamente o espectro final.

Tabela 6 - Resultados de desconvolução e testes estatísticos para a velocidade de varredura.

\begin{tabular}{|c|c|c|c|c|c|c|c|c|}
\hline \multirow{3}{*}{$\begin{array}{c}\text { Velocidade de } \\
\text { varreduras } \\
(\mathrm{nm} / \mathrm{min})\end{array}$} & \multirow{3}{*}{ Método } & \multirow{3}{*}{$\begin{array}{c}\text { Proporção de } \\
\alpha \text {-hélices }\end{array}$} & \multirow{3}{*}{$\boldsymbol{\sigma}$} & \multirow{3}{*}{ NRMSD } & \multicolumn{2}{|c|}{ Modelo PDBMD2CD } & \multicolumn{2}{|c|}{ Modelo SESCA } \\
\hline & & & & & Teste $\mathbf{Z}$ & Teste $\mathbf{t}$ & Teste $\mathbf{Z}$ & Teste $\mathbf{t}$ \\
\hline & & & & & \multicolumn{2}{|c|}{$\mathrm{p}$ valor } & \multicolumn{2}{|c|}{$\mathrm{p}$ valor } \\
\hline \multirow[t]{3}{*}{20} & CDSSTR & 0,759 & 0,035 & 0,015 & 0,776 & 0,778 & 0,520 & 0,526 \\
\hline & Selcon 3 & 0,688 & 0,012 & 0,079 & 0,987 & 0,987 & 0,618 & 0,620 \\
\hline & ContinLL & 0,702 & 0,026 & 0,058 & 0,722 & 0,724 & 0,966 & 0,966 \\
\hline \multirow[t]{3}{*}{50} & CDSSTR & 0,799 & 0,023 & 0,012 & 0,092 & 0,099 & 0,092 & 0,101 \\
\hline & Selcon 3 & 0,710 & 0,014 & 0,074 & 0,332 & 0,337 & 0,332 & 0,337 \\
\hline & ContinLL & 0,743 & 0,015 & 0,062 & 0,203 & 0,209 & 0,203 & 0,209 \\
\hline \multirow[t]{3}{*}{100} & CDSSTR & 0,701 & 0,043 & 0,014 & 0,328 & 0,336 & 0,449 & 0,456 \\
\hline & Selcon 3 & 0,678 & 0,012 & 0,102 & 0,650 & 0,652 & 0,313 & 0,318 \\
\hline & ContinLL & 0,701 & 0,015 & 0,065 & 0,610 & 0,613 & 0,980 & 0,980 \\
\hline \multirow[t]{3}{*}{200} & CDSSTR & 0,721 & 0,046 & 0,015 & 0,606 & 0,610 & 0,778 & 0,781 \\
\hline & Selcon 3 & 0,684 & 0,016 & 0,066 & 0,877 & 0,877 & 0,548 & 0,551 \\
\hline & ContinLL & 0,696 & 0,014 & 0,059 & 0,455 & 0,458 & 0,817 & 0,818 \\
\hline \multirow[t]{3}{*}{500} & CDSSTR & 0,609 & 0,039 & 0,007 & 0,002 & 0,004 & 0,002 & 0,006 \\
\hline & Selcon 3 & 0,649 & 0,031 & 0,116 & 0,265 & 0,273 & 0,149 & 0,161 \\
\hline & ContinLL & 0,645 & 0,024 & 0,097 & 0,025 & 0,031 & 0,044 & 0,054 \\
\hline
\end{tabular}


Figura 15 - Espectros de CD com diferentes velocidades de varredura.

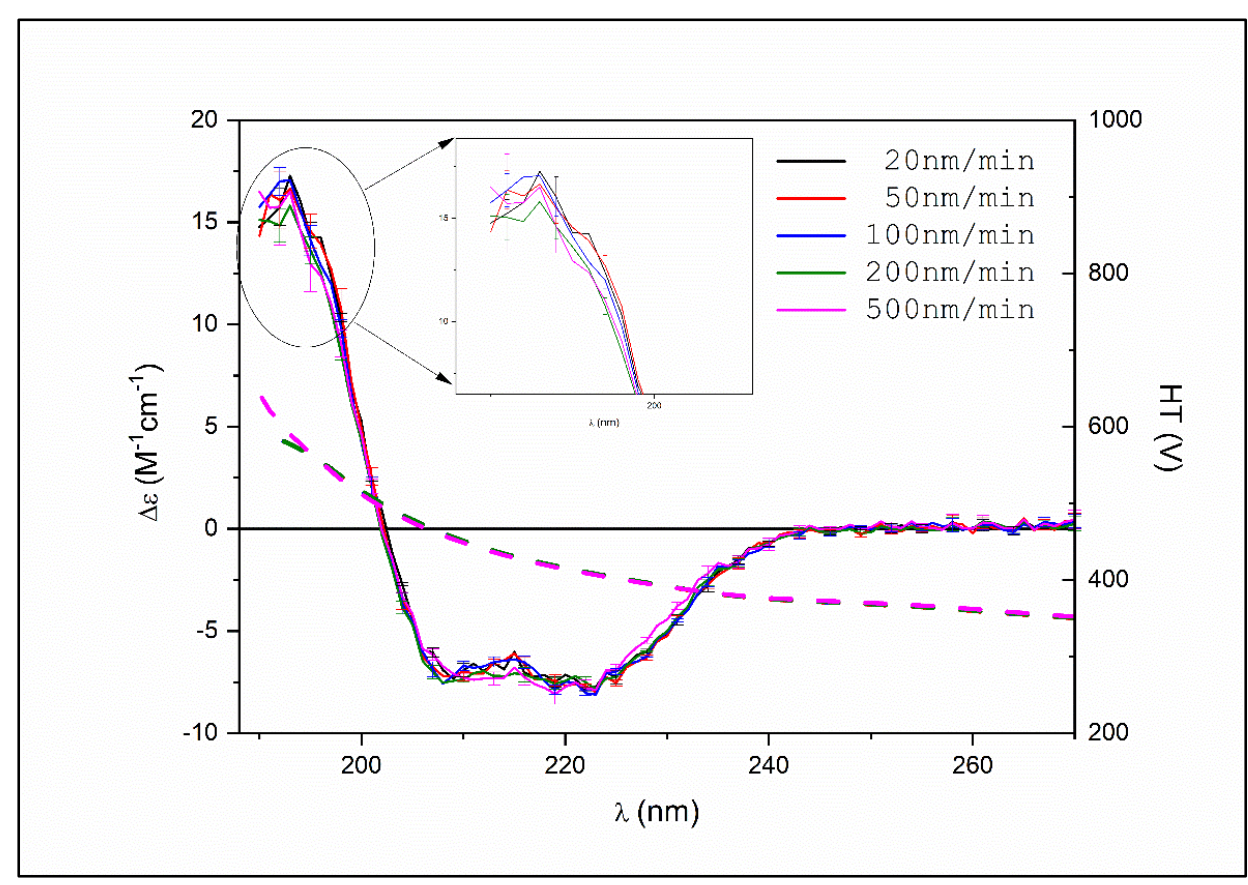

Fonte: Elaborado pelo autor

Figura 16 - Espectros gerados pelo método tipo-Monte Carlo, para diferentes $v$.
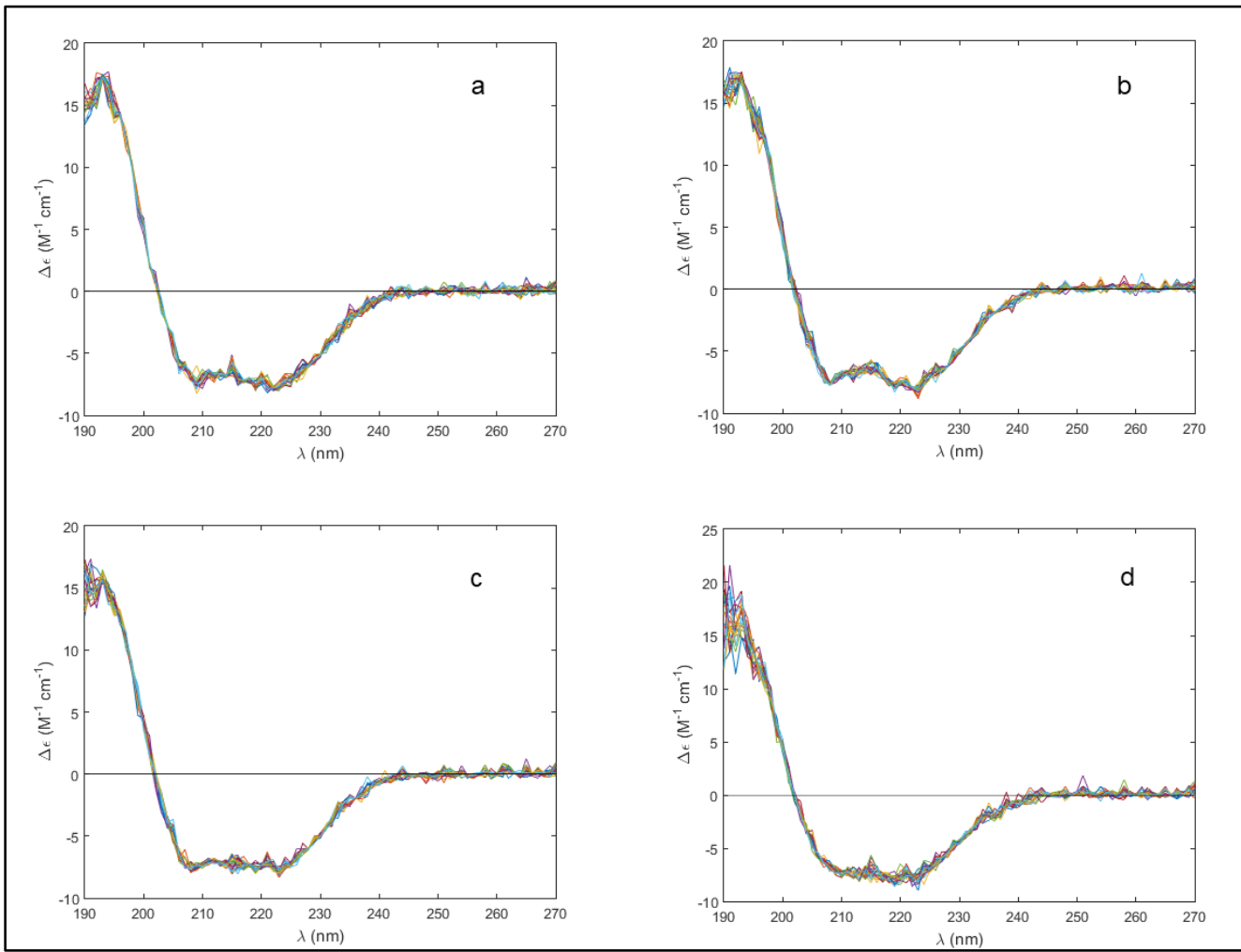

(a) $\mathrm{v}=20 \mathrm{~nm} / \mathrm{min}$, (b) $\mathrm{v}=100 \mathrm{~nm} / \mathrm{min}$, (c) $\mathrm{v}=200 \mathrm{~nm} / \mathrm{min}$ e (d) $\mathrm{v}=500 \mathrm{~nm} / \mathrm{min}$ Fonte: Elaborado pelo autor 


\section{V.6 Resposta de varredura}

Conforme a figura 17 é evidente que uma menor resposta de varredura diminui a relação sinal-ruído. Para 0,25 s nota-se um espectro mais ruidoso, que se torna ainda mais visível ao observar os espectros gerados pelo método tipo-Monte Carlo presentes na figura 18, que apresenta diversos bicos não diferenciáveis. À medida que aumentamos a resposta, há uma melhora na relação $S / R$. A partir da equação (38), uma mudança no D.I.T. de 0,25 s para $2 \mathrm{~s}$ aumenta a relação $S / R$ em um fator de $\sqrt{8}$, o que se traduz na figura 18-c apresentando um espectro muito menos ruidoso.

Pela da tabela 7 é notável que para um D.I.T. de 0,25s o algoritmo CDSSTR apresentou uma porcentagem de $\alpha$-hélice muito abaixo de 70\%, mesmo apresentando um NRMSD baixo, o que deixou o resultado fora da zona de confiança na figura 12. Utilizar uma resposta de $0,5 \mathrm{~s}$, aumentando $S / R$ em um fator de $\sqrt{2}$ foi o suficiente para obter uma porcentagem de $\alpha$-hélice aceitável para todos os algoritmos, o que não permite a rejeição da hipótese nula em nenhum dos testes.

Figura 17 - Espectros de CD com diferentes respostas de varredura.

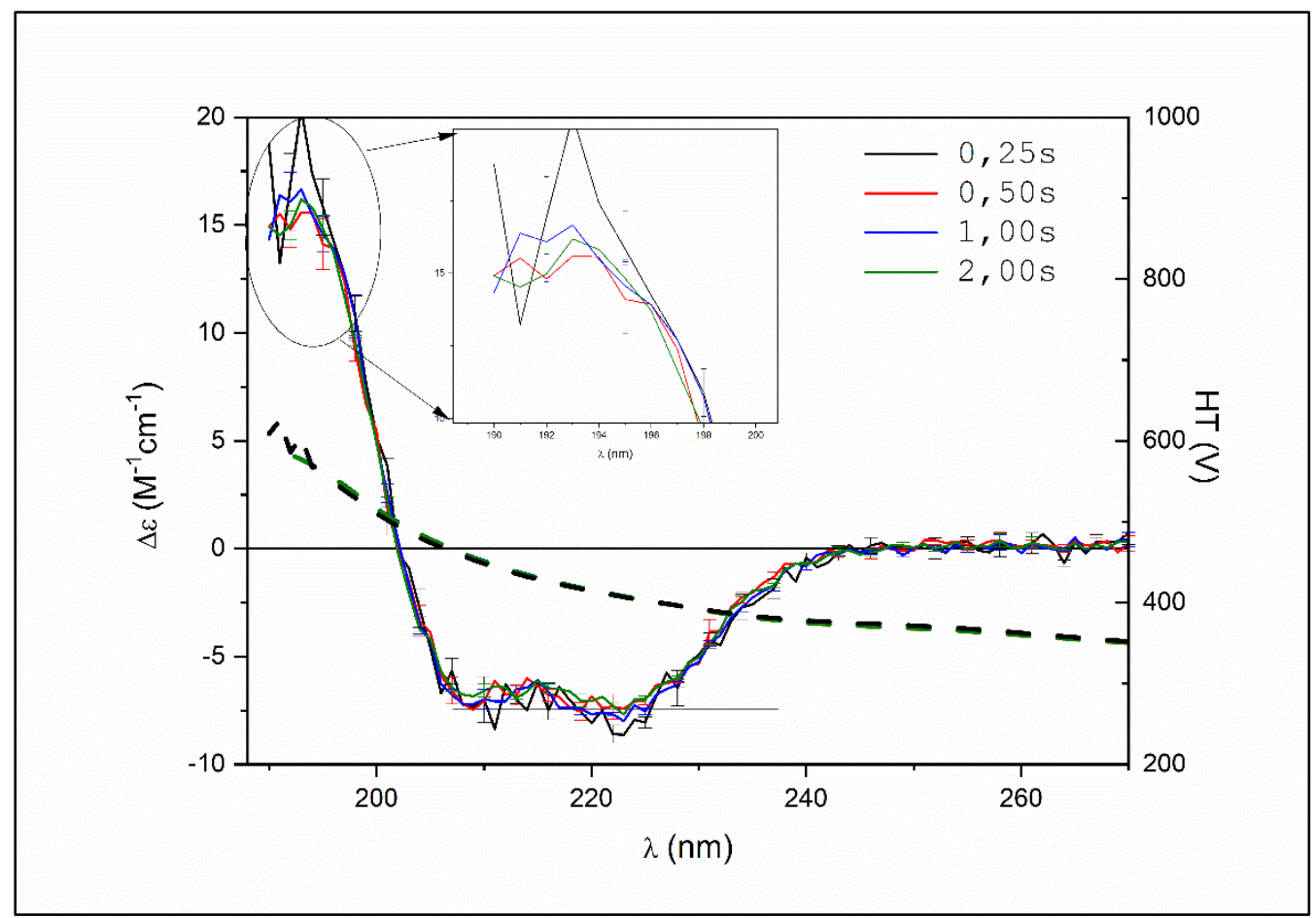

Fonte: Elaborado pelo autor 
Figura 18 - Espectros gerados pelo método tipo-Monte Carlo para diverentes

\section{D.I.T}

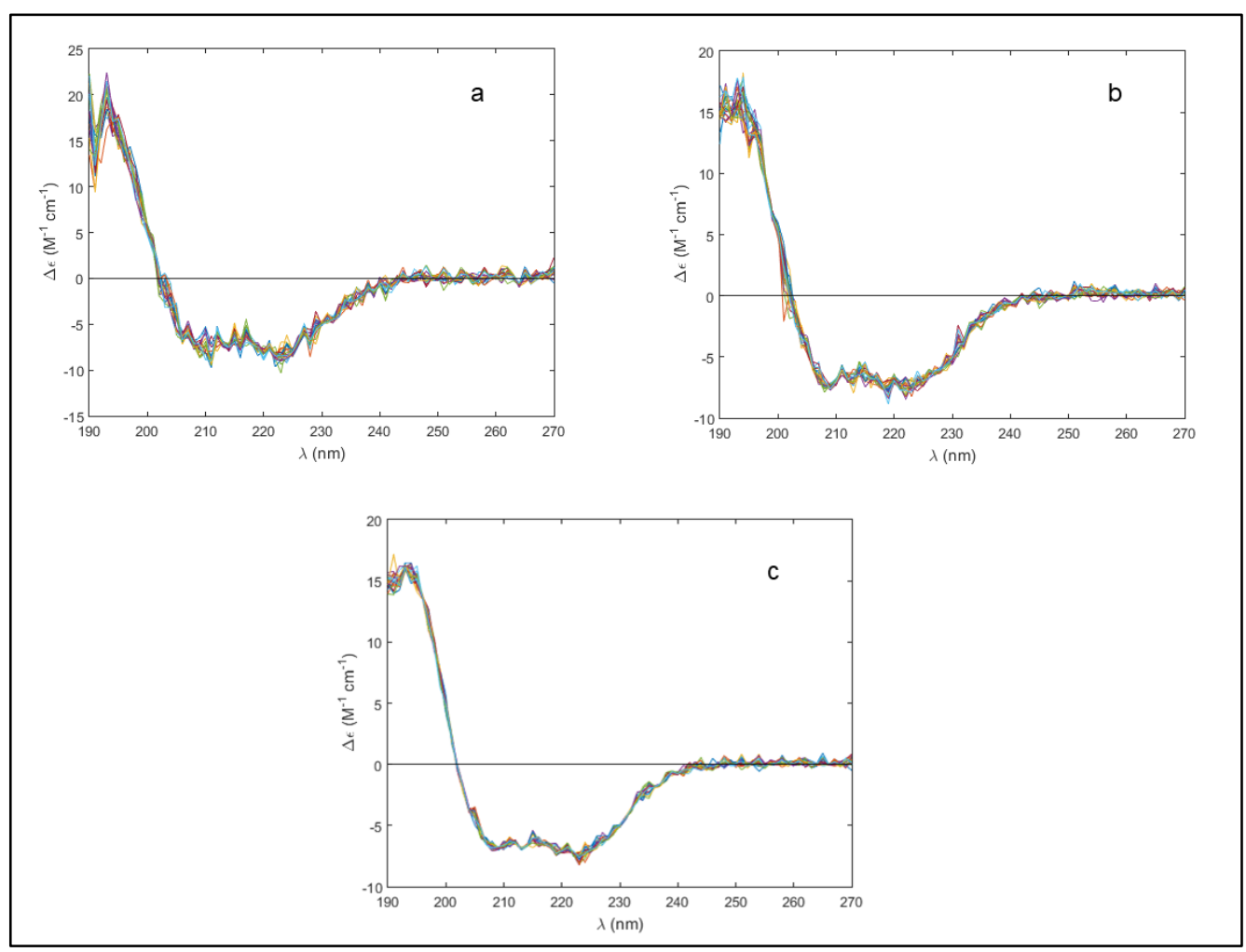

(a) D.I.T. $=0,25 \mathrm{~s}$, (b) D.I.T. $=0,5 \mathrm{~s}$, (c) D.I.T. $=2 \mathrm{~s}$.

Fonte: Elaborado pelo autor

Tabela 7 - Resultados de desconvolução e testes estatísticos para a resposta de varredura.

\begin{tabular}{|c|c|c|c|c|c|c|c|c|}
\hline \multirow{3}{*}{$\begin{array}{l}\text { D.I.T. } \\
(\mathrm{s})\end{array}$} & \multirow{3}{*}{ Método } & \multirow{3}{*}{$\begin{array}{c}\text { Proporção de } \\
\alpha \text {-hélices }\end{array}$} & \multirow{3}{*}{$\sigma$} & \multirow{3}{*}{ NRMSD } & \multicolumn{2}{|c|}{ Modelo PDBMD2CD } & \multicolumn{2}{|c|}{ Modelo SESCA } \\
\hline & & & & & Teste $\mathbf{Z}$ & Teste $t$ & Teste $\mathbf{Z}$ & Teste $\mathbf{t}$ \\
\hline & & & & & \multicolumn{2}{|c|}{$\mathrm{p}$ valor } & \multicolumn{2}{|c|}{$\mathrm{p}$ valor } \\
\hline \multirow[t]{3}{*}{0,25} & CDSSTR & 0,594 & 0,043 & 0,002 & 0,001 & 0,003 & 0,002 & 0,005 \\
\hline & Selcon 3 & 0,723 & 0,037 & 0,146 & 0,389 & 0,397 & 0,501 & 0,508 \\
\hline & ContinLL & 0,727 & 0,024 & 0,139 & 0,636 & 0,639 & 0,328 & 0,335 \\
\hline \multirow[t]{3}{*}{0,50} & CDSSTR & 0,689 & 0,046 & 0,008 & 0,244 & 0,254 & 0,336 & 0,346 \\
\hline & Selcon 3 & 0,688 & 0,018 & 0,094 & 0,992 & 0,992 & 0,706 & 0,708 \\
\hline & ContinLL & 0,717 & 0,032 & 0,086 & 0,923 & 0,924 & 0,640 & 0,644 \\
\hline \multirow[t]{3}{*}{1,00} & CDSSTR & 0,799 & 0,023 & 0,012 & 0,092 & 0,099 & 0,092 & 0,101 \\
\hline & Selcon 3 & 0,710 & 0,014 & 0,074 & 0,332 & 0,337 & 0,332 & 0,337 \\
\hline & ContinLL & 0,743 & 0,015 & 0,062 & 0,203 & 0,209 & 0,203 & 0,209 \\
\hline \multirow[t]{3}{*}{2,00} & CDSSTR & 0,764 & 0,038 & 0,014 & 0,703 & 0,706 & 0,476 & 0,483 \\
\hline & Selcon 3 & 0,665 & 0,009 & 0,100 & 0,251 & 0,258 & 0,051 & 0,057 \\
\hline & ContinLL & 0,690 & 0,008 & 0,057 & 0,234 & 0,241 & 0,468 & 0,472 \\
\hline
\end{tabular}




\section{V.7 Intervalo de varredura}

A figura 19 apresenta os espectros tomados utilizando diferentes intervalos de varredura. É possível notar que, quanto menor o intervalo, mais ruidoso é o espectro final. Por mais que com um intervalo de 2,0 nm podemos de obter informação sobre o formato do espectro, esse intervalo não se mostrou vantajoso, dado que nenhum dos servidores de desconvolução utilizados foram capazes de analisá-lo.

Em relação a intervalos menores do que 1,0 nm houve uma melhora aparente na precisão dos resultados, principalmente em relação ao algoritmo CDSSTR. Entretanto, um passo de $1,0 \mathrm{~nm}$ foi o suficiente para produzir um espectro de qualidade e um resultado de desconvolução incapaz de rejeitar a hipótese nula.

Figura 19 - Espectros de CD com diferentes intervalos de varredura.

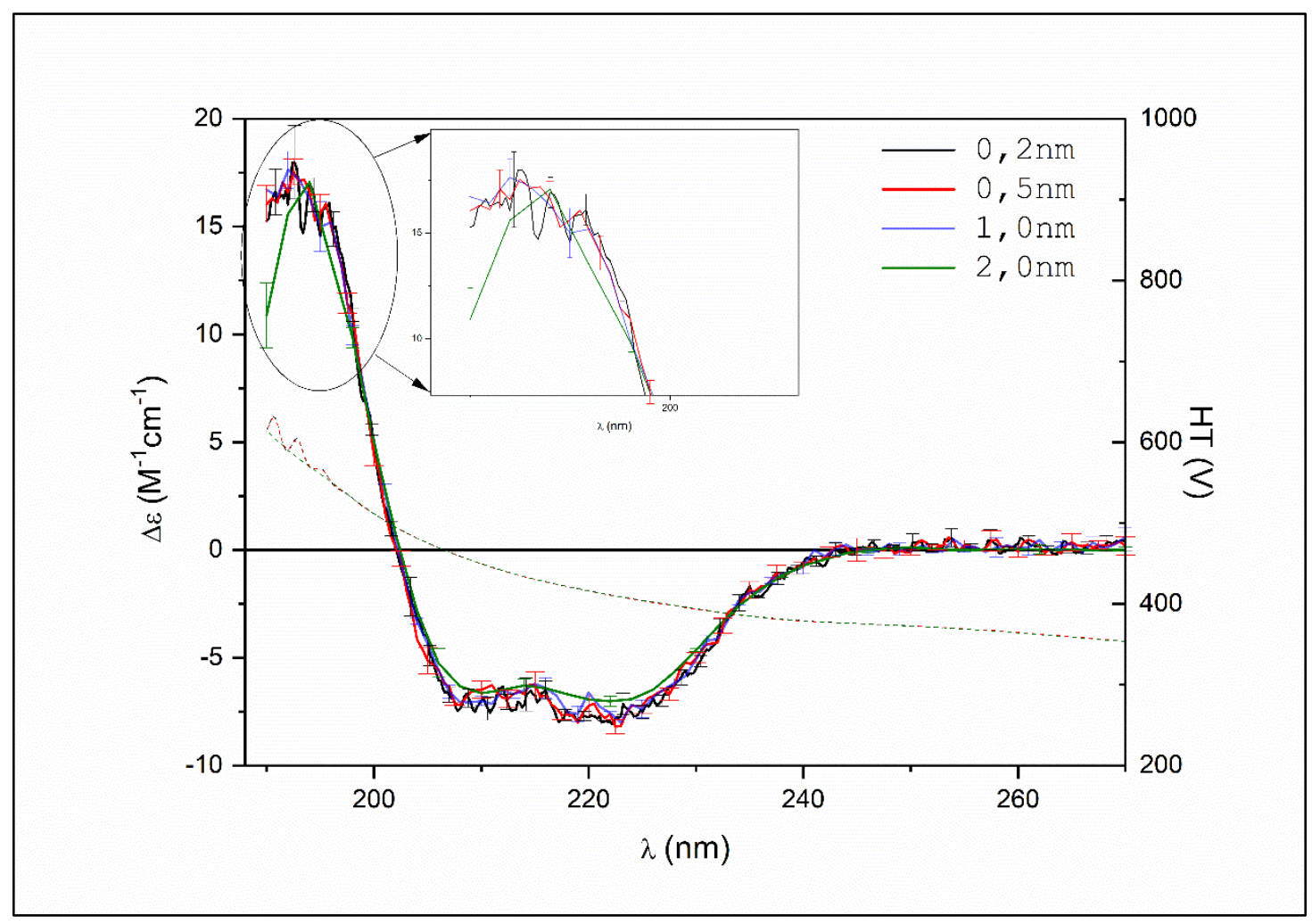

Fonte: Elaborado pelo autor 
Figura 20 - Espectros gerados pelo método tipo-Monte Carlo, para intervalos de (a) $0,2 \mathrm{~nm}$ e (b) $0,5 \mathrm{~nm}$.

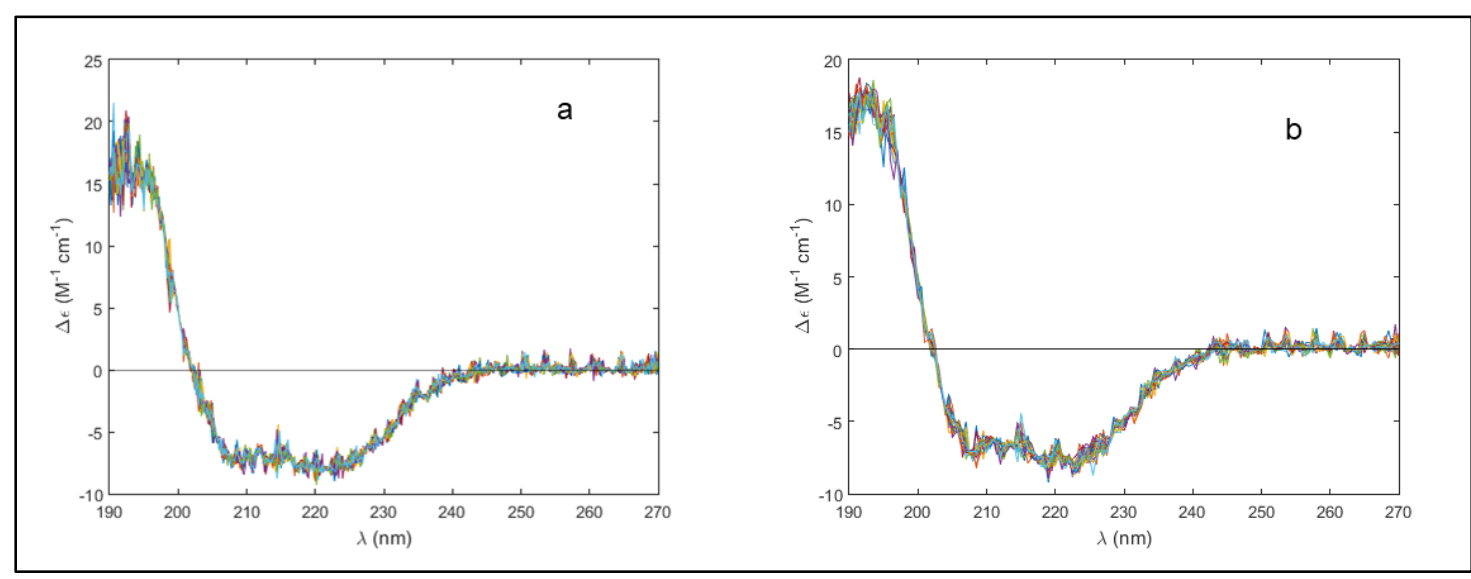

Fonte: Elaborado pelo autor

Tabela 8 - Resultados de desconvolução e testes estatísticos para o intervalo de varredura.

\begin{tabular}{|c|c|c|c|c|c|c|c|c|}
\hline \multirow{3}{*}{$\begin{array}{l}\text { Intervalo } \\
\quad(\mathrm{nm})\end{array}$} & \multirow{3}{*}{ Método } & \multirow{3}{*}{$\begin{array}{c}\text { Proporção de } \\
\alpha \text {-hélices }\end{array}$} & \multirow{3}{*}{$\sigma$} & \multirow{3}{*}{ NRMSD } & \multicolumn{2}{|c|}{ Modelo PDBMD2CD } & \multicolumn{2}{|c|}{ Modelo SESCA } \\
\hline & & & & & Teste Z & Teste t & Teste Z & Teste $t$ \\
\hline & & & & & \multicolumn{2}{|c|}{$\mathrm{p}$ valor } & \multicolumn{2}{|c|}{$\mathrm{p}$ valor } \\
\hline \multirow[t]{3}{*}{0,2} & CDSSTR & 0,750 & 0,041 & 0,011 & 0,951 & 0,957 & 0,729 & 0,732 \\
\hline & Selcon 3 & 0,708 & 0,013 & 0,090 & 0,375 & 0,379 & 0,566 & 0,568 \\
\hline & ContinLL & 0,704 & 0,023 & 0,077 & 0,764 & 0,765 & 0,887 & 0,888 \\
\hline \multirow[t]{3}{*}{0,5} & CDSSTR & 0,763 & 0,029 & 0,011 & 0,667 & 0,670 & 0,389 & 0,397 \\
\hline & Selcon 3 & 0,699 & 0,014 & 0,105 & 0,644 & 0,646 & 0,929 & 0,930 \\
\hline & ContinLL & 0,707 & 0,018 & 0,076 & 0,819 & 0,820 & 0,758 & 0,759 \\
\hline \multirow[t]{3}{*}{1,0} & CDSSTR & 0,799 & 0,023 & 0,012 & 0,092 & 0,099 & 0,449 & 0,456 \\
\hline & Selcon 3 & 0,710 & 0,014 & 0,074 & 0,332 & 0,337 & 0,313 & 0,318 \\
\hline & ContinLL & 0,743 & 0,015 & 0,062 & 0,203 & 0,209 & 0,980 & 0,980 \\
\hline \multirow[t]{3}{*}{2,0} & CDSSTR & - & - & - & - & - & - & - \\
\hline & Selcon 3 & - & - & - & - & - & - & - \\
\hline & ContinLL & - & - & - & - & - & - & - \\
\hline
\end{tabular}

\section{V.8 Menor comprimento de onda}

O menor comprimento de onda em que se pode tomar um espectro de CD com confiança é um importante parâmetro a ser controlado. Geralmente esse controle se dá através do HT. Lâmpadas Xenon em equipamentos de bancada emitem menos fótons na região abaixo dos $200 \mathrm{~nm}$, desta forma, nessa região há um aumento natural do HT, o qual deve ser mantido 
preferencialmente abaixo de $700 \mathrm{~V}$. Alguns fatores como a pureza do gás $\mathrm{N}_{2}$ utilizado no equipamento e o tempo de vida da lâmpada podem contribuir para esticar por alguns nanômetros a região de medição, sem aumentar significativamente o ruído no espectro.

Com o espectrofotômetro da Jasco, obtivemos um espectro de CD até $185 \mathrm{~nm}$ com HT abaixo de 700 V. Em $183 \mathrm{~nm}$ o HT alcançou um valor de $770 \mathrm{~V}$, ainda abaixo de sua saturação $(1000 \mathrm{~V})$. Nos espectros gerados pelo método tipo-Monte Carlo, é possível notar um leve aumento no ruído abaixo de $190 \mathrm{~nm}$. Entretanto, o ruído não afetou significativamente os resultados de desconvolução (tanto com cutoff em $190 \mathrm{~nm}$, quanto $200 \mathrm{~nm}$ ). Por outro lado, realizar um cutoff manual, ou seja, tomar o espectro até $200 \mathrm{~nm}$ não apresentou nenhuma vantagem evidente. Perder a informação contida no pico em $190 \mathrm{~nm}$ aumentou tanto o desvio padrão, quando o NRMSD obtidos (tabela 9).

Figura 21 - Espectros de CD com diferentes cutoff

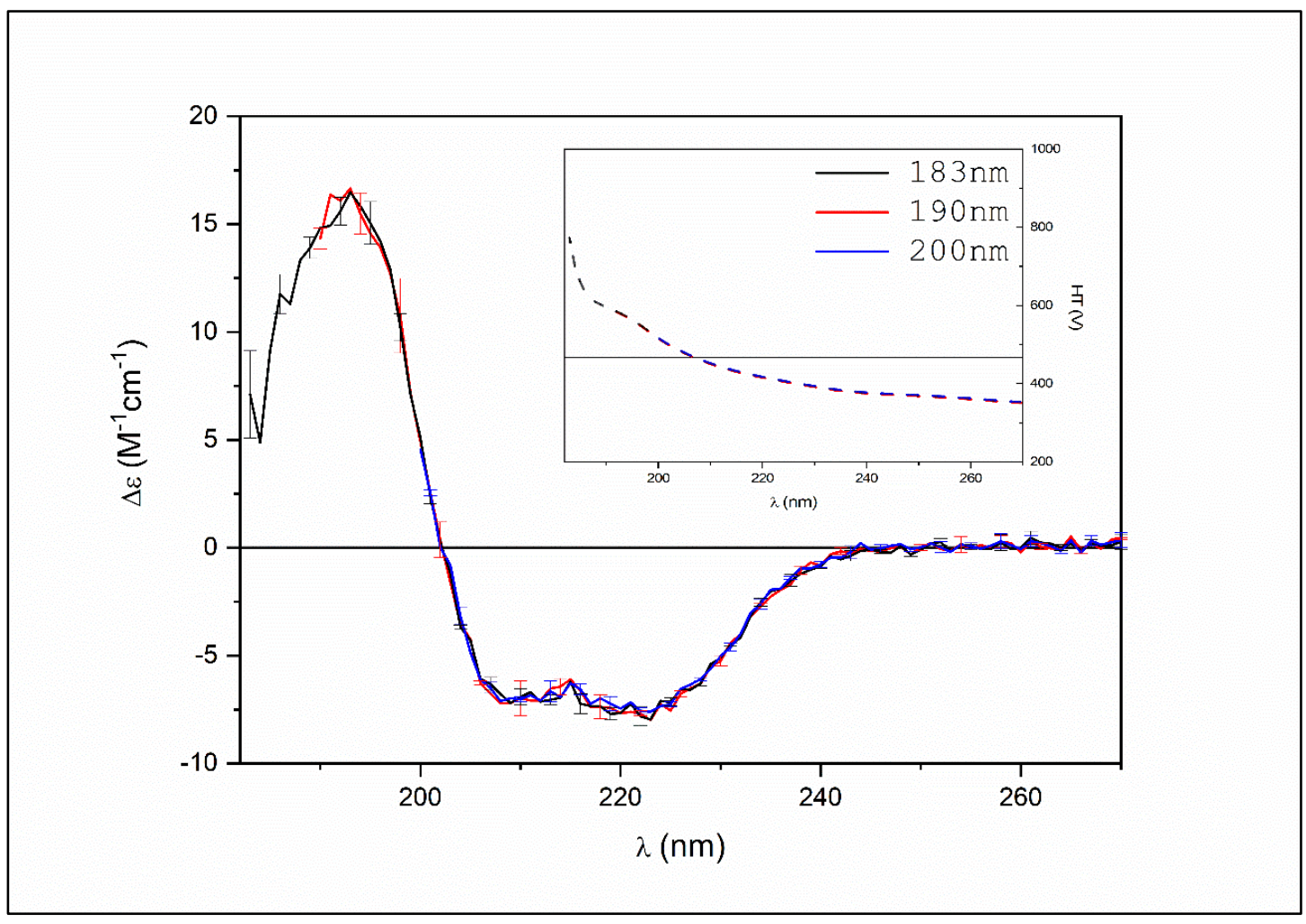

Fonte: Elaborado pelo autor 
Figura 22 - Espectros gerados pelo método tipo-Monte Carlo para diferentes cutoff

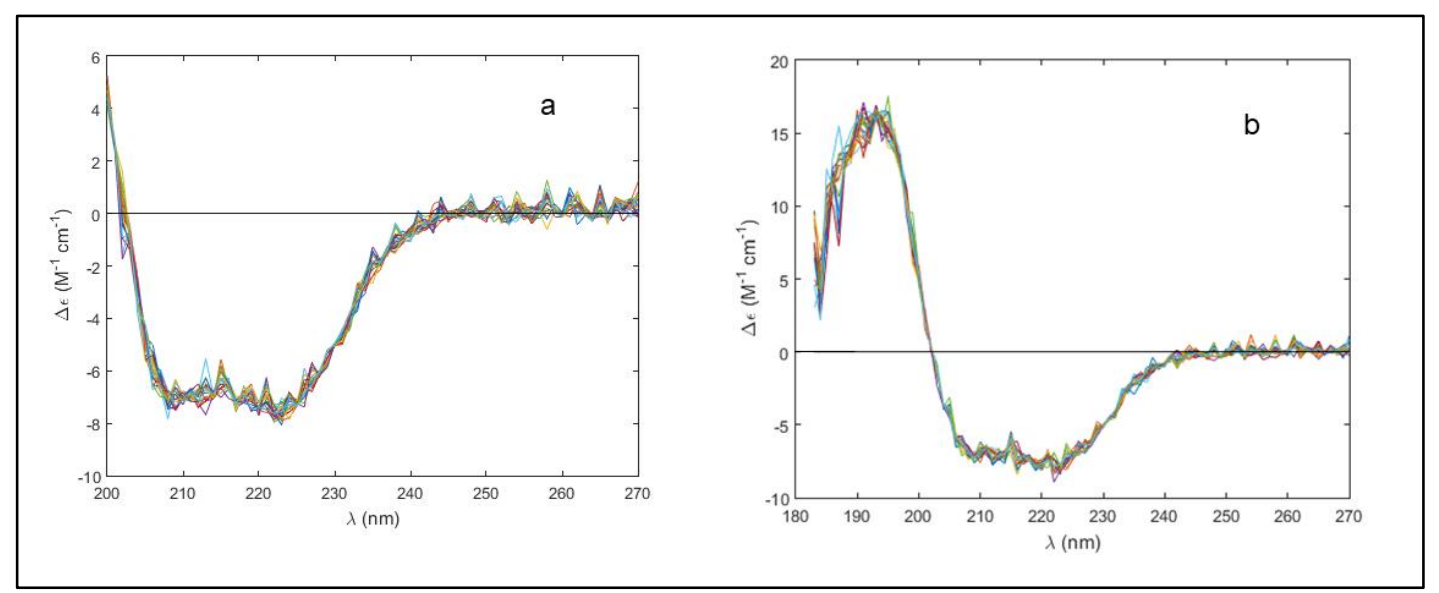

(a) $200 \mathrm{~nm}$ e (b) $183 \mathrm{~nm}$

Fonte: Elaborado pelo autor

Tabela 9 - Resultados de desconvolução e testes estatísticos para o menor comprimento de onda.

\begin{tabular}{|c|c|c|c|c|c|c|c|c|}
\hline \multirow{3}{*}{$\begin{array}{c}\text { Menor } \lambda \\
\quad(\mathrm{nm})\end{array}$} & \multirow{3}{*}{ Método } & \multirow{3}{*}{$\begin{array}{c}\text { Proporção de } \\
\alpha \text {-hélices }\end{array}$} & \multirow{3}{*}{$\sigma$} & \multirow{3}{*}{ NRMSD } & \multicolumn{2}{|c|}{ Modelo PDBMD2CD } & \multicolumn{2}{|c|}{ Modelo SESCA } \\
\hline & & & & & Teste $\mathbf{Z}$ & Teste $t$ & Teste $\mathbf{Z}$ & Teste $t$ \\
\hline & & & & & \multicolumn{2}{|c|}{$\mathrm{p}$ valor } & \multicolumn{2}{|c|}{$\mathrm{p}$ valor } \\
\hline \multirow[t]{2}{*}{183} & Bestsel $^{1}$ & 0,653 & 0,028 & 0,019 & 0,911 & 0,911 & 0,397 & 0,869 \\
\hline & Bestsel $^{2}$ & 0,649 & 0,037 & 0,025 & 0,869 & 0,870 & 0,170 & 0,179 \\
\hline \multirow[t]{2}{*}{190} & Bestsel $^{1}$ & 0,689 & 0,024 & 0,018 & 0,312 & 0,317 & 0,397 & 0,170 \\
\hline & Bestsel $^{2}$ & 0,709 & 0,040 & 0,025 & 0,250 & 0,260 & 0,402 & 0,179 \\
\hline 200 & Bestsel $^{2}$ & 0,692 & 0,055 & 0,026 & 0,543 & 0,548 & 0,424 & 0,431 \\
\hline
\end{tabular}

${ }^{1}$ Cutoff de 190nm

${ }^{2}$ Cutoff de 200nm

\section{V.9 Concentração de proteína}

O efeito da concentração da amostra no espectro de CD está representado na figura 22, não normalizada para $\Delta \varepsilon$. Segundo a lei de Beer-Lambert, a absorbância é diretamente proporcional a concentração, e este fenômeno pode ser observado tanto na figura 23 , quanto na figura 25, que apresenta o ajuste linear dos valores de $\theta$ para os comprimentos de onda de 192 nm (figura 25-a) e 208 nm(figura 25-b). Se não há proteína em solução, a luz que chega ao fotomultiplicador é linearmente polarizada, logo não há espectro de $\mathrm{CD}$. Isso justifica a convergência de ambas as retas para o ponto $(0,0)$.

Com auxílio do método tipo-Monte Carlo (figura 24), é possível notar que quanto menor a concentração, mais ruidoso se torna o espectro, e é mais difícil de localizar os dois vales na 
região >200 nm. Por outro lado, quanto maior a concentração, mais fótons são absorvidos, aumentando consideravelmente o HT na região abaixo de $220 \mathrm{~nm}$.

Conforme a tabela 10, concentrações muito baixas de proteína afetam significativamente os resultados de desconvolução, isso pode surgir devido a diversos fatores, por exemplo, pela dificuldade de diferenciar dois vales na região acima de $200 \mathrm{~nm}$, ou então pelo aumento da fração $\sigma_{c} / c$ que segundo a seção V.12 pode gerar distorções na distribuição ponto a ponto dos valores de $\Delta \varepsilon$. Para as concentrações menores que $0,08 \mathrm{mg} / \mathrm{mL}$ houve uma baixa acurácia nos resultados preditos, e uma diminuição da precisão (aumento do desvio padrão) para os três algoritmos utilizados. É interessante ressaltar os valores elevados de NRMSD obtidos pelo ContinLL e pelo Selcon 3, o que demonstra uma dificuldade de ajustar os espectros contidos na base de dados, com o espectro de interesse. Muitos espectros gerados pelo método tipo-Monte Carlo foram estimados em poucos passos como possuindo $100 \%$ de $\alpha$-hélices pelo ContinLL, o que é um sinal claro de que o algoritmo não está conseguindo ajustar o espectro experimental.

Figura 23 - Espectros de CD com diferentes concentrações de proteína

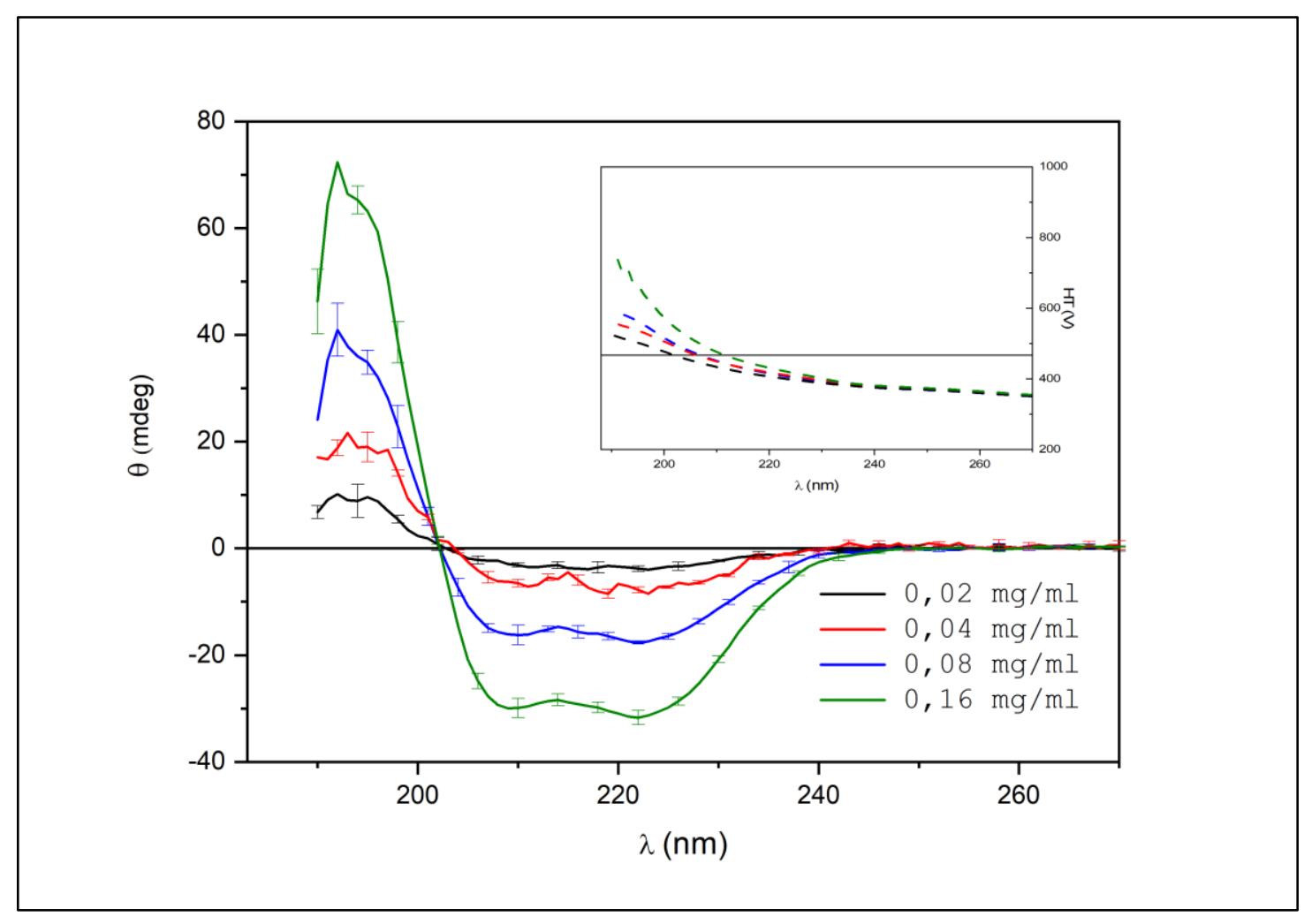

Fonte: Elaborado pelo autor

Figura 24 - Espectros gerados pelo método tipo-Monte Carlo, para diferentes concentrações de proteína. 


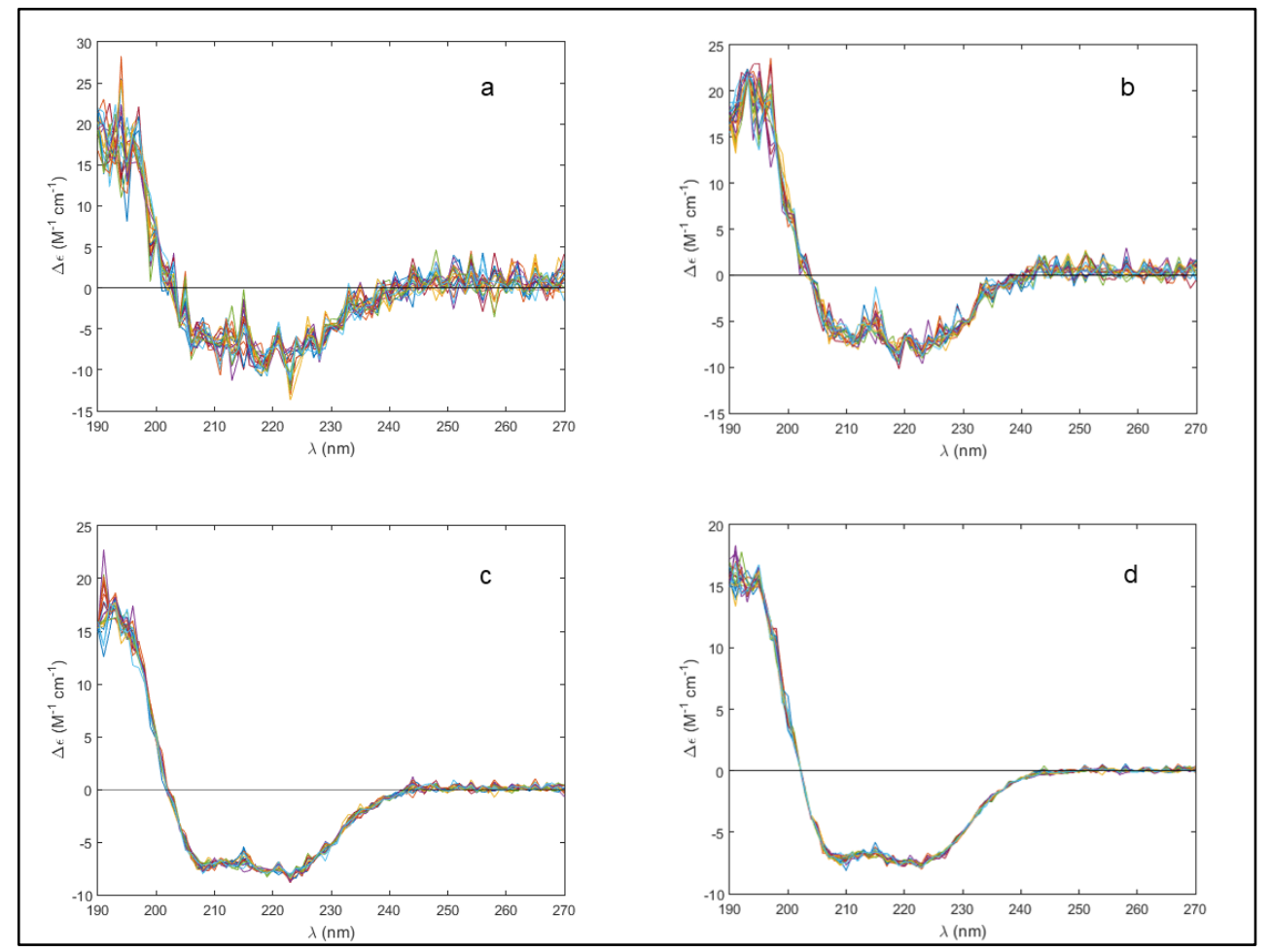

(a) $0,02 \mathrm{mg} / \mathrm{mL}$, (b) $0,04 \mathrm{mg} / \mathrm{mL}$, (c) $0,12 \mathrm{mg} / \mathrm{mL}$ e (d) $0,16 \mathrm{mg} / \mathrm{mL}$.

Fonte: Elaborado pelo autor

Tabela 10 - Resultados de desconvolução para a concentração de Mb.

\begin{tabular}{|c|c|c|c|c|c|c|c|c|}
\hline \multirow{3}{*}{$\begin{array}{c}\text { Concentração } \\
\text { de } \mathbf{M b} \\
(\mathrm{mg} / \mathrm{ml})\end{array}$} & \multirow{3}{*}{ Método } & \multirow{3}{*}{$\begin{array}{c}\text { Proporção de } \\
\alpha \text {-hélices }\end{array}$} & \multirow{3}{*}{$\boldsymbol{\sigma}$} & \multirow{3}{*}{ NRMSD } & \multicolumn{2}{|c|}{ Modelo PDBMD2CD } & \multicolumn{2}{|c|}{ Modelo SESCA } \\
\hline & & & & & Teste $\mathbf{Z}$ & Teste $\mathbf{t}$ & Teste $\mathbf{Z}$ & Teste $\mathbf{t}$ \\
\hline & & & & & \multicolumn{2}{|c|}{$\mathrm{p}$ valor } & \multicolumn{2}{|c|}{$\mathrm{p}$ valor } \\
\hline \multirow[t]{3}{*}{0,02} & CDSSTR & 0,510 & 0,050 & 0,001 & 0,000 & 0,000 & 0,000 & 0,000 \\
\hline & Selcon 3 & 0,767 & 0,041 & 0,223 & 0,077 & 0,089 & 0,104 & 0,118 \\
\hline & ContinLL & 0,959 & 0,082 & 0,221 & 0,003 & 0,008 & 0,002 & 0,005 \\
\hline \multirow[t]{3}{*}{0,04} & CDSSTR & 0,641 & 0,029 & 0,003 & 0,003 & 0,005 & 0,004 & 0,007 \\
\hline & Selcon 3 & 0,747 & 0,036 & 0,140 & 0,332 & 0,154 & 0,193 & 0,205 \\
\hline & ContinLL & 0,868 & 0,113 & 0,187 & 0,143 & 0,190 & 0,140 & 0,156 \\
\hline \multirow[t]{3}{*}{0,08} & CDSSTR & 0,799 & 0,023 & 0,012 & 0,092 & 0,099 & 0,449 & 0,456 \\
\hline & Selcon 3 & 0,710 & 0,014 & 0,074 & 0,332 & 0,337 & 0,313 & 0,318 \\
\hline & ContinLL & 0,743 & 0,015 & 0,062 & 0,203 & 0,209 & 0,980 & 0,980 \\
\hline \multirow[t]{3}{*}{0,12} & CDSSTR & 0,769 & 0,054 & 0,012 & 0,381 & 0,707 & 0,535 & 0,542 \\
\hline & Selcon 3 & 0,725 & 0,014 & 0,080 & 0,109 & 0,115 & 0,158 & 0,165 \\
\hline & ContinLL & 0,731 & 0,024 & 0,069 & 0,533 & 0,537 & 0,247 & 0,256 \\
\hline \multirow[t]{3}{*}{0,16} & CDSSTR & 0,773 & 0,041 & 0,013 & 0,452 & 0,587 & 0,384 & 0,393 \\
\hline & Selcon 3 & 0,702 & 0,014 & 0,079 & 0,618 & 0,540 & 0,787 & 0,788 \\
\hline & ContinLL & 0,729 & 0,012 & 0,059 & 0,452 & 0,456 & 0,101 & 0,108 \\
\hline
\end{tabular}

Figura 25 - Ajuste linear da elipticidade contra a concentração de mioglobina para (a) $192 \mathrm{~nm}$ e (b) $208 \mathrm{~nm}$. 


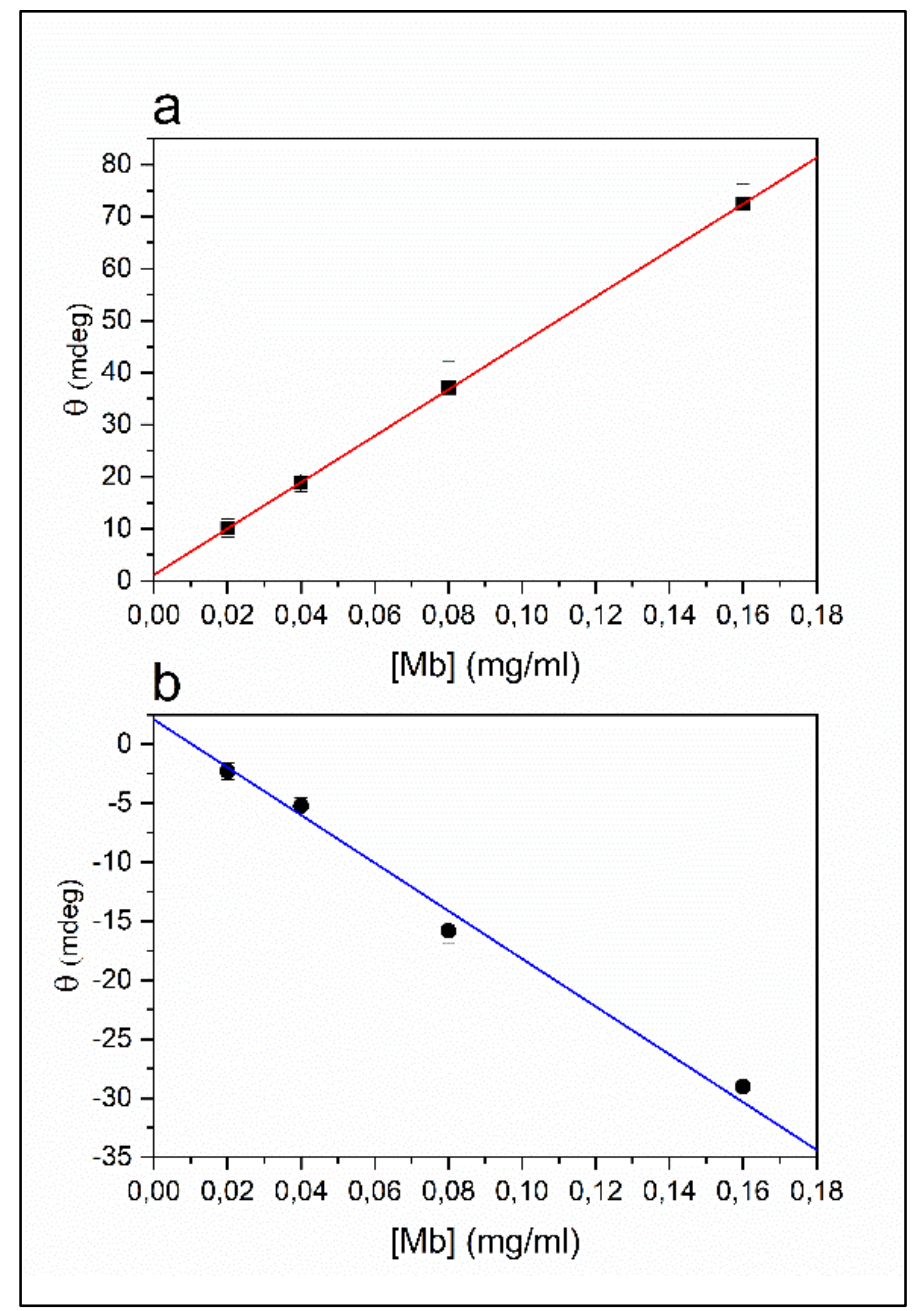

Em (a) o $R^{2}$ ajustado foi de 0,99994 , o coeficiente angular de 445,46 $\pm 2,54$ e um coeficiente linear de $1,14 \pm 0,15$. Em (b) o $R^{2}$ obtido foi 0,98235 e os coeficientes angular e linear foram $-202,73 \pm 19,22$ e 2,09913 $\pm 1,11221$, respectivamente. Fonte: Elaborado pelo autor

\section{V.10 Concentração de $\mathrm{NaCl}$}

O cloreto de sódio é utilizado em diversos tampões para mimetizar condições fisiológicas. Entretanto, o ânion cloreto possui alta taxa de absorção em comprimentos de ondas abaixo de $200 \mathrm{~nm}$. Então, por mais que esse ânion não apresenta um espectro de CD característico, ele pode aumentar abruptamente o ruído em medidas de CD. Dado que os fótons são absorvidos, menos luz é captada pelo fotomultiplicador e rapidamente o nível de HT é saturado. Isso se torna evidente ao analisar a figura 26.

Mesmo para a menor concentração de $\mathrm{NaCl}$ o espectro é altamente afetado na região de baixo comprimento de onda, isso é refletido em barras de erro maiores, que geram espectros mais dispersos pelo método tipo-Monte Carlo. A tabela 11 aponta o comprimento de onda de 
cutoff, ou seja, $\lambda$ para o qual o nível de HT é superior a $700 \mathrm{~V}$ para cada concentração de $\mathrm{NaCl}$. Sem sal em solução, seria possível obter um espectro com baixo ruído até a região de $185 \mathrm{~nm}$, entretanto, na presença de $\mathrm{Cl}^{-}$o limite passa a ser pelo menos $11 \mathrm{~nm}$ maior, o suficiente para perder informações sobre o pico em 190 nm. Esse fato já é conhecido pelos usuários de CD mais experientes, portanto, muitos espectros com a presença de $\mathrm{NaCl}$ são interrompidos na região de $200 \mathrm{~nm}$. Neste trabalho, foi avaliado o resultado de desconvolução dos espectros utilizando o comprimento de onda mínimo como sendo 190 e $200 \mathrm{~nm}$. A tabela 12 apresenta os resultados.

Considerando o cutoff de $190 \mathrm{~nm}$ em $75 \mathrm{mM}$ de NaCl, tanto o Selcon3 quanto o ContinLL obtiveram resultados de desconvolução que são incapazes de rejeitar a hipótese nula, entretanto isso apenas ocorreu devido à grande imprecisão dos dados. O primeiro algoritmo obteve um desvio padrão de $\sim 9 \%$, já o segundo, de $\sim 30 \%$, indicando que o resultado não é confiável. Para concentrações maiores de sal, a inacurácia no valor de $\alpha$-hélice predito foi muito alta para todos os algoritmos utilizados, o que acarretou a rejeição da hipótese nula.

O efeito do corte em $200 \mathrm{~nm}$ foi observado através do algoritmo BeStSel. Para este, considerar um cutoff de $190 \mathrm{~nm}$ leva à rejeição da hipótese nula em todas as concentrações de $\mathrm{Cl}^{-}$, entretanto, em $200 \mathrm{~nm}$ a porcentagem de $\alpha$-hélices foi predita com muito mais acurácia e pode ser considerada equivalente ao valor semi-teórico independente da concentração de sal. Entretanto, é importante ressaltar que em todos os casos o desvio padrão estimado foi relativamente alto, variando entre 4,5\% ( $\sim 6,9$ resíduos de aa ou $\sim 2$ voltas de hélice) e 7,0\% ( $\sim 10,7$ resíduos de aa ou $\sim 3$ voltas de hélice).

Tabela 11 - Região de Cutoff para cada concentração de NaCl

\begin{tabular}{ccc}
\hline$[\mathrm{NaCl}](\mathrm{mM})$ & Cutoff $(\mathrm{nm})(\mathrm{HT}<700 \mathrm{~V})$ & $\mathrm{HT}>593 \mathrm{~V}^{*}(\mathrm{~nm})$ \\
\hline 0 & 185 & 190 \\
75 & 196 & 197 \\
150 & 197 & 198 \\
300 & 198 & 199 \\
\hline
\end{tabular}

* Valor do HT a 190nm para solução sem $\mathrm{NaCl}$

Figura 26 - Espectros de CD com diferentes concentrações de $\mathrm{NaCl}$ 


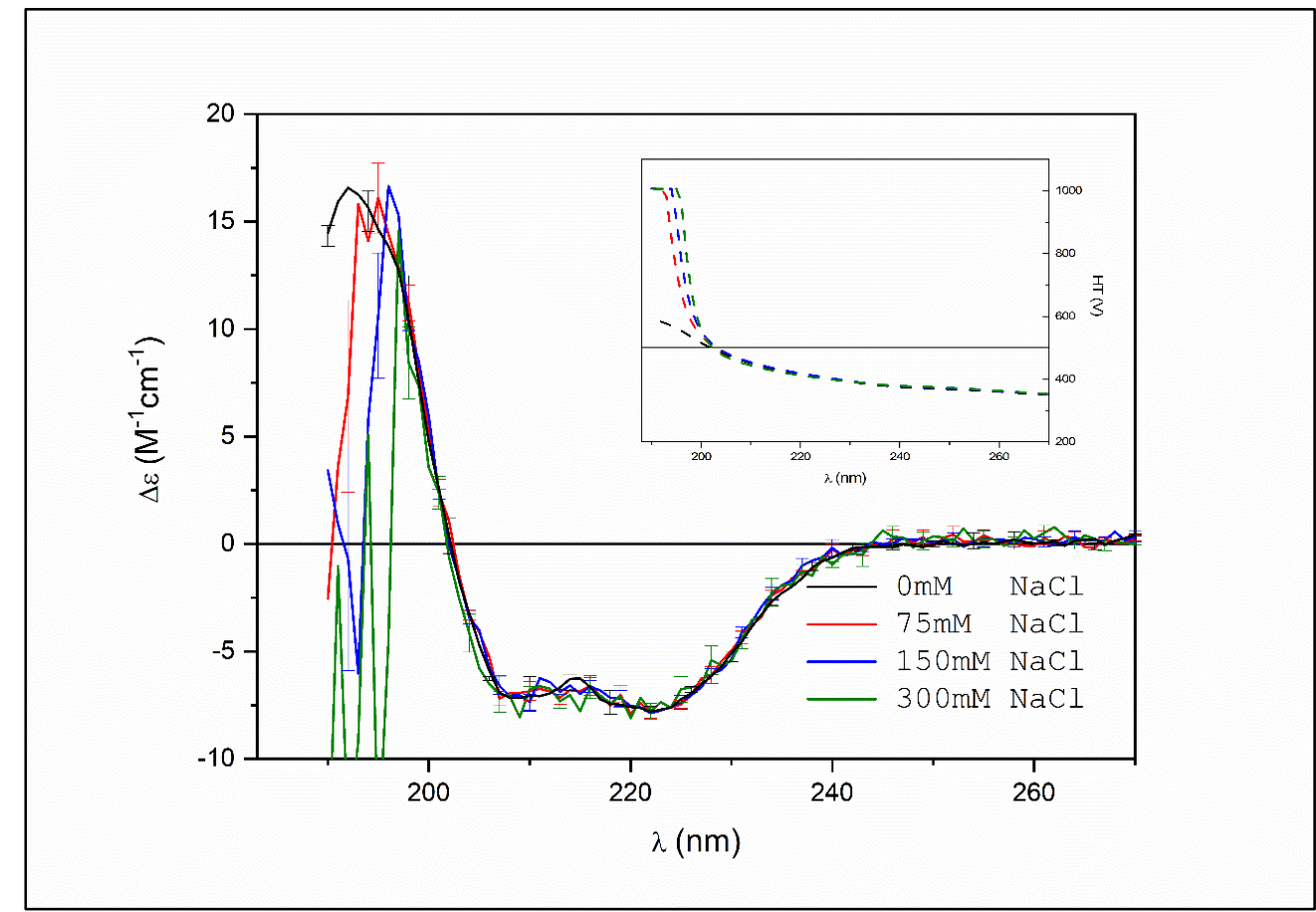

Fonte: Elaborado pelo autor

Figura 27 - Espectros gerados pelo método tipo-Monte Carlo para diferentes concentrações de $\mathrm{NaCl}$.

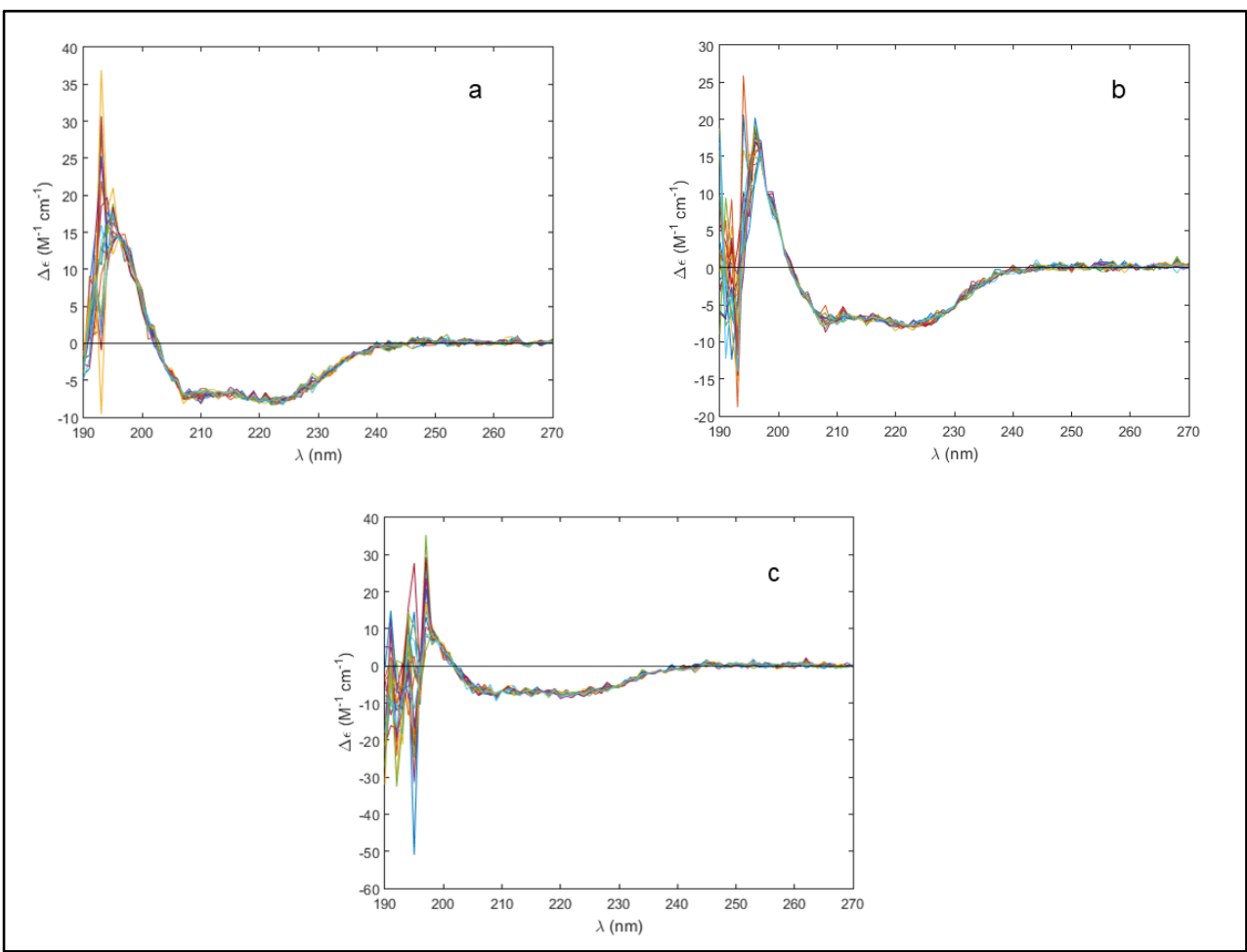

(a) $75 \mathrm{mM}$, (b) $150 \mathrm{mM}$ e (c) $300 \mathrm{mM}$.

Fonte: Elaborado pelo autor

Tabela 12 - Resultados de desconvolução e testes estatísticos para a concentração de NaCl. 


\begin{tabular}{|c|c|c|c|c|c|c|c|c|}
\hline \multirow{3}{*}{$\begin{array}{c}\text { Concentração } \\
\text { de NaCl } \\
(\mathrm{mM})\end{array}$} & \multirow{3}{*}{ Método } & \multirow{3}{*}{$\begin{array}{c}\text { Proporção de } \\
\alpha \text {-hélices }\end{array}$} & \multirow{3}{*}{$\boldsymbol{\sigma}$} & \multirow{3}{*}{ NRMSD } & \multicolumn{2}{|c|}{ Modelo PDBMD2CD } & \multicolumn{2}{|c|}{ Modelo SESCA } \\
\hline & & & & & Teste Z & Teste $\mathbf{t}$ & Teste Z & Teste $\mathbf{t}$ \\
\hline & & & & & \multicolumn{2}{|c|}{$\mathrm{p}$ valor } & \multicolumn{2}{|c|}{$\mathrm{p}$ valor } \\
\hline \multirow[t]{5}{*}{0} & CDSSTR & 0,799 & 0,023 & 0,012 & 0,092 & 0,099 & 0,092 & 0,101 \\
\hline & Selcon 3 & 0,710 & 0,014 & 0,074 & 0,332 & 0,337 & 0,332 & 0,337 \\
\hline & ContinLL & 0,743 & 0,015 & 0,062 & 0,203 & 0,209 & 0,203 & 0,209 \\
\hline & Bestsel $^{1}$ & 0,669 & 0,024 & 0,018 & 0,312 & 0,317 & 0,397 & 0,170 \\
\hline & Bestsel $^{2}$ & 0,709 & 0,040 & 0,025 & 0,250 & 0,260 & 0,402 & 0,179 \\
\hline \multirow[t]{5}{*}{75} & CDSSTR & 0,609 & 0,059 & 0,002 & 0,027 & 0,037 & 0,038 & 0,050 \\
\hline & Selcon 3 & 0,667 & 0,092 & 0,393 & 0,820 & 0,822 & 0,746 & 0,749 \\
\hline & ContinLL & 0,563 & 0,283 & 0,290 & 0,597 & 0,603 & 0,627 & 0,633 \\
\hline & Bestsel $^{1}$ & 0,474 & 0.026 & 0,080 & 0,000 & 0,000 & 0,000 & 0,000 \\
\hline & Bestsel $^{2}$ & 0,668 & 0.060 & 0,013 & 0,847 & 0,849 & 0,708 & 0,711 \\
\hline \multirow[t]{5}{*}{150} & CDSSTR & 0,527 & 0,045 & 0,002 & 0,000 & 0,002 & 0,001 & 0,002 \\
\hline & Selcon 3 & 0,560 & 0,025 & 0,542 & 0,000 & 0,000 & 0,000 & 0,000 \\
\hline & ContinLL & 0,415 & 0,462 & 0,488 & 0,520 & 0,528 & 0,538 & 0,545 \\
\hline & Bestsel $^{1}$ & 0,453 & 0,058 & 0,096 & 0,000 & 0,000 & 0,000 & 0,001 \\
\hline & Bestsel $^{2}$ & 0,606 & 0,045 & 0,025 & 0,326 & 0,355 & 0,464 & 0,470 \\
\hline \multirow[t]{5}{*}{300} & CDSSTR & 0,484 & 0,045 & 0,001 & 0,000 & 0,000 & 0,000 & 0,000 \\
\hline & Selcon 3 & 0,284 & 0,123 & 0,739 & 0,001 & 0,004 & 0,001 & 0,003 \\
\hline & ContinLL & 0,412 & 0,379 & 0,741 & 0,427 & 0,437 & 0,446 & 0,456 \\
\hline & Bestsel $^{1}$ & 0,334 & 0.071 & 0,108 & 0,000 & 0,000 & 0,000 & 0,000 \\
\hline & Bestsel $^{2}$ & 0,672 & 0.070 & 0,047 & 0,831 & 0,833 & 0,710 & 0,713 \\
\hline
\end{tabular}

${ }^{1}$ Cutoff de $190 \mathrm{~nm}$

${ }^{2}$ Cutoff de $200 \mathrm{~nm}$

\section{V.11 Desvio padrão por Monte Carlo x NRMSD}

O NRMSD é um dos parâmetros normalmente utilizados para verificar se uma desconvolução foi bem-sucedida ou não. Todos os algoritmos utilizados nesse trabalho procuram minimizar o valor de NRMSD, representando que o espectro modelo foi capaz de ajustar o espectro experimental. Entretanto, já é conhecido que um valor pequeno de NRMSD não necessariamente indica que a desconvolução gerou um resultado acurado (MILES et al., 2005), isso pode ser verificado facilmente olhando para os valores obtidos pelo CDSSTR na tabela 12 .

Nesse sentido, com uma análise ainda mais cuidadosa das tabelas apresentadas nos resultados desta dissertação, é ainda possível observar outro padrão interessante. O CDSSTR apresentou o menor valor de NRMSD em quase todos os casos, mas, por outro lado, ele também possui os valores mais elevados do $\sigma$, obtido pelo método tipo-Monte Carlo. 
A figura 27 apresenta uma comparação dos resultados de NMRSD e $\sigma$ dos três algoritmos presentes no Dichroweb, para os 12 resultados mais confiáveis. É possível notar um padrão: em todos os casos o CDSSTR apresentou um NMRSD menor do que o Selcon3 e o ContinLL, mas estes apresentaram $\sigma$ menores, possuindo então um resultado mais preciso. Um teste F de Fisher (HEUMANN; SHALABH, 2016) verificou a hipótese nula de que os desvios padrões obtidos para o CDSSTR e pelos outros algoritmos são equivalentes. Como $\sigma$ foi estimado com 19 graus de liberdade, para um nível de significância de 5\%, se a variável $\mathrm{F}$ for maior que 2,168, podemos rejeitar essa hipótese nula.

Os valores de F estão presentes na tabela 13. Em todos os casos para o Selcon3 somos capazes de rejeitar a hipótese nula e concluir que os desvios padrões do CDSSTR foram maiores, no nível de significância. Isso também é verdade para onze dos doze casos analisados para o ContinLL. Portanto, uma conclusão importante é que um NRMSD baixo não necessariamente indica que o resultado de desconvolução foi preciso e nem acurado. Nesse sentido, é necessário introduzir novos parâmetros para auxiliar a análise dos usuários, como, por exemplo o $\sigma$ calculado por Monte Carlo.

Figura 28 - Comparação do desvio padrão por Monte Carlo com o NRMSD

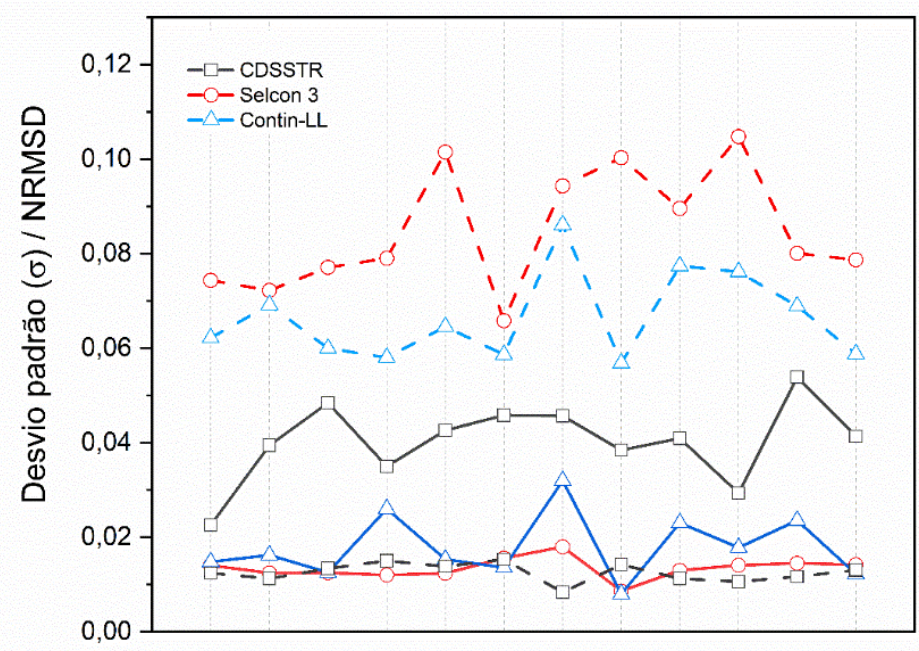

Comparação entre o desvio padrão estimado para o conteúdo de $\alpha$-hélices utilizando o método tipo-Monte Carlo (linha sólida) com os valores de NRMSD (linha tracejada) para três algoritmos de desconvolução. Os 
pontos do eixo horizontal representam os doze resultados experimentais mais acurados. Fonte: Elaborado pelo autor

Tabela 13 - Resultados do teste F de Fisher comparando os desvios padrões do CDSSTR com os demais algoritmos

\begin{tabular}{ccccc}
\hline CDSSTR & Selcon 3 & ContinLL & FSelcon3 & F $_{\text {ContinLL }}$ \\
\hline 0,023 & 0,014 & 0,015 & 2,587 & 2,323 \\
0,039 & 0,012 & 0,016 & 10,054 & 5,897 \\
0,048 & 0,012 & 0,013 & 15,096 & 14,889 \\
0,035 & 0,012 & 0,026 & 8,507 & 1,812 \\
0,043 & 0,012 & 0,015 & 11,854 & 7,731 \\
0,046 & 0,016 & 0,014 & 8,659 & 11,400 \\
0,046 & 0,018 & 0,032 & 6,474 & 2,037 \\
0,038 & 0,009 & 0,008 & 19,974 & 23,189 \\
0,041 & 0,013 & 0,023 & 9,910 & 3,154 \\
0,029 & 0,014 & 0,018 & 4,351 & 2,710 \\
0,054 & 0,014 & 0,024 & 13,828 & 5,236 \\
0,041 & 0,014 & 0,012 & 8,521 & 11,489 \\
& & & & \\
0 & & & & \\
0
\end{tabular}

\section{V.12 O problema da normalização}

A maioria das análises quantitativas e comparativas de espectros de CD depende de um processo de normalização dos dados para uma escala que independa da concentração e do caminho óptico do porta-amostras, seja para $\Delta \varepsilon$ ou $[\theta]$. Na literatura já existem alguns trabalhos explorando os problemas na acurácia da determinação da concentração de proteína utilizada. 
Por exemplo, Nagy e Grubmüller (2020), demonstram que inacuracia na concentração pode levar a desvios de até $30 \%$ entre o espectro medido e o espectro real.

Atualmente existem métodos capazes de auxiliar na estimativa da concentração ideal, aumentando a precisão do valor, como, por exemplo a absorção em $205 \mathrm{~nm}$ ou $280 \mathrm{~nm}$ (ANTHIS; CLORE, 2013; KELLY; PRICE, 2009), ou ainda métodos de renormalização do espectro, como a minimização do valore de NRMSD do algoritmo ContinLL (MILES et al., 2005). Além disso, foram desenvolvidos métodos capazes de estimar a estrutura secundária da proteína sem a necessidade de normalizar pela concentração (RAUSSENS et al., 2003; MCPHIE, 2008). Entretanto, vale ressaltar que os últimos ainda não apresentam todas as potencialidades dos métodos tradicionais.

De acordo com Miles e Wallace (2009) erros no comprimento do caminho óptico da cubeta também são de grande preocupação, visto que para caminhos ópticos pequenos $(<0,001$ $\mathrm{cm}$ ) pode haver desvios do valor nominal (do fabricante) para o verdadeiro de até $50 \%$. Entretanto, os autores demonstram um método para medir com precisão e acurácia o caminho óptico. Para comprimentos maiores que $0,01 \mathrm{~cm}$, a incerteza passa a ser da ordem de $1 \mu \mathrm{m}$ (desvio padrão relativo $\approx 0,01$ ), o que é suficientemente preciso. Sendo assim, é possível normalizar por $l$ sem afetar significativamente o espectro.

Tendo isto em vista, esta seção foca na origem estatística do problema da normalização, em especial da concentração, e em estimar uma precisão ideal para a essa grandeza em medidas de dicroísmo circular através do método de Monte Carlo, desconsiderando a incerteza no caminho óptico.

A função de distribuição que rege uma medida de CD é uma Poisson, mas devido ao teorema do limite central, a distribuição do espectro médio converge a uma normal. Em outras palavras, é esperado obter valores de $\theta(\lambda)$ distribuídos dentro de uma gaussiana centrada na média $\bar{\theta}(\lambda)$, sendo que cerca de apenas $2,27 \%$ dos pontos serão encontrados na região superior a $\bar{\theta}(\lambda)+2 \sigma_{\theta}$, e o mesmo valor para $\theta(\lambda)<\bar{\theta}(\lambda)-2 \sigma_{\theta}$.

Considerando a distribuição de probabilidade de uma medida de concentração como também sendo uma gaussiana, centrada em $\bar{c}$ e com desvio padrão $\sigma_{c}$. A distribuição de probabilidade da variável $\Delta \varepsilon$, calculada a partir da equação (40), em que $K(l)$ é a razão da massa molecular pelo caminho óptico dividida pela constante numérica presente na equação (31), passa a ser uma distribuição razão (DÍAZ-FRANCÉS; RUBIO, 2012), a qual pode não ser mais simétrica. 


$$
\Delta \varepsilon(\lambda)=K(l) \frac{\theta(\lambda)}{c}
$$

A incerteza associada a variável normalizada pode ser estimada através da teoria de propagação dos erros como sendo:

$$
\sigma_{\Delta \varepsilon}^{2}=\frac{K(l)^{2}}{c^{2}}\left(\sigma_{\theta}^{2}+\frac{\theta^{2} \sigma_{c}^{2}}{c^{2}}\right)
$$

Para essas análises, é interessante definir a incerteza relativa $\delta_{x}=\frac{\sigma_{x}}{x}$. Com ela, pode-se reescrever a equação (40) como:

$$
\sigma_{\Delta \varepsilon}^{2}=\left(\frac{\theta K(l)}{c}\right)^{2}\left(\delta_{\theta}^{2}+\delta_{c}^{2}\right)=\Delta \varepsilon^{2}\left(\delta_{\theta}^{2}+\delta_{c}^{2}\right)
$$

Assim, $\sigma_{\Delta \varepsilon}$ depende do valor absoluto de $\Delta \varepsilon$, logo, regiões de picos e vales tendem a apresentar uma maior incerteza. Este fato é corroborado em todos os espectros apresentados nesta dissertação.

Para avaliar os possíveis valores de $\delta_{\theta}$ foi utilizado os espectros semi-teóricos gerados para a Mb através do PDBMD2CD e do SESCA. Como ambos apresentam resultados independentes da concentração, o valor de $\delta_{\theta}$ é igual ao $\delta_{\Delta \varepsilon}$. Assim, foi tomada a razão $\frac{\sigma_{\Delta \varepsilon}}{\Delta \varepsilon}$ ponto a ponto para os dois espectros na região de $\operatorname{CD}(\lambda<240 \mathrm{~nm})$. Os valores encontrados estão presentes no gráfico da figura 29. Com este, ignorando a região em que $\theta \approx 0$, é possível verificar que $\delta_{\theta}$ está contido no intervalo $[0,01 ; 0,05]$, com média 0,031 e incerteza 0,010 . Em outras palavras, a incerteza média desses espectros (sem considerar erros na concentração) é de cerca de $3 \%$ do valor do $\Delta \varepsilon$.

Com esse intervalo definido, podemos avaliar o efeito de $\delta_{c}$ nos espectros de CD. Para tanto, foi selecionado o valor de $\Delta \varepsilon$ do espectro médio do PDBMD2CD, considerando uma concentração teórica de $c_{0}=0,1 \mathrm{mg} / \mathrm{mL}$ e um comprimento $l=0,1 \mathrm{~cm}$ para desnormalizar o espectro. Com o resultado, dois processos de Monte Carlo diferentes são realizados. 
Figura 29 - Valores de $\delta_{\theta}$ calculados para os espectros médio da $M b$.

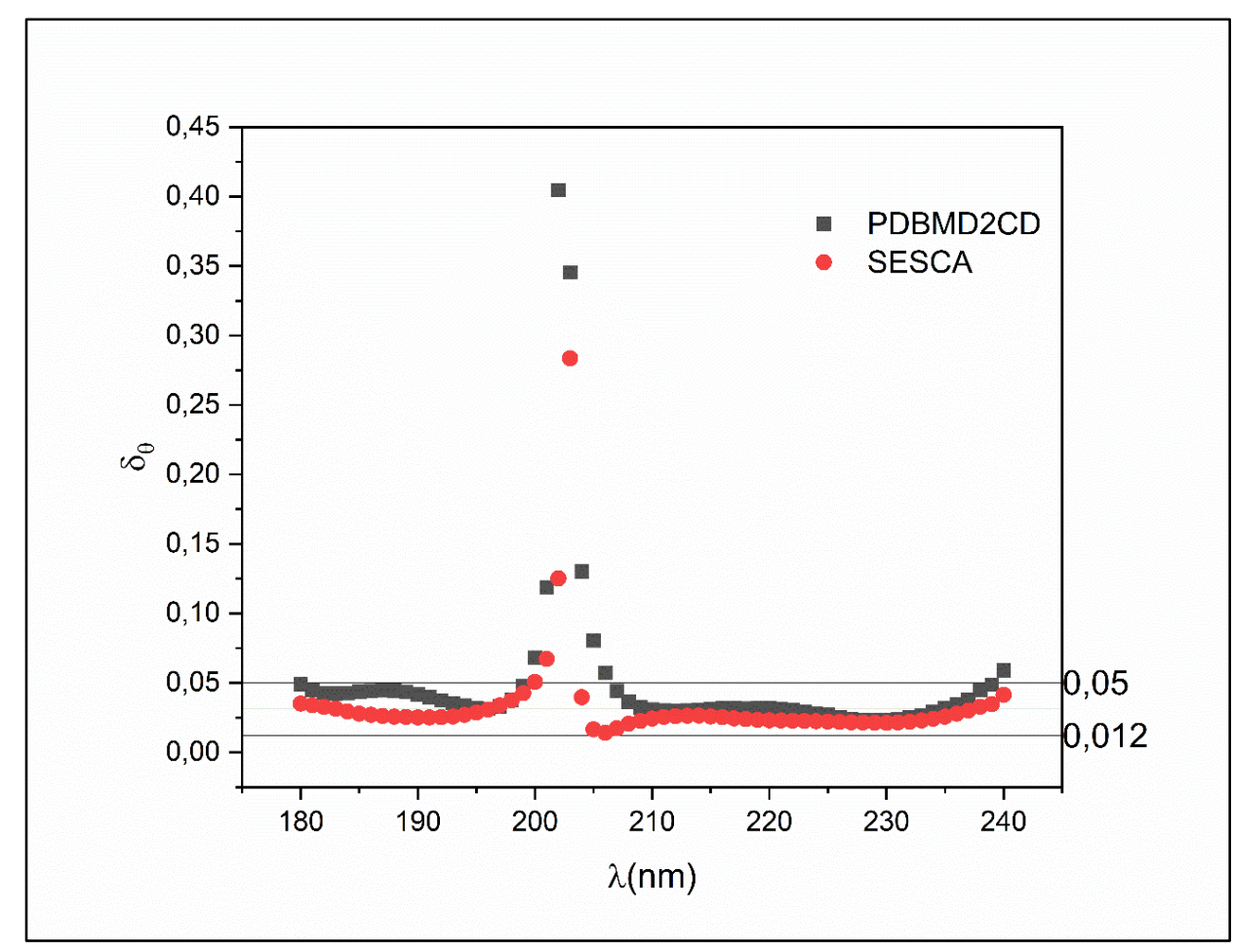

O pico presente na região entre 200 e $205 \mathrm{~nm}$ representa pontos $\operatorname{com} \theta \approx 0$.

Fonte: elaborado pelo autor.

O primeiro selecionou o comprimento de onda de $192 \mathrm{~nm}$ e gerou 10000 valores de $\theta$ e $c$ a partir das equações expressas em (43), em que $r_{c}$ e $r_{\theta}$ representam números aleatórios gaussianos no intervalo de $[-1 ; 1]$, para cada par calculamos o valor de $\Delta \varepsilon$ correspondente. Esses 10000 valores foram expressos em um histograma, e foi calculada a assimetria e a curtose das distribuições. Esse processo foi repetido mais 1000 vezes e foi tomada a média e o desvio padrão da assimetria e da curtose, para cinco valores de $\delta_{\theta}$ entre 0,01 e 0,05 e $\delta_{c}$ variando de 0 a 0,20 .

$$
\begin{aligned}
& c=c_{0}\left(1+r_{c} \cdot \delta_{c}\right) \\
& \theta=\bar{\theta}\left(1+r_{\theta} \cdot \delta_{\theta}\right)
\end{aligned}
$$

A figura 30 apresenta os valores de curtose e assimetria para as diferentes incertezas relativas da concentração e da elipticidade. Nota-se que a mudança de $\delta_{\theta}$ não afetou significativamente o comportamento das grandezas estatísticas.

Além disso, primeiro, entende-se a curtose como sendo um parâmetro capaz de caracterizar o achatamento da função de distribuição de probabilidade. Uma distribuição normal apresenta curtose igual a três. Quando a curtose é maior que três, a função é nomeada 
de leptocúrtica e possui caudas mais alongadas (apresenta mais outliers). No caso contrário, a função recebe o nome de platicúrtica e aparenta um caráter mais achatado (pontos mais próximos do valor médio). Conforme os resultados expressos em Fig. 30-a, a partir de $\delta_{c}=$ 0,04 o valor médio da curtose excedeu 3 , considerando as barras de erro, para $\delta_{c}>0,08$ podemos considerar a FDP como sendo leptocúrtica.

No que lhe concerne, a assimetria (ou obliquidade) traz informação sobre a simetria da FDP. Uma distribuição normal possui assimetria igual a zero. Caso a assimetria seja maior que zero, a FDP possui uma cauda direita mais pesada (com mais pontos acima da média). No caso contrário (assimetria < 0), a cauda esquerda é mais predominante. Segundo a figura 30, um $\delta_{c}=0,02$ é o suficiente para elevar a assimetria, mas apenas em $\delta_{c}>0,04$ a assimetria passa a ser maior que zero, nas barras de erro. Isso se reflete em uma probabilidade maior de, ao normalizar, obter-se um espectro mais "ampliado".

O segundo processo de Monte Carlo gerou 10000 espectros de CD utilizando $\delta_{\theta}=$ 0,037 a partir do espectro do PDBMD2CD, para $\delta_{c}$ variando de zero a 0,020. A figura 31 apresenta todos esses resultados, assim como o histograma da distribuição dos valores de $\Delta \varepsilon$ em 192nm e o das concentrações.

É possível notar que com o aumento de $\delta_{c}$ a distribuição dos espectros gerados se torna maior (o que é refletido no aumento da curtose). É interessante prestar atenção no comportamento da linha pontilhada em verde e vermelho nas figuras (b), que representam, respectivamente o intervalo de $2 \sigma_{\Delta \varepsilon}$ considerando ou não a incerteza da concentração. Para $\delta_{c}=0,04$ a diferença entre elas já se torna evidente, sendo que quanto maior a incerteza relativa na concentração, mais pontos ficam fora da região vermelha. A tabela 14 demonstra a probabilidade estimada de encontrar pontos acima $\left(P\left(\Delta \varepsilon>\overline{\Delta \varepsilon}\left(1+2 \delta_{\theta}\right)=P(A)\right)\right.$ e abaixo $P\left(\Delta \varepsilon<\overline{\Delta \varepsilon}\left(1+2 \delta_{\theta}\right)=P(B)\right)$ da região em vermelho com o aumento de $\delta_{c}$. Esses valores foram estimados como sendo o número de eventos de interesse divido por 10000 . A tabela 15 apresenta os resultados considerando a incerteza propagada $P\left(\Delta \varepsilon>\overline{\Delta \varepsilon}\left(1+2 \delta_{\Delta \varepsilon}\right)=P\left(A^{\prime}\right)\right)$ e $P\left(\Delta \varepsilon<\overline{\Delta \varepsilon}\left(1+2 \delta_{\Delta \varepsilon}\right)=P\left(B^{\prime}\right)\right)$. Em ambos casos as incertezas na probabilidade foram calculadas através do desvio padrão de 1000 passos de Monte Carlo.

Para $\delta_{c}=0$, tem-se uma simetria na distribuição e uma probabilidade igual para as caudas superiores e inferiores, $P(\mathrm{~A})=P(\mathrm{~B})=P\left(\mathrm{~A}^{\prime}\right)=P\left(\mathrm{~B}^{\prime}\right)$ que é o mesmo valor de uma gaussiana. Na tabela 14 , torna-se claro que um leve aumento de $\delta_{c}$ para 0,02 já é o suficiente para quase duplicar o valor de $\mathrm{P}(\mathrm{A})$. 
Tabela 14 - Probabilidade de encontrar valores de $\Delta \varepsilon$ nos intervalos acima de 2 desvios padrões calculados $\operatorname{com} \delta_{c}=0$.

\begin{tabular}{cccccc}
\hline$\delta_{c}$ & $P(\mathrm{~A})$ & $\sigma_{P(A)}$ & $P(B)$ & $\sigma_{P(B)}$ & $P(A) \cup P(B)$ \\
\hline 0,00 & 0,0228 & 0,0015 & 0,0228 & 0,0014 & 0,0456 \\
0,01 & 0,0274 & 0,0016 & 0,0261 & 0,0016 & 0,0535 \\
0,02 & 0,0418 & 0,0020 & 0,0367 & 0,0019 & 0,0785 \\
0,04 & 0,0959 & 0,0030 & 0,0787 & 0,0026 & 0,1746 \\
0,08 & 0,2145 & 0,0040 & 0,1857 & 0,0039 & 0,4002 \\
0,12 & 0,2904 & 0,0045 & 0,2635 & 0,0045 & 0,5539 \\
0,16 & 0,3368 & 0,0048 & 0,3139 & 0,0047 & 0,6507 \\
0,20 & 0,3668 & 0,0047 & 0,3476 & 0,0046 & 0,7144 \\
0,24 & 0,3881 & 0,0050 & 0,3714 & 0,0047 & 0,7595 \\
\hline
\end{tabular}

Analisando agora os valores presentes na tabela 15, torna-se evidente o caráter de assimetria positiva. Para $\delta_{c}=0,04$ já é possível notar que $P\left(\mathrm{~A}^{\prime}\right)>P\left(\mathrm{~B}^{\prime}\right)$, essa diferença $\left(P\left(A^{\prime}\right)-P\left(B^{\prime}\right)\right)$ tende a se acentuar com o aumento de $\delta_{c}$, mas atinge um máximo em torno de $\delta_{c}=0,42$, como apresentado na figura 32. Extrapolando para valores maiores de $\delta_{c}$, em $\delta_{c}=$ 0,84 , temos $P\left(A^{\prime}\right)=P\left(B^{\prime}\right)$, que pode indicar uma assimetria nula, mas, como ambas as probabilidades diferem de 0,0228 , a distribuição não volta a ser gaussiana. A partir de $\delta_{c}>$ 0,84 , temos $P\left(A^{\prime}\right)<P\left(B^{\prime}\right)$, o que indica uma assimetria negativa.

Tabela 15 - Probabilidade de encontrar valores de $\Delta \varepsilon$ nos intervalos acima de 2 desvios padrões considerando os valores de $\delta_{c}$.

\begin{tabular}{cccccc}
\hline$\delta_{c}$ & $P\left(\mathrm{~A}^{\prime}\right)$ & $\sigma_{P(A)}$ & $P\left(B^{\prime}\right)$ & $\sigma_{P(B)}$ & $P(A) \cup P(B)$ \\
\hline 0,00 & 0,0227 & 0,0015 & 0,0227 & 0,0015 & 0,0454 \\
0,01 & 0,0233 & 0,0015 & 0,0222 & 0,0014 & 0,0455 \\
0,02 & 0,0250 & 0,0015 & 0,0208 & 0,0014 & 0,0458 \\
0,04 & 0,0295 & 0,0017 & 0,0169 & 0,0013 & 0,0464 \\
0,08 & 0,0407 & 0,0020 & 0,0099 & 0,0010 & 0,0506 \\
0,12 & 0,0522 & 0,0022 & 0,0049 & 0,0007 & 0,0571 \\
0,16 & 0,0640 & 0,0024 & 0,0019 & 0,0004 & 0,0659 \\
0,20 & 0,0760 & 0,0025 & 0,0005 & 0,0002 & 0,0765 \\
0,24 & 0,0876 & 0,0028 & 0,0001 & 0,0001 & 0,0877 \\
\hline
\end{tabular}


Figura 30 - Curtose e Assimetria estimadas por Monte Carlo da distribuição de valores de $\Delta \varepsilon$ em 192nm.

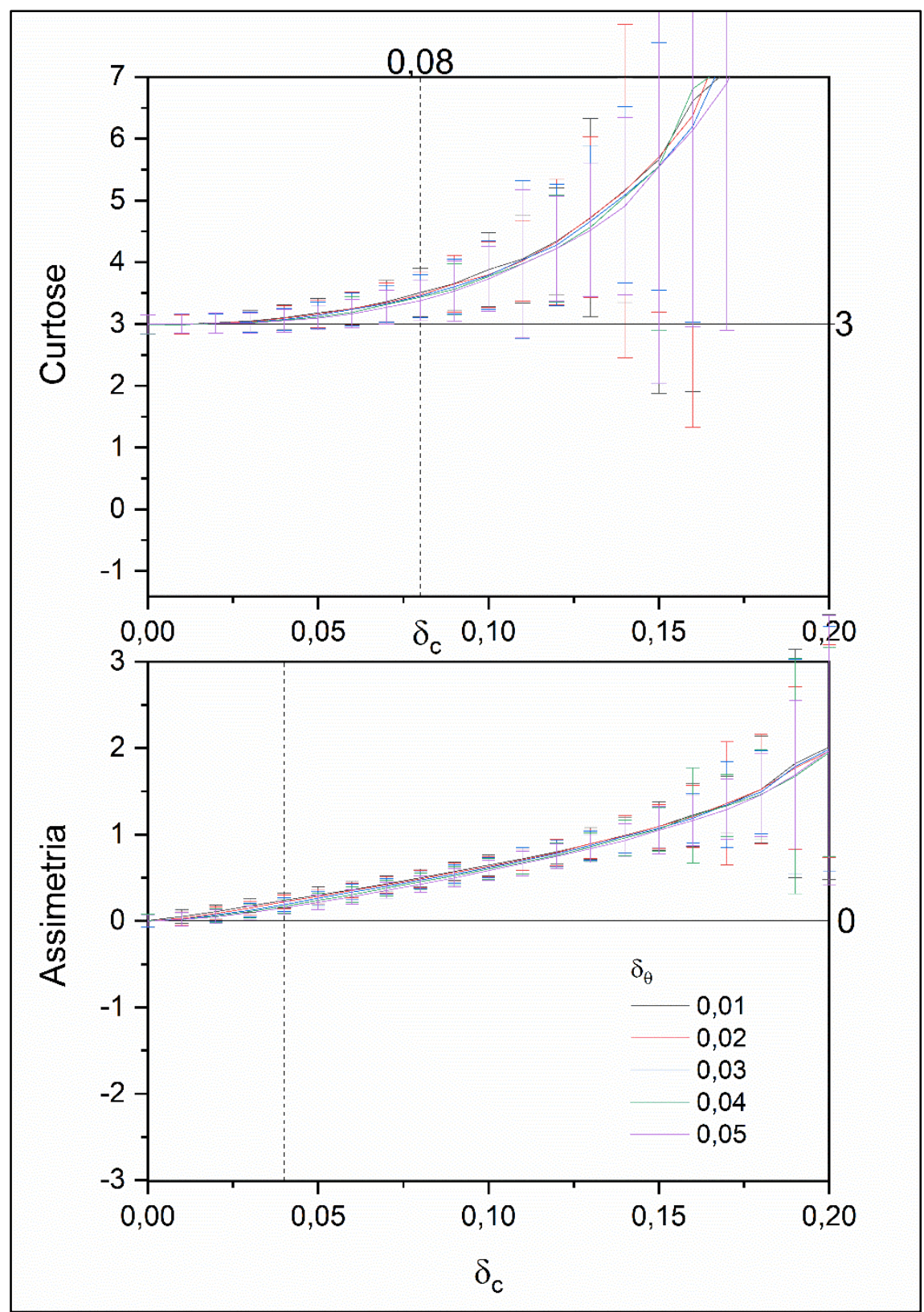

Curtose (a) e Assimetria (b) estimadas por Monte Carlo (1000 pontos) da distribuição de valores de $\Delta \varepsilon$ em $192 \mathrm{~nm}$ para o espectro médio da $\mathrm{Mb}$ gerado pelo PDBMD2CD. As barras de erro também foram estimadas por Monte Carlo, utilizando o desvio padrão de 1000 histogramas. Foram alterados cinco valores de $\delta_{\theta}$ presentes na região de interesse destacada na figura 29. Fonte: Elaborado pelo autor. 
Figura 31 - Resultados de 10000 variações de Monte Carlo para diferentes razões $\delta_{\mathrm{c}}$

(i)
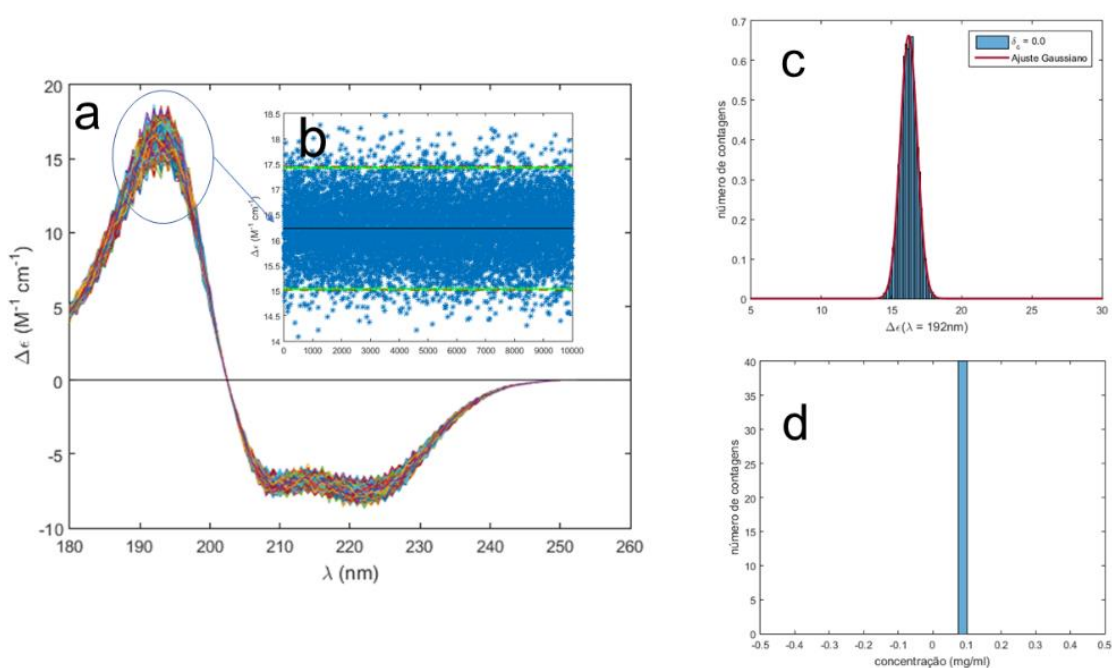

(ii)
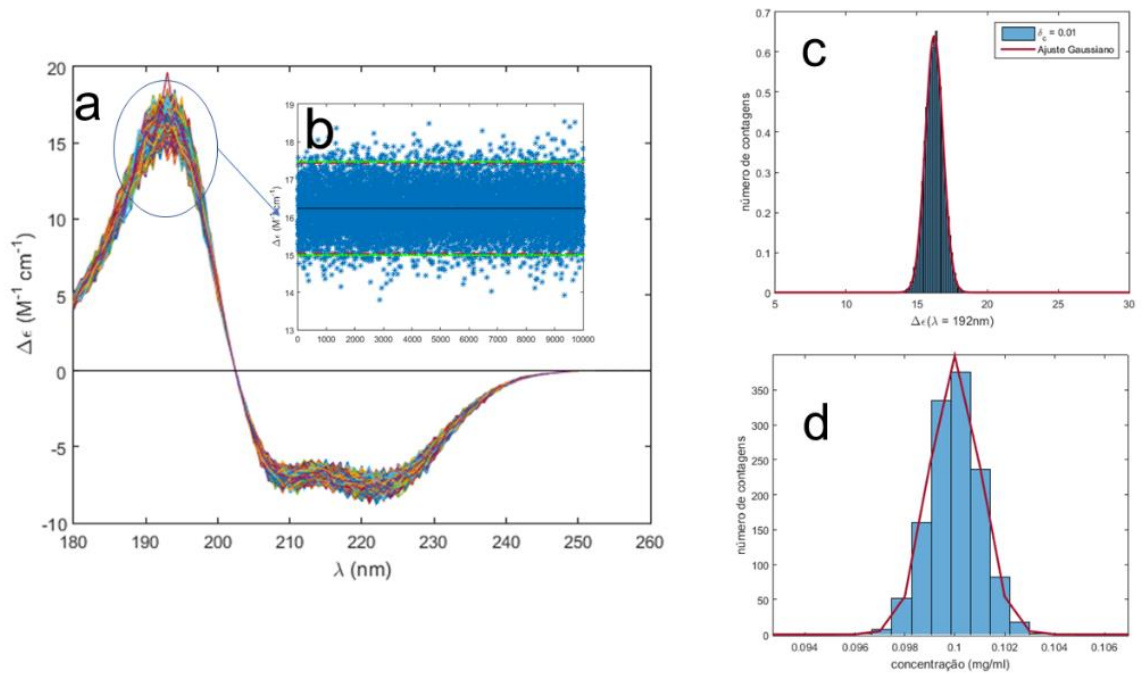

(iii)
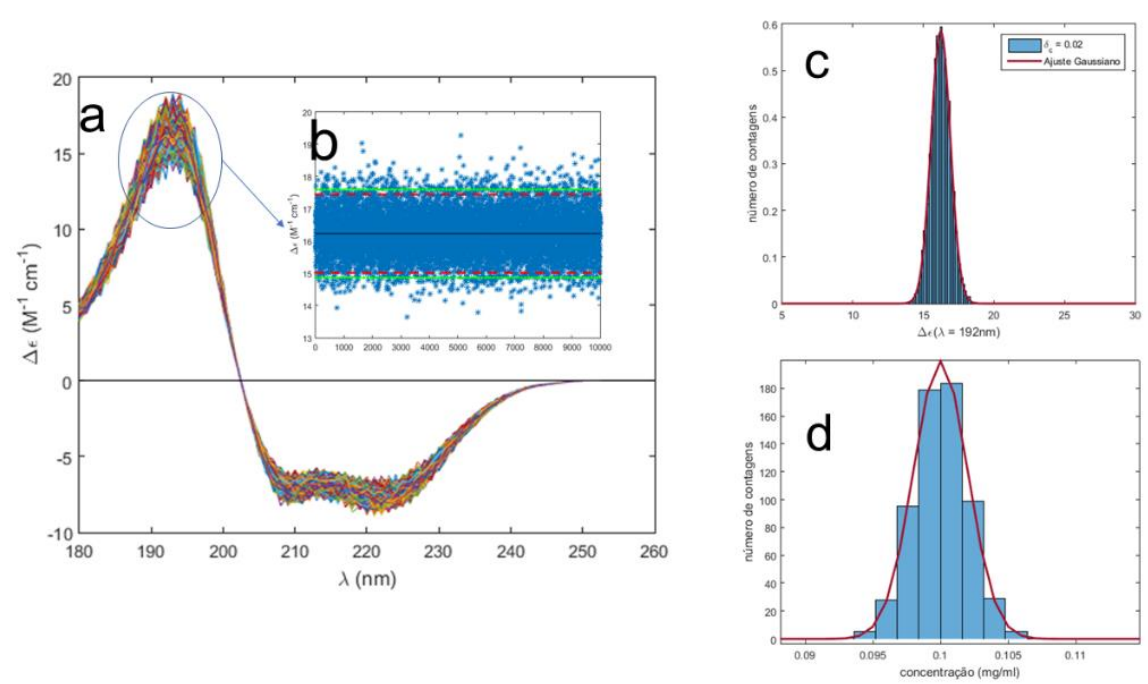
(iv)
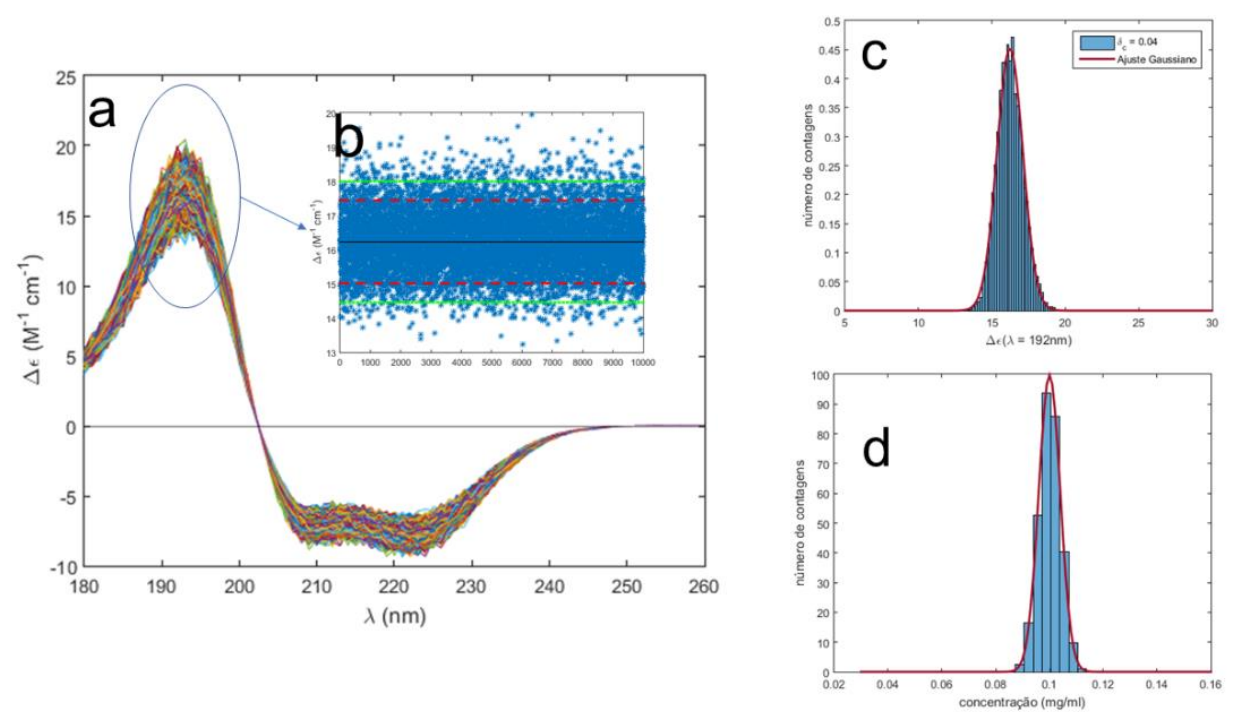

(v)
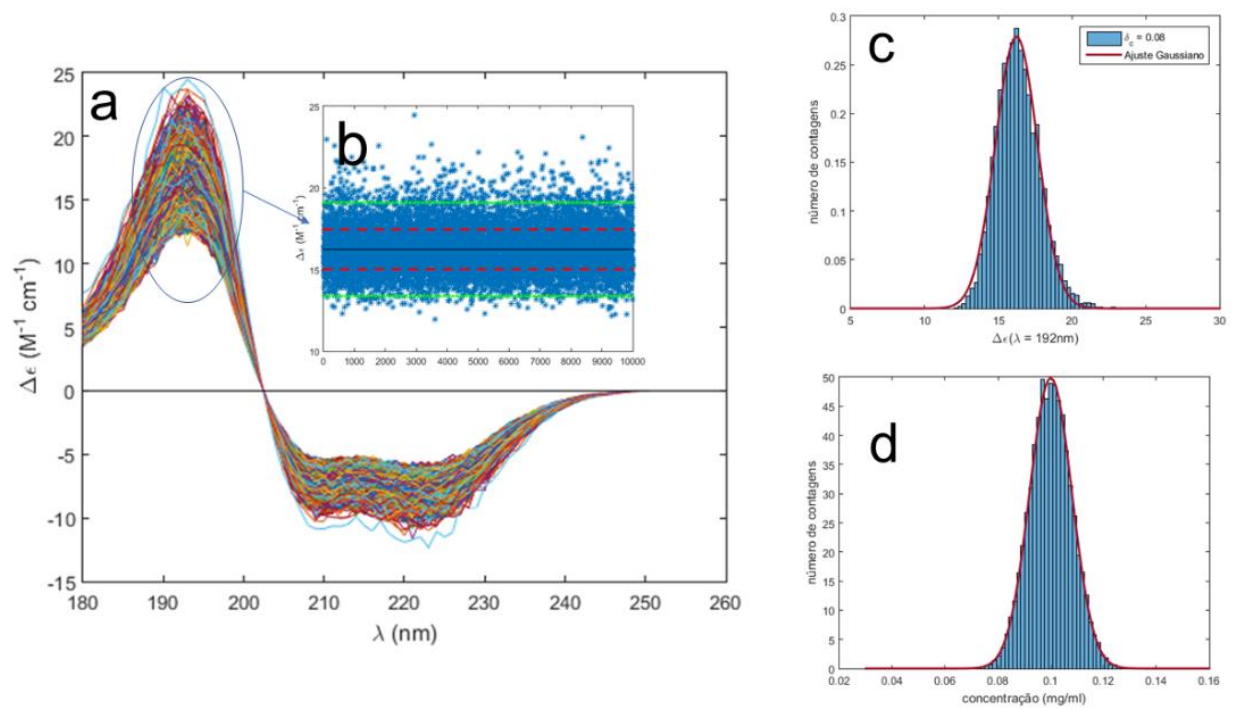

(vi)
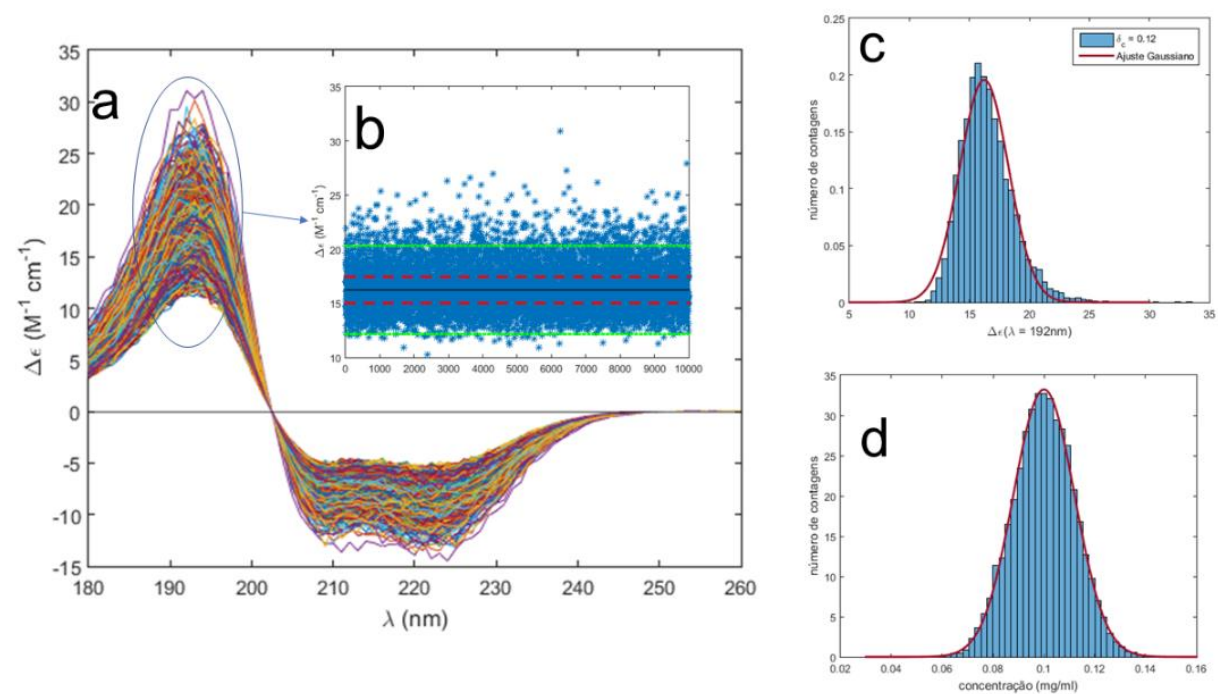
(vii)
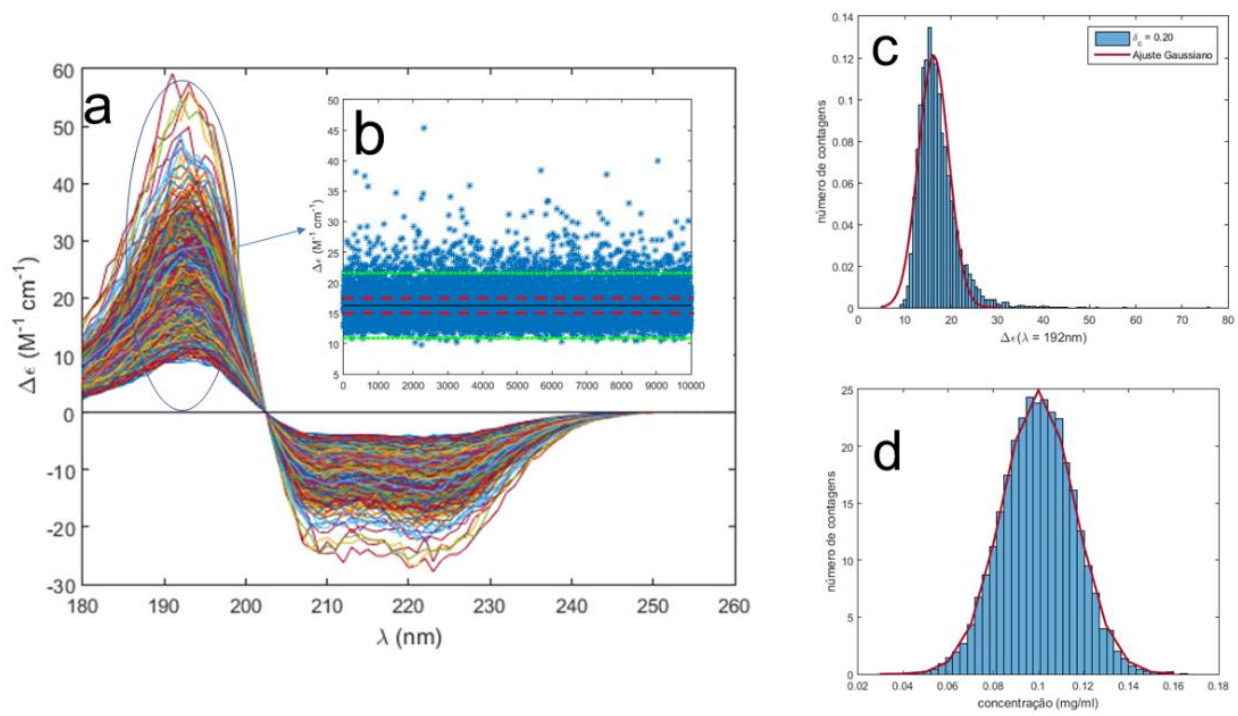

(viii)
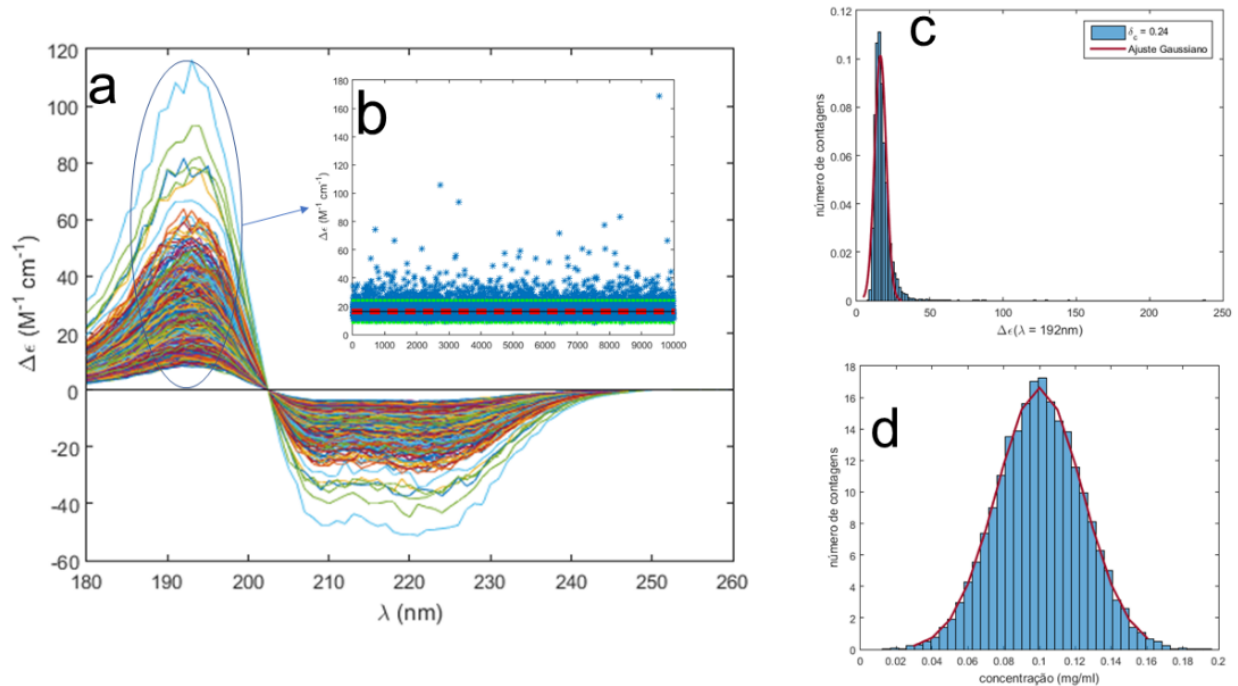

(a) 10000 espectros gerados a partir do espectro médio obtido pelo PDBMD2CD utilizando o método de Monte Carlo, fixando $\delta_{\theta}=0,037$. (b) dispersão dos 10000 valores de $\Delta \varepsilon$ em $192 \mathrm{~nm}$, a linha tracejada em vermelho representa o intervalo de dois desvios padrões considerando $\delta_{c}=0$, já a linha pontilhada em verde, representa o intervalo de duas incertezas considerando o valor real de $\delta_{c}$. (c) histograma normalizado dos valores obtidos para $\Delta \varepsilon$ para os 10000 pontos, a curva em vermelho representa uma gaussiana centrada em $\Delta \varepsilon=16,23 \mathrm{M}^{-1} \mathrm{~cm}^{-1} \mathrm{e}$ desvio padrão igual a $|\Delta \varepsilon| \sqrt{\delta_{c}^{2}+\delta_{\theta}^{2}}$. (d) histograma das 10000 concentrações obtidas simuladas por Monte Carlo utilizando o respectivo valor de $\delta_{c}$.

Os valores de $\delta_{c}$ são: (i) $\delta_{c}=0,00$, (ii) $\delta_{c}=0,01$, (iii) $\delta_{c}=0,02$, (iv) $\delta_{c}=0,04$, (v) $\delta_{c}=0,08$, (vi) $\delta_{c}=0,12$, (vii) $\delta_{c}=0,16 e$ (viii) $\delta_{c}=0,20$.

Fonte: Elaborado pelo autor 
Com esses resultados evidencia-se que a função de distribuição dos pontos do espectro após normalização pela concentração permanece sendo aproximadamente gaussiana, considerando valores em miligraus precisos $\left(\delta_{\theta}<0,05\right)$, com incerteza relativa na concentração da ordem, ou menor que, $4 \%$. Para tanto é necessário o uso de equipamentos de alta precisão durante o preparo da amostra, além de garantir uma homogeneidade da solução.

Figura $32-P\left(A^{\prime}\right), P\left(B^{\prime}\right)$ e a diferença entre eles em função de $\delta_{c}$ variando de 0 a 2 em passos de 0,01 .

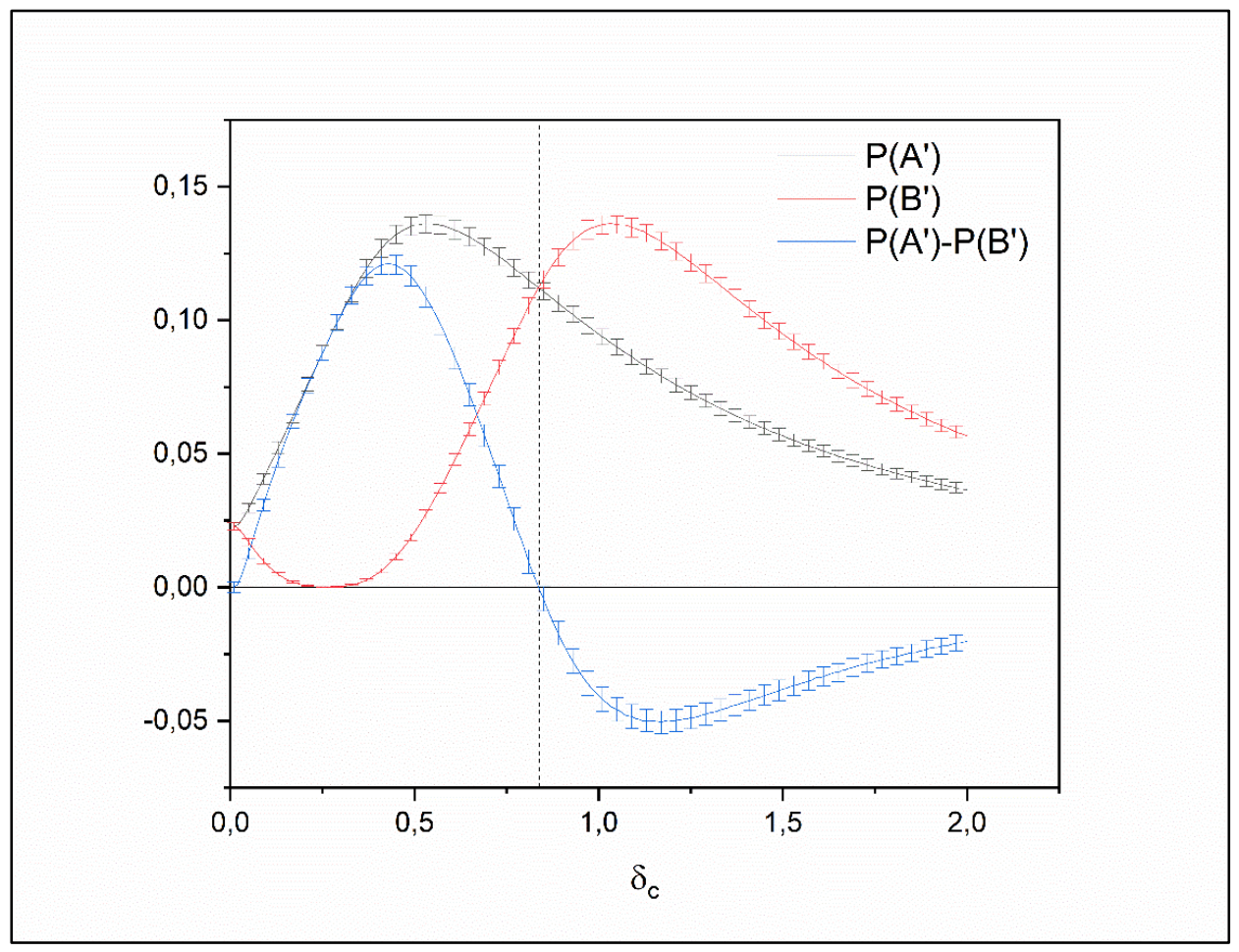

A figura foi obtida tomando a média e o desvio 1000 distribuições contendo 10000 pontos cada, geradas por Monte Carlo. Fonte: Elaborado pelo autor.

Em teoria é possível obter soluções com este nível de acurácia para amostras pequenas realizando a medição da massa em uma balança analítica de altíssima precisão e utilizando uma micropipeta bem calibrada. A partir da teoria dos erros, é possível propagar a incerteza relativa na concentração para esse cenário como sendo:

$$
\delta_{c}^{2}=\delta_{m}^{2}+\delta_{V}^{2}
$$


$\delta_{m}$ está totalmente influenciado pela quantidade de proteína que está sendo medida: quanto maior a massa, menor essa grandeza. Entretanto, medir massas muito grandes não é vantajoso e pode gerar desperdícios. Já $\delta_{V}$ depende da acurácia da micropipeta escolhida, que varia dependendo do fabricante, do volume nominal, além de sua calibração.

Alternativas, consideradas mais confiáveis, para a medição da concentração são as técnicas de absorção nos $280 \mathrm{~nm}$, que observa a absorção do triptofano e da tirosina, e a absorção nos 205 nm, na qual o cromóforo é a ligação peptídica. Anthis e Clore (2013) compararam a incerteza relativa das medidas de absorção nas duas faixas para diferentes proteínas. Para a absorção em $280 \mathrm{~nm}$, os valores de $\delta_{A_{280}}$ variaram dentre 0,009 à $~ 0,10$, já os valores de $\delta_{A_{205}}$ ficaram entre 0,009 e 0,08 . O cálculo da incerteza na concentração pelas técnicas de absorção também depende do erro relativo no caminho óptico $\left(\delta_{l}\right)$, que é mais difícil de ser mensurado.

\section{V.13 Espectros de SRCD da Pln149}

O CD é uma técnica também capaz de verificar mudanças conformacionais em peptídeos e proteínas. Como exemplo de tal estudo, neste trabalho foram obtidos os espectros de SRCD do peptídeo antimicrobiano Pln149. Os resultados apresentados nas figuras 33 e 34 corroboram os dados publicados por (LOPES et al., 2009; LOPES et al., 2010; LOPES et al., 2013a; LOPES et al. 2013b; KUMAGAI et al., 2019). A Pln149 é um PAM catiônico, linear e majoritariamente não-ordenado em solução aquosa, mas na presença de membranas negativamente carregadas, apresenta uma estrutura helicoidal.

A implementação do SRCD para essas medidas foi de fundamental importância, dado que com o alto fluxo de fótons podemos avançar em regiões de menor comprimento de onda $(\lambda<190 \mathrm{~nm})$ sem haver uma perda na qualidade do espectro. Essa região apresenta bandas importantes para a caracterização de estruturas desordenas, além de uma banda extra (vale em $\lambda \sim 175 \mathrm{~nm}$ ) no espectro de $\alpha$-hélices. Ademais, a grande intensidade da luz nos permite estudar amostra com presença de membranas, as quais espalham parte da luz incidente podendo gerar distorções nos espectros submetidos à baixa intensidade luminosa. (WALLACE 2009; MILES; WALLACE, 2016).

A Pln149 em solução aquosa e na presença do lipídio zwitteriônico apresenta um espectro característico de estrutura desordenada, com um vale na região de $198 \mathrm{~nm}$. Todavia, na presença de lipossomas de POPG (negativamente carregadas), o espectro resultante é típico 
de uma estrutura em $\alpha$-hélices, com um pico em $192 \mathrm{~nm}$ e dois vales na região entre $208 \mathrm{~nm}$ e $222 \mathrm{~nm}$. Este último com um valor de $\Delta \varepsilon_{\text {exp }}=-7,20 \pm 0,06 \mathrm{M}^{-1} \mathrm{~cm}^{-1}$.

Figura 33 - Espectro de SRCD da Pln149 em solução aquosa e na presença de lipossomas de POPC e POPG.

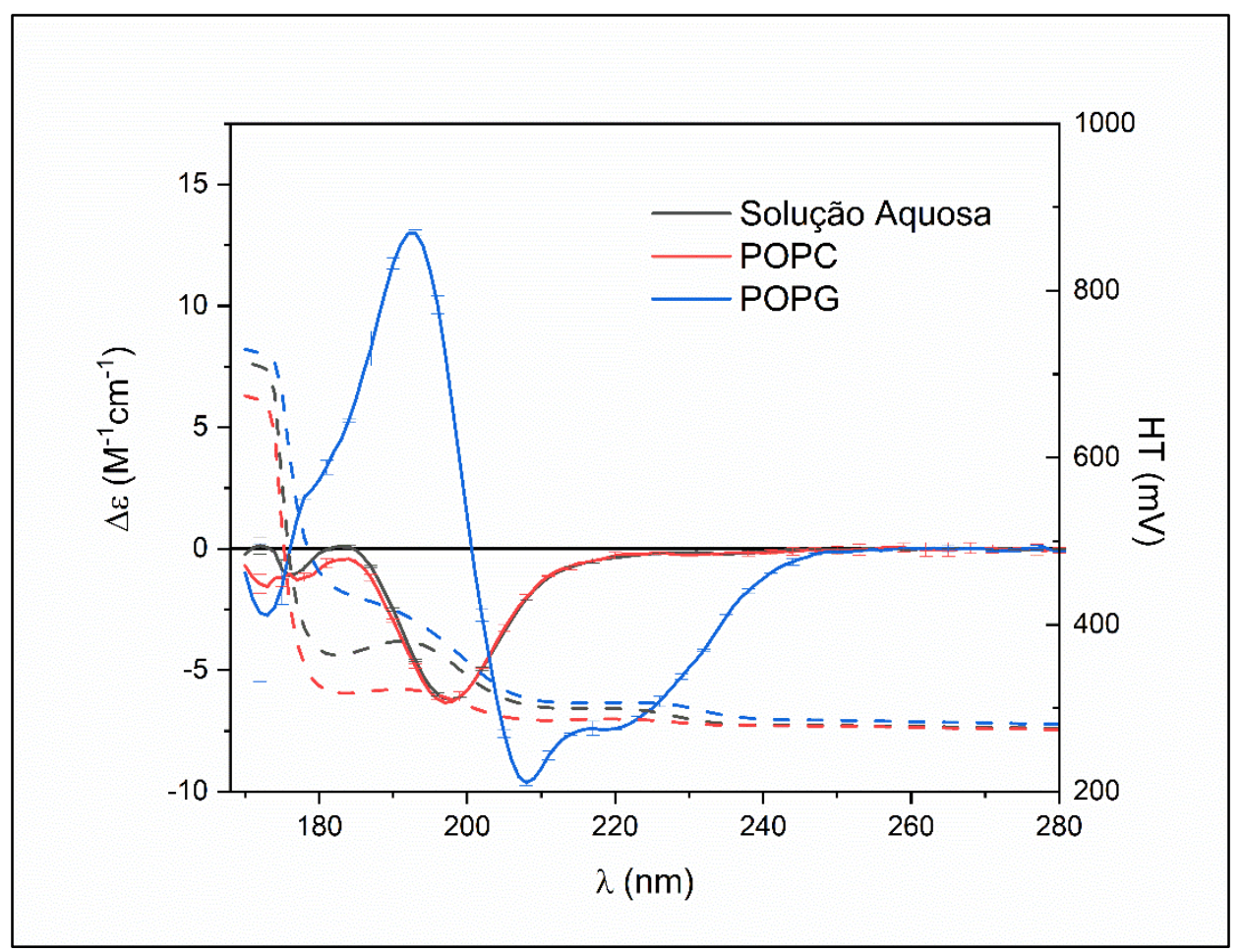

Fonte: Elaborado pelo autor.

Utilizando a equação (33), obtemos uma taxa $\frac{\Delta \varepsilon_{\text {exp }}}{\Delta \varepsilon_{\infty}} \approx 0,58$. Com $k=4,58$ obtém-se então, $n \approx 10,9$ amidas. Com essa estimativa simples esperamos encontrar em média entre 10 e 12 dos 22 resíduos de aa da Pln149 formando a estrutura helicoidal ( 45\% do PAM). Este valor é muito próximo ao estimado em estudos anteriores (LOPES, 2010), que indicam que os primeiros 8 resíduos de aa do $\mathrm{N}$-terminal permanecem desordenados, sendo que a $\alpha$-hélice é formada na região C-terminal. Vale ressaltar que peptídeos são moléculas altamente dinâmicas, que estão em equilíbrio ordem-desordem, logo, alternando com frequência a sua estrutura secundária. O espectro de CD é um retrato desse equilíbrio e é também uma sobreposição das contribuições individuais de todos os peptídeos em solução, dessa forma, a não ser que se garanta que todos os PAM estejam com a mesma conformação, análises quantitativas podem não ser tão eficazes. Este é um dos motivos que grande parte dos usuários de $\mathrm{CD}$ não recomendam desconvoluir os espectros de CD de PAM.

A figura 34 nos permite analisar as contribuições das interações eletroestáticas na ligação da Pln149 nas vesículas aniônicas. Com a presença de sal em solução há o aumento da 
força iônica, havendo uma competição de cargas e uma blindagem dos grupos carregados nas cabeças polares dos lipídios, causando uma redução da partição do peptídeo nos modelos lipídicos, portanto deixando uma maior fração do peptídeo na fase aquosa (desordenado). No espectro é notável a redução da intensidade da banda em $222 \mathrm{~nm}$, acompanhada de um deslocamento das bandas de $208 \mathrm{~nm} 192 \mathrm{~nm}$ para a esquerda. Em primeira instância é possível compreender os espectros na presença de $\mathrm{NaF}$ como sendo a sobreposição dos espectros do PAM em solução aquosa e com POPG, como descrita na equação (45), em que $\gamma$ é a proporção de peptídeos na forma não-ordenada.

Figura 34 - Espectros de SRCD da Pln149 na presença de NaF

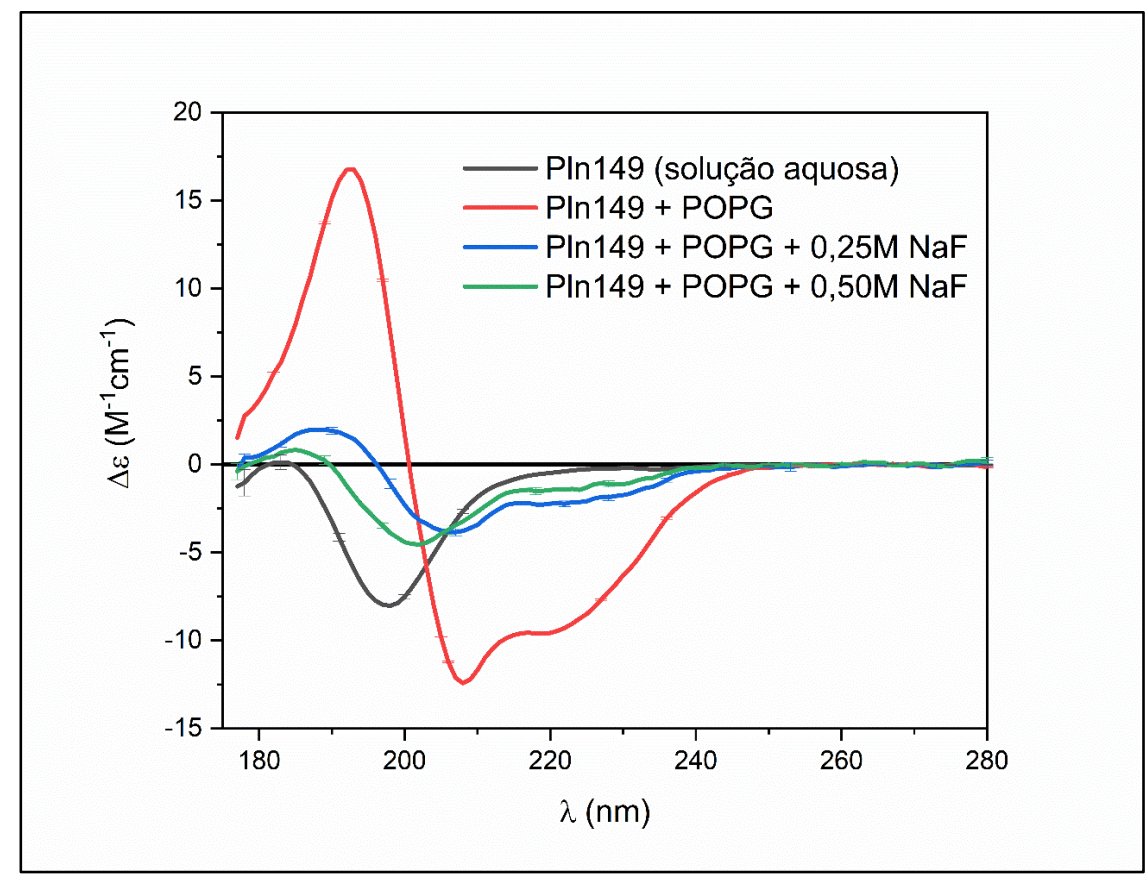

Fonte: Elaborado pelo autor.

$$
S_{N a F}^{\text {teórico }}=\gamma \cdot S_{\text {aquosa }}+(1-\gamma) \cdot S_{P O P G}
$$

Podemos estimar o $\gamma$ ideal como sendo aquele que minimiza o valor de NMRSD calculado a partir da equação (37), em que $S_{\text {exp }}$ representa o valor do espectro contendo $\mathrm{NaF}$, e $S_{\text {mod }}=S_{N a F}^{\text {teórico }}$. A figura 35 apresenta o espectro mais bem ajustado para cada caso. Para $[\mathrm{NaF}]=0,25 \mathrm{M}$ a proporção $\gamma$ otimizada foi igual a 0,71 , a qual gerou um NRMSD igual a 0,3298. Já para $[\mathrm{NaF}]=0,50 \mathrm{M}$, obtivemos $\gamma=0,83$ e NRMSD $=0,1284$. Em ambos casos, o espectro sobreposto gerou picos e vales nos mesmos comprimentos de onda que os espectros experimentais, mas com intensidade maior, essa diferença pode ser fruto de algum problema na normalização dos espectros (incerteza na concentração, por exemplo), ou então a existência de 
algum outro cromóforo (estrutura intermediária, por exemplo) em solução. De todo modo, é interessante notar o aumento de $\gamma$ com o aumento de $[\mathrm{NaF}]$, isso nos demonstra que há uma proporção maior de PAM desordenado em solução, o que pode indicar a importância da interação eletroestática para interação peptídeo-membrana.

Figura 35 - Comparação dos espectros de Pln149 na presença de NaF com a sobreposição dos espectros da fase desordenada com a fase em $\alpha$-hélices.

(a)

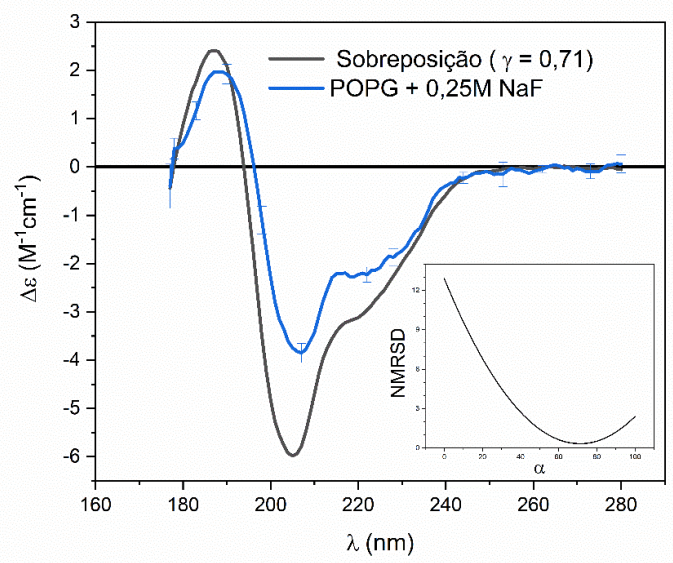

(b)

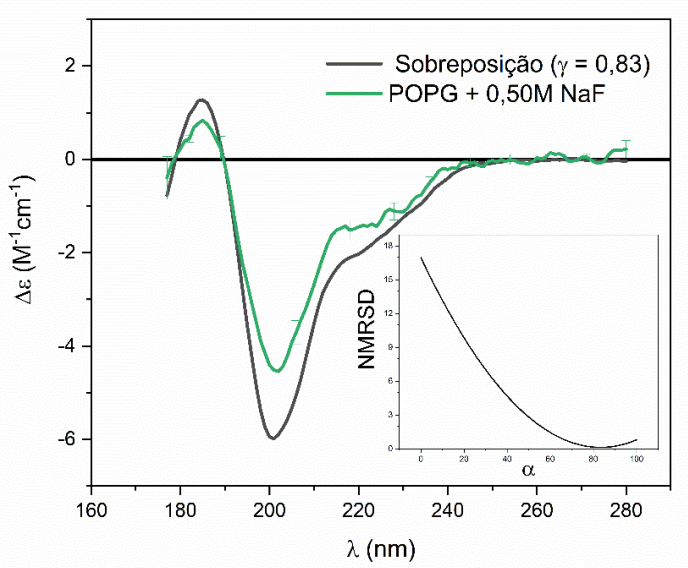

Fonte: Elaborado pelo autor. 


\section{VI - Conclusões}

A espectroscopia de dicroísmo circular é uma técnica com grande potencialidade em identificar e descrever a estrutura secundária de proteínas e peptídeos nas mais diversas condições, e de caracterizar mudanças estruturais nessas moléculas. Como visto neste capítulo, a confiança em seus resultados está diretamente ligada a qualidade do espectro coletado, que pode ser severamente prejudicada pelas condições da amostra (concentração e tampão), assim como pelos parâmetros escolhidos para medição. Nesse trabalho, sete parâmetros de coleta foram selecionados e variados como uma forma de verificar se pequenas mudanças neles poderiam afetar significativamente o espectro e os processos de desconvolução. Em seguida, foi realizada uma análise estatística sobre o problema da normalização pela concentração, e foi verificada qual é a precisão ideal da concentração para que a variável normalizada siga uma distribuição gaussiana.

Para a mioglobina, nas condições apresentadas nesse trabalho, é possível concluir que quando o objetivo do usuário é realizar análises qualitativas de CD (i.e. sem realizar processos de desconvolução), é possível variar a maioria dos parâmetros utilizados, sem alterar significativamente o formato dos espectros. Entretanto, notou-se a necessidade de utilizar pelo menos três varreduras e evitar velocidades de varredura muito maiores que $200 \mathrm{~nm} / \mathrm{min}$. Uma maior cautela, todavia, deve ser tomada ao escolher o tampão, a concentração da proteína e o cutoff. O primeiro pode danificar completamente o espectro em presença de alguns íons na região de interesse, como, por exemplo o íon $\mathrm{Cl}^{-}$. Além disso, em regimes de baixa concentração, torna-se difícil distinguir os dois vales na região > $200 \mathrm{~nm}$, e há um aumento na relação $S / R$. Por outro lado, ao comparar os valores de desconvolução foi possível notar que algumas outras pequenas mudanças nos parâmetros foram capazes de gerar resultados incompatíveis, como por exemplo a diminuição da resposta de varredura.

Além disso, é interessante ressaltar o poder do método tipo-Monte Carlo para estimar a incerteza nos resultados de desconvolução, considerando a incerteza experimental do espectro. Isso é um resultado pioneiro desta dissertação, e a implementação de tal método em servidores 'online' como o Dichroweb, poderá enriquecer análises futuras. É importante notar, entretanto, que o método é totalmente dependente da qualidade do espectro medido e da forma com que as incertezas experimentais foram estimadas, dessa forma é preciso cautela ao utiliza-lo. Com tal método, foi possível concluir que valores de NRMSD baixos não implicam em um aumento na acurácia e nem na precisão dos valores de desconvolução. 
Com os modelos semi-teóricos gerados pelo PDBMD2CD e pelo SESCA, utilizando Monte Carlo para gerar distribuições de probabilidade para diferentes incertezas relativas na concentração foi possível observar que para $\delta_{c}>0,04$ as distribuições deixam de possuir um perfil gaussiano. Nesse sentido, é importante investir em métodos para estimar a concentração com grande precisão.

Por fim, foi realizado um estudo do peptídeo antimicrobiano Plantaricina149 na presença de lipossomas lipídicas de diferentes cargas, como um exemplo da aplicação de CD no estudo de PAM. Foi possível verificar a mudança da fase não-ordenada para a helicoidal através de medidas de SRCD. Na presença de POPG, o PAM adquiriu uma estrutura em $\alpha$ hélice, essa interação é fortemente dirigida devido as cargas opostas do peptídeo e modelo aniônico do lipídio, o próximo capítulo contém uma discussão mais detalhada sobre a Plantaricina 149. 


\section{Capítulo 2 - Estudos de peptídeos antimicrobianos: síntese de peptídeos em fase sólida e tensiometria em monocamadas de Langmuir.}

\section{I - Introdução}

O interesse nos PAM cresceu durante as últimas décadas, principalmente com a declaração de 2015 da Organização Mundial da Saúde sobre a urgência no desenvolvimento de novos fármacos e estratégias capazes de inibir as enfermidades infecciosas geradas por microrganismos resistentes a antibióticos (WHO,2015). Os PAM possuem baixa massa molecular ( 10 a 50 resíduos de aa) e são produzidos como parte do sistema imunológico de organismos, onde desempenham um papel fundamental: inibir o crescimento de bactérias, protozoários, fungos, leveduras e até vírus (AGEITOS et al., 2017). Em células eucarióticas, por exemplo, os PAM representam uma das primeiras formas de defesa natural contra invasão por um microrganismo.

O modo de ação de muitos PAM lineares e catiônicos envolve a interação com a bicamada lipídica da membrana celular do microrganismo-alvo, via interações eletromagnéticas (cargacarga), hidrofóbicas, e outras (HOLLMANN et al., 2018), com o intuito de gerar a ruptura de membranas bacterianas e/ou de capsídeos virais (DIAS et al., 2017); ou ainda pode depender da penetração do peptídeo no interior das células para se ligar em alvos intracelulares e/ou moléculas que interferem na estrutura do DNA (girases e/ou topoisomerares) (BROGDEN, 2005). Geralmente, a ligação dos PAM às membranas-alvo envolve sua atração eletrostática para a superfície das membranas bacterianas. Ao se ligarem às membranas, tais peptídeos podem adotar uma estrutura tridimensional mais ordenada (em $\alpha$-hélice, fitas- $\beta$ ou mesmo estruturas mistas) e se integram à superfície externa da membrana.

Mais comumente, um PAM catiônico linear assume uma conformação de uma hélice anfipática, com uma das faces catiônica e outra hidrofóbica (GIANGASPERO et al., 2001). Dentre os mecanismos de ação propostos para explicar a desestabilização da membrana causada por um PAM (SHAI, 2002), os modelos mais conhecidos são o poro-barril, o poro-toroidal e o carpete. Embora diferentes entre si, estes três mecanismos dependem do balanço entre as propriedades físico-químicas do peptídeo e também da composição lipídica da membrana plasmática do patógeno. Da mesma forma, estes mecanismos não precisam ser mutuamente 
exclusivos. Um processo pode representar o passo inicial, ou o intermediário de outro (EPAND, 1999).

Assim, a informação sobre a estrutura dos PAM é fundamental para descrever o mecanismo de ação destas moléculas. Entretanto, não é fácil cristalizar esses peptídeos, e muitas vezes é necessário alterar as condições da solução para se obter uma estrutura utilizando NMR. Nesse sentido, como foi explorado no capítulo anterior, o dicroísmo circular tem sido amplamente utilizando como uma forma confiável de caracterizar a estrutura de tais moléculas.

Neste capítulo serão exploradas duas técnicas implementadas com este trabalho no grupo de Biofísica Aplicada do IFUSP no estudo de PAM, a síntese de peptídeos em fase sólida, cujo protocolo foi utilizado para a síntese de peptídeos da família das Temporinas e a tensiometria em monocamadas de Langmuir, a qual nos permite verificar a interação de PAM com diferentes grupos fosfolipídicos. 


\section{II - Objetivos}

O capítulo possui como objetivo geral explorar aspectos e aplicações de duas técnicas biofísicas utilizadas pelo Grupo de Biofísica Aplicada do IFUSP no estudo de peptídeos antimicrobianos, como o intuito de auxiliar e guiar os futuros membros do grupo. Para tanto foram realizados:

- Revisão bibliográfica da SPFS e da tensiometria em monocamadas de Langmuir;

- Ajuste do protocolo da SPFS na síntese de peptídeos da família das temporinas;

- Mensuração e análise tensiométrica da interação do peptídeo Pln149 com monocamadas de Langmuir na presença de diferentes fosfolipídios. 


\section{III - Materiais e Métodos}

III.1 - Síntese de peptídeos em fase sólida.

Como explorado no capítulo anterior, peptídeos são polímeros de resíduos de aminoácidos (resíduos de aa) conectados através de ligações peptídicas, que são geradas através de uma reação de desidratação entre dois aa. Essas moléculas estão presentes nos mais diversos seres vivos e são de fundamental importância na manutenção dos processos biológicos. A primeira síntese em laboratório de um dipeptídeo (dois resíduos de aa ligados pela ligação peptídica), ainda protegido (ou seja, sem seus terminais livres) foi realizada em 1882 por Theodor Curtius (JARADAT, 2017), sendo que o primeiro dipeptídeo livre foi sintetizado apenas duas décadas depois por Ernest Fourneau e Emil Fischer na Universidade de Berlim (JARADAT,2017), muitos autores dão à Fischer o título de "pai” da síntese de peptídeos (PALOMO, 2014). Fisher realizou diversos trabalhos em síntese química, sendo laureado o prêmio Nobel de química em 1902 pela sua contribuição na síntese de açúcares e de purina.

Existem duas principais formas de se sintetizar peptídeos, a síntese em solução e a síntese em fase sólida (SPFS) (MERRIFIELD, 1963). A diferença mais fundamental delas é o grupo utilizado para proteger o terminal carboxílico do primeiro aa da sequência. Se o grupo for solúvel aos solventes utilizados durante a reação, a síntese será em solução, caso contrário, ou seja, o grupo consista de uma resina insolúvel temos então a SPFS (JARADAT,2017). Esta segunda técnica foi desenvolvida por Bruce Merrifield em 1963 e o consagrou o prêmio Nobel de química no ano de 1984. Entre as vantagens da SPFS se encontram a utilização de apenas um recipiente durante toda a síntese, o que agiliza e simplifica o processo, e promove um aumento da eficiência, uma vez que só é preciso clivar o peptídeo no final da síntese e não há grandes problemas se o peptídeo deixar de ser solúvel durante o processo (PALOMO, 2014). Essas vantagens nos permitem realizar a síntese de cadeias peptídicas mais longas, e até mesmo de pequenas proteínas, além de permitir automatizar a síntese (MERRIFIELD, 1986).

O primeiro passo para a SPFS consiste em selecionar a resina e o linker que será utilizado. Existem diversas possibilidades de escolha no mercado, e o desenvolvimento de novas resinas continua sendo fruto de pesquisas em andamento. $\mathrm{O}$ principal fator que define a qualidade da resina é a sua capacidade de inchaço ( "swelling capacity” ou "swelling factor"), quanto maior esse fator, maior será a taxa de difusão entre os reagentes na rede polimérica, aumentando a sua chance de interação (JARADAT,2017). Outro fator importante na escolha da 
resina é o seu valor de funcionalização ( $f u n)$, em $\mathrm{mmols} / \mathrm{g}$, que diz respeito à quantidade de sítios ativos que ela possui por grama e está relacionada a massa de resina a ser pesada.

A escolha do linker se dá, normalmente, junto a compra da resina, e ele guiará o tipo de clivagem que será realizada no final da síntese. O linker pode ser uma grande variedade de grupos, como amidas e ésteres, e será o responsável por conectar o primeiro resíduo de aa à resina, dessa forma, deve ser um grupo capaz de resistir aos processos de acoplamento e desacoplamento. Os linkers mais comuns conectam o C-terminal do primeiro resíduo de aa (primeiro da síntese, último do peptídeo final) à resina, mas existem outras possibilidades, como linkers que imobilizam o resíduo de aa via $\mathrm{N}$-terminal, cadeias laterais, e via backbone (JARADAT,2017). Neste trabalho foi implementado a resina Rink amida (RINK, 1987), cuja modificação já se mostrou eficiente para otimizar a ação dos peptídeos catiônicos nas membranas de microrganismos, possuindo um grupo amida como linker e uma funcionalização de $0,67 \mathrm{mmols} / \mathrm{g}$.

Em seguida, é necessário escolher os reagentes utilizados para o acoplamento, nessa etapa as carbodiimidas são as mais utilizadas. Para este trabalho foi escolhido a diisopropilcarbodiimida (DIC) (SHEEHAN et al. 1961), mas de acordo com Jaradat (2017) há pelo menos outras três carbodiimidas que podem ser implementadas. A figura 36, demonstra os dois caminhos possíveis de reação do DIC, ambos incluem a ligação do oxigênio presente no grupo - $\mathrm{OH}$ do aminoácido com o carbono central da carbodiimida, formando um estágio zwitteriônico intermediário que logo se transforma na O-acilisourea com o rearranjo dos hidrogênios. No primeiro caminho, essa molécula interage com o grupo amino livre preso à resina, gerando ureia e acoplando o resíduo de aminoácido na cadeia peptídica. No caminho alternativo, a O-acilisourea reage com outro aminoácido livre em solução e forma o anidrido simétrico de aminoácidos, que pode reagir com o grupo amina livre e acoplar o aminoácido (JARADAT, 2017).

Entretanto, a presença da O-acilisourea é capaz de gerar um processo de racemização, ou seja, a conversão de compostos quirais em uma mistura racêmica (solução com $50 \%$ dos compostos levogiros e a outra metade dextrogiro). Para minimizar essa quebra de quiralidade, é comumente utilizado o 1-hidroxibenzotriazole (HOBt) (PALOMO, 2014), que na presença de carbodiimidas (DIC, por exemplo) é capaz de interagir com o grupo carboxílico livre do aminoácido em solução, formando uma molécula do tipo Ester ativa, que reage com o grupo amina livre da cadeia peptídica acoplando mais um resíduo de aminoácido a ela. 
Figura 36 - Reações de acoplamento

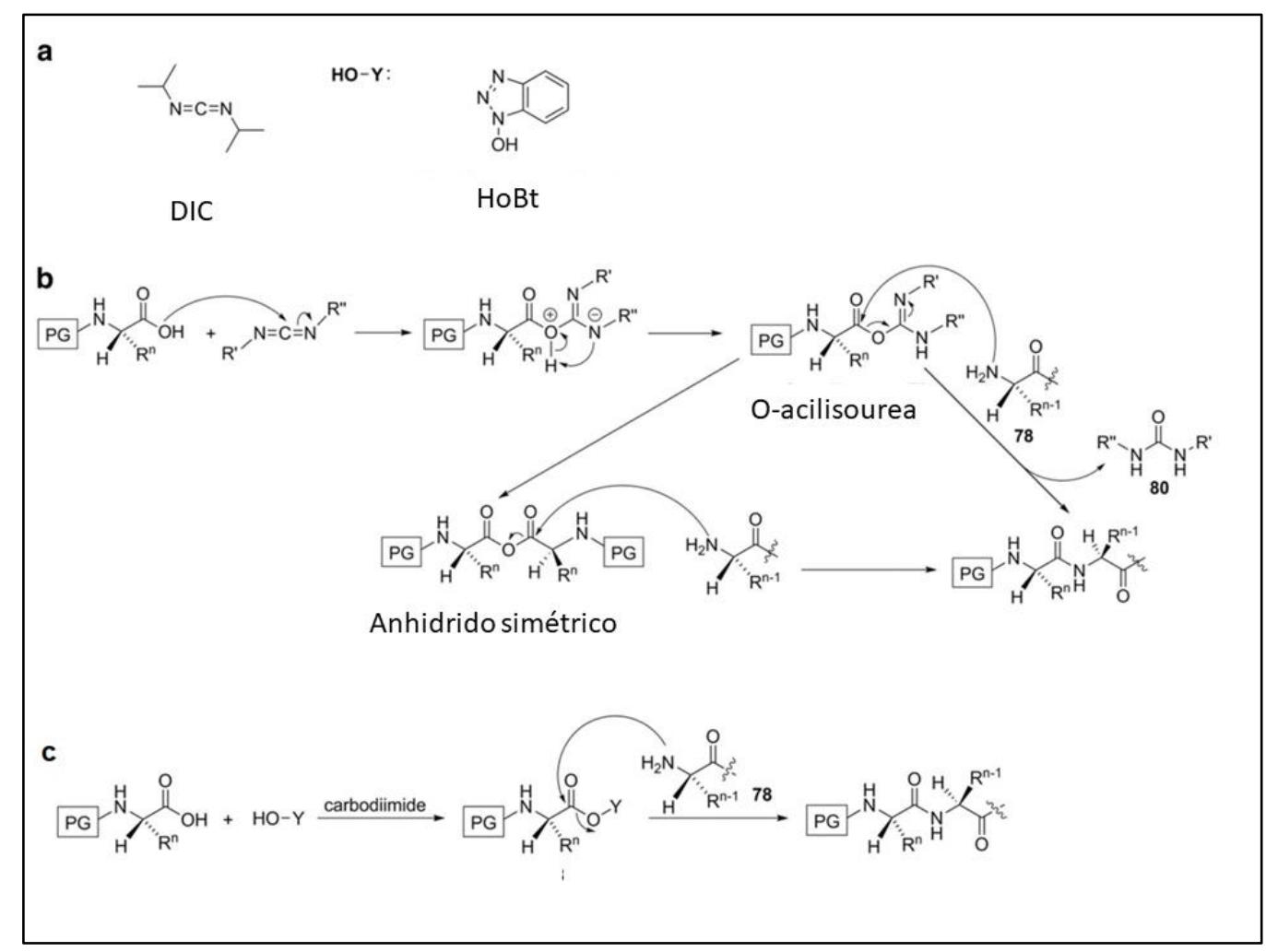

(a) Estrutura molecular do DIC e do HOBt; (b) esquematização das etapas de reação do DIC; c) etapas de reação do HOBt. Adaptado de Jaradat (2017).

Por último, é necessário escolher a estratégia utilizada para a proteção do aa que será acoplado. A proteção é importante, pois evita acoplar dois ou mais aa iguais em sequência no mesmo peptídeo, podendo acarretar desperdícios e ineficiência. Há duas estratégias de proteção mais utilizadas, e elas vão depender do terminal de origem da síntese $(\mathrm{C}$ ou $\mathrm{N})$; geralmente, o $\mathrm{N}$-terminal é bloqueado com um grupo tertiloxicarbonil (Boc) ou o 9-fluorenilmethoxicarbonyl (Fmoc) (JARADAT,2017). Nesta dissertação, o Fmoc foi o grupo de proteção implementado. Após cada ciclo de acoplamento, esse grupo é removido utilizando uma solução de piperidina $20 \%$ em DMF (dimetilformamida). É importante ressaltar que alguns aa também precisam de grupos protetores na sua cadeia lateral, Jaradat (2017) apresenta detalhes sobre esse tipo de proteção.

Com essas informações já é possível iniciar o protocolo de síntese. O protocolo implementado no grupo de biofísica aplicado do IFUSP está descrito na seção a seguir. 


\section{III.1.1 - Protocolo SPFS manual}

A SPFS acontece em ciclos de acoplamento e de desacoplamentos. As figuras 38 e 39 resumem os passos adotados durante a síntese dos peptídeos dessa dissertação. O protocolo implementado segue os seguintes passos:

\section{(1) Escolha da massa final desejada e cálculo do número de mols(n) e excesso}

A SPFS manual, em geral não nos permite obter uma grande massa final de peptídeo de forma tão eficiente quanto uma síntese automatizada, mas é o suficiente para obter resultados da ordem de miligramas, dependendo, é claro, do tamanho da coluna utilizada. Uma vez definida a massa final $\left(M_{f}\right)$, foi necessário calcular o número de mols do peptídeo a partir de sua massa molar $(M M), n=M_{f} / M M$.

Em seguida, calculou-se a escala (Esc) que será utilizada para pesar a quantidade de aa a ser utilizada, em que o excesso é uma garantia de que o acoplamento acontecerá. Geralmente ele é escolhido como 2 (assim como neste trabalho), mas pode variar dependendo da dificuldade do acoplamento.

$$
E s c=10 \cdot n \cdot \text { excesso }
$$

\section{(2) Escolha e preparo da coluna}

Para este trabalho foi utilizada uma seringa descartável de $10 \mathrm{~mL}$, nela não é recomendável obter mais do que $100 \mathrm{mg}$ de peptídeo, valores muito maiores são o suficiente para haver transbordamento e desperdício de material. É interessante se atentar ao formato e o material do êmbolo móvel, como este será bastante exigido durante a síntese. De acordo com nossos testes, alguns modelos ofereceram maior resistência a se movimentar e maior desgaste após vários acoplamentos, o que dificultou a síntese.

Após a escolha da coluna desejada, é necessário colocar a placa de filtro (frit column

plate), usualmente de polietileno, na coluna. Uma espátula pode auxiliar nesse processo. É importante garantir que ela se encontre completamente paralela ao êmbolo e que não haja frestas para vazamentos. 


\section{(3) Pesagem da resina}

A massa da resina a ser pesada foi calculada a partir da funcionalização da resina (fun). A massa foi calculada pela divisão: $n / f$ un. É vantajoso pesar a resina diretamente na coluna, a fim de evitar perdas de partículas da resina em frascos.

\section{(4) Solvatação da resina}

A solvatação foi realizada com DCM (diclorometano) e DMF (os solventes podem variar dependendo do protocolo). Os dois solventes foram despejados alternadamente duas vezes na coluna, com um volume variável, mas é importante garantir que os solventes cubram toda a resina. É importante secar a resina com a bomba de vácuo, ou embolo móvel, antes de colocar o novo solvente.

Segundo o protocolo de Coin et al. (2007), agitar gentilmente a coluna por 1 min antes de secar a resina é uma boa prática. Além disso, na primeira lavagem com DCM, os autores recomendam deixar a solução descansar por $15 \mathrm{~min}$.

\section{(5) Desbloqueio do grupo Fmoc}

Incubou-se a solução de $20 \%$ de piperidina (em DMF) na coluna foi submetida a agitação leve por 20 minutos. Em seguida solvatamos a resina com DCM e DMF pelo menos duas vezes intercaladamente.

\section{(6) Ensaio colorimétrico de Ninhidrina}

Nesse passo foi verificado se houve o desacoplamento por meio do teste Kaiser (KAISER et al, 1970), conforme descrito a seguir.

- Colocamos duas gotas das soluções A, B e C em um tubo de ensaio (anexo).

- Em seguida inserimos uma pequena porção da resina no tubo e homogeneizamos a solução.

- Incubamos o tudo de ensaio por 5 minutos em banho seco à $100^{\circ} \mathrm{C}$.

- Se a solução se tornar azul, o grupo Fmoc foi desacoplado, então podemos seguir para o passo (7). 
- Se a solução permanecer amarelada, voltamos para etapa (5).

\section{(7) Ativação do aminoácido}

Pesamos o aa $(M M \cdot E S c)$ num Becker, e no mesmo recipiente adicionamos o $\mathrm{HOBt}$ $\left(M M_{H o B t} \cdot E S C\right)$. Em seguida adicionamos na proporção 1:1 (vol:vol) DMF e DCM e sonicamos solução até homogeneizar. Por fim adicionamos o volume correto de DIC $\left(M M_{D I C} \cdot E S C \cdot \rho_{D I C}^{-1}\right)$ e sonicamos novamente ( $\sim 30 \mathrm{~s})$. A solução foi adicionada na coluna e incubada por pelo menos 2 horas.

\section{(8) Solvatação da resina e ensaio colorimétrico da nihidrina}

Solvatamos a resina com DMF e DCM duas vezes intercaladas, em seguida repetimos o teste da Nihidrina explicado em 6. Se a solução ficar azul, significa que o AA não acoplou, então devemos voltar para a etapa 7, podendo deixar mais tempo durante a etapa, ou então trocar o ativador. Se a solução permanecer amarelada, podemos seguir para etapa 9.

\section{(9) Desbloqueio do Fmoc}

Colocamos a solução de $20 \%$ de piperidina (em DMF) na coluna e deixamos em agitação por 20 minutos. Em seguida solvatamos a coluna com DMF e DCM (intercalando) duas vezes.

\section{(10) Ensaio colorimétrico de ninhidrina}

Se a solução ficar azul, o grupo Fmoc foi desacoplado, então seguimos para a etapa 5 ou para etapa 11. Se a solução permanecer amarelada, voltamos para etapa 9.

\section{(11) Clivagem do peptídeo da resina}

A clivagem é uma das etapas mais delicadas da síntese, e é nela em que pode haver quedas no rendimento. Dessa forma, existem alguns cuidados que devem ser tomados antes do início da clivagem. 
É importante lavar a resina duas vezes com ácido acético glacial por um minuto, em seguida lavar duas vezes com DCM por mais um minuto, lavar a resina com metanol (2 vezes por $1 \mathrm{~min}$ ), e por fim lavar a resina três vezes com éter etílico, por dois minutos. Em seguida é necessário secar totalmente a resina com uma bomba de vácuo e deixar a resina no dessecador (de preferência overnight).

O coquetel de clivagem é tipicamente preparado com uma mistura de TFA (ácido trifluoracético), água, TIS (triisopropilsilano) e/ou EDT (etanoditiol). As proporções variarão dependendo dos resíduos de aa presentes na cadeia peptídica. A figura 37, retirada de Cilli et al. (2016), apresenta as proporções utilizadas em cada caso.

Figura 37 - Coquetéis para clivagem dos peptídeos utilizando a química Fmoc/tBu.

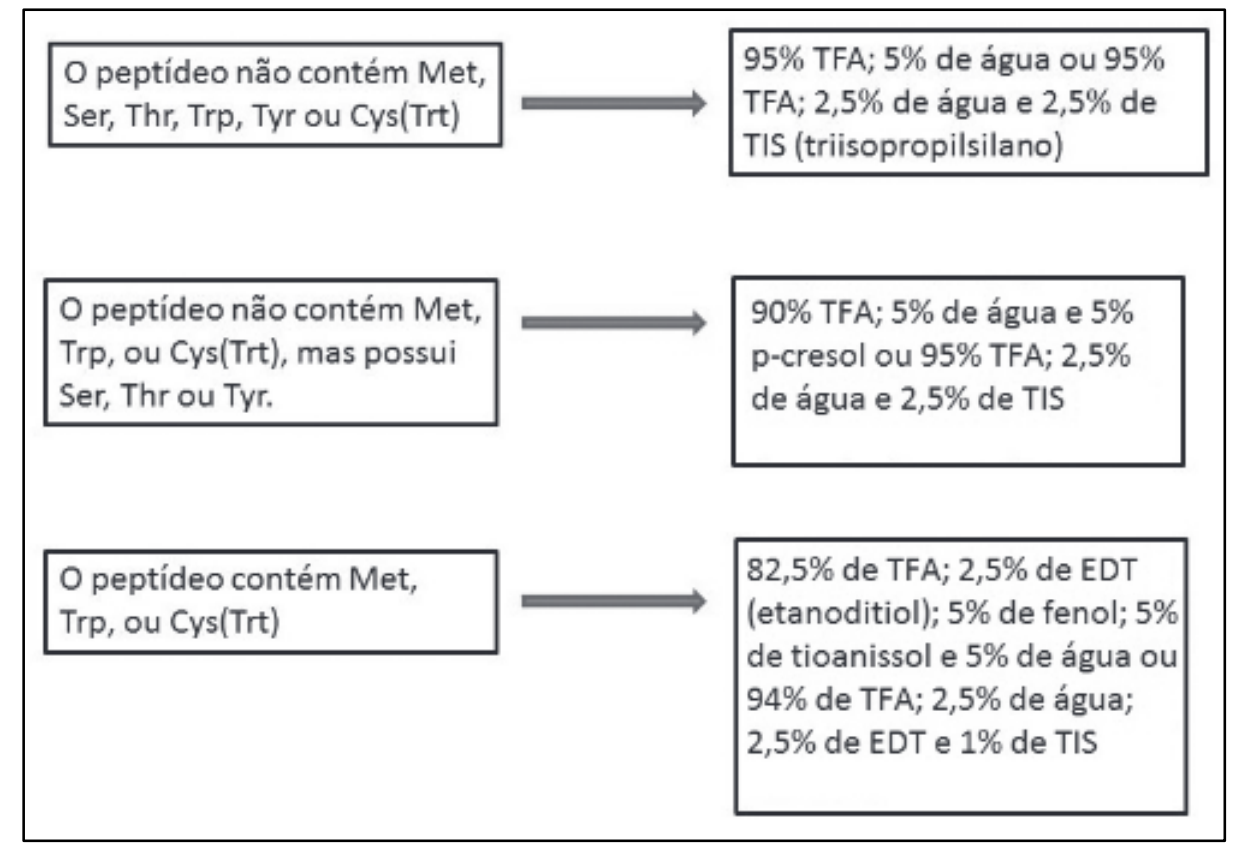

Fonte: retirado de Cilli et al, 2016.

Cilli et al. (2016) ainda descrevem os passos da clivagem para $100 \mathrm{mg}$ de peptidil-resina. Primeiro é adicionado $1 \mathrm{~mL}$ da do coquetel, sob agitação, adicionando primeiramente os supressores da cadeia lateral, seguida do TFA, deixando sobre agitação por $2 \mathrm{~h}$ ou $4 \mathrm{~h}$ para aminoácidos polares ou apolares, respectivamente. Em seguida, adicionamos $25 \mathrm{~mL}$ de éter etílico, centrifugamos e desprezamos o sobrenadante (duas vezes). Após isso, a resina foi seca (em vácuo), uma solução de água acidulada foi adicionada $(0,045 \%$ de TFA em água) e reservamos o sobrenadante. Repetimos a adição ao menos duas vezes, e por fim liofilizamos o sobrenadante. 
Para facilitar o cálculo das massas dos aminoácidos, resina, HOBt e volume de DIC a serem utilizados durante o processo de síntese, foi desenvolvido um script em Python que recebe como entrada a sequência do peptídeo, sua massa molecular, a funcionalização da resina e a massa em gramas do peptídeo que se quer obter com a síntese. Este programa ainda será mais otimizado e ficará como usufruto de novos membros do nosso grupo no IFUSP, e futuramente disponibilizado em algum servidor de bioinformática.

Figura 38 - Etapas da SPFS.

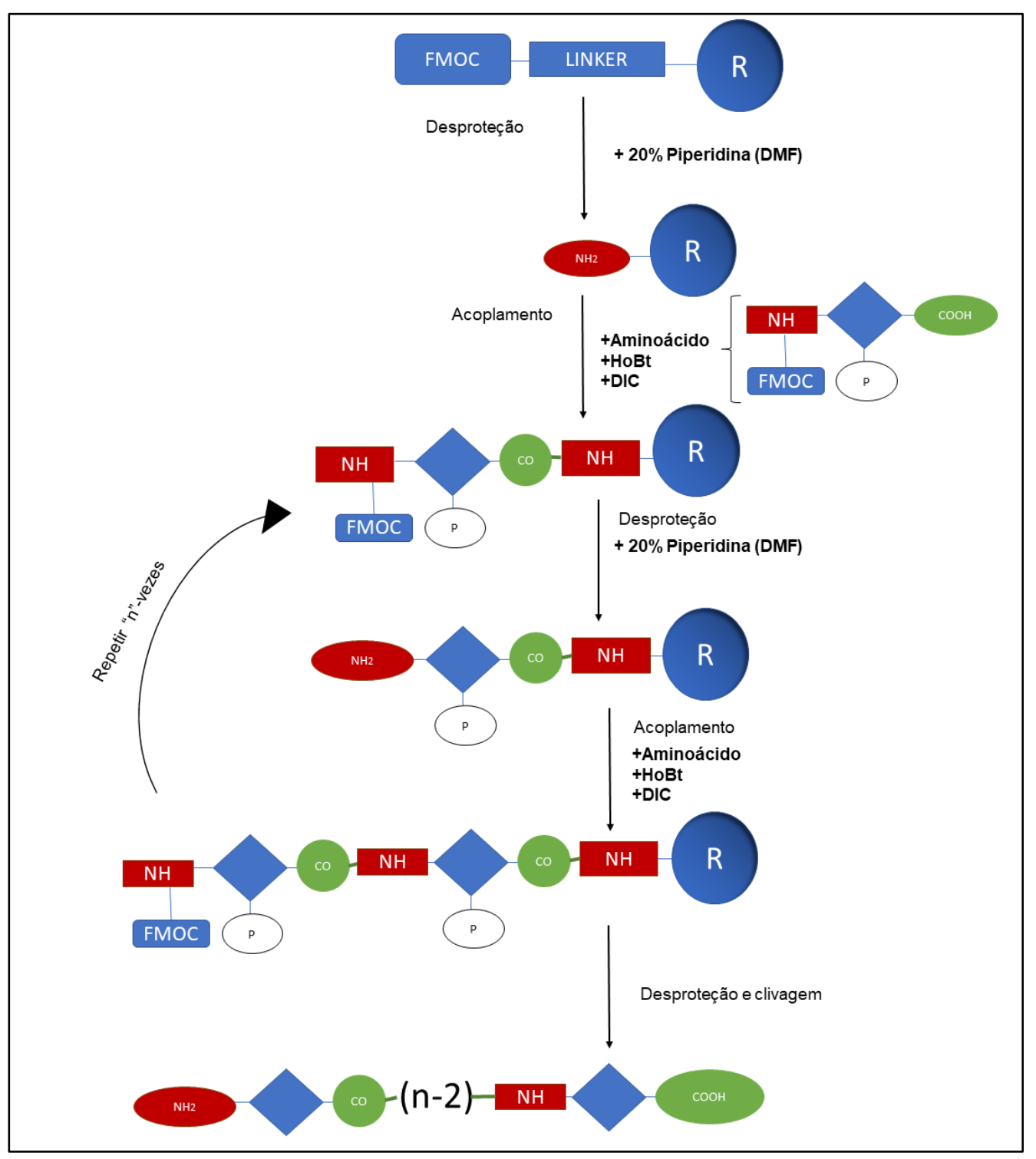

Fonte: Elaborado pelo autor.

Figura 39 - Protocolo da SPFS implementado no IFUSP 


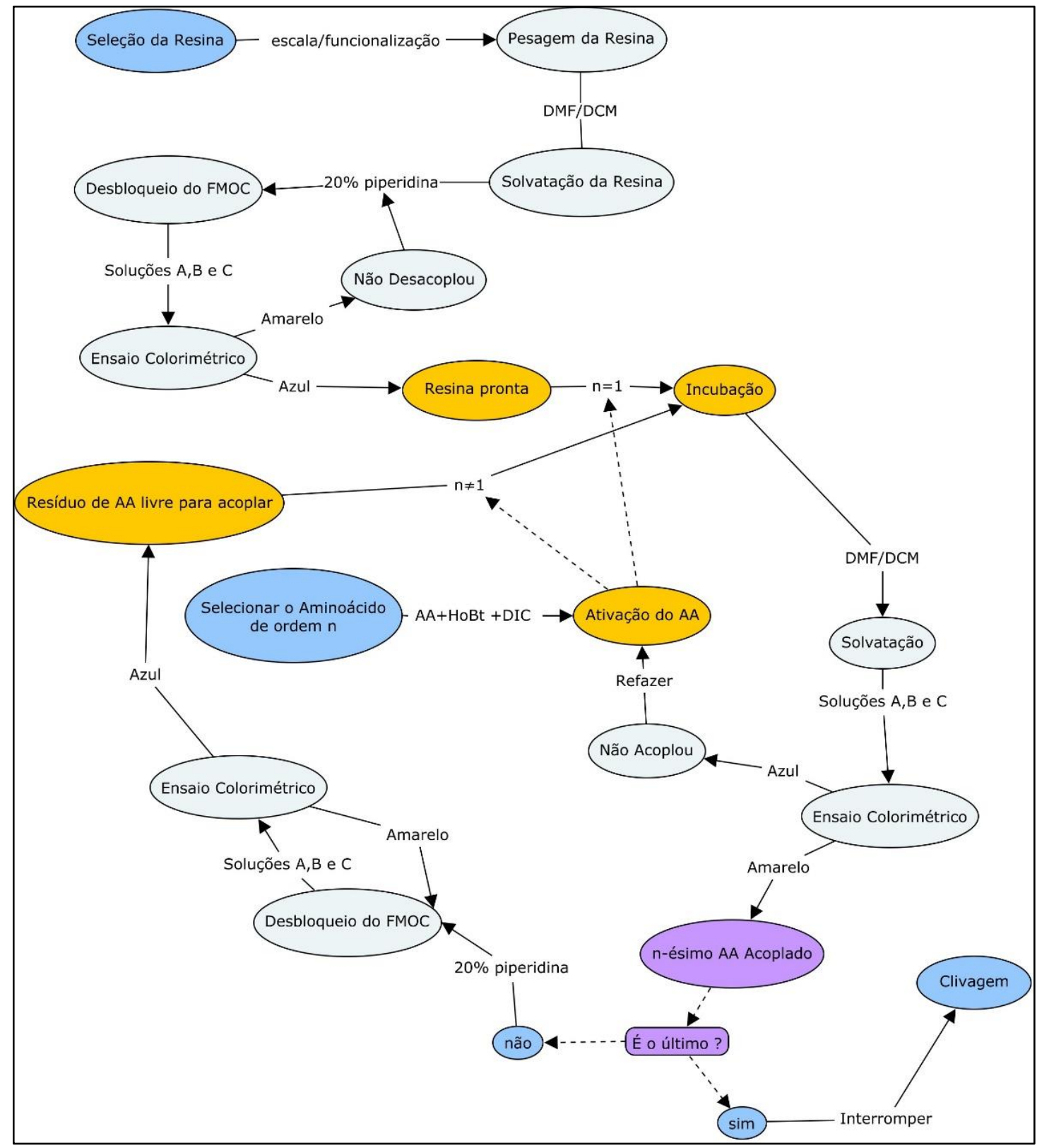

Fonte: Elaborado pelo autor.

\section{III.1.2 - SPFS de peptídeos da família das temporinas}

As temporinas (SIMMACO et al., 1998; ROMERO et al., 2020) são uma família de PAM que foram originalmente extraídos de secreções da pele do anfíbio Rana temporaria (SIMMACO et al., 1996), mas, atualmente, mais de 130 outros membros desta família foram encontrados em diversas espécies de anfíbios (Romero et al., 2020). Esses peptídeos são um dos menores PAM encontrado na natureza, variando de 10 a 14 resíduos de aminoácidos, o que desperta a atenção e os torna muito interessante para a indústria farmacêutica, visto que podem ser mais rapidamente sintetizados, com menor custo e maior rendimento quando comparado 
com PAM de cadeias maiores. Além disto, as temporinas são os PAM com o menor tamanho em $\alpha$-hélice encontrados na natureza, representando um modelo mínimo para os peptídeos desestabilizadores da membrana celular de microrganismos. Tipicamente, temporinas possuem a maioria dos seus resíduos de aa hidrofóbicos ( 70\%), sendo a leucina o resíduo mais abundante.

Outras propriedades interessantes desta família de PAMs incluem o fato de serem geralmente moléculas anfipáticas, com sequências conservadas, amidados na extremidade Cterminal e portadores de carga líquida catiônica fraca em $\mathrm{pH}$ neutro (variando de $+2 \mathrm{a}+3$ ). Além disso, as temporinas atuam contra uma ampla variedade de microorganismos patogênicos (bactérias, vírus, fungos filamentosos e leveduras) e apresentam baixa toxicidade para células de mamíferos (MAHALKA; KINNUNEN, 2009).

Para melhor estudar este cenário e colaborar no entendimento do mecanismo de ação de peptídeos desta família, propomos a síntese de dois PAM pertencentes a família das temporinas, além da síntese de peptídeos mutantes com uma maior carga e momento hidrofóbico, para que em próximos trabalhos possam ser utilizadas técnicas biofísicas para investigar as interações estabelecidas pelas temporinas em sistemas que mimetizam as membranas de bactérias e eucariotos. Tais estudos trarão informação sobre como ocorrem a adsorção e a ligação dos peptídeos nestes modelos lipídicos, discriminando quais fatores efetivamente regulam sua ligação, e ainda, qual a orientação destes peptídeos nestes sistemas, que pode ser correlacionada com o mecanismo de ação utilizado por estes peptídeos.

A temporina 1Ca, com sequência: FLPFLAKILTGVL (HALVERSON et al., 2000) foi escolhida para ser o primeiro peptídeo sintetizado no IFUSP utilizando o protocolo descrito na seção anterior. Esse PAM foi identificado na secreção da pele do sapo norte-americano Rana clamitans, em 2000. Possuindo 13 resíduos de aa, sendo 69\% deles hidrofóbicos, com uma carga líquida em pH 7,0 de +2 . No estudo original não foi publicado resultados de MIC para esse PAM, entretanto, de acordo com a base de dados APD3 (disponível online, 2021), em maio de 2020 foi identificada atividade anti-bactérias gram positivas (em S. aureus, MIC de $17 \mu M$ ), anti-bacterías gram negativas (em E.coli MIC de $4 \mu M$ ) e antifungal (em C. albicans, MIC de $14 \mu M)$, entretanto esses dados ainda não foram publicados em um jornal com revisão por pares. Neste trabalho, propusemos a síntese de três análogos, substituindo alguns resíduos de aminoácido por lisinas (aminoácido catiônico em pH 7,0) nas posições 6, 10 e em ambas, com intuito de investigar o efeito da carga, e a diminuição da hidrofobicidade. A tabela 16 apresenta as projeções em hélices para cada PAM e suas respectivas Hidrofobicidade e momento hidrofóbico, calculados pelo servidor heliQuest (GAUTIER et al., 2008). 
Tabela 16 - Projeção em hélice da Temporina 1Ca e análogos.

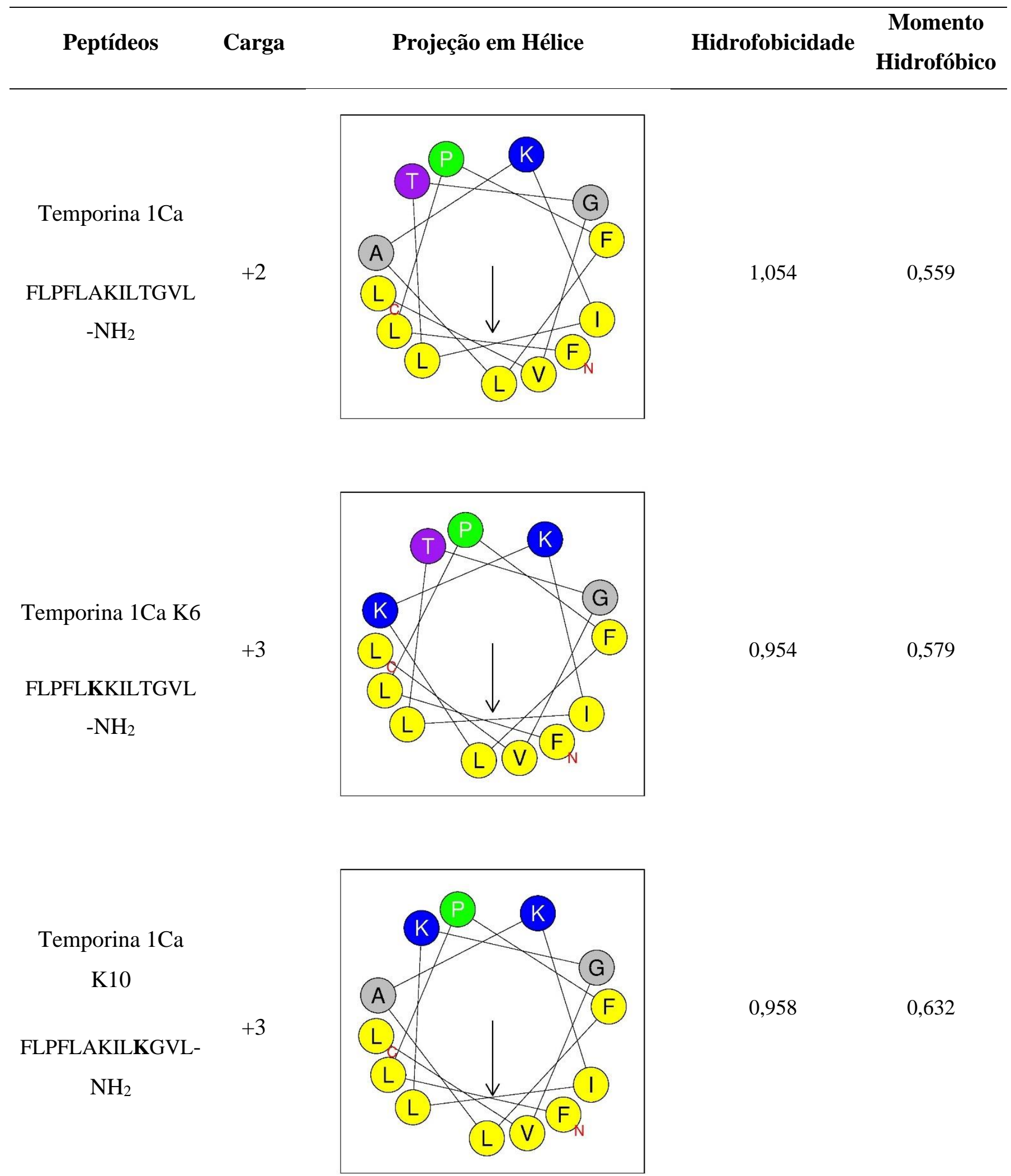


Temporina 1Ca K6

K10

FLPFLKKILKGVL- $\quad+4$

$\mathrm{NH}_{2}$

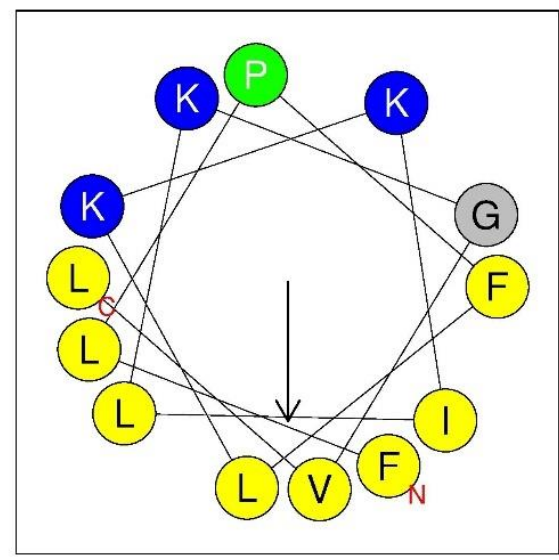

25 mg de cada análogo foi sintetizado. Como os PAM mantém a sequência igual dos três últimos resíduos de aa, a síntese se iniciou utilizando a mesma coluna, até o décimo primeiro resíduo. Em seguida, a peptidil-resina foi dividida em duas colunas em proporções 1:1, e os acomplamentos aconteceram paralelamente até o sétimo resíduo, em que as peptidilresinas foram novamente divididas e separadas em 4 colunas. A tabela 17 apresenta as massas, calculadas através do MAACalc.py, para cada etapa do acoplamento. 
Tabela 17 - Massas de aa pesadas para cada etapa de acoplamento (em mg)

\begin{tabular}{|c|c|c|c|c|c|c|c|}
\hline $1 \mathrm{Ca}$ & & $1 \mathrm{CaK6}$ & & 1CaK10 & & 1CaK6K10 & \\
\hline $\mathbf{L}$ & & & & 466,2 & & & \\
\hline V & & & & 447,8 & & & \\
\hline G & & & & 392,2 & & & \\
\hline $\mathbf{T}$ & & 262,2 & & $\mathbf{K}$ & & 309,0 & \\
\hline $\mathbf{L}$ & & 233,1 & & L & & 233,1 & \\
\hline I & & 233,1 & & I & & 233,1 & \\
\hline $\mathbf{K}$ & & 372,3 & & $\mathbf{K}$ & & 372,3 & \\
\hline $\mathbf{A}$ & 123,3 & $\mathbf{K}$ & 123,6 & $\mathbf{A}$ & 82,2 & $\mathbf{K}$ & 223,2 \\
\hline $\mathbf{L}$ & 139,9 & $\mathbf{L}$ & 93,24 & $\mathbf{L}$ & 93,24 & $\mathbf{L}$ & 139,9 \\
\hline $\mathbf{F}$ & 165,3 & $\mathbf{F}$ & 102,2 & $\mathbf{F}$ & 102,2 & $\mathbf{F}$ & 165,3 \\
\hline $\mathbf{P}$ & 133,5 & $\mathbf{P}$ & 89,0 & $\mathbf{P}$ & 89,0 & $\mathbf{P}$ & 133,5 \\
\hline $\mathbf{L}$ & 139,9 & $\mathbf{L}$ & 93,24 & $\mathbf{L}$ & 93,24 & $\mathbf{L}$ & 139,9 \\
\hline $\mathbf{F}$ & 165,3 & $\mathbf{F}$ & 102,2 & $\mathbf{F}$ & 102,2 & $\mathbf{F}$ & 165,3 \\
\hline
\end{tabular}

A massa da resina utilizada foi $985 \mathrm{mg}$, a massa de HOBt foi de $202 \mathrm{mg}$ e o volume de DIC de $204 \mu$ L. Essas duas últimas grandezas foram divididas pela metade a partir do quarto acoplamento, e por quatro a partir do oitavo.

\section{III.2 - Tensiometria em monocamadas de Langmuir}

A tensão superficial $(\gamma)$ gerada pelas interações das forças de coesão entre as moléculas de água em solução, existe de forma a minimizar a área da interface líquido-ar. A unidade dessa grandeza no sistema internacional é $N / m$, sendo que a tensão superficial típica da água pura $\left(\gamma_{\mathrm{H}_{2} \mathrm{O}}\right)$ em temperatura ambiente é $72,8 \mathrm{mN} / \mathrm{m}$. É comum definir uma variável normalizada para a água, conhecida como pressão superficial $(\pi)$, como na equação (47).

$$
\pi=\gamma_{\mathrm{H}_{2} \mathrm{O}}-\gamma
$$

Surfactantes, como os detergentes, são capazes de reduzir bruscamente $\gamma$, aumentando $\pi$. Outras moléculas, como os fosfolipídios, também são capazes de alterar essas grandezas. Os fosfolipídios possuem uma cabeça polar e caldas apolares, assim, quando despejados na 
interface líquido-ar, formam uma estrutura ordenada, as monocamadas lipídicas de Langmuir, de forma a minimizar a energia livre. Lentes também são passiveis de serem formadas, se as gotas do fosfolipídio não se espalharem por toda a superfície (OLIVEIRA, 2007).

A figura 40 esquematiza um experimento típico de adsorção em monocamadas de Langmuir. Primeiro, a monocamada é formada a partir do espalhamento de uma pequena alíquota de um fosfolipídio (com o uso de uma seringa do tipo Hamilton) solubilizado em solução de metanol-hexano (10:1, v:v) sob a interface água-ar de um recipiente circular contendo água MiliQ pura. A solução de metanol-hexano é altamente volátil, dessa forma, em poucos minutos as moléculas fosfolipídicas se encontram em uma película superficial. Os fosfolipídios usados neste projeto foram o 1-palmitoil 2-oleoil fosfatidilcolina (POPC), o 1palmitoil 2-oleoil fosfatidilglicerol (POPG), 1-palmitoil 2-oleoil fosfatidilserina (POPS), dipalmitoilfosfatidilglicerol (DPPG).

Figura 40 - Esquematização de um ensaio de tensiometria em monocamadas de Langmuir.

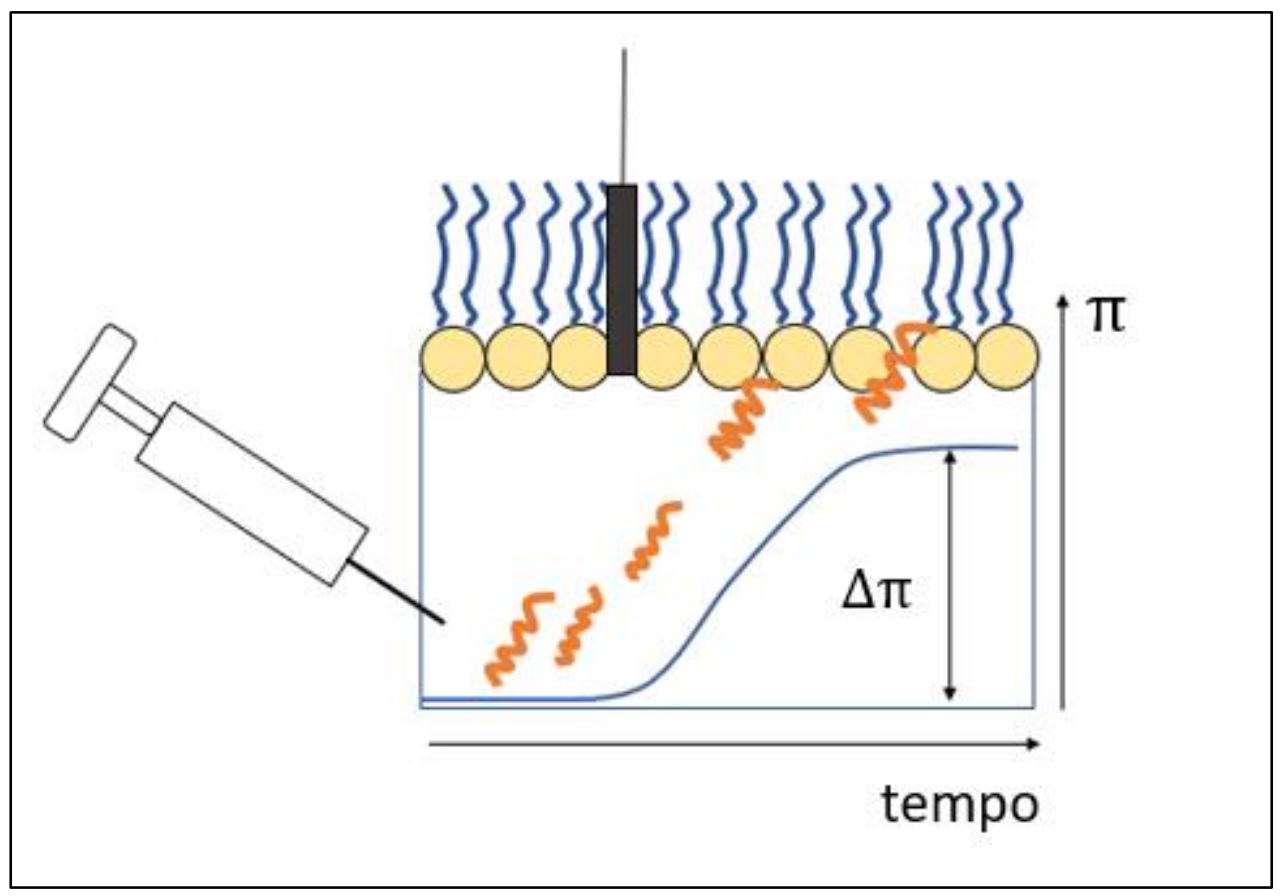

Fonte: Elaborado pelo autor.

Dependendo da pressão superficial, da temperatura e da área superficial, os fosfolipídios podem ser encontrados em três fases distintas: líquida-expandida (LE), líquida-condensada (LC) ou sólida-condensado (SC) (BREZESINSKI; MÖHWALD, 2003; BOISSELIER et al., 2017). A figura 41 (adaptada de ROKE et al., 2003) apresenta o diagrama de fase da monocamada. 
Figura 41 - Diagrama de fase das monocamadas de Langmuir.

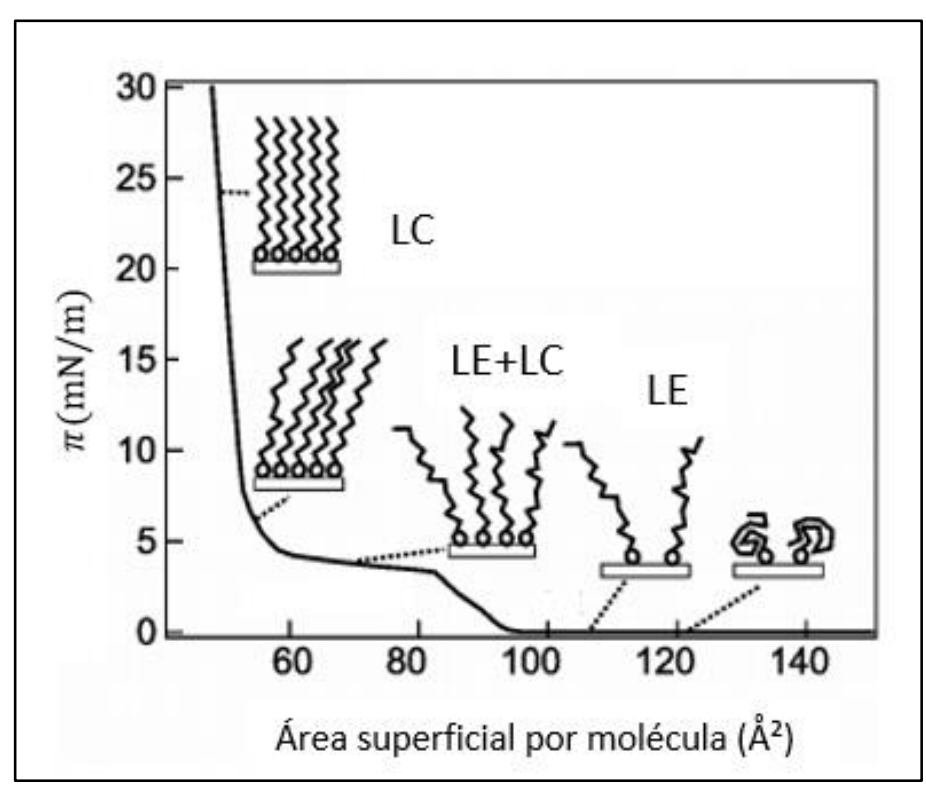

Adaptado de ROKE et al., 2003

Após a estabilização da monocamada, a molécula de interesse (proteína ou peptídeo) é inserida na subfase aquosa através de um orifício lateral (utilizando uma seringa tipo Hamilton). Caso exista propriedade tensoativa, a molécula migrará para a região da monocamada e será adsorvida. Tipicamente, a adsorção pode ser verificada a partir da alteração na pressão superficial, cuja evolução temporal pode ser descrita pela equação (48) (BOISSELIER et al., 2017), em que $k$ é uma constante.

$$
\pi(t)=\pi_{\text {equilíbrio }}-\pi_{\text {inicial }} e^{-k t}
$$

Diferentes curvas de $\pi(t)$ são tomadas utilizando pressões de empacotamento iniciais distintas. Com isso, a variação total da pressão superficial $\left(\Delta \pi=\pi_{\text {equilíbrio }}-\pi_{\text {inicial }}\right)$ é calculada, e um gráfico de $\Delta \pi \times \pi_{\text {inicial }}$ é desenhado. Tipicamente, esse gráfico pode ser ajustado por uma regressão linear, cujo coeficiente linear representa uma extrapolação para $\Delta \pi$ máximo, o coeficiente angular é utilizado para calcular a sinergia ( sinergia = coeficiente angular + 1), e a intersecção com o eixo x representa a pressão de máxima inserção (PMI) (BOISSELIER et al., 2017).

A sinergia é um parâmetro que indica a propensão de ligação da molécula de interesse com a monocamada, dessa forma, uma sinergia positiva, indica uma tendência de adsorção. Já 
a PMI indica a pressão limite na qual a molécula é capaz de ser adsorvida (BOISSELIER et al., 2017).

\section{III.2.1 - Tensiômetro DeltaPI}

Os experimentos foram realizados em um tensiômetro modelo Delta Pi Langmuirtensiometer (Kibron, Finland), utilizando uma microplaca de PTFE (politetrafluoroetileno) com 8 poços, contendo $1,5 \mathrm{~mL}$ de água Milli-Q por poço. As medições de tensão superficial são adquiridas por meio de um sensor de prova (filamento de níquel de $0,51 \mathrm{~mm}$ ) que é posicionado de modo a tatear a superfície da interface líquido-ar de cada poço, e as mudanças de pressão superficial são registradas pela interface computacional DeltaGraph. Tal sensor é capaz de medir a tensão e pressão superficial de líquidos expostos em pequenos recipientes circulares através de um sistema de medição de tensão elétrica de entrada e saída vinculado à ponta de seu receptor. Seu funcionamento é muito similar aos experimentos com planos de Wilhelmy. O equipamento é capaz de medir resultados num intervalo de 0 a $300 \mathrm{mN} / \mathrm{m}$, com uma resolução de $10 \mu \mathrm{N} / \mathrm{m}$ (KIBRON, 2021). Uma desvantagem desse equipamento é a impossibilidade de variar a área de cada poço durante uma mesma medida, assim, a pressão superficial nas camadas de Langmuir deve ser controlada através da quantidade de fosfolipídios depositados na superfície.

Figura 42 - Tensiometro DeltaPI

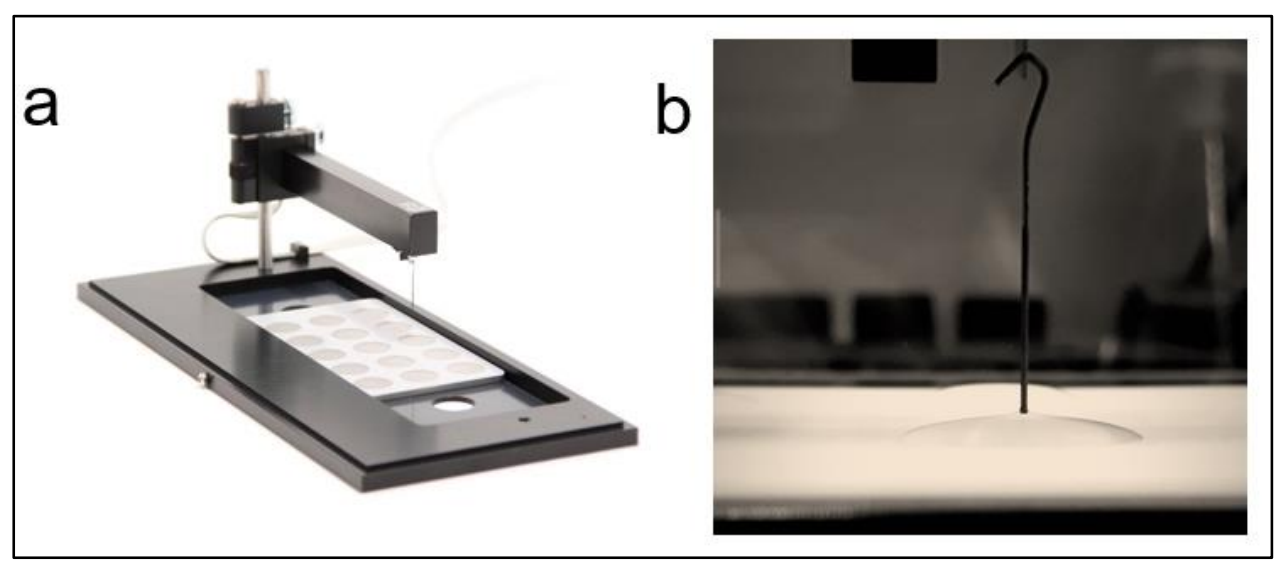

(a) Tesiometro DeltaPI (retirado de Kibron, ${ }^{6}$ 2021)

(b) sensor de prova tateando a superfície da interface líquido-ar.

Fonte: Elaborado pelo autor.

\footnotetext{
${ }^{6}$ Disponível online: <https://www.kibron.com/deltapilangmuir-tensiometer>. Acesso em: 19 maio 2021
} 


\section{III.2.2 - Ensaios com a Pln149}

Como foi verificado no capítulo anterior, a Pln149 apresenta diferentes estruturas secundárias dependendo da carga do fosfolipídio a qual está interagindo. Nessa etapa será verificado se a carga afeta não somente a estrutura, mas também a interação da Pln149 em diferentes monocamadas de Langmuir.

Em cada ensaio, promove-se a formação de uma monocamada lipídica na superfície de cada poço da microplaca, conforme representado na figura 40, com a cabeça polar do fosfolipídio voltada para a interface com a água, e o sensor de prova (arame) inserido entre a monocamada lipídica formada. Após a estabilização da monocamada e evaporação do solvente orgânico, uma alíquota do peptídeo Pln149 foi injetada no interior do recipiente (na subface aquosa, sem atrapalhar o empacotamento da monocamada lipídica). Desta forma, se ele for tensoativo nas condições do experimento, ele migrará para a superfície e começará a interagir com a monocamada lipídica, o que alterará a pressão medida pelo sensor de prova. Assim a pressão de superfície aumentará até encontrar um ponto de saturação, em que se estabelece um novo equilíbrio e a quantidade de peptídeo fixado à membrana é máxima.

Desta forma, os ensaios com a Pln149 foram realizados com três objetivos diferentes:

1) Verificação da tensoatividade dos próprios peptídeos isolados em água;

2) Determinar a relação entre a variação da pressão de superfície da monocamada $(\Delta \pi)$ com o aumento da concentração da Pln149 em solução aquosa;

3) Determinar a relação entre a variação da $\Delta \pi$ com a interação de Pln149 em monocamadas com diferentes graus de empacotamento (diferentes pressões iniciais da monocamada). 


\section{IV - Resultados e Discussão}

\section{IV.1 - Pressão superficial da água}

A medição do controle foi a primeira etapa dos experimentos de tensiometria. A tensão e pressão superficial da água foram medidas até o ponto em que a ponta da prova se desconecta da superfície devido à evaporação natural da água. De acordo com a figura 43, após 220 min do início do experimento, houve um aumento abrupto da pressão superficial, indicando a perda de contato da prova com a superfície. É interessante notar que a partir de 200min houve um aumento gradual de $1 \mathrm{mN} / \mathrm{m}$ da pressão durante 20 minutos até a perda de contato.

Figura 43 - Pressão superficial da água.

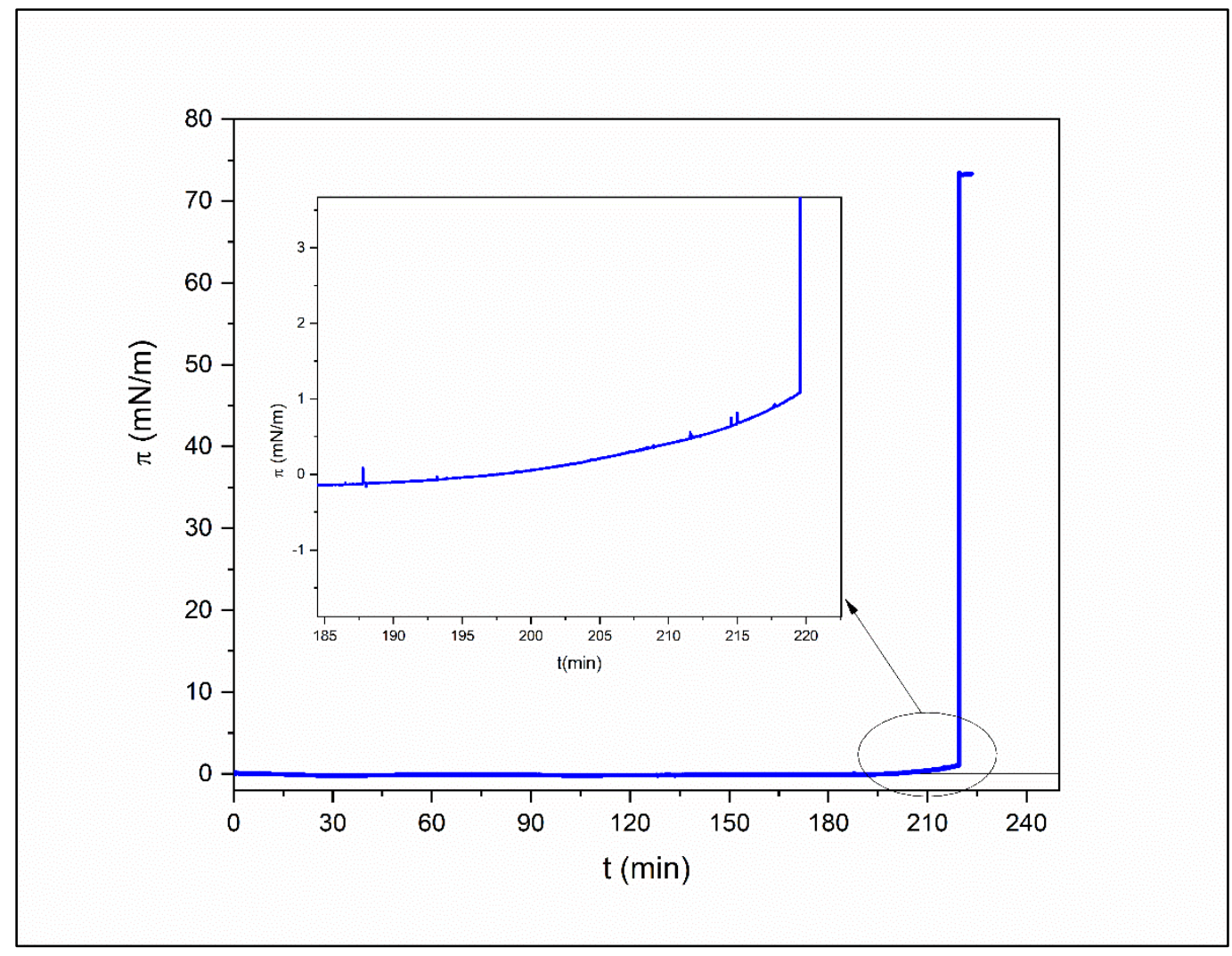

Fonte: Elaborado pelo autor.

IV.2 - Tensoatividade da Pln149 em água.

A Pln149 não apresenta atividade tensoativa apenas na presença de água pura. Diferentes ensaios foram tomados variando a concentração da Pln149 no intervalo de $0,16 \mu \mathrm{M}$ até 10,0 $\mu \mathrm{M}$. Durante o período de medição não houve alteração na pressão superficial. A figura 
44 apresenta esses resultados. Houve apenas um leve aumento na pressão superficial inicialmente devido à perturbação da superfície durante a injeção do peptídeo.

Figura 44 - Pressão superficial da Pln149 em água.

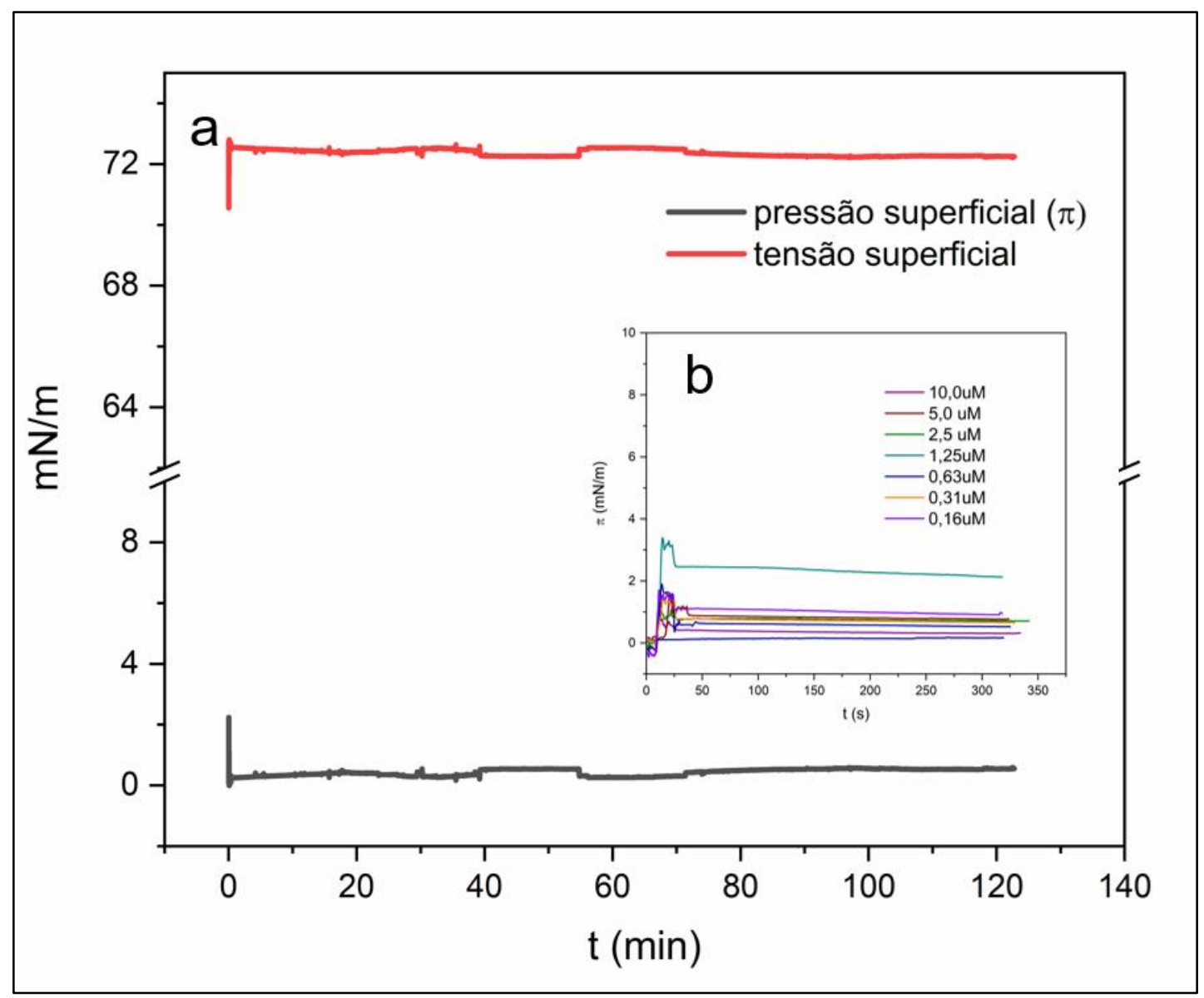

(a) Pressão e tensão superficial da Pln149 em água a 5,0 $\mu \mathrm{M}$ por 2 horas (b) variação da concentração da Pln149 em água por 6 minutos.

Fonte: Elaborado pelo autor.

\section{IV.3 - Tensoatividade da Pln149 em monocamadas lipídicas.}

Há uma dependência da concentração da Pln149 na interação com monocamadas lipídicas. Foram construídas monocamadas de POPC e POPG (figura 45) na superfície de cada poço da microplaca com pressão próxima a $25 \mathrm{mN} / \mathrm{m}$, nas quais injetamos diferentes concentrações do peptídeo original, variando de $2,5 \mu \mathrm{M}$ à $50 \mu \mathrm{M}$, de modo a se observar se quanto maior a concentração do peptídeo em solução, maior seria a nova pressão de equilíbrio estabelecida das monocamadas, ou seja, maior o $\Delta \pi$. 
Nota-se que diferentemente de quando a Pln149 estava exposta apenas à água, o peptídeo apresenta uma tensão superficial induzida quando injetado em um ambiente com presença da monocamada de lipídios do tipo PG e também PC, o que corrobora estudos anteriores (LOPES, 2010), e reafirma a habilidade do peptídeo em adsorver em monocamadas majoritariamente zwitteriônica.

Além disto, para as mesmas concentrações, as monocamadas de POPG sofreram maior alteração de pressão superficial, o que indica que o peptídeo melhor adsorveu com este tipo de lipídio, como de fato esperado pela atração eletrostática entre o peptídeo catiônico e a monocamada negativamente carregada (figura 45). A concentração de $5 \mu \mathrm{M}$ foi fixa para a realização dos ensaios seguintes.

O peptídeo foi então inserido em quatro monocamadas distintas (POPC, POPG, POPS e DPPG) e apresentou interação com todas, contudo, a variação da pressão superficial foi maior para as monocamadas carregadas (PG e PS), além disso, a presença de uma cadeia insaturada (PO) também causou a redução na variação da tensão superficial e uma cinética de interação mais lenta. Os resultados destes testes se encontram na figura 46 e representam a variação da pressão superficial devido à adsorção do peptídeo. Observamos também a cinética de adsorção do peptídeo nas monocamadas formadas com diferentes pressões iniciais de empacotamento, variando de 10 a $35 \mathrm{mN} / \mathrm{m}$, por pelo menos 30 minutos.

Analisando as curvas da figura 46, é importante ressaltar a tendência da diminuição da variação na pressão superficial em função do aumento da pressão de superfície inicial das quatro monocamadas estudadas. Isto indica e concorda com o fato de que quando os fosfolipídios apresentam elevadas pressões de empacotamento, há um aumento na dificuldade do peptídeo em adsorver e se inserir nestas monocamadas mais rígidas. Tal fato é interessante para se determinar a pressão de exclusão (PMI) do peptídeo nas monocamadas investigadas, de modo a expressar a inserção ou não do peptídeo numa célula real (com empacotamento por volta de 30-35 mN/m). O valor de PMI é determinado graficamente como o ponto no eixo das abscissas em que a reta do ajuste linear o intersecta, ou seja, valor onde $\Delta \pi$ é igual a zero.

Em todos os quatro casos vemos que a adsorção do peptídeo levou a uma pressão lateral final muito maior em comparação com a pressão de equilíbrio no início, indicando uma forte interação. No entanto, apenas os lipídios negativamente carregados apresentaram uma PMI acima de $35 \mathrm{mM} / \mathrm{m}$, concordando com o menor efeito perturbador nas monocamadas do lipídio zwitteriônico POPC. O fosfolipídio saturado apresentou o maior valor de PMI, o que pode indicar que a insaturação nos fosfolipídios dificulta a adsorção da Pln149. 
Desta forma, em membranas com empacotamento próximo aos das células naturais o peptídeo é capaz de causar alterações pouco significativas em monocamadas compostas majoritariamente de POPC, que são os mais abundantes em células eucarióticas e em leveduras. Entretanto, há um efeito mais pronunciado nestes sistemas com o aumento da concentração do peptídeo, podendo perturbar mais significativamente e causar grandes alterações no empacotamento lipídico de compostos zwitteriônicos. Tal fato corrobora com os rompimentos das células de leveduras descritos em estudos anteriores (realizado na presença de $400 \mu \mathrm{M}$ do peptídeo (LOPES et al., 2009)).

Figura 45 - Interação da Pln149 em monocamadas lipídicas em diferentes regimes de concentração.

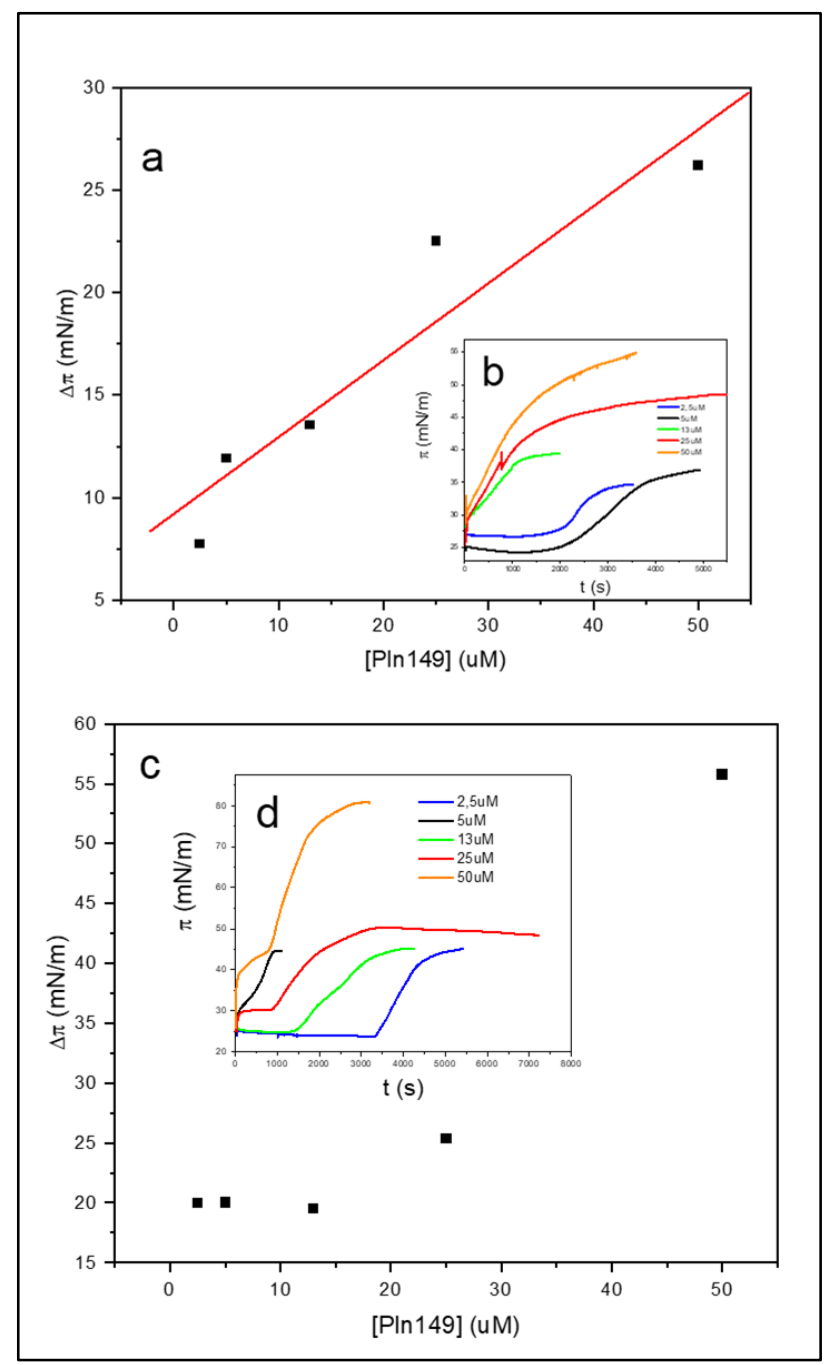

POPC (a) e POPG (c), e cinética de interação está apresentada em (b) e (d), respectivamente.

Fonte: Elaborado pelo autor. 
Figura 46 - Cinética de tensoatividade de Pln149 (5 $\mu M)$ em diferentes monocamadas lipídicas.
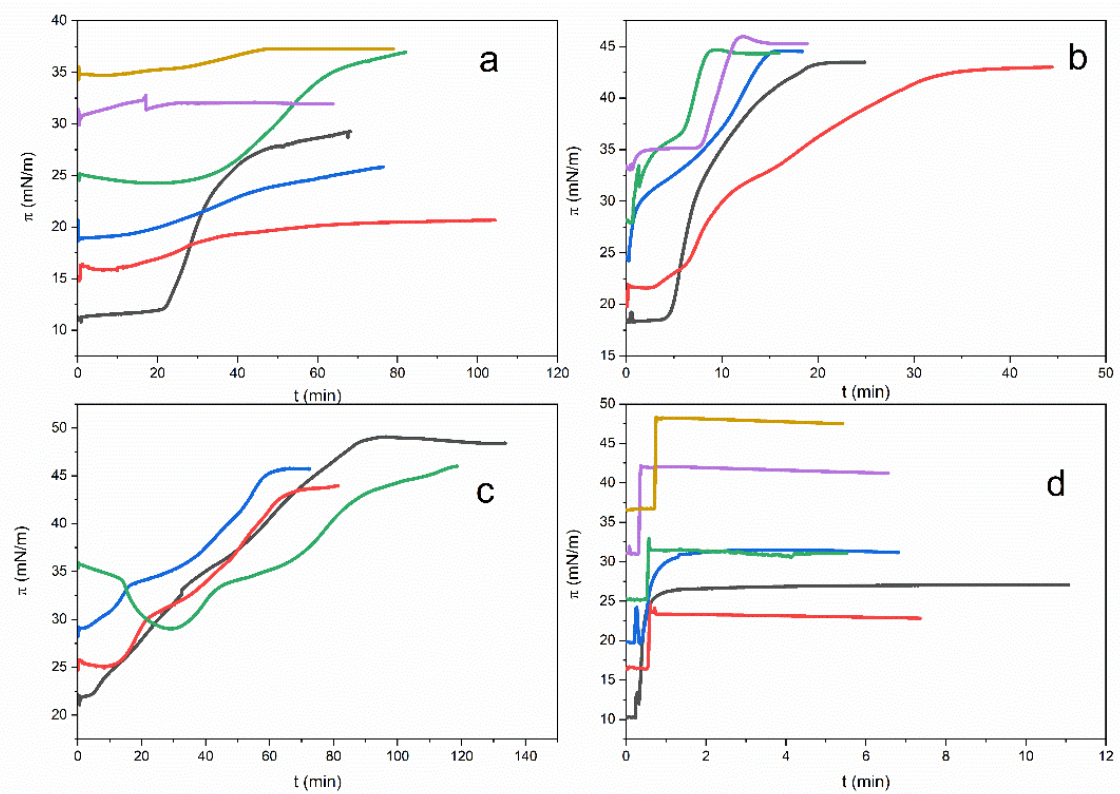

(a) POPC, (b) POPG, (c) POPS e (d) DPPG

Fonte: Elaborado pelo autor.

Figura 47 - Curvas $\Delta \pi \times \pi_{0}$ da Pln149 em diferentes monocamadas.

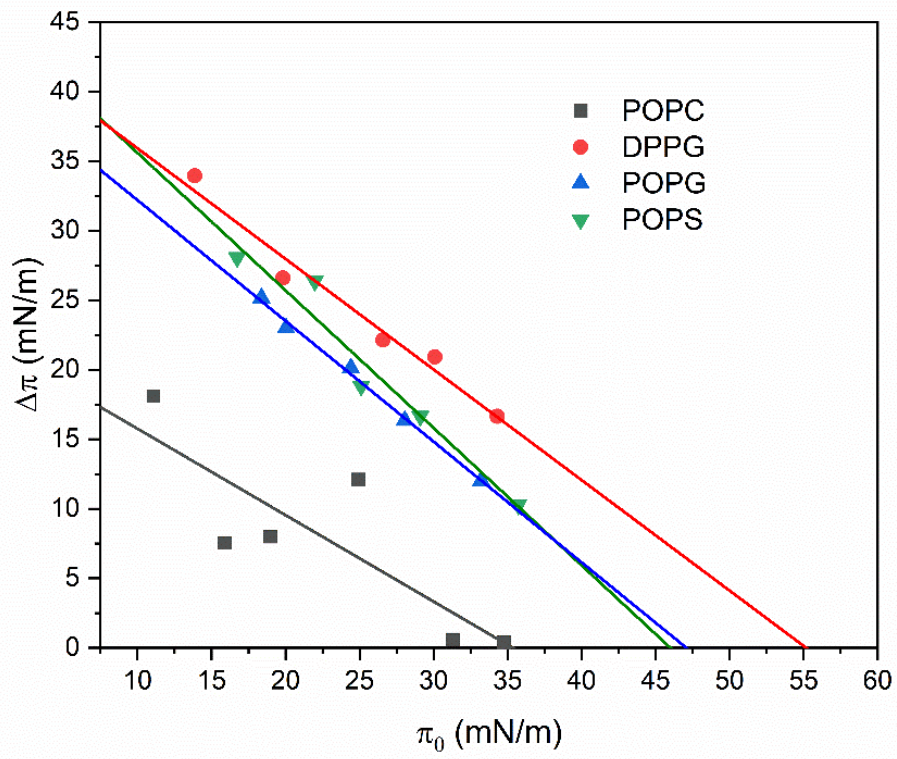


As retas foram ajustadas através do OriginLab, os valores de $\mathrm{R}^{2}$ foram 0,700, 0,972, 0,994, 0,948, respectivamente para as curvas do POPC, DPPG, POPG e POPS. Fonte: Elaborado pelo autor.

Tabela 18 - Parâmetros do gráfico $\Delta \pi \times \pi_{0}$

\begin{tabular}{ccccc}
\hline & POPC & DPPG & POPG & POPS \\
\hline PMI & $35,4 \pm 0,1$ & $55,1 \pm 0,1$ & $47,2 \pm 0,1$ & $45,9 \pm 0,1$ \\
$(\mathrm{mN} / \mathrm{m})$ & $0,38 \pm 0,20$ & $0,20 \pm 0,08$ & $0,13 \pm 0,03$ & $0,01 \pm 0,13$ \\
Sinergia & $21,9 \pm 4,9$ & $43,9 \pm 2,0$ & $40,9 \pm 0,9$ & $45,5 \pm 3,5$ \\
$\Delta \pi_{\max }$ & & & \\
$(\mathrm{mN} / \mathrm{m})$ & & & \\
\hline
\end{tabular}




\section{V - Conclusões}

Os ensaios que monitoram pressão lateral de monocamadas lipídicas na presença de Pln149, mostraram que a tensoatividade do peptídeo é induzida na presença de camadas fosfolipídicas, e que por menor que seja a variação da pressão de empacotamento, este peptídeo consegue interagir com monocamadas zwitteriônicas, reafirmando a sua ação na membrana celular de leveduras como a S.cereviseae. Entretanto, é notável que a presença de grupos negativamente carregados nos fosfolipídios, assim como os presentes em membranas de indivíduos Gram (+), acarretam uma maior perturbação devido à presença desse peptídeo, provocando uma maior variação de pressão superficial em condições de tensão próximas às células naturais. Essa diferença de comportamento é relativamente alta, o que justifica a não predição de interação com camadas de POPC nas literaturas anteriores.

Em sintonia com os resultados do capítulo anterior, a interação acentuada da Pln149 em membranas negativamente carregadas pode estar relacionada a formação de uma estrutura em $\alpha$-hélices. Dessa forma, evidencia-se que a carga é fundamental para a formação da estrutura helicoidal, o que realça a interação do PAM. Entretanto, neste trabalho, foi apresentada a primeira evidência experimental que a Pln149 é capaz de interagir com membranas zwitteriônicas. 


\section{Referencias}

AGEITOS, J.M.; SÁNCHEZ-PÉREZ, A.; CALO-MATA, P.; VILLA, T.G.. Antimicrobial peptides (AMPs): ancient compounds that represent novel weapons in the fight against bacteria. Biochemical Pharmacology, [S.L.], v. 133, p. 117-138, jun. 2017. Elsevier BV. http://dx.doi.org/10.1016/j.bcp.2016.09.018.

AMDURSKY, N.; STEVENS, M.M.. Circular Dichroism of Amino Acids: following the structural formation of phenylalanine. Chemphyschem, [S.L.], v. 16, n. 13, p. 2768-2774, 10 ago. 2015. Wiley. http://dx.doi.org/10.1002/cphc.201500260.

ANTHIS, N. J.; CLORE, G. M.. Sequence-specific determination of protein and peptide concentrations by absorbance at $205 \mathrm{~nm}$. Protein Science, [S.L.], v. 22, n. 6, p. 851-858, 29 abr. 2013. Wiley. http://dx.doi.org/10.1002/pro.2253.

APD3. Antimicrobial Peptide AP00104. 2021. Disponível em: https://wangapd3.com/database/query_output.php?ID=00104. Acesso em: 19 maio 2021.

BEROVA, N.; POLAVARAPU, P.L.; NAKANISH, K.; WOODY, R. W. (ed.). Comprehensive Chiroptical Spectroscopy: applications in stereochemical analysis of synthetic compounds, natural products, and biomolecules. New Jersey: John Wiley \& Sons, Inc., 2012. 853 p. 2 v. (ISBN 978-1-118-01292-5).

BOISSELIER, E.; DEMERS, E.; CANTIN, L.; SALESSE, C.. How to gather useful and valuable information from protein binding measurements using Langmuir lipid monolayers. Advances In Colloid And Interface Science, [S.L.], v. 243, n. 1, p. 60-76, maio 2017. Elsevier BV. http://dx.doi.org/10.1016/j.cis.2017.03.004.

BREZESINSKI, G.; MÖHWALD, H.. Langmuir monolayers to study interactions at model membrane surfaces. Advances In Colloid And Interface Science, [S.L.], v. 100-102, n. 1, p. 563-584, fev. 2003. Elsevier BV. http://dx.doi.org/10.1016/s0001-8686(02)00071-4.

BROGDEN, K. A.. Antimicrobial peptides: pore formers or metabolic inhibitors in bacteria?. Nature Reviews Microbiology, [S.L.], v. 3, n. 3, p. 238-250, mar. 2005. Springer Science and Business Media LLC. http://dx.doi.org/10.1038/nrmicro1098.

BULHELLER, B. M.; RODGER, A.; HIRST, J. D.. Circular and linear dichroism of proteins. Physical Chemistry Chemical Physics, [S.L.], v. 9, n. 17, p. 2020, 2007. Royal Society of Chemistry (RSC). http://dx.doi.org/10.1039/b615870f.

BÜRCK, J.; WADHWANI, P.; FANGHÄNEL, S.; ULRICH, A.S.. Oriented Circular Dichroism: a method to characterize membrane-active peptides in oriented lipid bilayers. Accounts Of Chemical Research, [S.L.], v. 49, n. 2, p. 184-192, 12 jan. 2016. American Chemical Society (ACS). http://dx.doi.org/10.1021/acs.accounts.5b00346.

CHEN, Yee-Hsiung; YANG, Jen Tsi; CHAU, Kue Hung. Determination of the helix and $\beta$ form of proteins in aqueous solution by circular dichroism. Biochemistry, [S.L.], v. 13, n. 16, p. 3350-3359, jul. 1974. American Chemical Society (ACS). http://dx.doi.org/10.1021/bi00713a027. 
CILLI, E. M.; PICCOLI, J. P.; ERNANDES, J. R.; NAKAIE, C. R.; JUBILUT, G. N.. Reações de clivagem ácida de aminoácidos e peptídeos ligados a polímeros: relevância para a metodologia de síntese de peptídeo. In: RESENDE, Rodrigo Ribeiro (org.). Biotecnologia Aplicada à Agro\&Indústria vol.4: fundamentos e aplicações. São Paulo: Blucher, 2016. Cap. 5. p. 175-196.

COIN, I.; BEYERMANN, M.; BIENERT, M.. Solid-phase peptide synthesis: from standard procedures to the synthesis of difficult sequences. Nature Protocols, [S.L.], v. 2, n. 12, p. 32473256, dez. 2007. Springer Science and Business Media LLC. http://dx.doi.org/10.1038/nprot.2007.454.

COMPTON, L. A.; JOHNSON, W.C.. Analysis of protein circular dichroism spectra for secondary structure using a simple matrix multiplication. Analytical Biochemistry, [S.L.], v. 155, n. 1, p. 155-167, maio 1986. Elsevier BV. http://dx.doi.org/10.1016/0003-2697(86)902411.

DIAS, S.A.; FREIRE, J.M.; PÉREZ-PEINADO, C.; DOMINGUES, M. M.; GASPAR, D.; VALE, N.; GOMES, P.; ANDREU, D.; HENRIQUES, S. T.; CASTANHO, M. A. R. B.. New Potent Membrane-Targeting Antibacterial Peptides from Viral Capsid Proteins. Frontiers In Microbiology, [S.L.], v. 8, n. 1, p. 1-9, 4 maio 2017. Frontiers Media SA. http://dx.doi.org/10.3389/fmicb.2017.00775.

DÍAZ-FRANCÉS, E.; RUBIO, F. J.. On the existence of a normal approximation to the distribution of the ratio of two independent normal random variables. Statistical Papers, [S.L.], v. 54, n. 2, p. 309-323, 24 jan. 2012. Springer Science and Business Media LLC. http://dx.doi.org/10.1007/s00362-012-0429-2.

DREW, E. D; JANES, R. W. 2StrucCompare: a webserver for visualizing small but noteworthy differences between protein tertiary structures through interrogation of the secondary structure content. Nucleic Acids Research, [S.L.], v. 47, n. 1, p. 477-481, 22 maio 2019. Oxford University Press (OUP). http://dx.doi.org/10.1093/nar/gkz456.

DREW, E. D; JANES, R. W. PDBMD2CD: providing predicted protein circular dichroism spectra from multiple molecular dynamics-generated protein structures. Nucleic Acids Research, [S.L.], v. 48, n. 1, p. 17-24, 28 abr. 2020. Oxford University Press (OUP). http://dx.doi.org/10.1093/nar/gkaa296.

EPAND, R. M.; VOGEL, H. J.. Diversity of antimicrobial peptides and their mechanisms of action. Biochimica Et Biophysica Acta (Bba) - Biomembranes, [S.L.], v. 1462, n. 1-2, p. 11 28, dez. 1999. Elsevier BV. http://dx.doi.org/10.1016/s0005-2736(99)00198-4.

EVANS, S. V.; BRAYER, G. D.. High-resolution study of the three-dimensional structure of horse heart metmyoglobin. Journal Of Molecular Biology, [S.L.], v. 213, n. 4, p. 885-897, jun. 1990. Elsevier BV. http://dx.doi.org/10.1016/s0022-2836(05)80270-0.

FASMAN, G. D. (ed.). Circular Dichroism and the Conformational Analysis of Biomolecules. New York: Springer Science, 1996. 739 p. (ISBN 978-1-4419-3249-5). GANS, Paul J.; LYU, Pingchiang C.; MANNING, Mark C.; WOODY, Robert W.; KALLENBACH, Neville R.. The helix-coil transition in heterogeneous peptides with specific 
side-chain interactions: theory and comparison with cd spectral data. Biopolymers, [S.L.], v. 31, n. 13, p. 1605-1614, nov. 1991. Wiley. http://dx.doi.org/10.1002/bip.360311315.

GAUTIER, R.; DOUGUET, D.; ANTONNY, B.; DRIN, G.. HELIQUEST: a web server to screen sequences with specific -helical properties. Bioinformatics, [S.L.], v. 24, n. 18, p. 21012102, 28 jul. 2008. Oxford University Press (OUP). http://dx.doi.org/10.1093/bioinformatics/btn392.

GIANGASPERO, A.; SANDRI, L.; TOSSI, A.. Amphipathic $\alpha$ helical antimicrobial peptides. European Journal Of Biochemistry, [S.L.], v. 268, n. 21, p. 5589-5600, nov. 2001. Wiley. http://dx.doi.org/10.1046/j.1432-1033.2001.02494.x.

GRIFFITHS, D. J.. Eletrodinâmica. 3. ed. São Paulo: Pearson Universidades, 2010. 424 p. (ISBN-13 : 978-8576058861). Tradução: Heloísa Coimbra de Souza.

HALES, B. J.. Magnetic Circular Dichroism Spectroscopy. Nitrogen Fixation, [S.L.], p. 207219, 2011. Humana Press. http://dx.doi.org/10.1007/978-1-61779-194-9_14.

HALVERSON, T.; BASIR, Y. J.; KNOOP, F. C.; CONLON, J.M.. Purification and characterization of antimicrobial peptides from the skin of the North American green frog Rana clamitans 弥. Peptides, [S.L.], v. 21, n. 4, p. 469-476, abr. 2000. Elsevier BV. http://dx.doi.org/10.1016/s0196-9781(00)00178-9.

HEUMANN, C.; SHALABH, M. S.. Introduction to Statistics and Data Analysis: with exercises, solutions and applications in r. Switzerland: Springer International, 2016. 456 p. (ISBN 978-3-319-46160-1).

HOLLMANN, A.; MARTINEZ, M.; MATURANA, P.; SEMORILE, L. C.; MAFFIA, P. C.. Antimicrobial Peptides: interaction with model and biological membranes and synergism with chemical antibiotics. Frontiers In Chemistry, [S.L.], v. 6, p. 1-12, 5 jun. 2018. Frontiers Media SA. http://dx.doi.org/10.3389/fchem.2018.00204.

J.A. WOOLLAM (Estados Unidos da América). Polarized Light. 2021. Disponível em: https://www.jawoollam.com/resources/ellipsometry-tutorial/polarized-light. Acesso em: 19 maio 2021.

JACKSON, D. Y.; KING, D. S.; CHMIELEWSKI, J.; SINGH, S.; SCHULTZ, P. G.. General approach to the synthesis of short.alpha.-helical peptides. Journal Of The American Chemical Society, [S.L.], v. 113, n. 24, p. 9391-9392, nov. 1991. American Chemical Society (ACS). http://dx.doi.org/10.1021/ja00024a067.

JACKSON, John David. Eletrodinâmica Clássica. 2. ed. Rio de Janeiro: Guanabara Dois, 1983. 587 p. Tradução de Annita Macedo e Horacio Macedo.

JANES, R. W.; WALLACE, B. A.. An Introduction to Circular Dichroism and Synchrtron Radiation Circular Dichroism Spectroscopy. In: WALLACE, Bonnie Ann; JANES, Robert William (ed.). Modern Techniques for Circular Dichroism and Synchrotron Radiation Circular Dichroism Spectroscopy. Amsterdam: Iod Press Bv, 2009. Cap. 1. p. 1-18. 
JARADAT, D. M. M.. Thirteen decades of peptide synthesis: key developments in solid phase peptide synthesis and amide bond formation utilized in peptide ligation. Amino Acids, [S.L.], v. 50, n. 1, p. 39-68, 28 nov. 2017. Springer Science and Business Media LLC. http://dx.doi.org/10.1007/s00726-017-2516-0.

JASCO INC.. Circular Dichroism: -1000 series circular dichroism spectropolarimeters. -1000 Series Circular Dichroism Spectropolarimeters. 2021. Disponível em: https://jascoinc.com/products/spectroscopy/circular-dichroism/. Acesso em: 18 maio 2021.

JOHNSON Jr, W. C.. Analyzing protein circular dichroism spectra for accurate secondary structures. Proteins: Structure, Function, and Genetics, [S.L.], v. 35, n. 3, p. 307-312, 15 maio 1999. Wiley. http://dx.doi.org/10.1002/(sici)1097-0134(19990515)35:33.0.co;2-3.

JOHNSON Jr, W. C.. Circular Dichroism Instrumentation. In: FASMAN, Gerald D. (ed.). Circular Dichroism and the Conformational Analysis of Biomolecules. New York: Springer Science, 1996. Cap. 18. p. 653-696.

JONES, C.; SCHIFFMANN, D.; KNIGHT, A.; WINDSOR, S.. Val-CiD Best Practice Guide: CD spectroscopy for the quality control of biopharmaceuticals. London: Crown, 2004. 24 p. (ISSN 1744-0602).

KAISER, E.; COLESCOTT, R.L.; BOSSINGER, C.D.; COOK, P.I.. Color test for detection of free terminal amino groups in the solid-phase synthesis of peptides. Analytical Biochemistry, [S.L.], v. 34, n. 2, p. 595-598, abr. 1970. Elsevier BV. http://dx.doi.org/10.1016/00032697(70)90146-6.

KATO, T.; MATSUDA, T.; OGAWA, E.; OGAWA, H.; KATO, H.; DOI, Umeyuki; NAKAMURA, Ryo. Plantaricin-149, a bacteriocin produced by Lactobacillus plantarum NRIC 149. Journal Of Fermentation And Bioengineering, [S.L.], v. 77, n. 3, p. 277-282, jan. 1994. Elsevier BV. http://dx.doi.org/10.1016/0922-338x(94)90234-8.

KELLY, S. M.; JESS, T. J.; PRICE, N. C.. How to study proteins by circular dichroism. Biochimica Et Biophysica Acta (Bba) - Proteins And Proteomics, [S.L.], v. 1751, n. 2, p. 119-139, ago. 2005. Elsevier BV. http://dx.doi.org/10.1016/j.bbapap.2005.06.005.

KELLY, S. M.; PRICE, N. C.. Sample Preparation and Good Practice in Circular Dichroism Spectroscopy. In: WALLACE, Bonnie Ann; JANES, Robert William (ed.). Modern Techniques for Circular Dichroism and Synchrotron Radiation Circular Dichorism Spectroscopy. Amsterdam: Ios Press, 2009. Cap. 4. p. 91-107.

KIBRON. Delta-PI Langmuir Tensiometer. Disponível em: https://www.kibron.com/deltapilangmuir-tensiometer. Acesso em: 19 maio 2021.

KIRKWOOD, J. G.. On the Theory of Optical Rotatory Power. The Journal Of Chemical Physics, [S.L.], v. 5, n. 6, p. 479-491, jun. 1937. AIP Publishing. http://dx.doi.org/10.1063/1.1750060.

KUMAGAI, P. S.; ARAUJO, A. P. U.; LOPES, J. L. S.. Going deep into protein secondary structure with synchrotron radiation circular dichroism spectroscopy. Biophysical Reviews, 
[S.L.], v. 9, n. 5, p. 517-527, 19 ago. 2017(a). Springer Science and Business Media LLC. http://dx.doi.org/10.1007/s12551-017-0314-2.

KUMAGAI, P. S.; DEMARCO, R.; LOPES, J. L. S.. Advantages of synchrotron radiation circular dichroism spectroscopy to study intrinsically disordered proteins. European Biophysics Journal, [S.L.], v. 46, n. 7, p. 599-606, 3 mar. 2017(b). Springer Science and Business Media LLC. http://dx.doi.org/10.1007/s00249-017-1202-1.

KUMAGAI, P. S.; SOUSA, V. K.; DONATO, M.; ITRI, R.; BELTRAMINI, L. M.; ARAUJO, Ana P. U.; BUERCK, Jochen; WALLACE, B. A.; LOPES, Jose L. S.. Unveiling the binding and orientation of the antimicrobial peptide Plantaricin 149 in zwitterionic and negatively charged membranes. European Biophysics Journal, [S.L.], v. 48, n. 7, p. 621-633, 19 jul. 2019. Springer Science and Business Media LLC. http://dx.doi.org/10.1007/s00249-01901387-y.

KWIT, M.; SKOWRONEK, Pawel; GAWRONSKI, Jacek; FRELEK, Jadwiga; WOZNICA, Magdalena; BUTKIEWICZ, Aleksandra. Some Inherently chiral chromophores: empirical rules and quantum chemical calculations. In: BEROVA, Nina; POLAVARAPU, Prasad L.; NAKANISH, Koji; WOODY, Robert W. (ed.). Comprehensive Chiroptical Spectroscopy: applications in stereochemical analysis of synthetic compounds, natural products, and biomolecules. New Jersey: John Wiley \& Sons, Inc., 2012. Cap. 2. p. 39-72.

LEES, J.G.; SMITH, B.R.; WIEN, F.; MILES, A.J.; WALLACE, B.A.. CDtool—an integrated software package for circular dichroism spectroscopic data processing, analysis, and archiving. Analytical Biochemistry, [S.L.], v. 332, n. 2, p. 285-289, set. 2004. Elsevier BV. http://dx.doi.org/10.1016/j.ab.2004.06.002.

LEES, J. G.; MILES, A. J.; WIEN, F.; WALLACE, B. A.. A reference database for circular dichroism spectroscopy covering fold and secondary structure space. Bioinformatics, [S.L.], v. 22, n. 16, p. 1955-1962, 20 jun. 2006. Oxford University Press (OUP). http://dx.doi.org/10.1093/bioinformatics/btl327.

LOPES, J. L. S.. Plantaricina 149 e análogos: atividade antimicrobiana, estudos estruturais e mecanismo de ação. 2010. 225 f. Tese (Doutorado), Instituto de Física de São Carlos, Universidade de São Paulo, São Carlos, 2010.

LOPES, J. L. S. ; HISSA, D. C.; MELO, V. M. M.; BELTRAMINI, L. M.. Interaction of antimicrobial peptide Plantaricin149a and four analogs with lipid bilayers and bacterial membranes. Brazilian Journal Of Microbiology, [S.L.], v. 44, n. 4, p. 1291-1298, dez. 2013 b. FapUNIFESP (SciELO). http://dx.doi.org/10.1590/s1517-83822014005000007.

LOPES, J. L. S.; MILES, A. J.; WHITMORE, L.; WALlACE, B. A.. Distinct circular dichroism spectroscopic signatures of polyproline II and unordered secondary structures: applications in secondary structure analyses. Protein Science, [S.L.], v. 23, n. 12, p. 17651772, 30 out. 2014. Wiley. http://dx.doi.org/10.1002/pro.2558.

LOPES, J. L. S.; NOBRE, T. M.; SIANO, A.; HUMPOLA, V.; BOSSOLAN, N. R.s.; ZANIQUELLI, M. E. D.; TONARELLI, G.; BELTRAMINI, L. M.. Disruption of Saccharomyces cerevisiae by Plantaricin 149 and investigation of its mechanism of action with biomembrane model systems. Biochimica Et Biophysica Acta (Bba) - Biomembranes, [S.L.], 
v. 1788, n. 10, p. 2252-2258, out. 2009. Elsevier BV. http://dx.doi.org/10.1016/j.bbamem.2009.06.026.

LOPES, J.; GÓMARA, M.; HARO, I.; TONARELLI, G.; BELTRAMINI, L.. Contribution of the Tyr-1 in Plantaricin149a to Disrupt Phospholipid Model Membranes. International Journal Of Molecular Sciences, [S.L.], v. 14, n. 6, p. 12313-12328, 7 jun. 2013a. MDPI AG. http://dx.doi.org/10.3390/ijms140612313.

MAGYARFALVI, G.; TARCZAY, G.; VASS, E.. Vibrational circular dichroism. Wiley Interdisciplinary Reviews: Computational Molecular Science, [S.L.], v. 1, n. 3, p. 403-425, 11 abr. 2011. Wiley. http://dx.doi.org/10.1002/wcms.39.

MAHALKA, A. K.; KINNUNEN, P. K.J.. Binding of amphipathic $\alpha$-helical antimicrobial peptides to lipid membranes: lessons from temporins b and 1. Biochimica Et Biophysica Acta (Bba) - Biomembranes, [S.L.], v. 1788, n. 8, p. 1600-1609, ago. 2009. Elsevier BV. http://dx.doi.org/10.1016/j.bbamem.2009.04.012.

MANAVALAN, P.; JOHNSON, W.C. Variable selection method improves the prediction of protein secondary structure from circular dichroism spectra. Analytical Biochemistry, [S.L.], v. 167, n. 1, p. 76-85, nov. 1987. Elsevier BV. http://dx.doi.org/10.1016/0003-2697(87)90135$\underline{7}$.

MANAVALAN, P.; JOHNSON, W.C.. Variable selection method improves the prediction of protein secondary structure from circular dichroism spectra. Analytical Biochemistry, [S.L.], v. 167, n. 1, p. 76-85, nov. 1987. Elsevier BV. http://dx.doi.org/10.1016/0003-2697(87)901357.

MATSUO, K.; GEKKO, K.. Synchrotron-Radiation Vacuum-Ultraviolet Circular-Dichroism Spectroscopy for Characterizing the Structure of Saccharides. Glycobiophysics, [S.L.], p. 101117, 2018. Springer Singapore. http://dx.doi.org/10.1007/978-981-13-2158-0_6.

MCHALE, J. L.. Molecular Spectrocopy. 2. ed. Boca Raton: Crc Press, 2017. 457 p. (ISBN13: 978-1-4665-8658-1).

MCPHIE, Peter. Concentration-independent estimation of protein secondary structure by circular dichroism: a comparison of methods. Analytical Biochemistry, [S.L.], v. 375, n. 2, p. 379-381, abr. 2008. Elsevier BV. http://dx.doi.org/10.1016/j.ab.2008.01.024.

MERRIFIELD, B. Solid phase synthesis. Science, [S.L.], v. 232, n. 4748, p. 341-347, 18 abr. 1986. American Association for the Advancement of Science (AAAS). http://dx.doi.org/10.1126/science.3961484.

MERRIFIELD, R. B.. Solid Phase Peptide Synthesis. I. The Synthesis of a Tetrapeptide. Journal Of The American Chemical Society, [S.L.], v. 85, n. 14, p. 2149-2154, jul. 1963. American Chemical Society (ACS). http://dx.doi.org/10.1021/ja00897a025.

MICSONAI, András; WIEN, Frank; BULYÁKI, Éva; KUN, Judit; MOUSSONG, Éva; LEE, Young-Ho; GOTO, Yuji; RÉFRÉGIERS, Matthieu; KARDOS, József. BeStSel: a web server for accurate protein secondary structure prediction and fold recognition from the circular dichroism spectra. Nucleic Acids Research, [S.L.], v. 46, n. 1, p. 315-322, 11 jun. 2018. Oxford University Press (OUP). http://dx.doi.org/10.1093/nar/gky497 
MILES, A. J.; WALLACE, B. A.. Circular dichroism spectroscopy of membrane proteins. Chemical Society Reviews, [S.L.], v. 45, n. 18, p. 4859-4872, 2016. Royal Society of Chemistry (RSC). http://dx.doi.org/10.1039/c5cs00084j.

MILES, A. J.; WHITMORE, L.; WALLACE, B. A.. Spectral magnitude effects on the analyses of secondary structure from circular dichroism spectroscopic data. Protein Science, [S.L.], v. 14, n. 2, p. 368-374, 1 fev. 2005. Wiley. http://dx.doi.org/10.1110/ps.041019905.

MILES, A. J.; WALLACE, B. A.. Calibration Techniques for Circular Dichroism and Synchrotron Radiation Circular Dichroism Spectroscopy. In: WALLACE, Bonnie Ann; JANES, Robert William (ed.). Modern Techniques for Circular Dichroism and Synchrotron Radiation Circular Dichorism Spectroscopy. Amsterdam: Ios Press, 2009. Cap. 3. p. 73-90.

MIYAHARA, T.; NAKATSUJI, H.; SUGIYAMA, H. Similarities and Differences between RNA and DNA Double-Helical Structures in Circular Dichroism Spectroscopy: a sac: ci study. The Journal Of Physical Chemistry A, [S.L.], v. 120, n. 45, p. 9008-9018, 3 nov. 2016. American Chemical Society (ACS). http://dx.doi.org/10.1021/acs.jpca.6b08023.

MOFFITT, W.; FITTS, D. D.; KIRKWOOD, J. G.. CRITIQUE OF THE THEORY OF OPTICAL ACTIVITY OF HELICAL POLYMERS. Proceedings Of The National Academy Of Sciences, [S.L.], v. 43, n. 8, p. 723-730, 15 ago. 1957. Proceedings of the National Academy of Sciences. http://dx.doi.org/10.1073/pnas.43.8.723.

MOFFITT, W.; MOSCOWITZ, A.. Optical Activity in Absorbing Media. The Journal Of Chemical Physics, [S.L.], v. 30, n. 3, p. 648-660, mar. 1959. AIP Publishing. http://dx.doi.org/10.1063/1.1730025.

MOSCOWITZ, A..; MISLOW, K..; GLASS, M. A. W.; DJERASSI, Carl.. Optical Rotatory Dispersion Associated with Dissymmetric Non-conjugated Chromophores. An Extension of the Octant Rule1-3. Journal Of The American Chemical Society, [S.L.], v. 84, n. 10, p. 19451955, maio 1962. American Chemical Society (ACS). http://dx.doi.org/10.1021/ja00869a036.

NAGY, G.; GRUBMÜLLER, H.. How accurate is circular dichroism-based model validation? European Biophysics Journal, [S.L.], v. 49, n. 6, p. 497-510, 26 ago. 2020. Springer Science and Business Media LLC. http://dx.doi.org/10.1007/s00249-020-01457-6.

NAGY, G.; IGAEV, M.; JONES, N. C.; HOFFMANN, S. V.; GRUBMÜLLER, Helmut. SESCA: predicting circular dichroism spectra from protein molecular structures. Journal Of Chemical Theory And Computation, [S.L.], v. 15, n. 9, p. 5087-5102, 11 ago. 2019. American Chemical Society (ACS). http://dx.doi.org/10.1021/acs.jctc.9b00203.

NELSON, D. L; COX, M. M. Lehninger Principles of Biochemistry. 4. ed. New York: W.H.Freeman, 2004. 1100 p. (ISBN-13: 978-0716743392).

OLIVEIRA, J. E. de. Estudo de monocamadas fosfolipídicas nanoestruturadas obtidas por LB para aplicações em biossensores. 2007. 94 f. Dissertação (Mestrado) - Curso de Engenharia Metalúrgica e de Minas, Univesidade Federal de Minas Gerais, Belo Horizonte, 2007. 
PALOMO, J. M.. Solid-phase peptide synthesis: an overview focused on the preparation of biologically relevant peptides. Rsc Adv., [S.L.], v. 4, n. 62, p. 32658-32672, 2014. Royal Society of Chemistry (RSC). http://dx.doi.org/10.1039/c4ra02458c.

PROVENCHER, S. W.; GLOECKNER, J.. Estimation of globular protein secondary structure from circular dichroism. Biochemistry, [S.L.], v. 20, n. 1, p. 33-37, 6 jan. 1981. American Chemical Society (ACS). http://dx.doi.org/10.1021/bi00504a006.

RAUSSENS, Vincent; RUYSSCHAERT, Jean-Marie; GOORMAGHTIGH, Erik. Protein concentration is not an absolute prerequisite for the determination of secondary structure from circular dichroism spectra: a new scaling method. Analytical Biochemistry, [S.L.], v. 319, n. 1, p. 114-121, ago. 2003. Elsevier BV. http://dx.doi.org/10.1016/s0003-2697(03)00285-9.

RINK, H.. Solid-phase synthesis of protected peptide fragments using a trialkoxy-diphenylmethylester resin. Tetrahedron Letters, [S.L.], v. 28, n. 33, p. 3787-3790, jan. 1987. Elsevier BV. http://dx.doi.org/10.1016/s0040-4039(00)96384-6.

ROKE, S.; SCHINS, J.; MÜLLER, M.; BONN, Mischa. Vibrational Spectroscopic Investigation of the Phase Diagram of a Biomimetic Lipid Monolayer. Physical Review Letters, [S.L.], v. 90, n. 12, p. 1-4, 26 mar. 2003. American Physical Society (APS). http://dx.doi.org/10.1103/physrevlett.90.128101.

ROMERO, S. M.; CARDILlO, A. B.; CERON, M. C. M.; CAMPERI, Silvia Andrea; GIUDICESSI, Silvana Laura. Temporins: an approach of potential pharmaceutic candidates. Surgical Infections, [S.L.], v. 21, n. 4, p. 309-322, 1 maio 2020. Mary Ann Liebert Inc. http://dx.doi.org/10.1089/sur.2019.266.

SCHELlMAN, J. A.; ORIEL, P.. Origin of the Cotton Effect of Helical Polypeptides. The Journal Of Chemical Physics, [S.L.], v. 37, n. 9, p. 2114-2124, nov. 1962. AIP Publishing. http://dx.doi.org/10.1063/1.1733432.

SHAI, Y.. Mode of action of membrane active antimicrobial peptides. Biopolymers, [S.L.], v. 66, n. 4, p. 236-248, 2002. Wiley. http://dx.doi.org/10.1002/bip.10260.

SHEEHAN, J.; CRUICKSHANK, P.; BOSHART, G.. Notes- A Convenient Synthesis of Water-Soluble Carbodiimides. The Journal Of Organic Chemistry, [S.L.], v. 26, n. 7, p. 2525-2528, jul. 1961. American Chemical Society (ACS). http://dx.doi.org/10.1021/jo01351a600.

SIMMACO, Maurizio; MIGNOGNA, Giuseppina; BARRA, Donatella. Antimicrobial peptides from amphibian skin: what do they tell us?. Biopolymers, [S.L.], v. 47, n. 6, p. 435-450, 1998. Wiley. http://dx.doi.org/10.1002/(sici)1097-0282(1998)47:63.0.co;2-8.

SIMMACO, M.; MIGNOGNA, G.; CANOFENI, S.; MIELE, R.; MANGONI, M. L.; BARRA, .. Temporins, Antimicrobial Peptides from the European Red Frog Rana temporaria. European Journal Of Biochemistry, [S.L.], v. 242, n. 3, p. 788-792, 15 dez. 1996. Wiley. http://dx.doi.org/10.1111/j.1432-1033.1996.0788r.x.

SREERAMA, N.; WOODY, R.W.. A Self-Consistent Method for the Analysis of Protein Secondary Structure from Circular Dichroism. Analytical Biochemistry, [S.L.], v. 209, n. 1, p. 32-44, fev. 1993. Elsevier BV. http://dx.doi.org/10.1006/abio.1993.1079. 
SREERAMA, N.; WOODY, R. W.. Estimation of Protein Secondary Structure from Circular Dichroism Spectra: comparison of contin, selcon, and cdsstr methods with an expanded reference set. Analytical Biochemistry, [S.L.], v. 287, n. 2, p. 252-260, dez. 2000. Elsevier BV. http://dx.doi.org/10.1006/abio.2000.4880.

TINOCO Jr, I.. Theoretical aspects of optical activity. In: PRIGOGINE, Ilya; RICE, Stuart A. (ed.). Advances in Chemical Physics: volume 8. New Jersey: John Wiley \& Sons, 1962. p. 113-160.

TOKMAKOFF, A.. Interaction of Light and Matter. In: TOKMAKOFF, Andrei. Time dependent quantum mechanics and spectroscopy. Chicago: Libretexts, 2021. Cap. 7. p. 96113. Disponível em: https://chem.libretexts.org/@ go/page/107215. Acesso em: 15 maio 2021.

VAN STOKKUM, I. H.M.; SPOELDER, H. J.W.; BLOEMENDAL, M.; VAN GRONDELLE, R.; GROEN, F. C.A.. Estimation of protein secondary structure and error analysis from circular dichroism spectra. Analytical Biochemistry, [S.L.], v. 191, n. 1, p. 110-118, nov. 1990. Elsevier BV. http://dx.doi.org/10.1016/0003-2697(90)90396-q.

VENYAMINOV, S. Yu; YANG, J. T.. Determination of protein secondary structure. In: FASMAN, Gerald D. (ed.). Circular Dichroism and the Conformational Analysis of Biomolecules. New York: Springer Science, 1996. Cap. 3. p. 69-108.

WALLACE, B.A.. Analyses of circular dichroism spectra of membrane proteins. Protein Science, [S.L.], v. $12, \quad$ n. $4, \quad$ p. 875-884, 1 abr. 2003. Wiley. http://dx.doi.org/10.1110/ps.0229603.

WALLACE, B. A.; JANES, R. W. (ed.). Modern Techniques for Circular Dichroism and Synchrotron Radiation Circular Dichroism Spectroscopy. Amsterdam: Ios Press Bv, 2009. $232 \mathrm{p}$.

WHITMORE, L.; WALLACE, B. A.. DICHROWEB, an online server for protein secondary structure analyses from circular dichroism spectroscopic data. Nucleic Acids Research, [S.L.], v. 32, n. , p. 668-673, 1 jul. 2004. Oxford University Press (OUP). http://dx.doi.org/10.1093/nar/gkh371.

WOODY, Robert W.. Improved Calculation of the $n \pi^{*}$ Rotational Strength in Polypeptides. The Journal Of Chemical Physics, [S.L.], v. 49, n. 11, p. 4797-4806, dez. 1968. AIP Publishing. http://dx.doi.org/10.1063/1.1669962.

WOODY, R. W.. Theory of Circular Dichorism of Proteins. In: FASMAN, Gerald D. (ed.). Circular Dichroism and the Conformational Analysis of Biomolecules. New York: Springer Science, 1996. Cap. 2. p. 25-67.

WORLD HEALTH ORGANIZATION (org.). Global Action Plan on Antimicrobial Resistance. Switzerland: World Health Organization, 2015. 28 p. Disponível em: www.who.int. Acesso em: 19 maio 2021. 


\section{Apêndice I - Absorção da luz e dicroísmo linear}

Para entender a origem da interação da luz com a matéria precisamos introduzir o formalismo da mecânica quântica; para tanto será necessário construir um Hamiltoniano para o nosso sistema eletrodinâmico (TOMAKOFF, 2020; MCHALE, 2017; SCHELLMAN, 1975). Uma forma de obter esse operador é iniciar com uma abordagem clássica do eletromagnetismo um pouco diferente do que fizemos no capítulo I. É possível definir o Potencial Vetor $(\vec{A})$ e o potencial escalar $(\Phi)$, tal que os vetores elétrico e magnético podem ser reescritos como:

$$
\begin{gathered}
\vec{E}=-\nabla \Phi-\frac{1}{c} \frac{\partial \vec{A}}{\partial t} \\
\vec{B}=\vec{\nabla} \times \vec{A}
\end{gathered}
$$

Há uma liberdade de gauge envolvida nessas definições, que nos permite realizar uma transformação de calibre que nos seja mais vantajosa. Assim, escolhendo o calibre de Coloumb ( $\Phi=0$ e $\vec{\nabla} \cdot \vec{A}=0$ ) e para uma corrente transversal nula, temos que o potencial vetor segue uma equação de onda descrita por (51), cuja solução é uma onda plana, linear e monocromática. De (50) nós também recuperamos a solução de onda plana da seção anterior, com $\vec{E}_{0}=$ $-2 \omega i \vec{A}_{0}$ (TOMAKOFF, 2020; MCHALE, 2017).

$$
\nabla^{2} \vec{A}=\frac{1}{c^{2}} \frac{\partial^{2} \vec{A}}{\partial t^{2}}
$$

Em termos do potencial vetor, podemos escrever o hamiltoniano para uma partícula clássica de massa $m$, carga $q$, em um potencial ligado $\left(V_{0}(\vec{x})\right)$ e submetida a um campo eletromagnético como sendo:

$$
H=\frac{\vec{p}^{2}}{2 m}+V_{0}(\vec{x})-\frac{q}{2 m}(\vec{p} \cdot \vec{A}+\vec{A} \cdot \vec{p})+\frac{q^{2}}{2 m}|\vec{A}|^{2}
$$

Em que $\vec{p}$ é o momento linear da partícula. No tratamento quântico, ele é substituído pelo operador $\hat{p}=-i \hbar \nabla$. Além disso, esse Hamiltoniano pode ser simplificado se considerarmos apenas os termos da ordem de $O[A]^{1}$, que é uma aproximação de campo fraco. 
Assim, a equação (52) pode ser reescrita como (53) a soma de um Hamiltoniano não perturbado $\left(H_{0}(\vec{x})=\frac{\vec{p}^{2}}{2 m}+V_{0}(\vec{x})\right)$, com um potencial perturbador que varia no tempo $\left(V(t)=-\frac{q}{2 m}(\vec{p}\right.$. $\vec{A}+\vec{A} \cdot \vec{p})$ ) (TOMAKOFF, 2020; MCHALE, 2017).

$$
H=H_{0}+V(t)
$$

No tratamento quântico e no calibre de Coulomb, o potencial perturbador é simplificado para $V(t)=-\frac{q}{2 m} \vec{A} \cdot \hat{\vec{p}}=\frac{i \hbar q}{2 m} \vec{A} \cdot \vec{\nabla}$. Agora, para um sistema de $n$ partículas com carga $q$, o novo potencial perturbador pode ser expresso como uma somatória de $V_{i}(t)$, substituindo a solução de onda plana para o potencial vetor, temos:

$$
V(t)=-\frac{q}{2 m} \sum_{i}\left(A_{0} \hat{\mathrm{e}}_{1} \hat{p}_{i} e^{i\left(\vec{k} \cdot \vec{x}_{i}-\omega t\right)}+A_{0}^{*} \hat{\mathrm{e}}_{1} \hat{p}_{i} e^{-i\left(\vec{k} \cdot \vec{x}_{i}-\omega t\right)}\right)
$$

As posições individuais de cada uma das partículas podem ser escritas como sendo $\vec{x}_{i}=$ $\vec{x}_{0}+\delta \vec{x}_{i}$. Então podemos expandir em série de Taylor o termo exponencial na condição de $\delta \vec{x}_{i} \ll 1$, como: $e^{-i\left(\vec{k} \cdot \vec{x}_{i}\right)}=e^{-i\left(\vec{k} \cdot \vec{x}_{0}\right)} e^{-i\left(\vec{k} \cdot \delta \vec{x}_{i}\right)}=e^{-i\left(\vec{k} \cdot \vec{x}_{i}\right)}\left(1+i \vec{k} \cdot \delta \vec{x}_{i}+O\left[\delta \vec{x}_{i}\right]^{2}\right.$. No limite em que $\left|\delta \vec{x}_{i}\right|$ tende a zero, escolhendo $\vec{x}_{0}=\overrightarrow{0}$ e substituindo $A_{0}=\frac{i E_{0}}{2 \omega}$ temos finalmente o potencial dado por (55) (TOMAKOFF, 2020; MCHALE, 2017).

$$
\begin{gathered}
V(t)=-\frac{q E_{0}}{2 m \omega} i\left(\hat{\mathrm{e}}_{1} \cdot \hat{p}\left(e^{-i \omega t}-e^{+i \omega t}\right)\right)=-\frac{q}{m \omega} \vec{E}_{0} \cdot \hat{p} \sin \omega t \\
=V_{1} \sin \omega t
\end{gathered}
$$

Com esse potencial, considerando $V_{1} \ll 1$, é possível aplicar a teoria de perturbação dependente do tempo para obter a evolução temporal do estado quântico do sistema $|\phi(t)\rangle=$ $\sum_{n} c_{n} e^{-i \omega_{n} t}|n\rangle$, em que $\omega_{n}=\frac{E_{n}}{\hbar}, E_{n}$ é o autovalor de energia do auto-estado $|n\rangle$, e $c_{n}(t)$ é uma amplitude cuja a evolução temporal é dada por (56), aonde $V_{n m}(t)=\langle n|V(t)| m\rangle=$ $\left\langle n\left|V_{1}\right| m\right\rangle \sin \omega t$ e $\omega_{n m}=\frac{E_{n}-E_{m}}{\hbar}$ (TOMAKOFF, 2020; MCHALE, 2017; SCHELLMAN, 1975). 


$$
\frac{d c_{n}}{d t}=-\frac{i}{\hbar} \sum_{m} V_{n m}(t) c_{m}(t) e^{-i \omega_{n m} t}
$$

A princípio, podemos considerar o elétron em um sistema de dois níveis (o estado fundamental $(o)$ e o estado excitado ( $a$ ). Nessa situação temos que a evolução temporal de $c_{a}$ é dada por:

$$
\frac{d c_{k}}{d t}=-\frac{i}{\hbar} \sum_{n=o, a} V_{k n} c_{n}(t) e^{-i \omega_{k n} t} \sin \omega t
$$

A teoria de perturbação consiste em expandir o termo $c_{n}$ em ordens de $V_{1}: c_{n}(t)=$ $c_{n}^{(0)}+V_{1} c_{n}^{(1)}+V_{1}^{2} c_{n}^{(2)} \cdots$. Substituindo essa expansão na equação (57), e comparando os termos até primeira ordem, obtemos que $\dot{c}_{k}^{(0)}=0$ e $\dot{c}_{k}^{(1)}$ é dado por (58). Para essa equação foi considerado que os elementos diagonais da matriz do potencial são nulos $\left(V_{i i}=0\right)$.

$$
\dot{c}_{k}^{(1)}(t)=\frac{1}{2 \hbar} c_{k}^{(0)} V_{k o}\left(e^{-i\left(\omega_{k o}-\omega\right) t}-e^{-i\left(\omega_{k o}+\omega\right) t}\right)
$$

Nesse sistema de dois níveis, em primeira ordem, a probabilidade de acontecer uma transição para um estado qualquer ( $a$ ) é dada por $P_{a}=\left|c_{a}^{(1)}\right|^{2}$. Para obter esse valor, precisamos primeiro integrar a equação (58), o que gera:

$$
c_{a}^{(1)}(t)=\frac{e^{i \omega_{a o} t}}{2 i \hbar}\left\langle a\left|V_{1}\right| o\right\rangle\left(\frac{e^{i\left(\omega_{a o}-\omega\right) t}-1}{\omega_{a o}-\omega}-\frac{e^{i\left(\omega_{a o}+\omega\right) t}-1}{\omega_{a o}+\omega}\right)
$$

Como $\omega_{a o}$ é próximo de $\omega$ o termo que carrega a subtração dessas duas frequências no denominador se sobressai, dessa forma podemos negligenciar a contribuição do segundo termo da equação (59). Assim a probabilidade do elétron ser excitado é dada por:

$$
\begin{gathered}
c_{a}^{(1)}(t) \cdot c_{a}^{*(1)}(t)=\frac{\left|\left\langle a\left|V_{1}\right| o\right\rangle\right|^{2}}{4 \hbar^{2}}\left(\frac{e^{i\left(\omega_{a o}-\omega\right) t}-1}{\omega_{a o}-\omega}\right)\left(\frac{e^{-i\left(\omega_{a o}-\omega\right) t}-1}{\omega_{a o}-\omega}\right)= \\
=\frac{\left\langle a\left|V_{1}\right| o\right\rangle^{2}}{4 \hbar^{2}} \frac{\sin ^{2}\left(\frac{\omega_{a o}-\omega}{2}\right) t}{\left(\frac{\omega_{a o}-\omega}{2}\right)^{2}}
\end{gathered}
$$


É conhecido que a razão $\frac{\sin ^{2}(\Delta) t}{t \pi \Delta^{2}}$ tende a função delta de Dirac $\delta(\Delta)$ no limite em que $\mathrm{t} \rightarrow \infty$. Assim, podemos manipular algebricamente a segunda razão da equação (60) para reescrevê-la como $\delta\left(\omega_{\text {ao }}-\omega\right)$ (TOMAKOFF, 2020; MCHALE, 2017; SCHELLMAN, 1975).

$$
c_{a}^{(1)}(t) \cdot c_{a}^{*(1)}(t)=\frac{\left|\left\langle a\left|V_{1}\right| o\right\rangle\right|^{2}}{2 \hbar^{2}} \mathrm{t} \delta\left(\omega_{\mathrm{ao}}-\omega\right)
$$

Assim sendo, o que nos resta é avaliar o valor de $\left|\left\langle a\left|V_{1}\right| o\right\rangle\right|^{2}$, o primeiro passo é substituir $V_{1}=-\frac{q E_{0}}{m \omega} i\left(\hat{\mathrm{e}}_{1} \cdot \hat{p}\right)$. Em seguida, vamos usar a relação de comutação do operador posição com o hamiltoniano não perturbado $\left[\hat{r}, \widehat{H}_{0}\right]=\frac{i \hbar \hat{p}}{m}$, para reescrever $\langle a|\hat{p}| o\rangle$ em função do operador posição.

$$
\langle k|\hat{p}| l\rangle=\frac{m}{i \hbar}\left\langle k\left|\hat{r} \widehat{H}_{0}-\widehat{H}_{0} \hat{r}\right| l\right\rangle=i m \omega_{k l}\langle k|\hat{r}| l\rangle
$$

Temos então que,

$$
\left|\left\langle a\left|V_{1}\right| o\right\rangle\right|^{2}=\left(\frac{q E_{0} \omega_{a o}}{\omega}\right)^{2}\left\langle a\left|\hat{\mathrm{e}}_{1} \cdot \hat{x}\right| o\right\rangle^{2}=\left(\frac{E_{0} \omega_{a o}}{\omega}\right)^{2}\left\langle a\left|\hat{\mathrm{e}}_{1} \cdot \hat{\mu}\right| o\right\rangle^{2}
$$

onde foi introduzido o operador $\hat{\mu}=q \hat{x}$, conhecido como operador momento de dipolo. Definindo $\left\langle a\left|\hat{\mathrm{e}}_{1} \cdot \hat{\mu}\right| o\right\rangle=\mu_{a o}$, a probabilidade de transição do elétron do estado fundamental para o estado excitado é escrita como:

$$
P(o \rightarrow a)=\frac{\pi}{2 \hbar^{2}} \frac{\omega_{a o}^{2}}{\omega^{2}} E_{o}^{2} \mu_{a o}^{2} t \delta\left(\omega_{a o}-\omega\right)
$$

Uma grandeza interessante de ser analisada é a taxa de absorção (65), definida como a derivada temporal da probabilidade de transição.

$$
w_{a o}=\frac{\pi}{2 \hbar^{2}} \frac{\omega_{a o}^{2}}{\omega^{2}} E_{o}^{2} \mu_{a o}^{2} \delta\left(\omega_{a o}-\omega\right)
$$

A partir dessa grandeza, somos capazes ainda de calcular a seção de choque de absorção $\alpha(\omega)$ (66), que representa a energia total absorvida por unidade de tempo dividida pela intensidade total da luz incidente. 


$$
\alpha(\omega)=\frac{\hbar w_{a o}}{I} \omega
$$

Em espectroscopia é comum reescrever a seção de choque de absorção em termos do coeficiente de extinção molar (67), em que $N_{A}$ é o número de Avogadro.

$$
\varepsilon(\omega)=\frac{\mathrm{N}_{\mathrm{A}}}{2303} \alpha(\omega)
$$

No caso de moléculas mais complexas em solução há uma imensidade de graus de liberdade de baixa energia possíveis de serem excitados. O espectro gerado por essas várias transições gera uma banda de absorção, cuja estrutura fina dificilmente é identificada em um espectrômetro convencional. Para levar em conta todos esses outros possíveis estados excitados, é introduzido a densidade de transição $(\rho(\omega))$. Assim, ao invés de apenas considerarmos o módulo quadrático do potencial $\left(\left|\left\langle a\left|V_{1}\right| o\right\rangle\right|^{2}\right)$ na expressão (61), incluímos também essa densidade $\left(\rho(\omega)\left|\left\langle a\left|V_{1}\right| o\right\rangle\right|^{2}\right)$, dessa forma estamos representando a probabilidade de uma transição $(o \rightarrow a)$ acontecer na frequência $\omega$ (SCHELLMAN, 1975).

O dicroísmo linear é definido como a diferença no coeficiente de extinção molar ao absorver ondas eletromagnéticas planas, linearmente polarizadas, com mesma frequência, mas polarizadas em direções diferentes. 


\section{Anexos}

\section{Teste KAISER}

Solução A: 5\% de ninhidrina em etanol absoluto (w/v)

Preparo: pesar 0,250g de ninhidrina e diluir em $5 \mathrm{~mL}$ de etanol absoluto.

Estocar em frasco âmbar entre 4 à $8^{\circ} \mathrm{C}$.

Cuidados: o preparo deve ser realizado em fluxo de ar.

Solução B: 80\% fenol em etanol absoluto (w/v)

Preparo: pesar $020 \mathrm{~g}$ de fenol e diluir em $5 \mathrm{~mL}$ de etanol absoluto. Aquecer até a diluição completa.

Estocar em frasco âmbar entre 4 à $8^{\circ} \mathrm{C}$.

Cuidados: o preparo deve ser realizado em fluxo de ar, é necessário a utilização de luvas. Em caso acidente com fenol, deixar a região afetada em fluxo de água gelada por ao menos 10 minutos, trocar as luvas antes de voltar ao preparo.

\section{Solução C: KCN em piridina}

Preparo: Pesar 0,65mg KCN em 1,0mL de água. Diluir $0,1 \mathrm{~mL}$ dessa solução em $5 \mathrm{~mL}$ de piridina.

Estocar em frasco âmbar entre 4 à $8^{\circ} \mathrm{C}$.

Cuidados: o preparo deve ser realizado em fluxo de ar, KCN é tóxico se inalado.

\section{Em caso de acidentes seguir o protocolo descrito por (em inglês):}

ANASPEC INC. (Fremont). Material Safety Data Sheet: ninhydrin test kit. Ninhydrin Test Kit. 2018. Disponível em: https://www.anaspec.com/products/product.asp?id=39383. Acesso em: 23 maio 2021.

Durabilidade: Estocadas nas condições adequadas (ambiente sem luz e à $4^{\circ} \mathrm{C}$ ) as soluções podem durar até 52 semanas. Mas recomenda-se testar a qualidade das soluções semanalmente e refazê-las se necessário. 